\title{
Barbara Lettmann-Sadony
}

\section{Karolina Karlovna Pavlova}

\author{
Eine Dichterin \\ russisch-deutscher Wechselseitigkeit
}

Verlag Otto Sagner München · Berlin · Washington D.C.

Digitalisiert im Rahmen der Kooperation mit dem DFG-Projekt „Digi20“

der Bayerischen Staatsbibliothek, München. OCR-Bearbeitung und Erstellung des eBooks durch den Verlag Otto Sagner:

http://verlag.kubon-sagner.de

( $)$ bei Verlag Otto Sagner. Eine Verwertung oder Weitergabe der Texte und Abbildungen, insbesondere durch Vervielfältigung, ist ohne vorherige schriftliche Genehmigung des Verlages unzulässig. 


\section{SLAVISTISCHE BEITRÄGE}

Unter Mitwirkung von M. Braun, Göttingen - † P. Diels, München - J. Holthusen, München - E. Koschmieder, München - W. Lettenbauer, Freiburg/Br. J. Matl, Graz

F. W. Neumann, Mainz $\cdot$ K.-H. Pollok, Regensburg $\cdot$ L. Sadnik-Aitzetmüller, Graz $\cdot J$. Schütz, Erlangen

HERAUSGEGEBEN VON † A. SCHMAUS, MÜNCHEN

Technische Redaktion: P. Rehder, München

Band 50 
BARBARA LETTMANN-SADONY

\section{KAROLINA KARLOVNA PAVLOVA EINE DICHTERIN RUSSISCH-DEUTSCHER WECHSELSEITIGKEIT}

\section{VERLAG OTTO SAGNER - MÜNCHEN \\ 1971}


ISBN 3876900603

Copyright by Verlag Otto Sagner, München 1971

Abteilung der Fa. Kubon \& Sagner, München

Druck: Alexander Großmann

8 München 19, Ysenburgstr. 7/I 


\section{INHALTSVERZEICHNIS}

Einleitung

Erster Teil

Biographie

Biographischer Abriß

1. Kapitel

Moi vospominanija

21

2. Kapitel

Partner

1. Adam Mickiewícz

2. Nikolaj Filippovic Pavlov 33

3. Boris Isaakovic Utin 45

3. Kapitel

Salon

4. Kapitel

Zeitgenossen

1. Frühe Jahre (bis zur Heirat mit N. F. Pavlov)

2. Mittlere Jahre (bis zur Übersiedlung nach Deutschland) 62

3. Späte Jahre (wăhrend der Dresdener Zeit)

Zweiter Teil

Werk

1. Kapitel

Eigene Dichtungen

1. Gedichte über den Dichter

2. Gedichte zu anderen Themen

3. Erzählungen in Versen und in Prosa

4. Fremdsprachige Gedichte

2. Kapitel

Über setzungen

1. Lyrik

2. Dramatik

Zusammenfassung

Literaturverzeichnis 


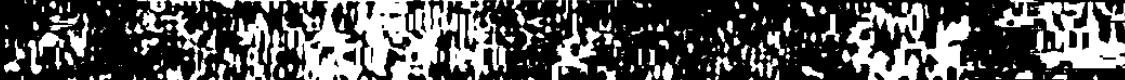

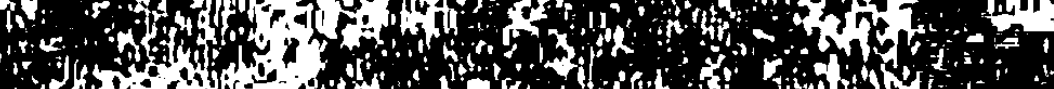

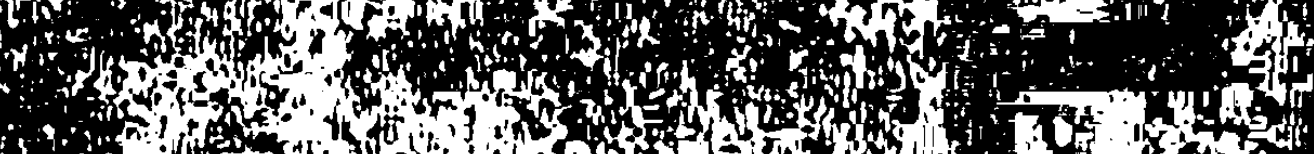

ond

ond

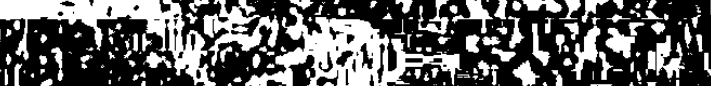

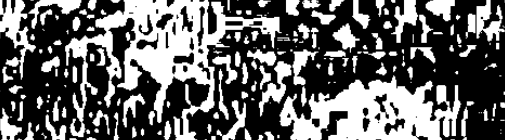

6 a d

if

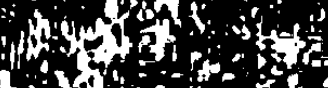

$$
\text { 1 }
$$

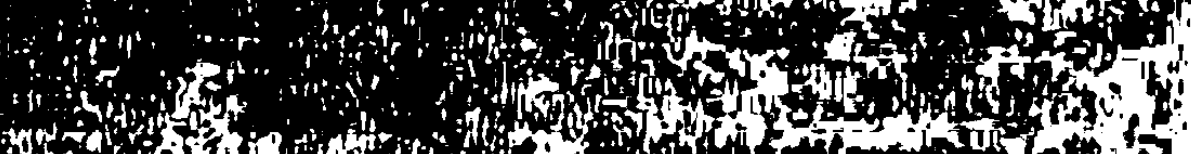

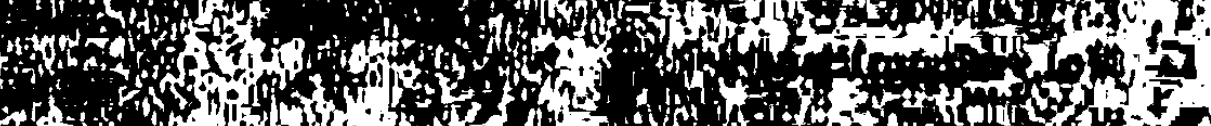
ats - . rop

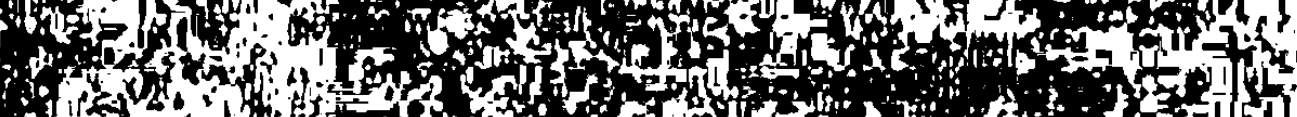

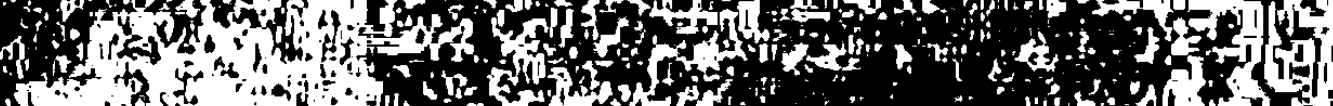

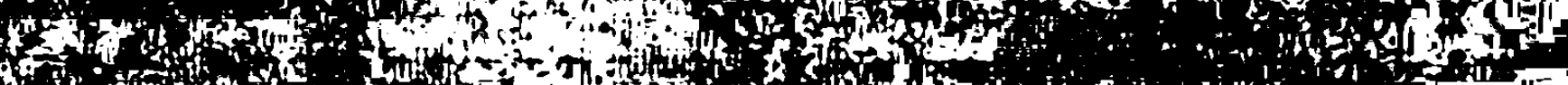

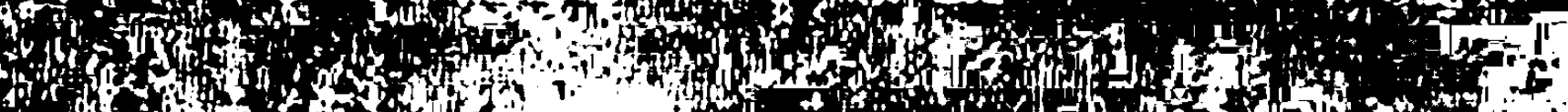

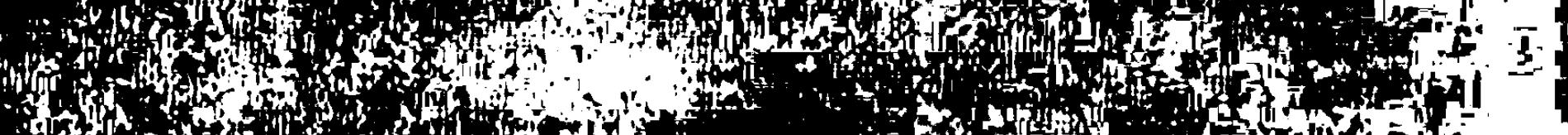
ald (1)

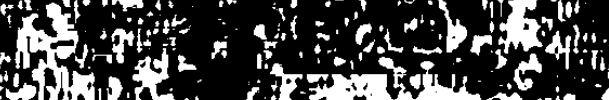
Sth zip

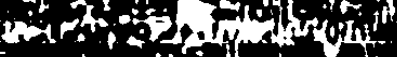

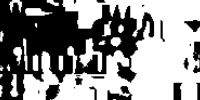
W ond

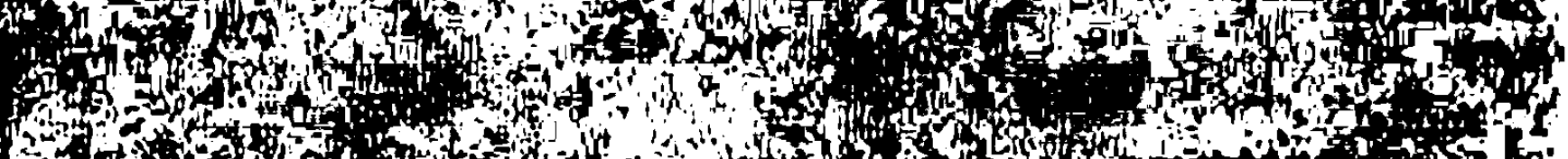

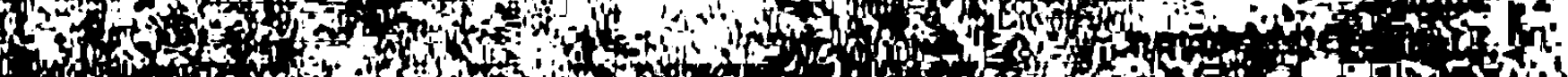
1) of 40 (s)

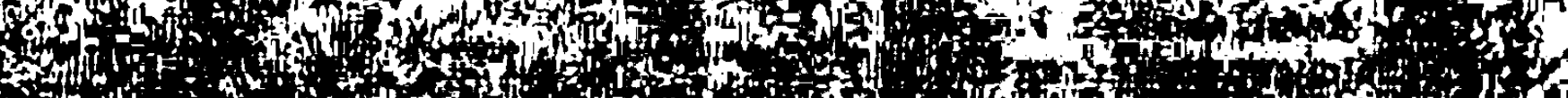
and

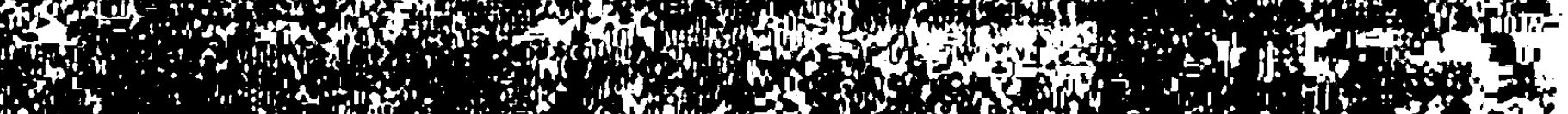
然
(1)
(3)

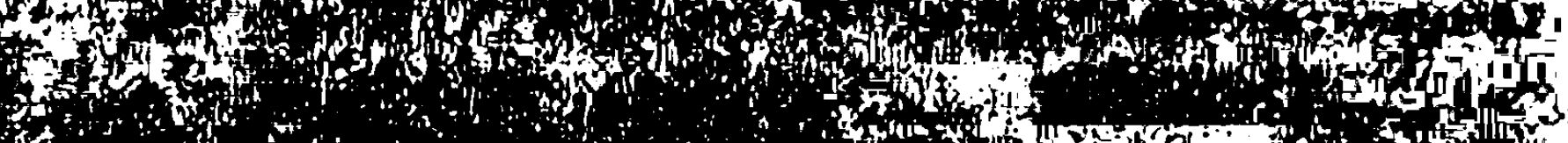


Einleitung

Die Urtelle über Leben und Werk Karolina Karlovna Pavl ov a 8 reichen von uneingeschrănkter Bewunderung bis zu entschiedener Ablehnung. An Versuchen, sie in eine Reihe mit den hervorragenden Gestalten des russischen Geisteslebens in der ersten Halfte des 19. Jahrhunderts zu stellen, hat es so wenig gefehlt wie an Versuchen, sie als belanglose Randerscheinung abzutun. In den Literaturgeschichten hat sich die Bewertung auf 'Mittelmaß' eingependelt; Karolina Pavlova wird - wenn über haupt - nur 'der Vollstăndigkeit halber' erwăhnt.

$\mathrm{Ob}$ und inwieweit diese so gegensätzlichen Beurteilungen richtig oder falsch sind, wird sich erst nach einer eingehenden Analyse des vorliegenden Materials sagen lassen. $\mathrm{Zu}$ dieser Unter suchung sollen einige Überlegungen über mögliche Ursachen der kontrover sen Meinungen hinführen. Daraus werden sich die Fragen an Karol ina Pavlovas Werk ergeben.

Dieses Werk ist, gemessen an der langen Schaffenszeit von mehr als fünfzig Jahren, vergleichsweise bescheiden. $\mathrm{Zu}$ den Arbeiten der dreiBiger und frühen vierziger Jahre liegen nur Äußerungen von Freunden und Bekannten vor. Der literarische Geschmack dieses Kreises hatte sich an den Bemühungen Puskkins und seiner Plejade um die Vollendung des russischen Verses ausgebildet; der geistige Standort war der Irrationalismus, in dem sich nationale Besinnung und romantische Univer salität, Selbstbewußtsein und Bewußtsein der Grenzen überwindenden Gemeinsamkeiten wider spruchslos vereinigen ließen. Bezeichnend für ein Mitteilungsbedürfnis aus gewonnener Selbstsicherheit sind solche symbolischen Titel wie "Das Nordlicht" - die erste Publikation der Pavlova (1833) - oder "Nordlichter" - eine Anthologie polnischer Dichtungen (1834) ${ }^{1}$. Die Ar-

Nordlichter. Eine Sammlung polnischer Dichtungen, in's Deutsche ubertragen von Ludwig Nabielak und J. B. Werner. Bd. 1, Stuttgart 1834. 
beiten Karolina Pavlovas figten sich formal und inhaltlich in diese Konzeption; der Betfall threr Freunde war ihr gewiß.

Die maBgebliche zeitgenössische Literaturkritik jedoch - reprăsentiert durch Polevoj und Belinskdj - hatte ihr Augenmerk auf Zeitgemäßeres gerichtet. Die Lyrik hatte ihren Hơhepunit mit Puskkin überschritten und bot - trotz ihrer Fulle - nichts Neues mehr. Hinzu kam, daß die Pavlova nicht eben zu den produktivsten Künstlern gehörte. So fehlte ganz einfach der Anstoß zu stăndiger Auseinandersetzung; einmal gefălte Urteile drohten sich zu Vorurtellen zu verfestigen.

Die einzige Sammlung ihrer Gedichte, die zu thren Lebzeiten in Rußland erschien, brachten Freunde 1863 in threm Auftrage heraus. Sie selbst lebte schon seit Jahren in Deutschland. Zu einer Zeit, in der sich die tonangebenden Dichter, Literaten und Kritiker der Umwelt zugewendet hatten, trat Karolina Pavlova mit einer Auswahl von Gedichten hervor, die fast ausnahmslos per sönliches Erleben zum Gegenstand hatten. Diese Befangenheit in der Selbstreflexion mußte von dem Tell dieser Generation, der Wegbereiter sozialer Umwalzungen sein wollte, als Anachronismus emprunden werden.

Vor 1863 hatte die Pavlova fünf geschlossene Veröffentlichungen vorgelegt; nur "Dvojnaja zizn'" (1 848) und "Razgovor v Kremle" (1854) erschienen in Rußland. In Deutschland war 1833 "Das Nordlicht. Proben der neuer en russischen Litteratur" herausgekommen. In Frankr eich folgten 1839 "Les préludes" und eine vollstăndige Übertragung von Schillers "Jungfrau von Orleans" ins Französische. Sowohl das "Nordlicht" als auch "Les préludes" enthielten in der Mehrzahl Über setzungen, daneben aber auch einige Originalgedichte in deutscher und französischer Sprache.

Man wird in der Vielseitigkeit und der dadurch bedingten Vielfalt kritischer Ansatzpunkte eine wesentliche Ursache für die unterschiedliche Bewertung suchen müssen. Karolina Pavlova beherrschte außer Russisch, Französisch und Deutsch auch Polnisch, Englisch, Italienisch und Dänisch. Wenn die geistige Durchdringung eines so umfassenden Kulturbereichs nicht gelingt, dann droht Vielseitigkeit in Oberflächlichkeit umzuschlagen, Dichtung unverbindlich zu bleiben und Literatur-Vermittlung auf Ubertra- 
gung des Gefalligen reduziert zu werden. Mit ihren Bemühungen, auch in ander en Literaturen Fuß zu fassen, verschob die Pavlova ihren Standort in der russischen Literatur an die Peripherie. Sie wollte aber auch mit den zentralen Anliegen, die aus der kulturellen und sozialen Situation erwuchsen, mit der Realitắ - auch als Vorlage für eine überhöhte dichterische Wirklichkeit - wenig zu tun haben.

Die letzten dreißig Lebensjahre verbrachte Karolina Pavlova in Deutschland. Auch hier fand sie kaum Anschluß an das literarische Leben. Wohl erschienen zahlreiche Arbeiten in Zeitschriften sowie vier Băndchen Tolstoj-Über'setzungen ${ }^{2}$, aber letztlich blieb sie aus den schon genannten Gründen isoliert. Ihre Übersiedlung von Dresden in das entlegene Dorf Hosterwitz scheint sinnfalliger Ausdruck der Resignation und Absage an eine gleichgültige Umwelt, aber wohl auch Zeichen der Introver sion und nachromantischen Sehnsucht nach Weltfer ne zu sein.

Am 14. Dezember $1893^{3}$ starb Karolina Pavlova; von ihrem Tod wurde in Deutschland und Rußland kaum Notiz genommen ${ }^{4}$. Sie hatte ihre Zeit um mehrere literarische Generationen, um ein halbes Jahrhundert uberlebt.

Nach ihrem Tode erschienen bislang drei Ausgaben ihrer Werke: In der Hinwendung zum Ich und dem Streben nach Vollendung der reinen

Es handelt sich um Übersetzungen der beiden historischen Dramen "Smert' Ioanna Groznogo" und "Car' Fedor Ioannovic", des dramatischen Gedichts "Don Zuan" sowie einer Gedichtauswahl Aleksej Tolstojs.

Nach russischer Zeitrechnung starb sie am 2. Dezember. Wird in dieser Arbeit nur e in Datum angegeben, so ist es stets neuen Stils. In Deutschland erschienen keine Nachrufe; dagegen brachten fünf russische Zeitschriften eine Würdigung:

Russkie vedomosti, M. 1893, Nr. 339;

Moskovskie vedomosti, M. 1893, Nr. 335 (5./17.12.);

Novoe vremja, $\mathrm{SPb}$. 1893, Nr. 6386;

Istor iceskij vestnik, $\mathrm{SPb} 1894$ (fevral ${ }^{\circ}$ );

Russkij archiv, 1894, Buch 1, S. 119-123.

N.N. Golicyn hatte in seinem 1888 erschienenen "Bibliograficeskij slovar ' russkich pisatel'nic" als Todesjahr "188?" angegeben(S.189)! S. I. Ponomarev schreibt 1891 (!) im "Sbornik otdel enija russkogo jazyka i slovesnosti": "Es ist merkwürdig und traurig, daß niemand sich das Todesjahr K. K. Pavlovas gemerkt hat..." (VII, S. 8). 
Kunst fanden die Symbolisten bei der Pavlova ein thnen verwandtes Selbstverstăndnis. 1903 erinnerte Valerij Brjusov in einem Auf satz in den "EZemesjačnye socinenija" 5 an die fast vergessene Dichterin. Diese kurze Monographie stellte er dem 1915 von ihm herausgegebenen "Sobranie socinenij" voran. Sein positives Urtell wurde unter anderen von Andrej B ely j geteilt, der sich besonders mit den formalen Merkmalen ihrer Gedichte beschăftigte ${ }^{6}$.

Im Zuge der Aufarbeitung der russischen Literatur brachte die Biblioteka poéta 1939 und 1964 je ein "Polnoe sobranie stichotvorenij" heraus.

Mit diesen einleitenden Bemerkungen soll angedeutet werden, daß sich Karolina Pavlova einem generellen Werturteil entzieht. Es ist zu erwarten, daß sie als Über setzer in und Literaturvermittler in einen anderen Platz einnimmt als durch ihr eigenes dichterisches Schaffen, daß ihr eigenes Werk wiederum, absolut genommen, anders eingeordnet wird als in Relation zur 'zeitgemăßen', engagierten Dichtung oder im Vergleich zu Puškin und seinen Erben. Es empfiehlt sich, bei den tbersetzungen die Frage nach den Auswahlkriterien gesondert von der Frage nach der Qualităt zu behandeln. Entsprechend ist bei den eigenen Dichtungen die Stoffwahl vor allem im Hinblick auf die Zeit und deren geistige und literarische Strömungen von der Beurteilung der Versifikation und des Stils zu trennen. Ohne der Werkanalyse vorgreifen zu wollen, kann schon jetzt gesagt werden, daß sich hier Diskrepanzen auftun. Wesentlich ist ferner die Frage, ob und inwieweit der Pavlova die künstlerische Objektivierung und Überhöhung des eigenen Erlebens gelang.

V. Brjusov, Karolina Pavlova; in: Eżemesjachye socinenija, o.0. 1903, Nr. 11-12, S. 273-290.

A. Belyj, Simvolizm. M. 1910; bes. S. 358-360, 628 .

Die statistischen Vergleiche Belyjs helfen bei der Bewertung der Dichtungen der Pavlova nicht viel weiter, denn eine Über einstimmung einmal mit diesem, einmal mit jenem, einmal mit Derzavin, einmal mit Tjutčev, dann wieder mit Puskkin - je nach dem Formkriterium, das gerade unter sucht wird - besagt ja noch nichts über den tatsächlichen Rang der Dichterin. 
Zum Schluß noch einige Bemerkungen zum Material, auf das sich diese Arbeit stützt. Biographische Mitteilungen liegen nur für einzelne Lebensabschnitte der Dichterin vor und sind in ihrem Aussagewert unterschiedlich. So sind für die er sten Lebensjahre bis 1820 , für die Zeit von 1826 bis 1829 und wieder von 1837 bis 1864 zahlreiche Nachrichten und sogar Selbstzeugnisse vorhanden. Dagegen ist über die Jahre 1820 bis 1825 , von 1829 bis 1836 und etwa von der Mitte der sechziger Jahre an bis zu threm Tode fast nichts bekannt. Über den Verbleib des Nachlasses, der hierüber eventuell hätte Auf schluß geben können und der nach dem Zeugnis von A. F. Koni aus "zwel großen Truhen mit Briefen und irgendwelchen anderen Handschriften" ${ }^{7}$ bestanden haben soll, konnte bis heute nichts festgestellt werden. Einerseits sollen sich 137 Gedichte, Briefe und Telegramme A.K. Tolstojs an die Pavlova und 15 Briefe der Dichterin an inn in der Handschriftenabteilung des "Institut russkoj literatury (Puskinskogo doma) Akademii nauk SSSR" befinden ${ }^{8}$, andererseits klagt Gajdenkov, das Pavlova-Archiv sei bis heute "nicht entdeckt und vielleicht für immer verloren" 9 . Die Frage, ob es sich bei den von Koni genannten Schriftstücken eventuell doch um einen Tell des Nachlasses handelt, konnte ich trotz aller Nachforschungen nicht klären. Fragwürdig ist außerdem die Behauptung des deutschen Handschriftensammlers Walther Kittler, er besitze den Nachlaß der Pavlova, der aber zum Teil noch in Dresden, zum Teil schon auf einem Schloß in Westdeutschland zusammen mit etwa zwei - bis dreihunderttausend anderen Stücken - nicht katalogisiert! - in Kisten lagere. Natürlich ist die Möglichkeit, daß der Nachlaß in der Dresdener Gegend geblieben ist, nicht von der Hand zu weisen. Der Enkel der Dichterin, der in Rußland lebte und dem das ganze Erbe zugefallen sein soll ${ }^{10}$, hat, außer einer kleinen Arbeit,

A. F. Koni, Karolina Pavlova; in: Evropa, o.O. 1918, Nr. 4-5, S. 24; da dieser Auf satz nicht gretfbar war, hier zitiert nach K. K. Pavlova 1964, S. 546.

A. K. Tolsoj, Sobranie socinenij, Bd. 4-1964, S. 524. Mehrfache Anfragen beim "Institut russkoj literatury AN SSSR" bl ieben leider ohne Antwort.

K. Pavlova 1964, S. 546.

P. Bartenev, K. K. Pavlova; in: Russkij archiv. M.1894, H.1, S.122. 
nichts daraus veröffentlicht ${ }^{11}$. Aber die wenigen Stücke, die der Sammler mir zugänglich gemacht hat (ein Rezept, drei Einladungsschreiben und einige fast unleserliche Widmungsgedichte), sind belanglos und als Beweise seiner Behauptung nicht überzeugend. Offensichtlich sind ledigttch einige lose Blătter aus einem Album der jungen Karolina Jaenisch mit Widmungen, die Max V a s m e ${ }^{12}$ als echt erkannt hat, in den Besitz des Sammlers gelangt.

Die Lücken in der Biographie lassen sich nur teilweise durch Vermutungen schließen. Aber es kam mir in dieser Arbeit auch weniger darauf an, eine Biographie im Sinne einer Chronik zu schreiben und die ganze Fülle dieses Lebens vor Augen zu führen, sondern mir schien es nützlicher zu sein, in diesem Lebensbild charakteristische Linien nachzuzeichnen, um den Um$r i ß$ der Persönlichkeit und des Wesens deutlich zu machen. Und das ist auf Grund der vorhandenen Zeugnisse möglich. Um aber auch die Verflechtung der von mir isolierten Strănge aufzuzeigen, habe ich den biographischen Kapiteln einen chronologischen Überblick vorangestellt.

Es gibt keine annathernd vollstăndige Werkausgabe der Dichterin. Das Bändchen von 1863 enthăt 90 Originalgedichte, 6 Übersetzungen und eine dramatische Szene. Dieser Bestand wurde von V. Brjusov erheblich erweitert: hinzu kamen 10 eigene Gedichte (nun 100), 19 Übertragungen (nun 25), die beiden Poeme "Kadril'" und "Fantasmagorii", der Roman "Dvojnaja Zizn', eine Erzăhlung "Za Cajnym stolom" sowie "Moi vospominanija" und "Vospominanija ob Ivanove" und zwei Briefe. Diese Ausgabe gibt trotz vieler Druck- und Datierungsfehler immer noch den besten Überblick über das gesamte Schaffen Karolina Pavlovas. Die beiden "Polnoe sobranie stichotvorenij" verzichten schon vom Titel her - sowohl auf die Erinnerungen und die Erzählung als auch auf die Briefe. Der übrige Bestand der Sammlung von 1915 ist 1939 um 36 Originalgedichte (auf 136) und um 2 Über setzungen (auf 27) erweitert worden. 1964 kamen weitere 8 eigene und 10 übertragene Gedichte hinzu.

Es handelt sich um "Fantasmagori1", veröffentlicht in: Russkoe obozrenie, 1894, Nr. 12, S. 964-970.

Max Vasmer, Russische und polnische Gedichte im Nachlaß von Karolina Pavlova, a.a.O., S. 35. 
Wenn die Herausgeber es schon für notwendig erachten, das Fehlen bestimmter Dramenübersetzungen anzumerken, dann müßte die Aufzăhlung aber auch vollstăndig sein ${ }^{13}$. Daß die frühen Veröffentlichungen "Das Nordlicht" und "Les préludes" nur mit einer unmotivierten kleinen Auswahl vertreten sind und die Übertragungen von Tolstoj-Gedichten sowie fast alle in Deutschland erschienenen Arbeiten nicht einmal als fehlend vermerkt sind, läßt sich mit dem Anspruch eines "Polnoe sobranie stichotvorenij" nicht vereinbaren.

Die von mir zusammengestellte Bibliographie der Werke kann als nahezu lückenloses Verzéichnis der veröffentlichten Arbeiten ${ }^{14}$ angesehen werden. Abgesehen von Briefen, würde wohl auch der verschollene Nachlaß nicht mehr viel Wesentliches erbringen.

13 So wird der Eindruck erweckt, daß A.K. Tolstojs "Don Żuan" und Schillers "Jungfrau von Orleans" die einzigen Dramenübersetzungen der Pavlova seien. Sie hat aber außerdem, wie bereits angemerkt, die beiden Zarendramen von Tol stoj, "Wallensteins Tod" von Schiller sowie unter dem Titel "Garrik vo Francii" eine Komödie Adam Gottlieb Oehlenschlägers (1779-1850) über setzt. (Der Originaltitel dieser Komödie um den englischen Shakespeare-Schauspieler und Lustspieldichter David Garrick (1716-1779) war weder in der mir zugänglichen Werkausgabe (21 Bde., dt., Breslau 1839) feststellbar noch in der "Dlustreret dansk Litteraturhistorie" von Carl S. Petersen und Vilhelm Ander sen, Kobenhavn 1924 ff. ).

14 Die den Herausgebern der Werkausgaben offensichtlich unbekannten Gedichte habe ich in "Die Welt der Slaven", Jg. XV, H. 1 (1970), S. 77-86 veröffentlicht. 
\%in

34 (3)

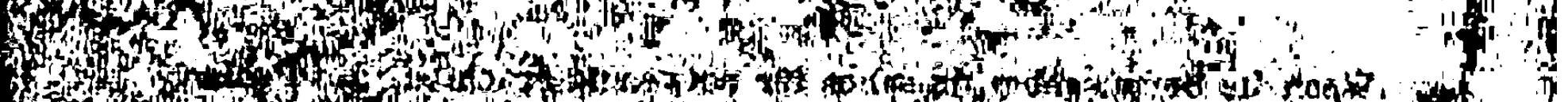

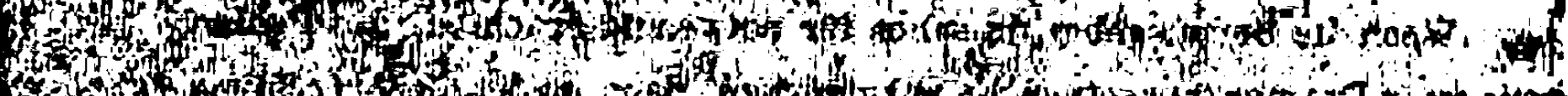

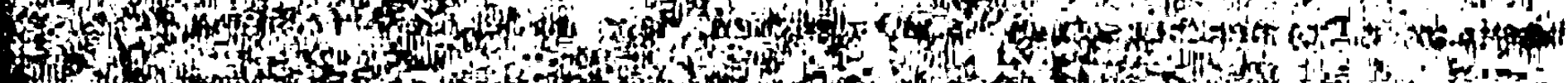

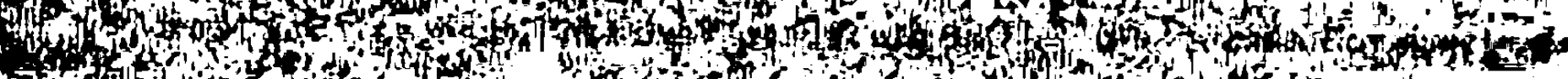
a d If

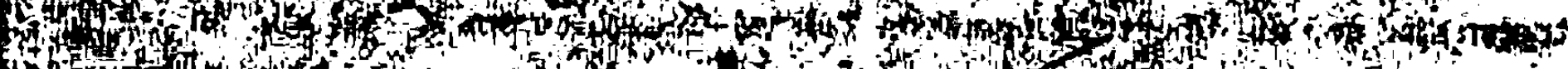
Antas Jos

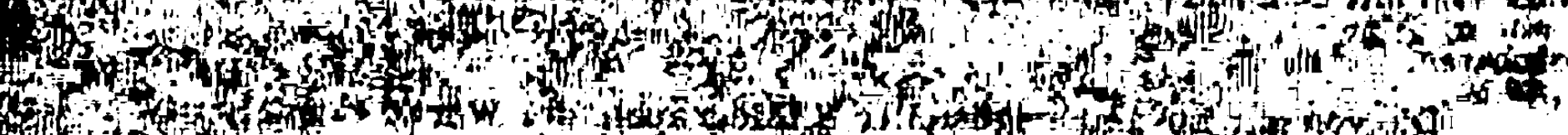

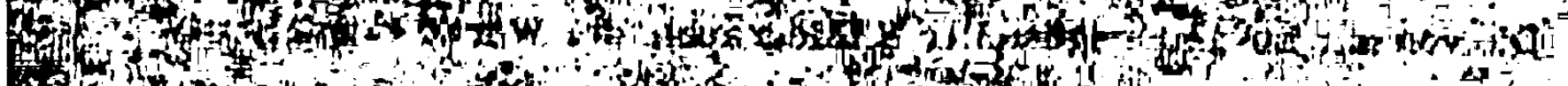

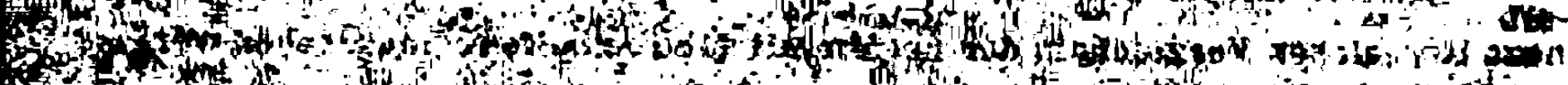

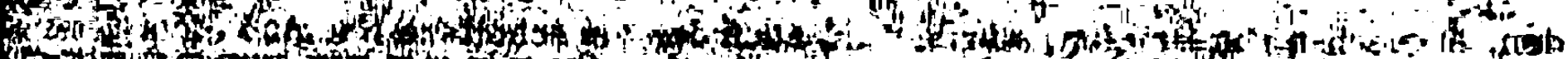
3r

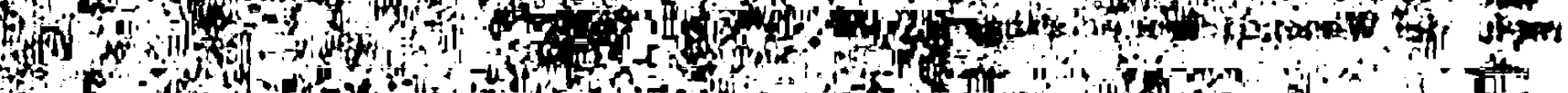
5.

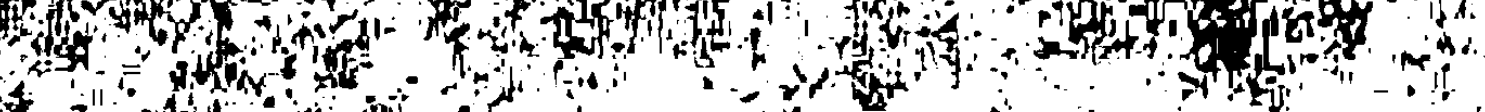

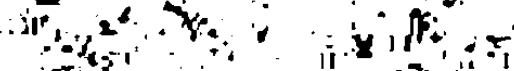

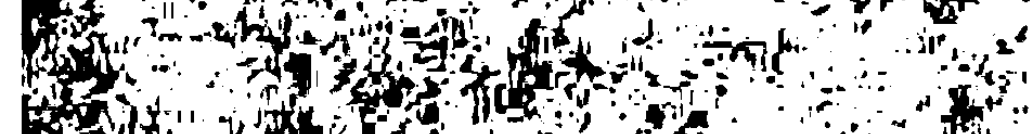

(t)

of

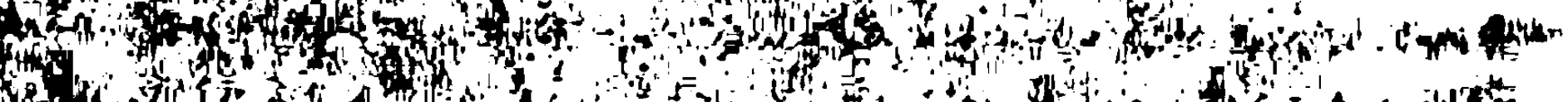
git.

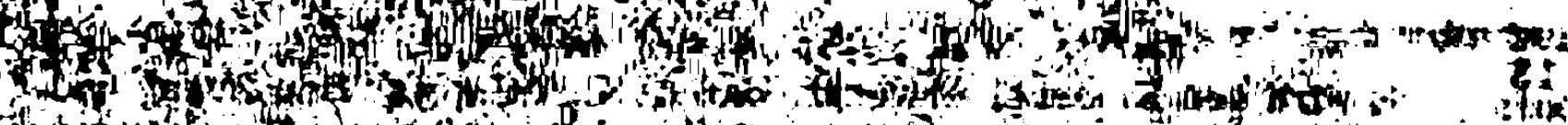
2. (4) (4) 2.

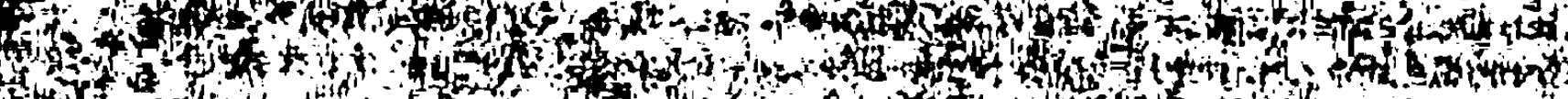

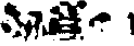

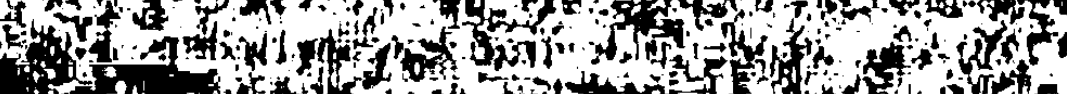
201 1

niL

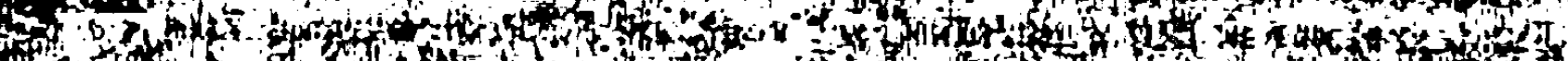

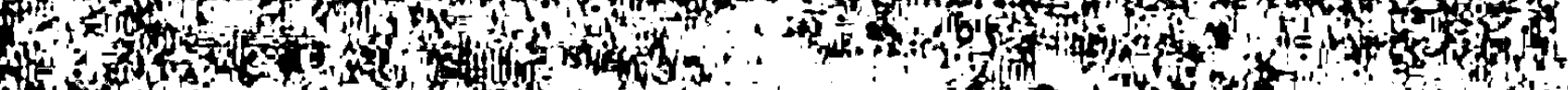

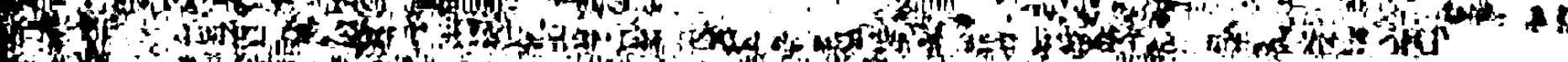

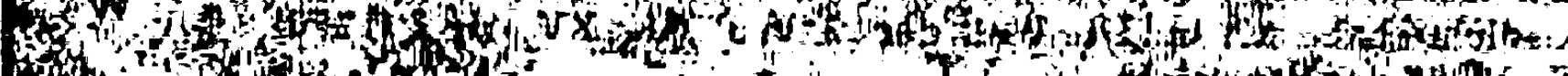
fly 8 (n)

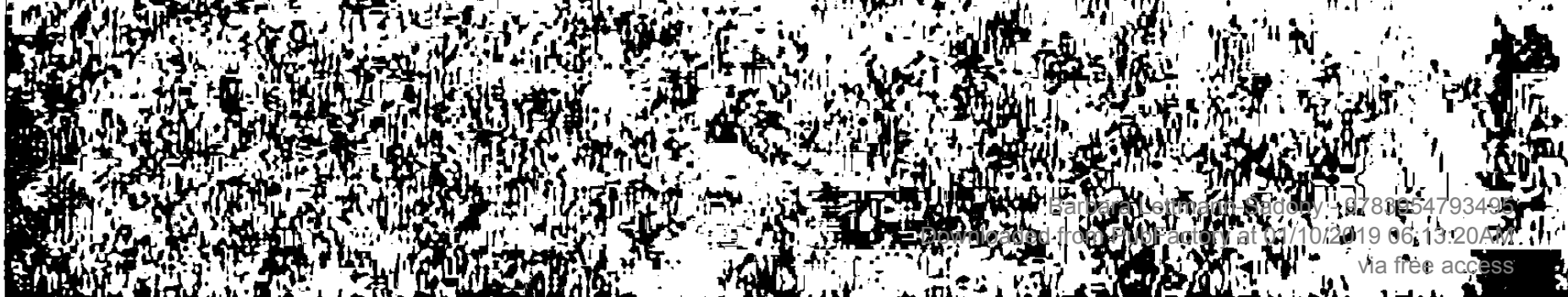




\section{ERSTER TEI}

Biographie

Biographischer Abriß

Der Lebenslauf Karolina Pavlovas, der sich aus dem vorliegenden Material er gibt, liest sich streckenweise wie ein zweitklassiger Roman. Jahre bedrückender Eintönigkeit wechseln mit Zeiten einer geradezu auf dringlichen Erlebnisfülle. Im Verlaufe dieser Arbeit wird sich immer wieder die Frage stellen, in welchem Maße es der Dichter in gelang, sich dem Zugriff der Er eignisse zu entziehen, andererseits die Spannung für ihr Schaffen fruchtbar zu machen.

Karolina Pavlova wurde am 10./22. Juli $1807^{15}$ in Jaroslavl als alteste Tochter des Arztes Karl Jaenisch geboren (den Namen der Mutter konnte ich nicht feststellen). Im folgenden Jahr berief ihn die Moskauer Medizinisch-Chirurgische Akademie auf den Lehrstuhl für Physik und Chemie.

1809 wurde die einzige Schwester Karolina Pavlovas geboren. Durch die Ereignisse des Jahres 1812 änderte sich die Lage der Familie von Grund auf. Am 27. 8. /8.9. flohen die Eltern mit beiden Kindern vor den anrücken-

Als Geburtsjahr wird etwa bis zur Jahrhundertwende fast durchweg 1810 angegeben, so z. B. in den Nachschlagewerken Bol'šaja ènciklopedija, Bd. 14 - SPb. 1896, S. 597, EnciklopediCeskij slovar ${ }^{\circ}, \mathrm{Bd} .23$ - SPb. $1897, \mathrm{~S} .560 \mathrm{re} / 561 \mathrm{li}$, Russkij biograficeskij slovar', Bd. 13 - SPb. 1902, S. $82 \mathrm{f}$. Dieser Fehler wiederholt sich sogar noch im

Großen Brockhaus, Bd. 14 - Leipzig 1933, S. 265 re und im Lexikon der Frau, Bd. 2 - Zürich 1954, Sp. 862.

K. K. Pavlova selbst gibt an, Napoleons Rußlandfeldzug 1812 als Fünfjăhrige erlebt zu haben (Moi vospominanija, S. 222).

V. Brjusov vermutet, daß sie als 'spätes Mădchen' selbst ihr Alter retouchiert habe: "Es ist möglich, daß der Fehler von drei Jahren von Karolina selbst herrührt, die zu einer gewissen Zeit ihres Lebens, als altes Mädchen, ihr Alter verringern wollte" (Ezemesjačnye socinenija, S. 273, Anm. 1). 
den franzð sischen Truppen nach Jaroslavl’. Ihr Moskauer Haus fiel dem großen Brand zum Opfer, das Gut im Smolensker Gouvernement wurde zer stört. Um ihren bescheidenen Wohl stand gebracht, mußten die Jaenischs sich über zwei Jahrzehnte mit sehr beschränkten wirtschaftlichen Verhăl nissen abfinden und waren immer wieder auf die Hilfe von Freunden angewiesen.

Nach der Rückkehr aus Jaroslavl' im Frühjahr 1813 verbrachte die Familie jahrelang die Sommermonate auf den Gutern von Bekannten; für die Winter wurde in Moskau ein Haus gemietet. Als jedoch 1816 die jüngere Tochter starb, wurde den Eltern der Aufenthalt in diesem Hause unertrăglich. Für einige Zeit fanden sie Aufnahme bei einer alten Freundin der Familie, Natal'ja Andreevna Karpova. Als diese zu Anfang des Jahres 1820 starb, nahm Fürst P.P. Odoevskij die Jaenischs auf.

Seit 1825 oder 1826 verkehrte Karolina Jaenisch, die in dieser Zeit ihre er sten Gedichte schrieb, im Salon der Fürstin Zinaida Aleksandrovna Volkonskaja. Dort begegnete sie A.S. Puskin, Baratynskij, Ševyrev, Jazykov, Vjazemskij, Cyprian Daszkiewicz und Adam Mickiewicz ${ }^{16}$. Eine tiefe Zuneigung verband schon bald Adam Mickiewicz und Karolina Jaenisch. Die Verlobung, die - in welcher Form auch immer - ${ }^{17}$ vermutlich im November 1826 stattfand, löste heftige Konflikte aus. Hătten die Eltern aus Liebe zur Tochter einer Heirat mit dem mittellosen Polen noch zugestimmt, so drohte der Erbonkel - ein Bruder Karl Jaenischs, von dem das Schicksal der Familie abhing - einfach mit Enterbung. Lange schwankte das junge Mădchen zwischen Liebe und Pflichtgefühl und gab schließlich dem Druck der Verwandten nach. $\mathrm{Zu}$ dieser Entscheidung mag beigetragen haben, da $\beta$ die Leidenschaft Adam Mickiewiczs bald nachließ. Im April 1829 trennte sich das Paar endgültig.

Zeugnisse sind Widmungsgedichte im Album des jungen Mädchens; sie wurden - mit Ausnahme der von Jazykov - von Max Vasmer in der "Zeitschrift für slavische Philologie" veröffentlicht (1959 XXVII, S. 35-49).

Vgl. hierzu S. $27 f$. 
Hier brechen die biographischen Mittellungen wieder ab, bis zum Jahr 1836. Vermutlich lebte Karolina Jaenisch, die die Enttăuschung ihrer ersten großen Liebe nur schwer überwinden konnte, in dieser Zeit sehr zurückgezogen, zumal sich auch der Kreis um die Fürstin Volkonskaja nach der en Übersiedlung nach Italien aufgelöst hatte. Sie scheint die Jahre zu eingehender Beschüftigung mit in- und ausländischer Literatur genutzt zu haben; sie übersetzte viel und schrieb auch wenigstens ein Dutzend eigener Gedichte. 1833 erschien "Das Nordlicht"; 1835 folgten Auszüge aus einer Übertragung von Schillers "Jungfrau von Orleans" 18 .

Im Jahre 1836 'ánderte sich durch den Tod des Onkels die wirtschaftliche Lage der Familie Jaenisch völlig. Die Nichte erbte außer einer ansehnlichen Geldsumme ein Haus in Moskau und ein Gut mit tausend Seelen im Gouvernement Rjazan'19; aus dem unvermögenden 'späten Mădchen' war plötzlich eine gute Partie geworden. Noch in demselben Jahr war die Heirat mit dem Schriftsteller Nikolaj Filippovic Pavlov beschlossene Sache; die Hochzeit fandAnfang 1837 statt. Das Ehepaar bezog das geerbte Haus. Ende 1837 oder Anfang 1838 wurde das einzige Kind, Ippol it Nikolaevič, geboren ${ }^{20}$.

In der ersten Schaffensperiode (etwa 1829 bis 1839) trat das originale dichterische Schaffen Karolina Pavlovas hinter einer regen Übersetzungstătigkeit zurück. Unter anderen wurden Puskin, Żukovskij, Jazykov und Baratynskij, Mickiewicz, Scott, Schiller, Goethe und Heine, Petrarca und Dante übertragen $^{21}$. Unter dem Einfluß ihres Mannes wandte sich Karolina Pavlova dann aber mehr und mehr eigener Dichtung zu. Thre neuesten Arbeiten

Revue germanique. - Troisième série. Tome quatrième. $12^{\text {me }}$ numéro. Paris 1835, S. 319-326.

Vgl. dazu I. I. Panaev, Literaturnye vospominanija, S. 177 und N.A. Mel'gunov, Pis'ma Gercenu; in: Literaturnoe nasledstvo, 1955 - Bd. 62, S. $354 \mathrm{ff}$.

1844 wird er als siebenjăhrig bezeichnet (Ċỉerin, Vospominanija, Bd. 1, S. 3). In sämtlichen Nachschlagewerken fehlt das Geburtsjahr.

Vgl. hierzu die Übersicht auf S. 146-148. 
trug sie zunächst den Besuchern threr Donnerstagabende ${ }^{22}$ vor. In diesem Salon verkehrten hervorragende Vertreter ver schiedener geistiger Richtungen. Gegen Ende der vierziger Jahre hatte sich diese Institution jedoch durch die zunehmende Verhärtung der Standpunkte überlebt.

Nach einigen harmonischen Jahren machten sich in der Ehe der Pavlovs wachsende Spannungen bemerkbar. Nikolaj Filippovic verspielte das Geld seiner Frau und betrog sie mit ihrer Cousine, die als 'arme Verwandte' von der Familie aufgenommen worden war. Der Konflikt blieb dem großen Bekanntenkr eis nicht verborgen. Karol ina răchte sich dadurch, daß sie ihren Mann bei jeder Gelegenheit zu demütigen suchte; durch ihr übersteigertes Geltungsbedürfnis verscherzte sie sich die Sympathien gemeinsamer Bekannter. 1852 beschwerte sich Karl Jaenisch, wohl im Auftrag seiner Tochter, beim Moskauer General-Gouverneur über seinen Schwiegersohn, weil dieser das ihm anvertraute Vermögen Karolina Pavlovas verschl eudere. Das war dem Souverneur ein willkommener Anlaß, Nikolaj Pavlov wegen seiner politischen Einstellung nach Perm ${ }^{\circ}$ zu verbannen (1853), aber er wurde noch im selben Jahr begnadigt. Seine Frau entzog sich den Anfeindungen der Moskauer Gesellschaft durch ausgedehnte Reisen, auf die sie ihre Eltern und den Sohn mitnahm. Die wichtigsten Stationen der nächsten vier Jahre waren Petersburg, wo im Juni 1853 Karl Jaenisch an der Cholera starb, Dorpat $(1853 / 54)$ und wieder Petersburg. Dort blieb Karolina Pavlova knapp zwei Jahre, bis Anfang 1856. Aufenthalte in Italien und Konstantinopel folgten. Aus den Jahren 1857 und 1858 liegen Zeugnisse aus der Schweiz sowie aus Weimar, Berlin und Dresden vor, wo sie sich im November 1858 für einige Jahre niederlieli; der Zeitpunkt ihrer Übersiedlung nach

22 Ċicerin berichtet: "Donnerstags traf sich bei ihnen die ganze zahlreiche literarische Gesellschaft der Hauptstadt" (Vospominanija, Bd. 1, S. 5).

Dagegen nennt L. Grossman schon im Titel seines Buches den Dienstag als Empfangstag: "Vtornik u Karoliny Pavlovoj. - Sceny iz Zizni moskov skich literaturnych salonov 40-ch godov". (Odessa 1915, 2. Aufl. Moskva 1922) Dieses Buch war mir trotz aller Bemühungen nicht zugänglich. - Vermutlich ist die Mitteilung des Zeitgenossen Cicer in zutreffend. 
Hosterwitz ist nicht bekannt. Moskau besuchte sie nur noch zweimal: im Sommer 1858, um Vermögensf ragen zu regeln, und 1866 auf Einladung des "Obšcestvo ljubitelej Rossijskoj slovesnosti pri Imperatorskom Moskovskom Univer sitete" ${ }^{23}$, dessen Ehrenmitglied sie seit Februar 1859 war, zu einer Lesung aus ihrer Wallenstein-Übersetzung.

Die erste Zeit nach der Über siedlung war sehr schwer für sie: die Mutter war bald nach dem Vater gestorben, der Sohn, um den sie erbittert gekămpft hatte, blieb bei ihrem Manne; das Vermögen, durch die Spielleidenschaft Nikolaj Pavlovs ohnehin stark geschmolzen, war durch die Reisen vollständig aufgezehrt. So mußte sie von den geringen Einkünften aus ihrer Arbeit leben. Wie in ihrer ersten Schaffensperiode widmete sich die Dichter in auch in der letzten fast ausschließ ich der Literaturvermittlung. Sie über setzte Schiller ins Russische, A. K. Tolstoj und Chomjakov ins Deutsche. - Erst 1864 besserte sich die wirtschaftliche Lage. Durch die Vermittlung Aleksej Tolstojs wurde ihr von der Groffüstin Elena Pavlovna eine Pension bewilligt.

Am 29.3./10.4.1864 starb in Moskau Nikolaj Filippovic Pavlov. In den siebziger Jahren werden die Mittellungen über Karolina Pavlova immer spärlicher. Den einzigen Freund, Aleksej Tolstoj, verlor sie im September 1875. - 1882 starb ihr Sohn Ippolit, an dem sie sehr gehangen hatte ${ }^{24}$, obgleich sie sich wegen seiner leichtsinnigen Heirat mit

In der Beilage zum Jubilăumsheft des "Obšcestvo...", S. 37 ist die Pavlova mit Datum vom 11.2.1859 eingetragen.

Wie sehr sie sich ihm verbunden gefühlt hatte, zeigt $z$. B. ein offensichtlich an ihn gerichtetes Gedicht in deutscher Sprache, das etwa Mitte der siebziger Jahre entstand (K. Pavlova 1964, S. 490):

$O$ rede nicht vom Scheiden und Entsagen, Von dem Gebot der unbarmherz'gen Pflicht!

Den feuchten Blick seh ${ }^{\circ}$ ich dich nieder schlagen Ich glaube nur was deine Träne spricht.

$O$ rede nicht!

Du bleibest mein, was auch die Lippen schwören, Du hörst dein Herz sie einer Lüge zeihn; Du fühlst es tief, daß wir uns angehören, Du weißt es wohl, es kann nicht anders sein,

Du bleibest mein! 
thm uberworfen hatte 25 . Damit waren die letzten Verbindungen zur Gegenwart abgerissen, sie spann sich ein in die Erinnerungen an ihre Jugendliebe; thre letzte Arbeit war eine Mickiewicz-Übertragung: "Die drei Söhne des Lithauers Budris. Von Adam Mickiewicz. Uebersetzt von Karolina v. Pawloff im 81. Jahre ihres Lebens" ${ }^{26}$.

1891 begann die Dichterin, ihre Werke zu sammeln, um sie neu her auszugeben. Da sie jedoch schon bald kränkelte, wurde der Plan nicht mehr ausgeführt. Karolina Karlovna Pavlova starb am 2./14. 12. 1893 in Hosterwitz bei Dresden.

Viele Einzelheiten dieses Lebens kann man als typisch ansehen für die Epoche und die damalige Gesellschaft. Es ist die Hăufung solch charakteristischer Episoden in e in e $m$ Leben, die diese Biographie ungewöhnlich macht, thr einen beinahe melodramatischen Grundzug verleiht. Das Motiv der Liebe zwischen dem armen, begabten Mădchen und dem genialen Dichter fehlt ebensowenig wie das der Geldheirat nach einer unerwarteten Erbschaft; der Ehemann verschleudert nicht nur das Vermögen seiner Frau, er betrügt sie auch noch; die klassische Blldungsreise nach Italien ist so unvermeidlich wie im Alter die Zurückgezogenheit in strenge Einsamkeit. Unverkennbar ist, daß der durch ăußere Umstănde bedingte romanhafte Zug von ihr selbst ubberzeichnet wurde.

25 Vgl. hierzu Ċicerin, Vospominanija, Bd. 1, S. 121: Dort wird berichtet, daß Ippolit leichtsinnig, ohne Liebe und ohne Berechnung geheiratet habe. Die Ehe sei gescheitert. Daten sind unbekannt. in: Feuilleton der Deutschen Roman-Zeitung, Berlin 1890, Sp. 57. 


\section{Kapitel}

"Moi vospominanija"

Die Erinnerungen Karolina Pavlovas erschienen 1875 im "Russkij ar chiv" $^{27}$, niedergeschrieben wurden sie in den späten sechziger Jahren ${ }^{28}$. Ursprünglich sollten sie ihr ganzes Leben umfassen, blieben aber ein Fragment, das schon 1820 abbricht $^{29}$. Der große zeitliche Abstand erklät, daß die Dichter in weniger Auf schluß über Tatsachen als vielmehr eine nachtrăgliche Deutung ihrer Kindheit bietet. Insgesamt sieht sie diese Jahre so: "Unser hăusliches Leben war still und einförmig. Die Mădchenjahre ver gingen für mich ohne Spuren. Es gab für mich nichts besonders Angenehmes und Frohes, es gab auch nichts besonders Lăstiges" ${ }^{30}$.

Von ihren Eltern erzăhlt sie nur wenig. Ihre Mutter wird als eine herzensgute, aber unselbständige und etwas farblose Frau geschildert, die in willenloser Liebe an der Tochter hing. Dagegen scheint der Vater eine ausgeprägte Persönlichkeit gewesen zu sein ${ }^{31}$. Er entstammte einer deut-

Russkij archiv, M. 1875, Nr. 10, S. 222-240.

Die Pavlova selbst schreibt am 11./23.6.1868 an M.M. Stasjulevic, sie habe gerade mit der Nieder schrift begonnen und wäre sehr glücklich, wenn er einige Auszüge in seiner Zeitschrift veröffentlichen könne (Stasjul evic i ego sovremenniki v ich perepiske, S. 455). Über ein Jahr später, am 7./19.10.1869, schreibt A.K. Tolstoj demselben Adressaten, $K$. Pavlova habe ihm ihre Aufzeichnungen vorgelesen; sie sei der schwierigen Aufgabe, objektiv, gleichsam von außen her zu berichten, durchaus gewachsen (Tolstoj, Sobranie socinenij, Bd. 4, S. $311 \mathrm{f}$.). In dem Brief der Pavlova an Stasjulevic (sh. Anm. 28) heißt es: "Es sollen übrigens nicht nur Erinnerungen aus den vierziger und fünziger Jahren werden, sondern Erinnerungen meines ganzen Lebens, mit der Kindheit beginnend" (ib. ).

K. Pavlova, Moi vospominanija, S. 236.

Vgl. I. I. Panaev, Literaturnye vospominanija, S. 180f. und B. N. CiCer in, Vospominanija, Bd. 1, S. 4. 
schen Familie, die aber schon lange in Rußland ansăssig war. Sein Medizinstudium hatte er in Leipzig absolviert; er praktizierte jedoch nicht, wollte nicht "am Tode eines Menschen schuldig" ${ }^{32}$ sein. Die Lehrtätigkeit an der Moskauer Akademie entsprach seiner mehr theoretischen Begabung. Neben seinem Beruf trieb er astronomische Studien, bei denen seine Tochter assistieren mußte; dieser Verpflichtung ver suchte sie bei jeder sich bietenden Gelegenheit zu entrinnen. Über ihre Ausbildung berichtet Karolina Pavlova fast nichts; aber aus einigen Bemerkungen ihrer Bekannten lassen sich Rückschlüsse ziehen. Rapgof behauptet, daß sie bei den Elagins ihre ersten Verse vorgetragen habe ${ }^{33}$. Adam Mickiewicz bewundert nicht nur ihr Zeichentalent ${ }^{34}$, sondern auch ihre Belesenheit und Sprachbegabung. In einem Brief an Karl Jaenisch schreibt er: "Mademoiselle hat in der polnischen Sprache Fortschritte gemacht, die alle in Erstaunen setzen, ausgenommen die, die ihre außergewöhnliche Begabung für jede Art von Studien kennen. In meiner Eigenschaft als ihr ehemaliger Lehrer dieser Sprache bin ich stolz, eine solche Schülerin gefunden zu haben" ${ }^{35}$. Wenn sich die Achtzehn- bis Zwanzigjăhrige schon durch so ausgeprăgte Făhigkeiten auszeichnete, so muß der Vater ihr wohl von Kindheit an eine sorgfaltige Ausbildung geboten haben. Karolina Pavlova spricht nur davon, daß thr mit fün Jahren neben dem Russischen auch das Französische gelăufig gewesen sei. Valerij Brjusovs Behauptung, sie habe in diesem Alter bereits vier Sprachen beherrscht ${ }^{36}$, ist zwar nicht belegt, aber vermutlich zutreffend: Deutsch und Englisch,

K. Pavlova, Moi vospominanija, S. 225.
B. Rapgof, K. Pavlova. Materialy..., S. 7.

Es wird belegt durch zwei erhaltene Portraits von Adam Mickiewicz und Konstantin Aksakov. Das erste lag mir als Abdruck vor (in: "Wiadomósci literackie", Warszawa 1929, Nr. 36). Mickiewicz schătzte ihr Können so, daß er Karolina Jaenisch in den zahlreichen Briefen an Daszkiewicz immer nur "malarka" nannte.

Brief (franz.) vom 23.12.1828/4.1.1829 aus Petersburgo in:

A. Mickiewicz, Dzieła, Bd. 14, S. 440 f.

V. Brjusov, K. Pavlova; in: Ezemesjačnye socinenija, S. 274. 
die Sprachen ihrer Eltern ${ }^{37}$, mögen bald neben Russisch und Französisch getreten sein.

Über die 24jăhrige schreibt N. M. Jazykov: "Sie kennt außergewöhnlich viele Sprachen: die russische, französische, deutsche, polnische, spanische, italienische, schwedische und holländische, - alle diese Zungen (Wortspiel mit "jazyki") streckt sie fortwăhrend heraus und prahlt mit ihnen" 38 .

Breiten Raum in der Schilderung der Kindheit nehmen die Ereignisse des Jahres 1812 ein. Vor diesem Hintergrund versucht Karolina Pavlova das Denken und Empfinden des Kindes nachzuzeichnen. Sie läßt die Fünfjährige während des Napol eonischen Feldzuges schon das Besondere des russischen Menschen erkennen. Pauschal wird das Gemeinschaftsgefühl der Russen und das Zusammenrücken zu einer großen Familie im Unglück gerühmt: "Die allgemeine Not brachte die Menschen einander nahe: Nachbar sorgte für Nachbar; besonders die Moskauer Flüchtlinge begegneten einander wie Verwandte" $^{39}$. Dagegen wird das Verhalten ebenfalls vor den Franzosen geflohener Ausländer - dargestellt am Beispiel eines naiven deutschen Gelehrten und einer französisch-englischen Familie - als dumm, anmaßend und egoistisch gekennzeichnet.

Eingehend werden die Menschen geschildert, mit denen die Eltern in Jaroslavl' und Moskau verkehrten. Zunächst werden zwei Frauen nebeneinander gestellt, die Grä in Stroganova und Natal'ja Andreevna Karpova, beide Zeitgenossinnen Katharinas $I$. und ganz dem 18. Jahrhundert ver-

37 Nach P.P. Gromov hat es in der Familie der Mutter eine englische und eine französische Linie gegeben (vgl. K. Pavlova 1964, S. 5). P. Bartenev behauptet, die Mutter sei, wie der Vater, deutscher Herkunft gewesen (Russkij archiv, M. 1894, H. 1, S. 119).

Brief (russ.) vom 20.1./1.2.1832 an die Brüder, vorhanden in:

Otdel rukopisej Instituta russkoj literatury (Puskinskij dom)

Akademil nauk SSSR; hier zitiert aus: Jazykov, Polnoe sobranie stichotvorenij, 1964, S. 639.

Moi vospominanija, S. 223. 
haftet. Die Grăfin schwelgt in Erinnerungen an ihre Pariser Zeit und an Voltaire; in Rußland umgibt sie sich am liebsten nur mit Aristokraten. Sie ist verweichlicht, egoistisch und hysterisch. Sie sei einer Ver sailler Gräfin am Hofe Marie-Antoinettes ăhnlicher gewesen als einer russischen, heißt es in den Erinnerungen ${ }^{40}$. - Ganz anders Natal'ja Karpova. Nie aus Rußland herausgekommen, verkörpert sie in jeder Hinsicht die russische 'barynja' des 18. Jahrhunderts. Obgleich ihr rüdes Verhalten gegenüber dem Gesinde das Kind abstößt, wird sie spăter als guter Mensch gezeichnet: ihresgleichen hatte sie stets freundlich behandelt! - Vermeintlich echt Russisches wird positiv gegen Fremdes abgesetzt.

Als dritte Figur wird Cerikov vorgeführt, ein reicher Kaufmann, auf dessen Landsitz Frau Jaenisch mit ihrer Tochter einige Wochen verbrachte. Hier erlebte die Neunjăhrige, daß der Lebenssinn einer ganzen Familie darin bestehen kann, von morgens früh bis spät abends zu essen; daß sich alles Streben darauf richten kann, die Funktionsfähigkeit des menschlichen Magens so zu vervollkommnen, daß er fast ohne Unterbrechung Speisen aufnehmen kann.

Der Kreis wird durch die Schilderung des Fürsten P. P. Odoevskij geschlossen. Er ist in jeder Hinsicht das Gegenteil Cerikovs. Feinfühligkeit und Phantasie, liebevolle Aufmerksamkeit und Hilfsbereitschaft si chern ihm die herzliche Dankbarkeit seiner Mitmenschen. Seinem harten Schicksal zum Trotz - er überlebte seine ganze Familie - verlor er seine heitere Gelassenheit bis zum Lebensende nicht.

Dieser Bericht ist weniger die Beschreibung eines doch immer mehr oder weniger - zufalligen Bekanntenkreises, sondern gibt vielmehr eine fast lückenlose Typologie der Gesellschaft des frühen 19. Jahrhunderts. Alles paßt ein wenig zu gut zusammen, wirkt ein wenig zu glatt, der Verdacht drängt sich auf, daß Karolina Pavlova den Blick des Kindes nachtrăglich geschärft hat.

Diesen Eindruck bestätigt der Versuch der Dichter in, in einem Bericht über drei Landaufenthalte die tiefe Empfänglichkeit des Kindes

ib. , S. 233. 
für Naturerlebnisse zu veranschaulichen. 1813 hatte sie in Bratcovo, auf dem Gute der Gräfin Stroganova, das Landleben kennengelernt. Uber die Ankunft berichtet sie: ". . seit diesem Tage war das Landleben zum Gegenstand meiner leidenschaftlichen Liebe geworden" ${ }^{41}$. In den Jahren 1814 und 1815 verbrachte sie die Sommermonate in Petrovskoe-Razumovskoe und "schwelgte noch sehr viel mehr" 42 als in Bratcovo. In der Rückschau verschwimmt alles zur Erinnerung an ein "berauschendes Gefüh grenzenlosen Genusses" ${ }^{43}$. Das Gedăchtnis hat nur die Bilder von Alleen, Treibhăusern mit üppigen Früchten und von kunstvoll angelegten Rosenbeeten festgehalten. Die Natur ist gezăhmt, ist schön und poetisch; sie gibt den passenden Rahmen für eine wohlbehütete Kindheit ab.

Die Ausführlichkeit, mit der sich Karolina Pavlova in ihren Erinnerungen den beiden Themenkr eisen Mensch und Natur widmet, tăuscht einen ausgeprăgten Sinn dafür nur vor, wirkt wie die Kompensation eines vielleicht nur unbewußt empfundenen Mangels. Von Menschenkenntnis und Naturempfinden zeugen Leben und Werk der Dichter in gerade nicht. Von hier aus erklärt sich auch in den "Vospominanija" das Typisieren, das $\mathrm{K}$ lischeehafte der Äußerungen zu diesen Bereichen. - Nur mit wenigen Zeilen bedenkt sie dagegen das, was sie nach übereinstimmenden Aussagen ihrer Zeitgenossen auszeichnete: umfangreiche Sprachkenntnisse, Belesenheit, feines Stilempfinden und das Zeichentalent.
41
42
ib. , S. 229 f.
43
tb. , s. $23 i$.
ib., S. 230. 


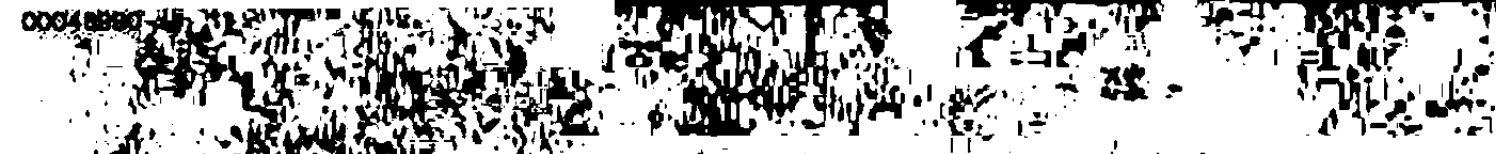

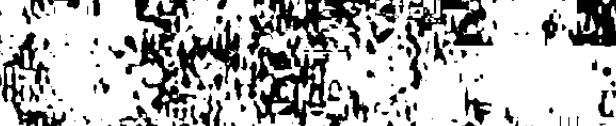

14 A

16 fop ybe

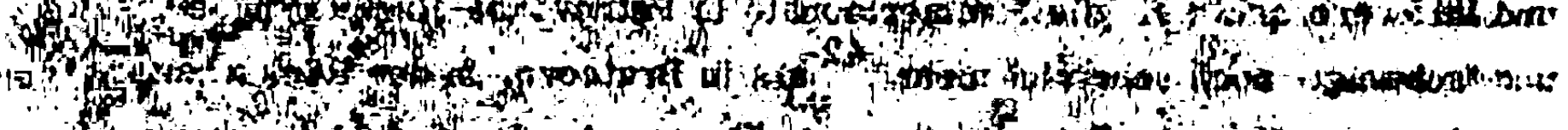

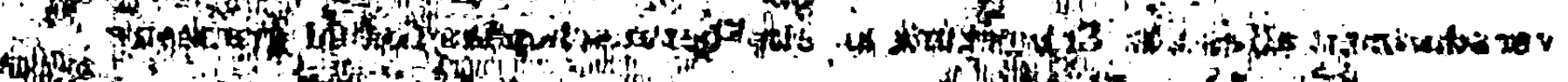

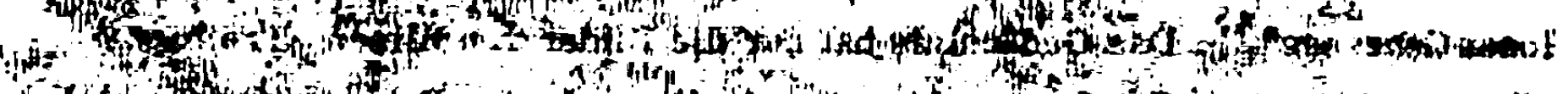

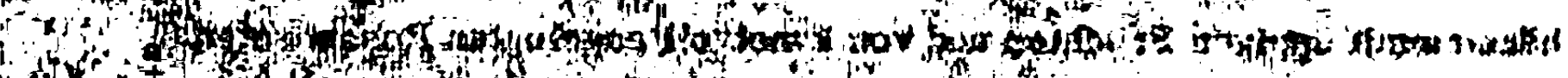

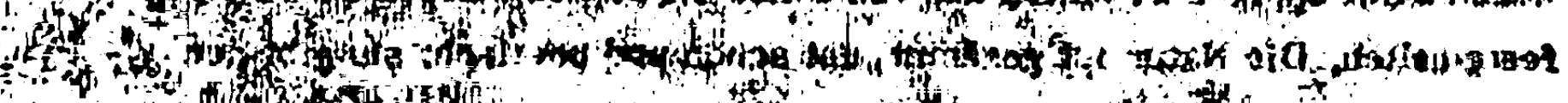

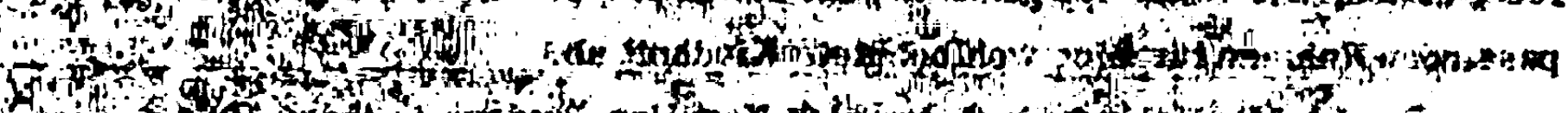

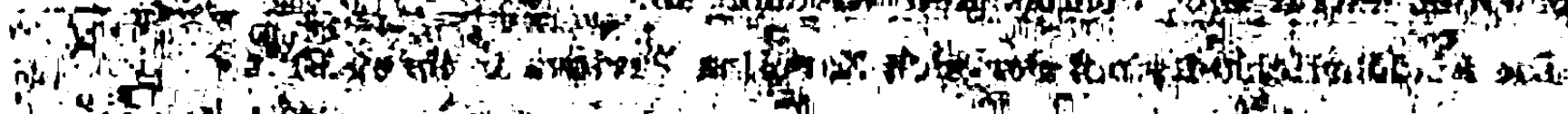

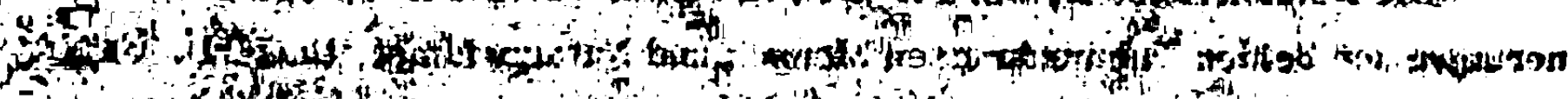

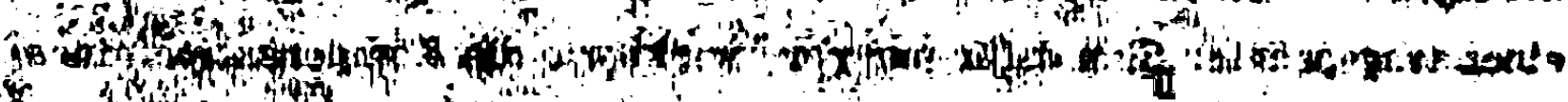

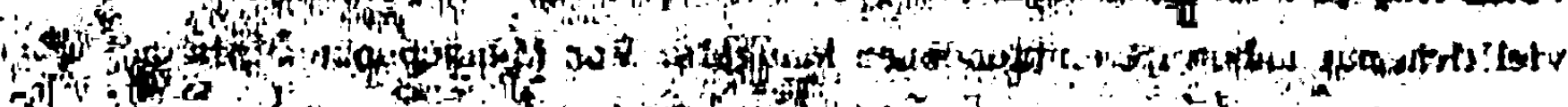

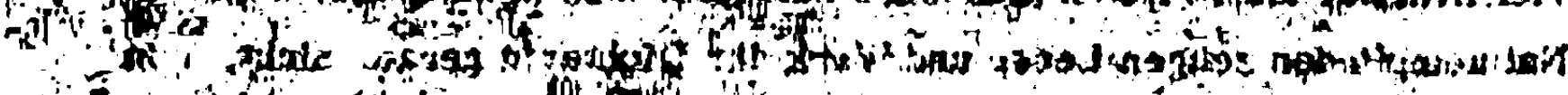

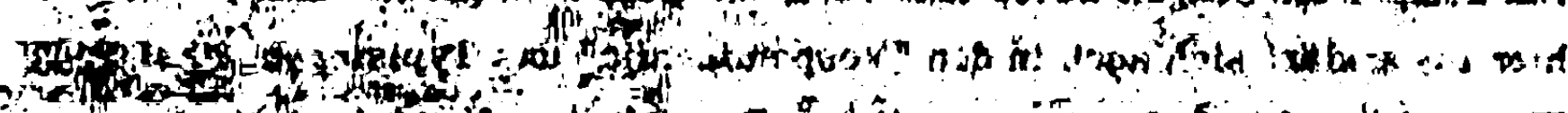

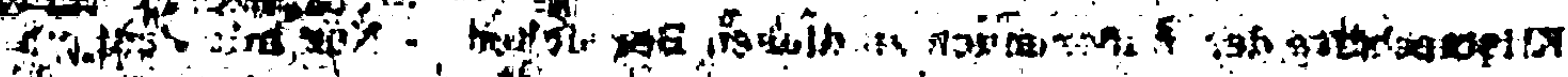

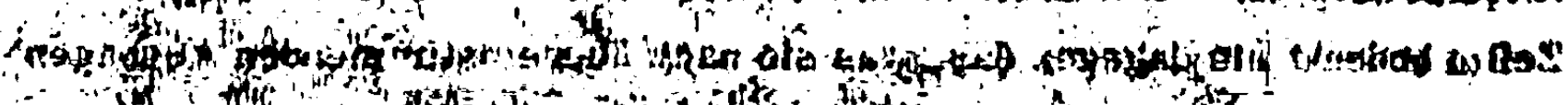

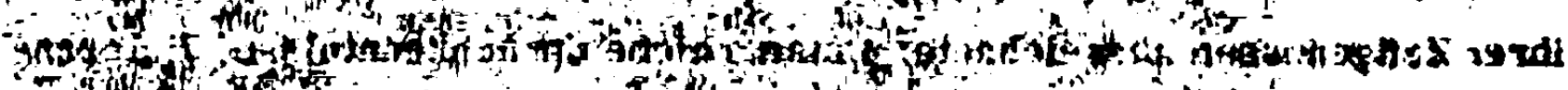
in

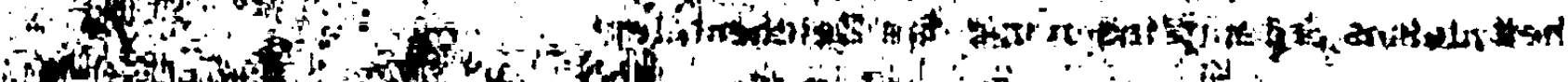

end

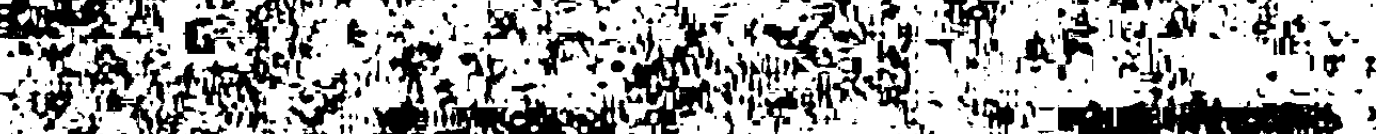

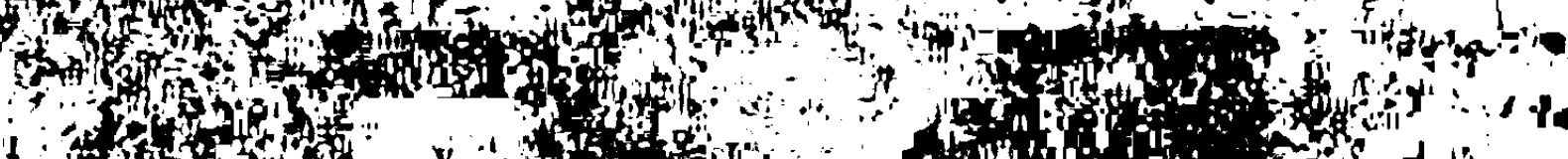
i
$\therefore$.
(t)
(c)
ind

It:

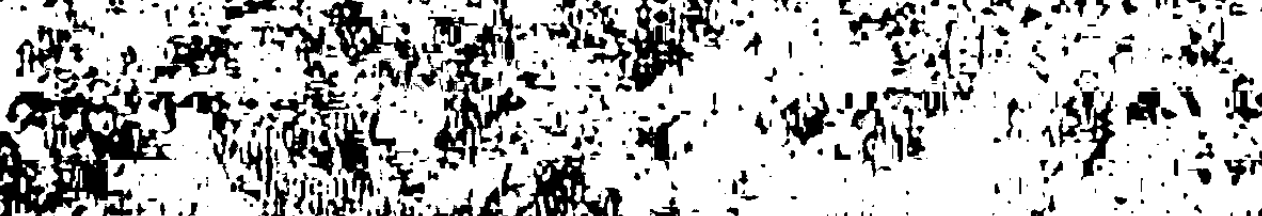

Fon

Jot

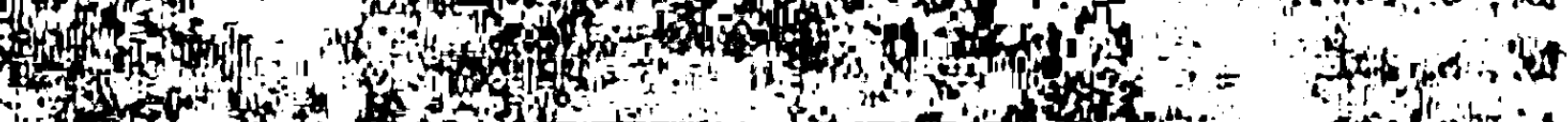

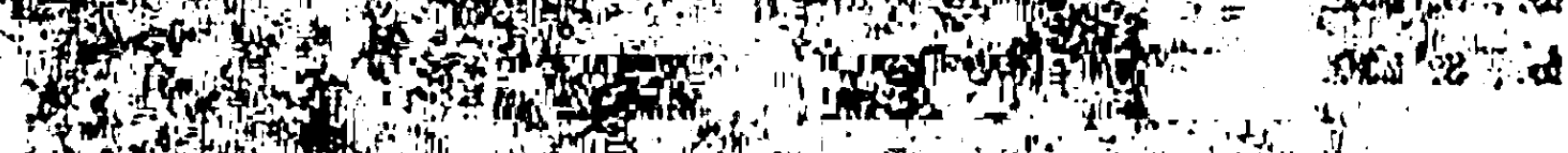

m

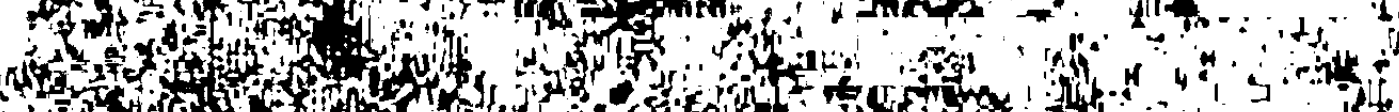
250

Wy

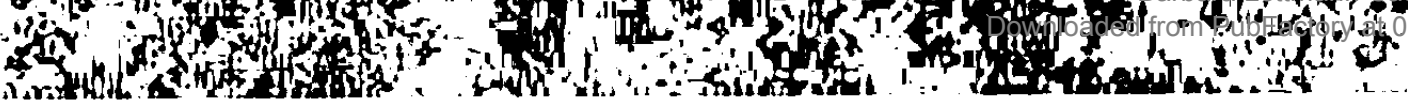

16 


\section{Kapitel}

Partner

1. Adam Mickiewicz

1826 kam Adam Mickiewicz, seit zwei Jahren - als politisch Verdăchtiger - aus der Heimat verbannt, nach Moskau, wo er schnell zu den höchsten Gesellschaftskreisen und zur Intelligenz Zugang fand. Unumstrittener Mittelpunkt des geistigen Lebens war der Salon der Für stin Zinaida Aleksandrovna Volkonskaja, in dem Professoren, Schriftsteller und Journalisten, Dichter, Musiker und Maler verkehrten. Hier war Karolina Jaenisch durch die Elagins eingefüht worden, und hier begegnete die Neunzehnjăhrige dem polnischen Dichter, der sie tief beeindruckte ${ }^{44}$. Wenn sie auch übereinstimmend als ein Mădchen geschildert wird, das sich durch seine früh hervorgetretenen und sorgsam ausgebildeten Talente vor den Altersgenossinnen auszeichnete, konnte sie in dieser auserlesenen Gesellschaft wohl kaum seine Aufmerksamkeit auf sich ziehen. So nahm sie thre Zuflucht zu einer List: sie bat ihren Vater, wie einige andere Damen bei Mickiewicz Polnisch-Unterricht nehmen zu dürfen. Schon bald entdeckte der Lehrer die ungewöhnliche Sprachbegabung und Belesenheit seiner Schullerin; ihr zeichnerisches Können entzückte ihn. Schnell entstand ein sehr vertrautes Verhalltnis zwischen thnen; gegen Ende des Jahres gestanden sie sich gegenseitig ihre Zuneigung. Ob es tatsächlich zu einer offiziellen Verlobung kam, ist nicht restlos zu klären. Karolina Pavlova spricht später in einem Brief an Włady staw Mickiewicz ausdrücklich von dem "glücklichen Tag, an dem der Gegenstand meiner grenzenlosen Liebe fragte, ob ich seine Frau werden wolle" ${ }^{45}$. Dagegen beteuert Adam Mickiewicz in Briefen an seinen Freund Daszkiewicz mehrmals, er habe keinerlei Versprechen gegeben. Daß

Rapgof und Chranevic geben als Datum der Bekanntschaft 1825 an. $\mathrm{Da}$ Mickiewicz aber erst ein Jahr später nach Moskau kam und Chranevic ander erseits von der 'neunzehnjährigen' Karol ina spricht, ist das Bekanntwerden wohl einwandfrei 1826 anzusetzen.

Brief (poln.) vom 20.4.1890; in: Wt. Mickiewicz, Zywot Adama Mickiewicza, Bd. 1, S. 271. 
der Dichter aber zumindest die Möglichkeit einer Heirat angedeutet haben muß, erscheint mir unzweif elhaft; zwei Gedichte der Pavlova auf den `10. November', aus den Jahren 1840 und 1841, in denen sie an jenen glücklichen Tag erinnert, sprechen dafür. Wäre von einer Ehe nie die Rede gewesen, so wäre auch der Widerstand der Familie Jaenisch nicht recht zu begreifen. Ihrer Ansicht nach hatte Mickiewicz drei entscheidende 'Fehler': er war Pole, er war Dichter (also mittellos) und er war politisch 'unzuverlässig'. Trotz dieser negativen Einstellung der Verwandtschaft scheint das Einvernehmen der beiden Liebenden zunăchst ungetrübt gewesen zu sein. Das beweist der übermütige Ton eines Briefes an Karolina aus dem Frühjahr 1827, in dem der Dichter von einem siegreichen Schachturnier gegen Aleksej Venevitinov berichtet: "Premier bulletin de la Grande Armée, donné au champ des échecs 26 mars" ${ }^{46}$. Schon bald ist eine Abkuihlung auf seiner Seite zu beobachten. In einem kurzen Schreiben an Professor Jaenisch heißt es nur im Nachsatz: "Der Lehrer der polnischen Sprache empfiehlt sich der Erinnerung seiner Schuller in" ${ }^{47}$. Mit seiner Reise nach Petersburg Ende 1827 bricht die Verbindung der beiden fast völlig ab. Karolina Jaenisch erfăhrt nur gelegentlich durch den gemeinsamen Freund Daszkiewicz etwas über den Mann, als dessen Braut sie sich fühlt. Über ein Jahr dauert die Ungewißheit, wie sich ihr Schicksal gestalten wird. Wăhrend sie in vollkommener Passivität wartet, ver sucht Mickiewicz in zahlreichen Briefen an Cyprian Daszkiewicz ${ }^{48}$, sich über sein Verhâltnis zu Karolina klar zu werden. Immer wieder betont er, daß sie keinerlei Ansprüche auf inn habe, nie sei von einer Heirat die Rede gewesen; und doch gesteht er ein, sich manchmal in einem ihm selbst unbegreiflichen Maße nach ihr zu sehnen. Kompliziert wird die Situation noch dadurch, daß Daszkiewicz sich selbst heftig in Karolina verliebt hat. Mickiewicz warnt eifersüchtig davor, sich irgendwelchen Hoffnungen hinzugeben, solange

A. Mickiewicz, Dzieła, Bd. 14, S. $332 \mathrm{f}$.

ib. , S. 336.

Der Brief (franz.) ist undatiert, muß aber zwischen dem 26.3./7.4. und der Abreise des Dichters nach Petersburg im November 1827 geschrieben worden sein.

48 Briefe (poln.) aus den Jahren 1828/29; in: A. Mickiewicz, Dzieła, Bd. 14, Nr. 174, 176, 180, 184, 188. 
er selbst noch keine Entscheidung getroffen habe. Sein Zögern hat zwei Gründe: nachdem die anfängliche Leidenschaft verflogen war, mußte ihm in seiner Lage eine Heirat als große Belastung erscheinen; die Unselbstăndigkeit Karolina Jaenischs, ihre Unfthigkeit, sich notfalls um seinetwillen von der Familie zu trennen, ließen ihn an der Richtigkeit dieser Verbindung zweifeln und ver letzten natürlich auch seinen Stolz.

Die drückende Ungewißheit wird für das junge Mădchen so unerträglich, daß der Vater sich zu einem Brief an Mickiewicz entschließt ${ }^{49}$. In seiner Antwort vom 23.12.1828/4.1.1829 stellt der Dichter mit höflichen, unverbindlichen Worten eine Reise nach Moskau in Aussicht und erwăhnt auch Karolina: "Ich höre mit viel Freude, daß Ihre Frau Gemahlin und Fräulein Caroline sich wohl befinden und daß sie ein wenig Erinnerung an mich bewahren" ${ }^{50}$. Unmittelbar darauf erhält er von Daszkiewicz die Nachricht, daß das junge Mådchen erkrankt sei und reagiert auf die "Grillen" sehr heftig, die er mit ihrer falschen Erziehung erklät. Anfang Februar will er das Verháltnis endlich klären: falls Karolina die Trennung allzu hart treffen sollte, so wäre er zur Heirat bereit. Er gibt seinem Freund, der die Verbindung zwischen Moskau und Peter sburg aufrechterhalt, die folgende Anwelsung:

"Beobachte die Maler in kaltblütig. Für den Fall, daß Du sehen solltest, daß sie ohne mich ganz und gar nicht leben kann, daß sie leidet, erkläre ihr meinen Plan, aber verheimliche auch nicht die letzten Zeilen meines Briefes, die mit einem Fortgang drohen, wenn sie es nicht bei den Grillen hat bewenden lassen. Wenn Du ihr meinen Entschluß bereits mitgeteilt hast, mußt Du sie von dem Augenblick an als meine Frau betrachten" 51 .

Daraufhin wendet sich Karolina Jaenisch in einem Brief direkt an Mickiewicz mit der Bitte, zu einer Aussprache nach Moskau zu kommen. Thre Liebe sei unwandelbar, dennoch wage sie nicht, an einen glücklichen Ausgang zu glauben. Er habe sie geliebt - welches Unglück könne die Größe dieser Glückseligkeit erreichen ${ }^{52}$ ? Am 16./28.3. verläßt Mickiewicz Pe-

Der Brief ist nicht erhalten, aber der Dichter geht auf ihn ein. Brief an Karl Jaenisch (franz.); in A. Mickiewicz, Dzieła, Bd. 14, S. 440. Brief an Daszkiewicz (poln.), Februar 1829; ib. , S. 457. Brief (franz.) vom 19.2./3.3.1829; in: Wt. Mickiewicz, Żywot Adama Mickiewicza, Bd. 1, S. XLIVf. 
ter sburg. Was in den wenigen Tagen seines Moskauer Aufenthaltes zwischen ihnen zur Sprache kam, bleibt im einzelnen dunkel; das Ergebnis war die Übereinkunft auseinanderzugehen. Charakteristisch für Karolina Jaenischs Verhalten ist der Versuch, im Abschiedsbrief ${ }^{53}$ die Trennung als Fügung Gottes darzustellen; der Gedanke, den Grund für das Scheitern im Verhalten des einen oder anderen Partners oder beider zu suchen, liegt ihr fern. Ihr Glaube an die gegenseitige Liebe ist unerschütterlich. Sie beschwört Mickiewicz, sich nie in der Erinnerung an sie Vorwürfe zu machen. Am Tage seiner Abreise widmet er ihr noch ein Gedicht, mit dem er ihre Hoffnung auf ein Wiedersehen năhrt:

Wenn die Zugvögel, vor Sturmwind und Rauhreif Fliehend, ihr wehmütiges Abschiedslied singen, Beschuldige sie nicht der Unbeständigkeit! Mit jedem Frühling Kehren sie in dieselben Länder zurück, auf denselben Wegen.

Ihrer Stimme lauschend, erinnere dich des Verbannten, des Freundes! Sooft ihm in Stürmen Hoffnung er strahlt,

Sooft fliegt sein Geist auf den Flügeln der Freude

Aufs neue nach Norden, aufs neue zu dir $\mathbf{5 4}$.

Es war eine endgültige Trennung. Nur einmal noch wollte Mickiewicz mit Karolina Jaenisch Verbindung aufnehmen, nachdem Cyprian Daszkiewicz im November 1829 in Moskau nach langer Krankheit gestorben war. Er bat seinen Freund Józef Jeżowski ${ }^{55}$ um Rat, ob er es wagen könne, an sie zu schreiben: er habe ihr nichts versprochen, und durch die gegenwärtigen Lebensumstände sei die Entfremdung noch größer geworden. Mickiewicz äußerte die Vermutung, daß die hoffnungslose Liebe die Gesundheit

Brief (dtsch.) vom 5./17.4.1829, am Abend, bevor Mickiewicz Rußland verläßt; in: Wz. Mickiewicz, Żywot Adama Mickiewicza, Bd. 1, S. XLVf.

"Przed wichrami i szronem...", Z albumu Karoliny Jaenisch (6. April 1829); in: A. Mickiewicz, Dzieła, Bd. 1, S. 211.

Im Unterschied zum II. Teil, in dem die zur Interpretation anstehenden Werke selbstverständlich im Original zitiert werden, habe ich hier grundsätzlich alle fremdsprachigen Zitate über setzt.

Jósef Jeżowski (1794, 1796 oder 1797 - 1855), klassischer Philologe, Über setzer, Dichter, zeitweise Präsident der "Filomaten". 
Daszkiewiczs untergraben habe ${ }^{56}$. Offensichtlich riet Jeżowski von einem neuen Kontakt ab.

Karolina Pavlova hat diese Jugendliebe nie überwunden. Unter dem unmittelbaren Eindruck des Abschieds hatte sie dem Dichter gelobt, seiner Liebe stets würdig zu sein; die Erinnerung an die glückliche Zeit mit ihm mache sie für immer "ruhig, zufrieden und glücklich... Ich werde für dich beten zu Gott, - und wenn Er dich zu sich nimmt in seinen Himmel, so werde ich Ihm dafür danken, und meine Liebe zu dir wird noch schöner werden!" 57 Unverăndert tritt diese Haltung in dem Brief zutage, den sie 61 Jahre spăter aus Hosterwitz an seinen Sohn Whady slaw schrieb: "Für mich hat er nicht zu leben aufgehört. Ich liebe inn heute, wie ich ihn uber so viele Jahre der Abwesenheit hinweg geliebt habe. Er ist mein, wie er es einst war" ${ }^{\circ 8}$. Sie akzeptiert nicht das Episodenhafte ihrer Begegnung mit Mickiewicz, umgibt sich mit der Gloriole der um der Erhabenheit willen notwendigen Entsagung 59 .

Brief (poln.) aus Rom, Ende Februar 1830 geschrieben; in: A. Mickiewicz, Dzieła, Bd. 14, S. $518 \mathrm{ff}$.

Brief (dtsch.) vom 5./17.4.1829; in: Wł. Mickiewicz, Żywot Adama Mickiewicza, Bd. I, S. XLV.

8 Brief (poln.) vom 20.4.1890; ib., S. 273.

In diesem Zusammenhang ist auch eine Tagebucheintragung Varnhagen von Enses vom 20.5.1858 interessant: " Frau von Pawloff war einst die Braut von Mickiewitsch, rettete ihn aus Rußland vor dem Ausbruche der polnischen Revolution, beweint noch heute seinen frühen Tod; sie sagt, Mickiewitsch sei ein Jude gewesen" (Tagebỉcher, Bd. 14, S. 276). Bezeichnend ist die Umdeutung, die die Episode erfuhr: Mickiewicz verließ Rußland nicht aus freien Stücken, sondern mußte aus politischen Gründen gehen, und sie selbst verschaffte ihm die Möglichkeit der Ausreise; außerdem wird - um die Geschichte noch zu dramatisieren - Mickiewicz zum Juden gemacht, und die Trennung im Fruhjahr 1829 wird zeitlich mit dem polnischen Novemberaufstand von 1830 zusammengelegt.

Der ausgeprägte Sinn für das Symbolische legt den Verdacht nahe, daß die Pavlova ihren spateren Wohnsitz wohl auch deshalb nach Dresden verlegte, weil Mickiewicz inr über Daszkiewicz für den Fall einer Verbindung ein "Rendez-vous" in Dresden in Aussicht gestellt hatte (vgl. den Brief von Ende Januar 1829; in: A. Mickiewicz, Dzieła, Bd. 14, S. 455). 
Diese Verklärung mußte ihre spătere Ehe, auch ohne das per sönliche Verschulden Nikolaj Pavlovs, von Anfang an belasten. "Nach dieser Trennung dachte ich lange, daß für mich jeder Reiz des Lebens verschwunden sei. Acht Jahre spăter erlag ich einer neuen Lockung. Sie wăhrte nur kurz, aber lange genug, um meine Zukunft zu vernichten" ${ }^{60}$. Damit interpretierte sie ihre Heirat als eine momentane Schwachheit, als Abweichung vom vorgezeichneten Weg. Letztlich fühlte sie sich stets als Braut. Nur so wird verstăndlich, warum sie als verheiratete Frau - von ihrer "Jungfrauenschaft" sprechen konnte, was ihr von Sobolevskij die ironische Bezeichnung "Mamsell Jaenisch" eintrug ${ }^{61}$.

Mit Kułakowski kann man sagen, daß Karolina Pavlova die romantische Theorie der idealen Liebe ihrem Leben anzupassen versuchte ${ }^{62}$.

60 Brief (poln.) rom 20.4.1890; in: Wł. Mickiewicz, Żywot Adama Mickiewicza, Bd. 1, S. 272.

61 S. Sobolevskij, Épigrammy i èksprompty, S. 125.

62 S. Kułakowski, Adam Mickiewicz i Karolina Jaenisch - Pawłowa; in: Wiadomosci literackie, $1929, \mathrm{Nr} .36$. 


\section{Nikolaj Fulippovic Pavlov}

Nikolaj Fulippovic Pavl ov wurde am 7./19.9.1805 geboren. Seine Mutter - eine Georgierin - war von Graf Valer'jan Aleksandrovic Zubov aus dem persischen Krieg nach Moskau mitgebracht und dann mit einem Lakaien verheiratet worden. Der aus dieser Ehe hervorgegangene Sohn wurde, noch halb ein Kind ${ }^{63}$, an der Moskauer Theater schule ausgebildet und von deren Direktor, Kokoskin, wegen seiner Intelligenz und Anpassungsf ahigkeit sehr gefördert. Er debütierte am Kaiserlichen Theater als Égisthe in Voltaires Tragödie "Mérope". Unter Kokoskins Führung gelang es ihm, nach und nach die Fesseln seiner Herkunft abzustreifen; er lernte Englisch und Französisch, er lernte es, sich frei und gewandt in der erlesensten Gesellschaft zu bewegen. So konnte er im Hause des Direktors, in dem die Moskauer Aristokratie verkehrte, viele Verbindungen anknüpfen. Nach zwei Jahren gab Nikolaj Pavlov den Beruf auf, der seinen Neigungen gar nicht entsprach, begann an der Moskauer Universităt das Jurastudium und schloß es 1825 ab.

In diese Zeit fallt auch seine erste Ehe. Uber seine Frau ist fast nichts bekannt. Rapgof berichtet, Pavlov habe eine Fuirstin Kasatkina geheiratet ${ }^{64}$; Nadezdin bezeichnet sie nur als "Zögling einer reichen Greisin, der Kvašnina-Samarina" ${ }^{65}$. Die Nachrichten über diese frühe Ehe - Nikolaj Filippovic war achtzehn oder neunzehn Jahre, seine Frau vermutlich noch jünger - weichen stark voneinander ab. Nach Nadezdin verführte der Student das junge Mădchen, um es so zur Heirat zu zwingen; dieser gewaltsame Beginn belastete das Verhălnis der beiden zueinander allzu sehr, als daß sie hätten zusammenfinden können. Wolfsohn dagegen berichtet von feuriger

63 Vermutlich war er erst zehn Jahre (Russkij biograficeskij slovar', Bd. 13, S. 97f.).

B. Rapgof, K. Pavlova. Materialy..., S. 15.

K biografii professora N. I. Nadezdina; in: Russkij archiv, 1885, Nr. 8, S. 578. 
Liebe ${ }^{66}$. Wie dem auch sei: die Ehe endete schon nach einem Jahr; die junge Frau starb an der Schwindsucht, Pavlov war mit zwanzig Jahren Witwer.

Whathrend seiner Studienzeit hatte er sich der Literatur zugewandt und trat 1825 mit seiner ersten Arbeit hervor: mit einer Übersetzung von Schillers "Maria Stuart" 67 , nach einer französischen Bearbeitung. Es folgten in den nächsten Jahren überwiegend Gedichte, 1835 erschienen seine "Tri povesti" 68 . Aleksandr Sergeevic Puskkin, der Pavlov persönlich gar nicht schätzte, schrieb: "Herr Pavlov hat bei uns als erster wirklich interessante Erzählungen geschrieben. Sein Buch gehört zu der Zahl derer, über denen man, nach der Äußerung einer Dame, sogar das Mittagessen vergißt" ${ }^{69}$. Wăhrend S. P. Śevyrevs Rezension ${ }^{70}$ unkxitisch-überschwenglich war, mahnte V.G. Belinskij zur Zurückhaltung: "... das Talent des Herrn Pavlov weckt schmeichelhafte Hoffnungen, aber dessen Entwicklung und das Maß der Kraft sind jetzt noch eine Frage, die erst seine künftigen Werke entscheiden werden" 71 . In Regierungskr eisen wirbelten diese Erzăhlungen viel Staub auf. Der Minister für Volksaufklărung, Uvarov, legte sie Nikolaj I. vor. Unter dem Vorwand vieler "unanständiger Stellen"72, in Wahrheit aber wohl, weil der Autor die Schwächen des russischen Gesell schaftssy stems bloßgelegt hatte, verbot der Zar den Nachdruck und machte dem Zensor Snegirev schwere Vorwürfe wegen der Erteilung der Druckerlaubnis.

W. Wolfsohn, Nikolaus Pawlow; in: Jahrbücher für slawische Literatur..., 1846, H. 9, S. 344.

Marija Stjuart, tragedija v 5 dejstvijach (S̈illera), perevod v stichach $s$ francuzskoj peredelki. M. 1825.

"Imeniny", "Aukcion", "Jatagan".

$$
\text { A.S. Puškin, Tri povesti; in: Polnoe sobranie socinenij v desjati }
$$
tomach, Bd. 7, S. $323 \mathrm{f}$.

S. P. Śevyrev, Tri povesti N. Pavlova; in: Moskovskij nabljudatel ${ }^{\circ}$, 1835, Teil I (März), Buch I, Abt. V, S. 120-130.
V.G. Belinskij, Polnoe sobranie socinenij, Bd. 1, S. 283.

M. Suchomlinov, Épizod iz literatury tridcatych godov (Tri povesti Pavlova); in: Drevnjaja i Novaja Rossija, 1875, Nr. 1, S. 55-65, hier S. 64. 
Karolina Jaenisch war stark beeindruckt von der dichterischen Kraft, mit der Pavlov seine Anklage gegen die Gesellschaft gestaltet, und von der Kühnheit, mit der er per 8 önliche bittere Erfahrungen aus der Zeit, bevor ihn eben diese Gesellschaft akzeptiert hatte, dargestellt hatte. Er, dessen äußere Erscheinung gar nicht anziehend wirkte - er war von kleinem Wuchs und früh ergraut, seine Augen waren stăndig entzündet -, wurde für sie interessant. Er erschien ihr als "kühner Kämpfer für die Erniedrigten und Beleidigten" 73 . Pavlov 8 Verhalten gegenuber der jungen Dichterin, anfangs nur ironisch-distanziert, wandelte sich. Das bezeugt ein Widmungsgedicht vom 12./24.10.1836. Darin konstatiert er, daß sein Leben durch ihren Blick und thren Vers vollig auf den Kopf gestellt worden sei; alle Erinnerungen an vergangene Freuden und Schmerzen seien hinter diesem Neuen zurückgetreten. Er bringe ihr wohl seine Bewunderung dar, danke ihr aber nicht: es sei keine Liebe, sondern ein Traum, ein Sonnenstrahl am düsteren Himmel ${ }^{74}$. Nur einen Monat später schreibt A. I. Turgenev bereits dem Fürsten Vjazemskij, Pavlov selbst habe zu thm von

V. Brjusov, K. Pavlova; in: Ezemesjachye socinenija, S. 280.

Sie, mit Threr europaischen Muse,

Sie, mit Ihrem Blick und Vers,

Haben jetzt auf den Kopf gestellt

Meine Moskauer Welt, meine Alltagswelt.

An den Duft der Poesie,

Und den Glauben meines Herzens,

Und sein erstes Leid,

Und seine erste Freude -

An sie erinnerte ich mich, erinnerte mich an irgendetwas,...!

An irgendein fernes Ideal...

Wenn ich weinte, wartete ich auf irgendetwas,

Wenn ich Schiller las!...

Ich bringe Ihnen den Tribut der Bewunderung,

Der Zauberei der Klänge, dem Glanz der Augen;

Aber für die Tráume, für die Wonne

Werde ich Thnen nicht danken:

Ich liebe nicht, wie an einem nebligen Tag,

Für einen Augenblick, aus schwarzen Wolken

Flog ein unerwarteter Gast auf die Erde hernieder,

Leuchtet mir ins Gesicht ein Strahl der Sonne.

In: Ztschr. f. slav. Phil., 1959 - XXVI, S. 39f. (in russ. Sprache). 
seiner bevor stehenden Heirat mit Karolina Jaenisch gesprochen ${ }^{75}$. Die Bekannten des Paares ver suchten, die Frage zu entrătseln, wie zwei charakterlich so verschiedene Menschen eine Verbindung eingehen konnten. Die Über schwenglichkeit des jungen Madchens hatte sich im Laufe der Jahre bis zur Affektiertheit gesteigert; ihre frühere Passivitait schlug jetzt zeitweise in Aggressivităt um. Nikolaj Filippovic dagegen wird als ein Mann geschildert, in dem hohe, kalt berechnende Intelligenz, auf richtige. Anteilnahme und unglaublicher Leichtsinn miteinander in Widerstreit lagen. Wolfsohn stellt die Zwiespáltigkeit dieses Charakters einige Jahre später treffend dar:

"Ich konnte nicht unterscheiden, war's eine späte Jugend oder ein frühes Alter, was dieses getente, zwetfelhafte Licht auf das ganze Wesen des Mannes warf, und dieses Wider spiel seiner Gebärdung hervorrief, in der eine fast ceremonielle Săuberlichkeit mit einfacher Würde, und eine unbewachte Lebhaftigkeit mit ver ständiger, selbst künstelnder Berechnung wechselte. Diese liebenswlirdige Weichheit, diese gefallige Rundung auf der einen, und diese spitzen Härten auf der anderen Seite, dies auffahr same Entgegentreten und diese lauernde Schmiegsamkeit, dieses Vordrängen einer schwunghaften Natur und das Nachkeuchen einer trăgen, dieses Schwanken und Rutteln einer kernfesten Innerlichkeit, dies gesellige Ver schwimmen und zugleich ein gewohnheitliches Anhảkeln alles das bewirkte ein solches Steigen und Sinken des physiognomischen Thermometers, daß sich hier selbst mit Lavater'schem Feingefühl die moralische Temperatur nicht bald herausf inden ließ"76.

Pavlov selbst soll gesagt haben, er heirate "ne iz deneg, no ne i bez deneg" 77. Seine wirtschaftliche Situation war bis zur Eheschließung keineswegs glănzend; die Wende in seinem Verhalten gegenüber Karolina Jaenisch läßst sich ungef ăhr auf den Zeitpunkt fixieren, als ihr durch den Tod des Onkels ein großes Vermögen zufiel. Dennoch muß man unterstellen,

Brief vom 16./28.11.1836; in: Ostaf'evskij archiv knjazej Vjazem skich,Bd. 3 a, Nr. 791 , S. 361 .

W. Wolfsohn, Nikolaus Pawlow; in: Jahrbuicher für slawische Literatur. .., 1846, H. 9, S. 338.

Diese Formulierung, die Pavlov gegenüber A.S. Chomjakov verwendet haben soll, übernimmt Chomjakov im Januar 1837 in einem Brief an A.V. Venevitinov (A.S. Chomjakov, Polnoe sobranie socinenij, Bd. 8, S. 39). 
daß Nikolaj Filippovic die Ehe nicht nur aus Berechnung einging: er schătzte das literarische Schaffen Karolina Karlovnas sehr hoch. Die Dichter in zollte seiner Arbeit ein ebensolches $\mathrm{MaB}$ an Anerkennung, und sie ubertrug ganz selbstverstăndlich ihre Bewunderung für den Künstler auf den Menschen. Daneben darf aber das Moment der 'Tor schlußpanik' nicht übersehen werden (sie war damals $29 \mathrm{Jahre}$ alt!); in der Moskauer Gesell schaft ging das Gerücht um, sie selbst habe den Heiratsantrag gemacht ${ }^{78}$.

Die gemeinsame literarische Arbeit war zunăchst ein starkes Bindeglied zwischen den Ehepartnern, aber auf die Dauer nicht haltbar. Die ersten Jahre verliefen harmonisch. Man war sich einig in der Freude an aufwendiger Lebensführung. Ein prächtig ausstaffierter Schweizer am Eingang, Lakaien mit Wappenknöpen an der Livree, ein Koch, der wahre Wunderwerke vollbrachte, auserlesene Festessen und literarische Abende legten Zeugnis ab vom Lebensstil der Pavlovs, machten das Haus am Sretenskij-Bul 'var' zum Anziehungspunkt für die Moskauer Gesellschaft. Diese Jahre sind gleichzeitig eine ăußerst schöpferische Periode. Nikolaj Pavlov veroffentlichte 1839 wiederum drei Erzathlungen ${ }^{79}$ sowie eine Prosaübersetzung von Shakespeares "Merchant $\alpha$ Venice"; seine Frau legte neben "Les préludes" und der Ubertragung der "Jungfrau von Orleans" zahlreiche eigene und übersetzte Gedichte vor. Ohne im Partner den literarischen Konkurrenten zu sehen, halfen sie einander durch sachliche Kritik und neidlose Anerkennung. Das zeigt ein Auszug aus einem Brief Nikolaj Pavlovs an A. A. Kraevskij:

"Wenn die Revue Germanique die Scenen (aus der "Jungfrau von Orleans"), die mit der Post geschickt worden waren, ohne jede Protektion annahm, dann ist das schon eine ausreichende Garantie. Im übrigen sind diese Ubersetzungen, soweit wir alle hier das beurteilen können, wirklich gut: das sagt ein Mann, der sich an die Methode håt, daß man Frauen nicht verwöhnen darf" ${ }^{80}$.

78

Vgl. D.V. Grigorovic, Literaturnye vospominanija, S. 193, sowie I. I. Panaev, Literaturnye vospominanija, S. 177 und V.Ja. Brjusov, K. Pavlova; in: Ezemesjacnye socinenija, S. 280. "Maskarad", "Demon", "Million".

80 Brief vom 19.6./1.7.1837; in: Otcet Imperator skoj publicnoj biblioteki za 1892 god. 1895 , S. 89. 
Allmathlich verschlechterte sich das Verhăltnis der Ehepartner zueinander; dabei sind Ursache und Wirkung nicht mehr klar zu scheiden. Nikolaj Filippovid zog sich von seiner Frau zurück; sie fühlte sich in ihren Erwartungen enttăuscht, thr verhärtetes und bitteres Wesen machten sie für ihn nicht anziehender. Das Kind war nicht, wie oft in brüchigen Ehen, Bindeglied, sondern Streitobjekt. - Anlaß zu hăufigen Auseinander setzungen gab die Spielleidenschaft Pavlovs. Schon 1831 hatte Puskin seinen Freund Našcokin vor ihr gewarnt ${ }^{81}$. Durch die Heirat verfügte er über die Mittel, sich dieser Schwäche hemmungslos hinzugeben. An einem Abend wurden 10 bis 15.000 Rubel gewonnen und verloren ${ }^{82}$. Als seine Frau ihm das Versprechen abgenötigt hatte, keine Karte mehr anzurühren, hielt er es ganz wörtlich: er ließ in Zukunft Freunde für sich spielen! Karolina Pavlova suchte die Erfüllung in ihrem dichterischen Schaffen. Hatte ihr Mann früher - wohl aus der Position der Überlegenheit heraus - sie angespornt, so fülte er sich jetzt bedroht; er, dem kontinuier liches Arbeiten nicht gelang und der gerade eine unproduktive Phase durchlebte, argwöhnte, von Karolina Karlovna in den Schatten gestellt zu werden ${ }^{83}$. Thre neuesten Schöpfungen trug sie wathrend der Abendgesellschaften vor. Brachte ein Tell der Găste ihr Bewunderung entgegen, so setzte sie sich durch ihre theatralische 'Dichter-Pose' dem bösen Spott der anderen aus $^{84}$.

Etwa um die Mitte der vierziger Jahre nahm die Dichter in eine arme Verwandte, gleich ihr deutscher Herkunft, bei sich auf: die hübsche

Brief vom 11./23.6.1831 an P.V. Našcokin; in: A.S. Puškin, Polnoe sobranie socinenij, Bd. 10, S. 353.

Vgl. I. I. Panaev, Literaturnye vospominanija, S. 179.

Bereits 1841 schrieb die Frau Chomjakovs an Jazykov: "Pavlov verliert neben ihr; sie richtet ihn zu Grunde. Bald wird man ihre Verse mehr lesen als seine Erzăhlungen. Er scheint sich davor zu fürchten. ."

A.S. Chomjakov, Polnoe sobranie socinenij, Bd. 8, S. 106. 
und kluge Evgenija Aleksandrovna Tannenberg. Mit der Begründung, dem jungen Madchen Zerstreuung zu bieten, aber wohl auch, um selbst 'noch etwas vom Leben zu haben', veranstaltete Karol ina Pavlova Vergnugungen, zu denen vorwiegend junge Leute geladen wurden. Zeitgenossen berichten, daß sie bei dieser Gelegenheit manches Mal die Grenzen des guten Ge schmacks über schritten habe.

"Sie begann, unbăndig nach weltlichen Vergnügungen zu düsten und sagte offen, daß thr als Frau nur noch wenige Jahre blieben, die sie genießen müsse. Aber da sie nicht zur großen Welt gehörte und es in dem Literaturzirkel keine Vergnügungen gab, und da die Literaten keineswegs geneigt waren, ihr den Hof zu machen, stürzte sie sich auf jugendliche Abendgesell schaften und tanzte dort bis zum Umfallen, wobel sie vor unerfahrenen Junglingen thre alternden Reize entfaltete... Sie arrangierte auch zu Hause Abende mit verschiedenen Darbietungen, bel denen sie selbstver stăndlich die Hauptrolle spielte. So zeigte sie sich in einer Scharade als Kleopatra und deklamierte, in einer Wanne sitzend, mit threr heulenden Stimme Verse. Für das Publikum war das regelrecht ein Gespott, und der arme Nikolaj Fillppovic, der sich für seine Frau schämte, entschuldigte sich vor den Gästen, daß man sie zu einem solchen Schauspiel geladen hatte. Aber da war schon jeglicher Einfluß seiner seits geschwunden; Karolina Karlovna entwickelte sich so, daß es kein Halten gab" 85.

So peinlich die Entgleisungen der Pavlova auch waren, so muß man inr doch die tragische Situation zugute halten, in der sie sich befand. Als Frau um die Vierzig mußte sie sich eingestehen, daß ihr Leben weit hinter ihren Erwartungen zuruckgeblieben war; in panischer Angst versuchte sie nun, Verpaßtes nachzuholen, ehe es zu spast war, das heißt, ehe sie zu alt sein wïrde.

B.N. Ċicerin, Vospominanija, Bd. 1, S. $116 f$.

Schon 1844 hatte I. S. Aksakov, der Karolina Pavlova sehr verehrte, seine Verwunderung uber deren Lebenswandel ausgedrilckt und darüber, daß thr Mann nicht dagegen vorgehe. Er merkt an: "Im allgemeinen muß man sagen, daß die Herrschaften eines gewissen Kreises, wenn sie Ernst und Bedeutung der Interessen vergessen haben, die sie verbinden oder verbunden haben, viel dadurch einbüßen, daß sie mit dem Staub und der Eitelkeit der Welt in Berthrung kommen". Er befürchtet, daß die Dichterin durch dieses Verhalten ihren Ruf untergraben könnte (Brief vom 8./20.2.1844; in: I.S. Aksakov v ego pis'mach, Bd. 1, S. 73). 
Zu dieser Zeit betrog ihr Mann sie bereits mit Evgenija Tannenbergo mit dem Gelde seiner Frau bezahlte er eine Wohnung und den Lebensunterhalt fur seine Geliebte, die ihm in den folgenden Jahren zwei Söhne und eine Tochter gebar. Alle Bekannten wußten davon, nur Karolina Pavlova war anscheinend ahnungslos.

Ihre Eltern, die von Anfang an bei dem Ehepaar gelebt hatten, konnten nicht $z w i s c h e n$ den Partnern vermitteln; voller Liebe und Bewunderung für die talentierte Tochter, hatten sie lăngst jede Făhigkeit zur Kritik verloren. Sie hielten sich stets bescheiden im Hintergrund; Frau Jaenisch erfülte die Pflichten einer Haushäterin. Die unermüdliche Für sorge der alten Leute galt dem einzigen Enkel, den sie maßlos verwöhnten. Panaev vergleicht sie mit den Gestalten auf einem flämischen Gemälde: der Vater mit langem silbernem Haar, sorgsam in der Mitte gescheitelt; die Mutter mit 'deutscher Akkuratesse' gekleidet - gefáltelter Kragen, Hăubchen ${ }^{86}$. Die Abneigung Nikolaj Pavlovs gegen alles Deutsche war wohl zu einem großen Teil Abneigung gegen diese - seiner Ansicht nach in den Schwieger eltern verkörperte - Biederkeit und Hausbackenheit.

Die tiefe Enttăuschung und Krănkung, die Karolina Pavlova von ihrem Mann erfuhr, von dem sie - wohl in völliger Verkennung seines Charakters - so viel erwartet hatte, spiegelt sich in einem Gedicht wider, in dem sie sein Portrắt entwirft. Es entstand im Mărz 1851.

Porträ 87

Zuerst dachte er, er wäre auch ein Dichter.

Und schrieb das Drama "Marina Mnisek".

Und Erzahlungen; aber bald verstand er die Welt

Und gab den Überfluß der Gefulhle und nichtigen Gedanken auf.

Er war ein Jüngling in sehr retfen Jahren,

Und, da er die Macht seiner Leidenschaften anerkannte,

Gab er ihnen nach, obgleich er dann immer

Kopf- oder Magenschmerzen hatte.

Aber, ein mit Vernunft ausgestatteter Mensch, war er eben so recht ein Sohn seines Jahrhunderts. 
Und das, was es in alten Zeiten an Gutem gab,

Weckte in inm lebhaftes Mitgefuhl;

Mit größter Weisheit legte er seiner Frau

Die Bedeutung einer Familiengründung dar,

Ihre ganze Pflicht kannte er vollständig,

Wăhrend er sich selbst aber in der Ehe wenig einschränkte.

Überhaupt lehnte er Einschränkungen $a b$,

$\mathrm{Da}$ er nach seiner Meinung eine starke Liebe zur Freiheit hegt,

Wie Richelieu, der in dieser Art

Unstreitig ein großer Liberaler war.

Mein Freund ging einen vernüntigen Weg,

Aber manchmal war er von seltsamen, idyllischen

Einfälen abhăngig: Făhigkeiten haben sich

In ihm im Verborgenen erhalten

Und viele Kr hafte, - so wie in seinem Vaterland?

Sie könnten nur durch ein Wunder hervorgelockt werden.

Und Wunder gibt es nicht. - So lebte er seit langer Zeit,

Dachte immer an dieselben Beschäftigungen,

Kagte nicht, dachte (immer) seltener nach

Und überzeugte sich davon, daß alle Träume - Unsinn sind.

Er ist nicht der einzige: es gibt ihrer viele, ach!

Mit unnützen herrschaftlichen Talenten;

Durch die Gesellschaften Moskaus bummelnd,

Schămen sie sich selbst, so das Leben zu vergeuden;

Manchmal trefft ihr einen von ihnen,

Und er läßst sich auf ein ernsthaftes Gespräch mit euch ein,

Er äußert sich vor euch über eine Unzahl von Vorhaben,

Aber wenn er dann den Zigarrenrauch durch die Zăhne gestoßen hat, Fügt er halblaut hinzu: "Wozu?.."

Gleich nach ihrer Heirat hatte Karolina Pavlova die Verwaltung inres ganzen Besitzes vertrauensvoll ihrem Mann übertragen und sich selbst um nichts gekümmert. Seine Spielleidenschaft und der Unterhalt für Evgenija Tannenberg und deren Kinder hatten im Laufe der Jahre Unsummen ver schlungen, das Gut war heruntergewirtschaftet. Als seine Frau im Herbst 1852 plötzlich die Verworrenheit ihrer wirtschaftlichen Lage erkannte, tat sie unter dem $\mathrm{Zwang}$, rasch handeln zu müssen, einen unüberlegten, verhängnisvollen Schritt. Auf ihren Wunsch hin reichte Karl Jaenisch beim Moskauer General-Gouverneur, Graf A.A. Zakrevskij, eine Beschwerde gegen den Schwiegersohn ein, weil er das Vermögen seiner 
Tochter leichtfertig vertan habe ${ }^{88}$. Streng genommen, hătte der Gouverneur es bei dem Rat an Karolina Pavlova bewenden lassen müssen, einfach die Vollmacht zurückzuziehen. Aber die Anklage gab ihm endlich $\mathrm{Ge}-$ legenheit, persönlich Rache an Pavlov zu nehmen: dieser hatte in einem Spottgedicht ${ }^{89}$, das in Moskau von Hand zu Hand ging, die Willkür und Borniertheit Zakrevskijs angeprangert. Unter dem Vorwand, daß man bei Nikolaj Filippovic gezeichnete Spielkarten vermute, wurde am 10./22.1.1853 eine Haussuchung durchgefuhrt; dabei wurden in der Bibliothek verbotene Bücher entdeckt, von Herzen, Dolgorukij und anderen. Dieser Fund hatte Verhaftung, wochenlange Einzelhaft und, Ende März 1853, die Verbannung nach Perm' zur Folge. Wahrend der neun Monate, die er dort verbrachte, konnte Pavlov das Verhalten seiner Familie nicht verwinden. In seinen Briefen aus dieser Zeit hebt er immer wieder hervor, wie sehr ihn der völlige Mangel an menschlichem Mitgefühl entsetze, wie sehr er unter der brutalen Trennung von seinem Sohn leide. Fast alle Bekannten nahmen Partei für den Verbannten, sie sprachen ihm Trost zu. Aber trotz ihrer Anteilnahme an seinem traurigen Schicksal hielten einige von ihnen nicht mit ihrer Kritik zurück. So schreibt A. I. Košelev:

"Natürlich, der Sache nach sind Sie im Recht; aber im Hinblick auf das Leben allgemein, auf die Leichtigkeit, mit der Sie den Lauf der Dinge betrachteten, im Hinblick auf den Enthusiasmus, mit dem Sie

88

In einigen Berichten heißt es, Karolina Pavlova habe die Beschwerde selbst geführt, so bei Rapgof (K. Pavlova. Materialy..., S. 31), Berg (Zapiski; in: Russkaja starina, 1891, S. 266f.) und Panaev (Literaturnye vospominanija, S. 179). Wahrscheinlicher ist jedoch die Darstellung, wie sie sich u.a. bei Ċicerin (Vospominanija, Bd. 1, S. 116), Bar sukov (Źizn'..., Bd. 12, S. 440) und Brjusov (Eźemesjacnye soc., S. 285) findet, daß sie nämlich den Vater mit dieser Anklage beauftragte. Dafür spricht auch ein Vers aus einem Gedicht, das Nikolaj Pavlov 1852 im Schuldgefängnis geschrieben hat:

... Du hast sehr streng gesprochen, Deutscher, Aber Du hast das Recht von den Himmeln empfangen: Es gibt keine Wahrheit, nichts Absolutes, Und es gibt nur einen Prozeß!

In: Russkij archiv, 1885, Nr. 1, S. 142.

"Ty ne molod, ne glup i ty ne bez duši. ."; zitiert nach B.N. Ċicerin, Vospominanija, Bd. 2, s. 79. 
sich den Karten und anderem hingaben, - sind Sie nicht im Recht... Sie sagen vielleicht: wozu diese Moralpredigt? Wen man liebt, mit dem soll man aufrichtig wie mit sich selbst sprechen. .." 90 .

Durch Vermittlung der Zarin wurde Pavlov bereits im Dezember 1853 begnadigt, am 27.12.1853/9.1.1854 feierte er mit seinen Freunden Wiedersehen.

Für seine Frau war durch ihre Kurzschluß-Handlung das Leben in Moskau unerträglich geworden. Sie entzog sich den Anfeindungen und dem boshaften Klatsch im Mai 1853 durch eine Reise nach Petersburg ${ }^{91}$, zusammen mit den Eltern und Ippolit. Kurz darauf, in der er sten Juni-Hảfte starb Karl Jaenisch dort an der Cholera. Sein Tod stürzte die beiden Frauen in panische Furcht; die Beerdigung überließen sie einem entfernten Verwandten und flüchteten nach Dorpat. Dort scheint Karolina Pavlova auch bald ihre Mutter verloren zu haben.

Das zerstrittene Ehepaar begann nun einen erbitterten Kampf um den Sohn. Von Perm' aus versuchte Nikolaj Pavlov, durch ausführliche, belehrende Briefe den starken deutschen Einfluß zu neutralisieren, dem Ippolit nicht nur von seiten der Mutter, sondern noch mehr durch den Besuch der deutschen Universitat in Dorpat ausgesetzt war. Schon bald nach der Begnadigung des Vaters, für den er tiefe Zuneigung und Bewunderung empfand, kehrte Ippolit Nikolaevič nach Moskau zurück. Er lebte dort, wie einem Brief Karolina Pavlovas zu entnehmen ist, mit seinem Vater und der Familie Tannenberg zusammen. Seine Mutter wollte inn aus dieser nach

90

Iz pisem k N. F. Pavlovu ego prijatelej (1853); in: Russkij archiv, 1894 , Buch 2, S. 219.

Zwei Jahre später (1855) nimmt sie in einem Gedicht an eine nicht identifizierte Person ("N. P. B-oj") zu den Vorwürfen Stellung. Bekannte, Freunde und Verwandte hătten eine "fröhliche Hetzjagd" veranstaltet; dabei hătten sie aber nicht versăumt, zu Gott zu beten, daß er ihnen verzeihen möge, so wie sie verzeihen. Als "Schande und Pest" sei ausgelegt worden, was "Leid und Unglück" gewesen sei. Die Dichterin dankt der Adressatin dafür, daß diese für ihr Verhalten Entschuldigungsgründe gefunden habe (K. Pavlova 1964, S. 186). 
ihren Begriffen unwïrdigen Situation retten und ihn zu sich nehmen ${ }^{92}$. Ihre Bemühungen waren umsonst, da Ippolit ihr völlig fremd gegenüberstand. In Moskau schloß er sein Studium an der philosophischen Fakultăt der Universitắt ab.

Die Vermögenslage der Pavlovs blieb noch jahrelang ungeklärt. Karolina Karlovna setzte ihrem Mann einen geringen Teil der jährlichen Pachteinnahmen als Unterhalt aus und ließ sich alles übrige ins Ausland schicken unter der Hand, denn der Besitz war hoch verschuldet ${ }^{93}$.

Die Glåubiger waren Bekannte der Pavlovs, die mit beträchtlichen Summen ${ }^{94}$ ausgeholfen hatten und nun durch das rücksichtslose Verhalten der Dichterin, für das es nur die Entschuldigung gibt, daß sie über keine ander en Einkünfte verfügte, selbst in große Bedrängnis gerieten. Erst nach 1860 scheinen die verwickelten wirtschaftlichen Verhăltnisse geordnet wor den zu sein.

Nikolaj Pavlov machte sich durch journalistische und literarische Arbeiten sehr schnell von seiner Frau unabhängig. 1860 gründete er die Zeitschrift "Naše vremja", die er jedoch 1863 aus finanziellen Gründen aufgeben mußte. Im Herbst desselben Jahres begann er, die "Russkie vedomosti" herauszugeben. Aber eine schwere Herzkrankheit zwang ihn schon bald, die Arbeit einzustellen. Er starb am 29.3./10.4.1864.

Brief vom 22.4.1860 an N. A. Mel'gunov; in: Rapgof, K. Pavlova. Materialy..., S. $71-73$.

Trotzdem tritt sie weiterhin als reiche Frau auf. Varnhagen von Ense notierte am 20.5.1858: "Sie reist nach Moskau um ihre 1800 Bauern freizulassen, sie will ihnen Land geben ohne Entgelt, sie denkt freisinnig, revolutionair, und will auch so handeln" (Tagebücher, Bd. 14, S. 275).

Nach Mel'gunovs Aussage hätte sie nur durch den Verkauf ihres gesamten Besitzes ihre Verbindlichkeiten ihm gegenüber begleichen können (N.A. Mel'gunov Gercenu, 9./21 .9.1858; in: Literaturnoe nasledstvo, 1955 - 62 , S. 378).

Es ist auf schlußreich, daß sie selbst in dieser Situation nicht auf theatralische Gesten verzichten kann.

94 N. P. Ogarev hatte ihnen nach eigenen Angaben 30.000 Silberrubel geliehen (vgl. Brief vom 21.12.1854/2.1.1855 an Annenkov; in: P. V. Annenkov i ego druz'ja, S. 647). - Die Schulden bei N. A. Mel'gunov betrugen 19.000 Silberrubel (vgl. dessen Brief an Herzen vom 9.9.1858; in: Literaturnoe nasledstvo, 1955 - 62, S. 378). 


\section{Boris Isaakovic Utin}

Um das Bild von dem merkwürdig ambivalenten Verhalten Karolina Pavlovas gegenüber einem Partner abzurunden, muß hier noch auf ihre Beziehung zu Boris Isaakovic $U t$ in ${ }^{95}$ eingegangen werden ${ }^{96}$. Wenn auch kein zeitgenössisches Zeugnis vorliegt, so läßt sich doch der Verlauf dieser Bekanntschaft auf Grund von zwölf Gedichten nachzeichnen, in denen die Dichterin das per sönliche Erlebnis verarbeitete ${ }^{97}$.

In Dorpat, wo die Pavlova nach dem Tode des Vaters mindestens ein Jahr lebte, begegnete sie auf einer Gesellschaft dem 25 Jahre jüngeren Jura-Studenten Boris Utin. Ohne einander zu kennen, entdeckte einer am anderen die gleiche innere Abneigung gegen das unverbindliche "leere Gerede" dieses Kreises, eine "Ähnlichkeit der Seele", die nicht auf Gefühl, sondern auf der Denkweise beruhte. Bei dem nächsten Zusammentreffen wurde diese erahnte Geistesverwandtschaft in einem erbitterten, ja fast feindseligen Streitgesprăch erprobt, das - allen gesellschaftlichen Gepflogenheiten zum Trotz - bis zum nächsten Morgen dauerte und in dem

Ein Bruder des Sozialrevolutionärs Nikolaj Isaakovic Utin (1840/41-1883).

Eine frühere Episode, die noch in die Zeit der Ehe mit Pavlov fiel, ist bewußt ausgelassen worden, da nur Cicerin über sie berichtet; der Wahrheitsgehalt dieses einzigen Zeugnisses schien mir nicht über alle Zweifel erhaben. Nach dieser Darstellung soll Karolina Pavlova mit einem der Besucher ihrer für die Jugend veranstalteten Gesellschaften, einem jungen Mann in unbedeutender Position, ein sehr vertrautes Verháltnis gehabt haben. Bei der Haussuchung im Januar 1853 seien Briefe gefunden worden, in denen sie ihm vorgeschlagen haben soll, gemeinsam nach Andalusien zu reisen (vgl. Ċicerin, Vospominanija, Bd. 1, S. $117 \mathrm{f}$.).

97 Pavel Gromov gibt in seinem Vorwort zu der Werk-Ausgabe von 1964 nicht an, wem die Identifizierung des Adressaten dieser Gedichte gelungen ist und auf welche Weise. In dem Sammelband von 1863 sprengte die Dichter in durch die Anordnung thematischen $\mathrm{Zu}$ sammenhang und zeitliche Folge. Den einzigen Anhaltspunkt bietet das Gedicht "Kogda odin, sredi stepi Sirijskoj. ." , das 1859, mit den Initialen "B. U." über schrieben, er schienen war (in: Russkij vestnik, 1859, Bd. 21, S. 698-700). 1863 fehlte dieser Titel. 
alles Persönliche beiseite gelassen wurde. "... und kr ðftig, wie Brüder,/ drückten wir uns dann die Hand" 98 .

Die beiden folgenden Gedichte ${ }^{99}$ zeigen, daß die Beziehung rasch sehr eng wurde. Die Dichter in mußte die Katastrophe ihrer Ehe bewătigen; und auch Utin scheint einen Schicksalsschlag erlitten zu haben, denn Karolina Pavlova spricht von seinen "Wunden", die heilen müssen 100 . Wăhrend er off enbar sein inneres Gleichgewicht verhălnismäßig schnell zurückgewonnen hatte, blieb ihr noch lange ihr Unglück gegenwärtig. Trotzdem begriff sie, daß sie inn nicht halten konnte und durfte. Diese Situation gestaltete sie in dem Gedicht vom 4./16. April. Ein Pilger bricht in der Wüste verdurstend zusammen. Ein Wanderer findet ihn, kann ihn aber nur kurzfristig erfrischen; sein eigener Wasservorrat reicht gerade noch für den langen Weg nach Hause, wo Mutter und Schwester ihn erwarten. Bevor er den Pülger seinem Schicksal überlassen muß, hört er noch dessen Lebensgeschichte. In den letzten Strophen deutet Karolina Pavlova dieses Bild: Utin hat ihr geholfen, soweit er es vermochte. Aber man kann nicht jedem beistehen; er muß jetzt ander en Pflichten gerecht werden. Er muß vorwärts gehen, unbeirrt von dem Gedanken, daß hinter ihm ein Mensch dem Tode ausgeliefert ist.

Dieser Aufforderung, dieser Bereitschaft zum Verzicht liegt ein konkr eter Anlaß zugrunde: Bor is Utin beendete zu dieser Zeit sein Studium in Dorpat und siedelte nach Petersburg über. - Bald darauf verlegte auch die Dichterin ihren Wohnsitz in die Residenz. Der Wunsch, in Utins Nähe zu sein, wird zu diesem Entschluß wohl in eben dem Maße beigetragen haben wie die Notwendigkeit, literarisch wieder Anschluß zu finden; in den vergangenen drei Jahren hatte sie kaum etwas veröffentlicht.

\footnotetext{
98 Vgl. dazu das Gedicht vom Januar 1854 "My stranno sošlis'..." (K. Pavlova 1964, S. 153f.).

99 "Menjajas' dolgimi recami...", vom 30.3./11.4.1854 (ib., S. 154f.) und "Kogda odin, sredi stepi Sirijskoj..." , vom 4./16.4.1854 (ib., S. 155-157).

100 "Menjajas' dolgimi rečami..." (sh. Anm. 99, hier S. 155).
} 
Zwei zeitlich wiederum nahe aufeinanderfolgende Gedichte sind Ausdruck des Bemühens, die unumgăngliche Trennung zu bewăligen ${ }^{101}$. Ihre Seele ist "dem Schicksal ungehor sam", sie nimmt den Kampf mit dem Leben wieder auf. "Den Glauben an Tränen, Worte und Lächeln / konnte mein Verstand nicht aus dem Herzen reißen" 102.

Karolina Pavlova und Utin scheinen sich noch einmal begegnet zu sein. In dem Gedicht "Dve komety" 103 wird das Bild zweier Sterne verwendet, die - von der vorgeschriebenen Bahn abgekommen - einander begegnen, vom Schicksal wieder getrennt werden und dann noch einmal einander näher kommen als je zuvor. - Bald darauf muß der endgültige Bruch erfolgt sein. Die letzten Gedichte dieser Reihe variieren ausnahmslos das Thema 'Resignation und schmerzliches Erinnern' ${ }^{104}$.

Die Gründe für diese etwas ungewöhnliche Freundschaft sind viel fältig. Bei Karolina Pavlova hat sicherlich das Gefühl, als Frau unerfüllt gebl ieben zu sein - es wurde schon darauf eingegangen - , eine bedeutende Rolle gespielt. Daneben war aber auch ihr Muttergefühl eine wichtige Komponente: ihr Sohn hatte sich ganz dem Vater zugewandt; Bor is Utin war nur wenige Jahre älter als Ippol it. - Der Student seiner seits wurde zunächst wohl von einer vermeintlichen geistigen Überlegenheit der Dichter in angezogen. Es ist aber auch nicht auszuschließen, daß er, noch unter dem unmittelbaren Eindruck eines traurigen Erlebnisses stehend, das Mütterliche in ihr suchte.

101

"Kogda suču ja naudač..." (K. Pavlova 1964, S. 169), "O bylom, o pogibsem, o starom..." (ib. , S. 170); beide Gedichte entstanden im Dezember 1854.

102 "O bylom..." (sh. Anm. 101, S. 170).

103 "Dve komety" (April 1855); (K. Pavlova 1964, S. 173f.).

104 "Prošlo spolna vse to, cto bylo..." (Oktober 1855); (ib., S. 184), "K. .. (Da, ja dušoj teper' zdorova. .)" (1855); (ib. , S. 187-189), "Za tjaźki cas, kogda ja dorogoju..." (1855 oder 1856); (ib., S. 189), "Umolk sum ulic, - pozdno..." (1858!); (ib., S. 216f.). 
Obgleich diese dritte und letzte Bindung der Pavlova unter ganz anderen Vorzeichen stand als die beiden früheren, nahm sie einen sehr ăhnlichen Verlauf.

Auf schlußreich ist eine Strophe aus einem Gedicht der Utin-Periode, im Dezember 1854 geschrieben:

"Nach jedem Irrtum ging ich aufs neue, Die grausame Lehre vergessend, Unbewaffnet in den Lebenskamp.. 105.

Was sie als Vorzug, als immer sich erneuernden Lebensmut begreift, ist in Wirklichkeit die Unfăhigkeit, sich mit dem Leben auseinanderzusetzen. Erfahrungen wurden nicht ausgewertet, sondern - wenn sich das Leben nicht dem Ideal bequemte - unbearbeitet gleichsam 'ad acta' gelegt. Ein neuer Anfang wurde gemacht, mit denselben alten Hoff nungen, mit immer dem gleichen Ende.

Die ideale Konzeption der Liebe verwandter Seelen scheiterte an der Realităt der charakterlichen Unterschiede, der Bedingungen des Alltags, am Menschlich-allzu-Menschlichen, das sich dem Schema nicht fügt.

105 "O bylom, o pogibšem, o starom..." (K. Pavlova 1964, S. 170). 


\section{Kapitel}

\section{Salon}

Seiner Besprechung der 1915 von Brjusov herausgegebenen Werk-Ausgabe Karolina Pavlovas gab der Rezensent V. Pereverzev den Titel "Salonnaja poètessa" ${ }^{106}$. Diese boshaft gemeinte Über schrift besagt zum einen, daß Pereverzev nicht viel von der Pavlova hielt, zum anderen nicht viel von der Einrichtung des Salons. Er sah hier wie dort nur das Äußerliche: am Salon nur den prachtvollen Rahmen, das belanglose Geplänkel; an Karol ina Pavlova nur ihr - unbestreitbar vorhandenes - Geltungsbedürfnis. In jedem Falle traf er damit lediglich einen Teil der Wahrheit.

Zweifellos war der Salon nicht nur ein Forum geistiger Auseinandersetzung, sondern auch eine glanzvolle gesellschaftliche Veranstaltung; außer ernsthaften Gesprächen gab es sicher auch viel Katsch und Oberflăchlichkeit. Wie die Gewichte verteilt waren, hing weitgehend von den Gastgebern und von der Zusammensetzung der Gesprächsrunde ab. Zum Beispiel war der Salon der Volkonskaja dank threr Persönlichkeit, der Auserlesenheit der Gäste und auch der thematischen Beschränkung auf rein kinstler ische Fragen Zentrum des kulturellen Lebens im Moskau der zwanziger Jahre gewesen. In den dreißiger und vierziger Jahren trat der philosophische und pol itische Disput in den Vordergrund. In dieser Zeit rigoros beschränkter Meinungsfreiheit hatte die Zahl der Salons stark zugenommen, waren mehr und mehr Inseln des ungehinderten Gedankenaustauschs geschaffen worden. "Am Montag kamen wir bei Čaadaev zusammen, am Freitag bei Sverbeev, am Sonntag bei A. P. Elagina" ${ }^{107}$, berichtet Herzen und übergeht den Donnerstag der Pavlovs, bei denen er auch verkehrte. Es darf jedoch nicht übersehen werden, daß die Einrichtung eines 'jour fixe' auch eine Frage des Prestiges, daß der Salon auch eine Art Statussymbol geworden war. Zweifellos erfuhr das geistige Leben

V. Pereverzev, Salonnaja poétessa; in: Sovremennyj mir, 1915, Nr. 12, Abt. II "Kritika i bibliografija", S. 185-188.
A. Gercen, Sobranie socinenij, Bd. 9, S. 156. 
der Stadt durch diese 'Konkurrenz' viele Impul se. Aber es lag auch in der Natur der Institution Salon ${ }^{108}$, daß die Gespr ăche einem gewissen gesellschaftlichen Reglement unterworfen waren, daß die Etikette manches Mal verbot, Kontrover sen mit aller Deutlichkeit auszutragen; Rücksichten auf Găste und Gastgeber zwangen oft zum Themenwechsel oder zum vorzeitigen Abbruch der Auseinander setzung. Herzen schildert das sehr plastisch:

"Die Rede kam auf die "Otecestvennye zapiski", das heißt auf Belinskij. Kireevskij ăußerte sich mit empörter Verachtung, Dmitriev mit einem Witz. Es war von irgendeinem unwichtigen Artikel die Rede, ich warf ihnen ebenso scharf meine Meinung zugunsten der "Otecestvennye zapiski" entgegen. Es trat Schweigen ein. Sogleich wurde das Gesprächsthema gewechselt. Als ob bei einer Hymne an Gott ein Atheist die Stimme erhoben hătte" 109.

Ilustre Găstelisten, geistreiches Extemporieren und brillante Rhetor ik dürfen nicht darüber hinwegtăuschen, daß das Gesprăch im Salon zu einer gewissen geistigen Disziplinlosigkeit verleitete und oft die Gewandtheit des Vortrags wichtiger war als der Inhalt. Nicht ganz frei von diesem Vorbehalt ist der folgende Bericht $\dot{C}$ icerins von einem Abend bei den Pavlovs:

"Am Donnerstag traf sich bei thnen die ganze zahlreiche literarische Gesellschaft der Hauptstadt. Hier gab es bis tief in die Nacht hinein lebhafte Dispute: Redkin mit Sevyrev, Kavelin mit Aksakov, Herzen und Krjukov mit Chomjakov. Hier erschienen die Kireevskijs und

Eine den politisch-philosophisch-ästhetischen Intentionen eher angemessene, d.h. effektivere Form der geistigen Auseinandersetzung war die Arbeitsgemeinschaft, wie sie beispielsweise der junge $\mathrm{Ba}-$ kunin oder, schon in den dreiBiger Jahren, Stankevic eingerichtet hatten. Ohne aufwendigen Rahmen wurde hier in kleinem Kreis ver sucht, ganze Themenkomplexe in den Griff zu bekommen.

Tschizewskij meint, man müsse "bei der Beurteilung der Salons... von denselben Voraussetzungen ausgehen wie bei den Zirkeln. Auch dort pul sierte das geistige Leben..." (D. Tschizewskij, Hegel bei den Slaven, S. 174). Diese Beurteilung trifft aber nur insofern zu, als beide Gruppen auf die Auseinander setzung in der Öfentlichkeit verzichten mußten; aber der Unter schied $z$ wischen der gezielten Diskussion und systematischen Erarbeitung eines Fragenkomplexes im Zirkel und dem mehr zufäligen Gesprăch im Salon wird dabei verwischt.

109 Eintragung vom 23.11./5.12.1842; in: A. Gercen, Sobranie socinenij, Bd. 2, S. 245. 
der damals noch junge Jurij Samarin. Stăndiger Gast war Caadaev mit seinem Kopf, so kahl wie eine Hand, mit seinen untadeligen geseil schaftlichen Umgangsformen, mit seinem gebildeten und originelien Geist und der ewigen Pose. Das war die glănzendste literarische Zeit Moskaus. Alle Fragen, philosophische, historische und politische, alles, was die bedeutendsten zeitgenössischen Köpfe beschätigte, wurde in diesen Versammlungen erörtert, wo die Gegner voll ausgerüstet erschienen, mit gegensätzlichen Meinungen, aber mit einem Vorrat an Wissen und dem Reiz der Beredsamkeit. Chomjakov führte damals einen erbitterten Kamp gegen Hegels Logik... Zu ihrer Verteidigung trat Krjukov hervor, klug, lebhaft, begabt, ein tiefer Kenner der Philosophie und des Alter tums. Sobald er im Empfangszimmer erschien, .... entbrannte der Streit um Sein und Nichtsein. Ebenso hitzige Diskussionen wurden auch über die grundlegende Frage der russischen Geschichte geführt, über die Reformen Peters des Großen. Um die Streitenden bildete sich ein Kreis von Zuhörern; das war ein ständiges Turnier, in dem sich Wissen, Geist und Schlagfertigkeit erwiesen, und das um so mehr Anziehungskraft besaß, als es - den Zeitumständen entsprechend - die literarische Polemik er setzte... " 110

Die Pavlova hielt sich aus diesen weltanschaulichen Str eitgesprächen weitgehend heraus, dagegen betont Cicerin ihre lebhafte Beteiligung an Literaturdiskussionen ${ }^{111}$. Er berichtet aber auch, daß sie gern die Gelegenheit ergriff, vor den Gästen "mit ihrem literarischen Talent zu prunken" 112. Wenn Pereverzev von einer Art "Spielzeugleben" 113 spricht, das sich im Salon abspielte, dann meint er wohl die dieser Einrichtung innewohnende Verführung zum Theatralischen. Nach allem, was von der Pavlova bekannt ist, trifft Pereverzevs Titulierung "Salonnaja poètessa" insofern zu, als die Dichter in von dieser Möglichkeit der Selbstdarstellung reichlich Gebrauch machte; nicht zuletzt wohl auch deshalb, wen die Etikette gegen scharfe Kritik abschirmte. Auf einer solch festlichen Veranstaltung, wie sie der Salon der Pavlovs war, ist den Gästen sicher Lob leichter über die Lippen gegangen als Tadel, zumal gegenüber der Gastgeberin.

110 B.N. CiČerin, Vospominanija, Bd. 1, S. $5 \mathrm{f}$.

ib. , S. 5 .

ib. , S. 4.

V. Pereverzev, Salonnaja poettessa; In: Sovremennyj mir, S. 186 (re.). 


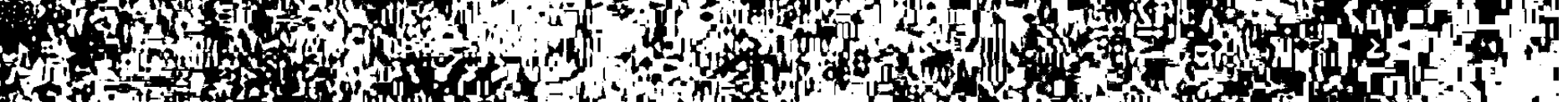

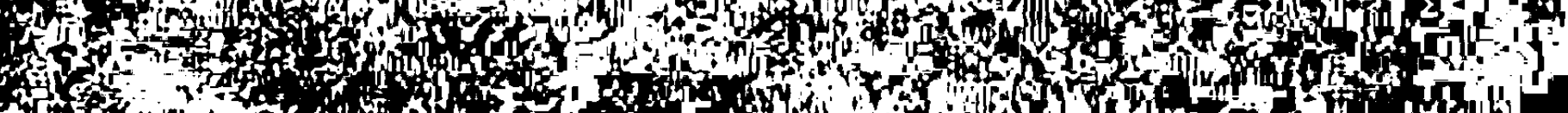

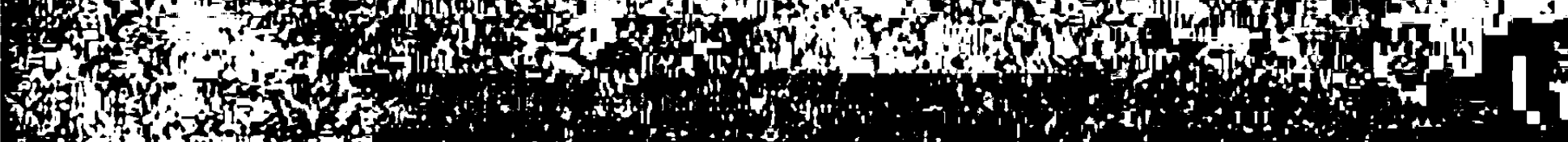

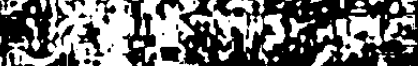

(n)

1010

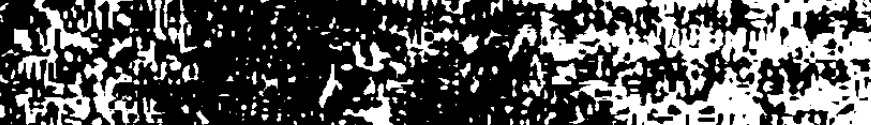

ind

(a)

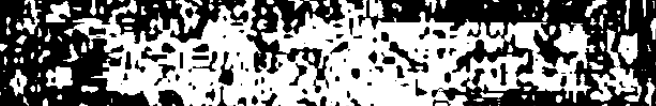

(1)

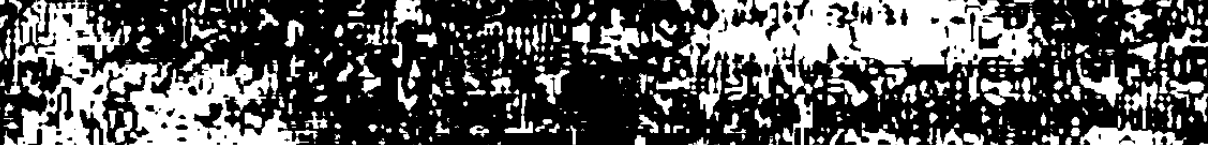

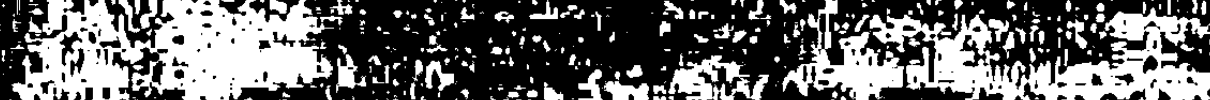

(x)

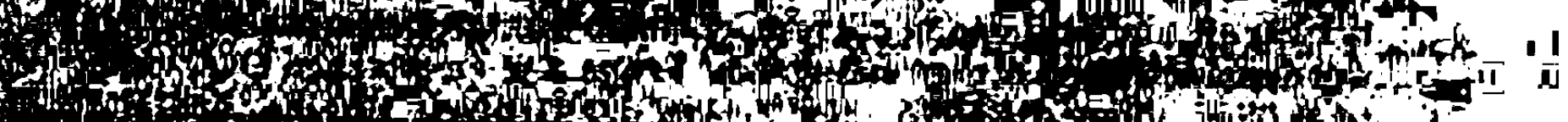

$10 y$ ond

Non

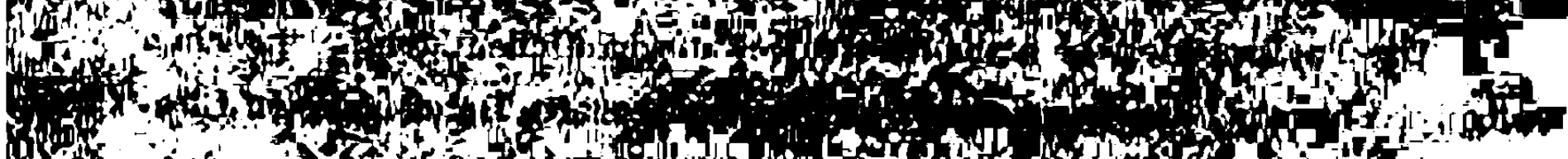

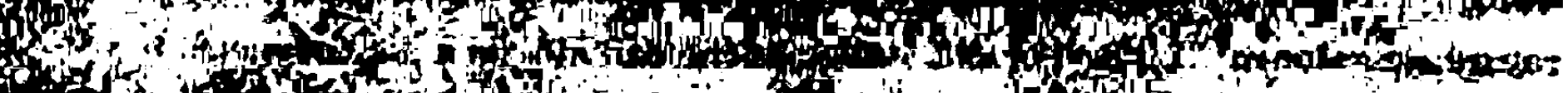

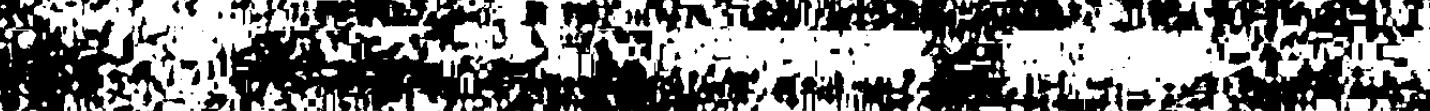
(1) (4)

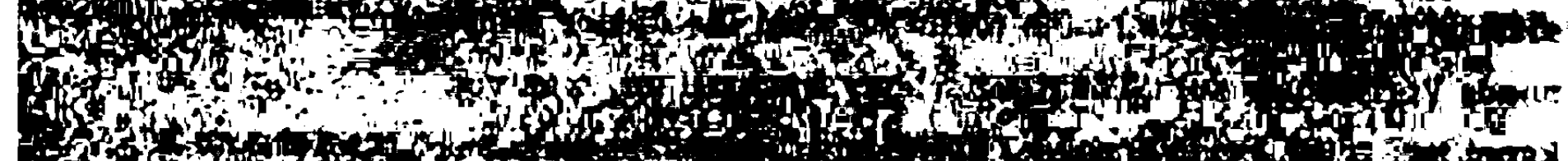

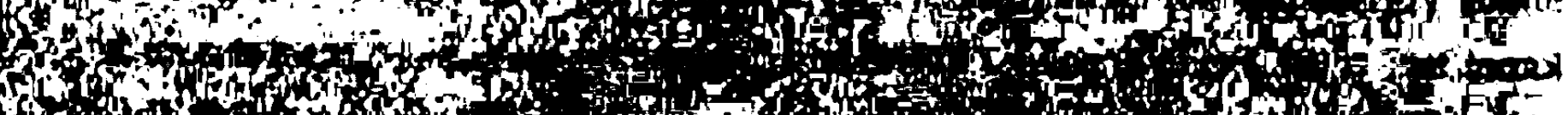
Now

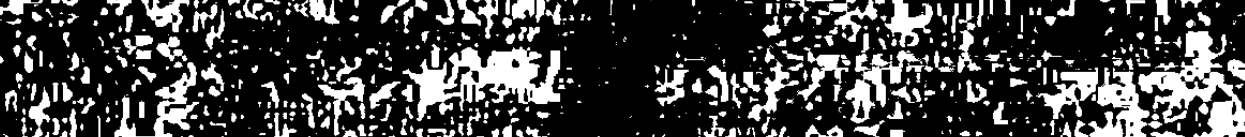

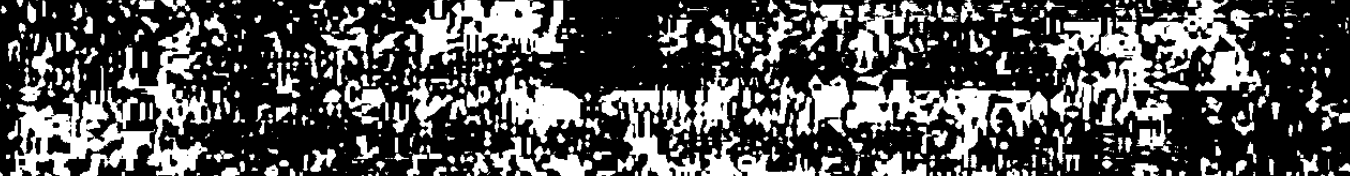

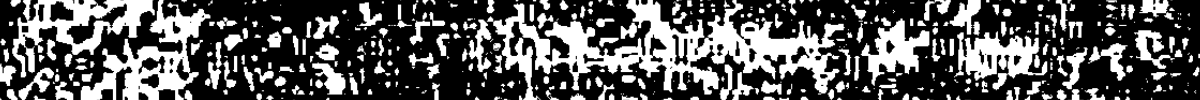
Sots 6)

If

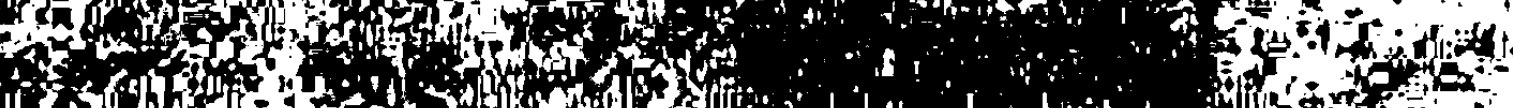

1.

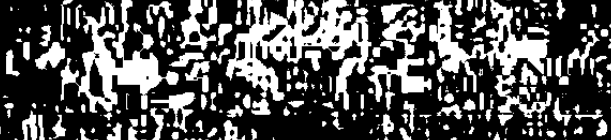

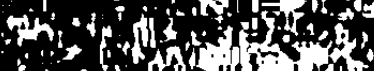
(1)

d

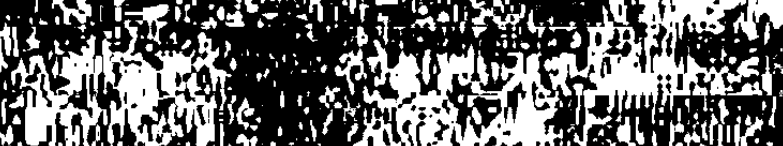

inivis ind 


\section{Kapitel}

Zeitgenossen

\section{Frühe Jahre}

Zeitgenössische Äußerungen zum Werk und zur Person Karolina Pavlovas beziehen sich zum größten Tell auf die Periode, die zwischen Heirat und Über siedlung nach Deutschland liegt, erfassen also knapp zwei Jahrzehnte. Dieser Schwer punkt ist zum einen damit zu erklären, daß die Dichterin in diesem Zeitraum sehr produktiv war, zum anderen auch damit, daß sie sich durch die sorgsam gepnegten Verbindungen zu bedeuten den Leuten ein verhălnismåßig großes und vor allem kompetentes Publikum verschafft hatte. Es fallt aber sofort auf, daß die Bemerkungen der maßgebenden Köpfe der Zeit über die Pavlova - es seien hier nur Gogol', Belinskij, Herzen, Pogodin genannt - absolut unerglebig sind, gleichsam nur in Nebensătzen hingeworfen. Låß man weiterhin gehässigen Klatsch und unkritische Lobhudelei außer Betracht, so bleibt ein schmaler Bestand an sachlichen Urteilen, der das bisher gezeichnete Bild Karolina Karlovnas bestautigt.

Die frühen Zeugnisse über das Verhảltnis der Zeitgenossen zu Karolina Jaenisch stammen aus den Jahren 1828 bis 1833 . Sie reichen vom galant-unverbindlichen Widmungsgedicht über aufrichtige Bewunderung ihrer Talente bis hin zur glühenden, der Dichterin-Übersetzerin wie der Person gleicherweise dargebrachten Ver ehrung. Allerdings klingt ber eits zu dieser Zeit in einer Glosse ganz deutlich auch der böse Spott an, dem sie sich durch ihr selbstgefalliges Gehabe später in zunehmendem Maße aussetzte.

Typische Erzeugnisse für ein Album, freundlich und nichtssagend, sind zwei Gedichte von Baratynskij und Zukovskij.

Die Eintragung Evgenij Abramovic Baratynskijs entstand $1829^{114}$. Hierin vergleicht der Dichter ein Album mit einem Friedhof: 
beide stehen allen als Behausung offen, hier wie dort finde sich eine Vielzahl von Namen, hierhin wie dorthin komme man mit Furcht vor dem Gericht und mit Hoffnung auf das ewige Leben. Nur er setze gelassen seinen Namen in diese Erinnerungsblätter, als Philosoph nichts fürchtend und nichts hoffend: in ihren Augen erkenne er seine Nichtigkeit.

Die Widmung Vasilij Andreevic Żukovskijs "Poét naš prav: Al’bom kladbišce..." 115 knüpt thematisch hier unmittelbar an; das Bild wird konsequent fortgeführt. Auf diesem Album-Friedhof finde das leichtlebige Völkchen der Poeten unter einer leichten Decke von Ver sen seine ewige Behausung. Er selbst, ein lăngst verstummter Sănger, eile, sich selbst in diesem Album zu begraben. Eine Inschrift verkünde: "Der alteingesessene Moskauer Peiniger der Saiten, ein Schreck für die Ohren, der Sănger der Teufel, Żukovskij" ${ }^{116}$ sei hier bestattet. Mit diesem Beisetzungsplatz sei er vollstăndig zưf rieden, er wünsche keine Auferstehung.

Diese glatten Albumver se Żukovskijs sind das einzige Zeugnis seiner Bekanntschaft mit Karolina Jaenisch. Anders ist das bei Baratynskij. Zwar findet sich auch in seinem Werk kein Hinweis auf spätere Kontakte, sie lassen sich aber aus den Arbeiten der Pavlova er schließen. So spricht sie 1842 in einem Baratynskij gewidmeten Gedicht ${ }^{117}$ davon, daß er ihr "schmeichelhafte Zeilen" gesandt habe. Als "Dichter" habe er sie bezeichnet und sein Gefallen an ihren Versen ausgedrückt. Mit diesen Worten habe er ihre erstorbenen Trăume zu neuem Leben erweckt. Daß diese Verbindung, in welcher Form auch immer, bis zum Tode Baratynskijs 1844 fortbestand, zeigt die Zueignung, die Karol ina Pavlova ihrem zwischen 1843 und 1859 entstandenen Poem "Kadril'" voranstellte:

Erstmals veröffentlicht aus der Handschriftensammlung Kittler von Max Vasmer; in: Ztschr.f. slav. Phil., 1959 - XXVI, S. 35 f. Obgleich dieses Gedicht nicht datiert ist, gehört es $\mathrm{m}$. E. wegen der engen thematischen Verbindung mit dem vorangegangenen auch etwa in denselben Zeitraum.

117 "E. A. Baratynskomu" (K. Pavlova 1964, S. 112f.). 
Du erwartetest ein glückliches Ende

Für das Geschöp meines Traumes...

Und getreu der Berufung meiner Seele,

Lege ich dieses Werk als traurigen Tribut

Auf das Grab des Săngers:

Im Gedenken an deine Gedanken, Evgenij,

Die voll reinen Feuers waren,

Im Gedenken an die lichte Inspiration,

Im Gedenken an frohe Augenblicke,

Im Gedenken an einen traurigen Tag.

Viel engagierter als die Widmungen von Baratynskij und Żukovskij sind die Zeugnisse von Vjazemskij, Śevyrev und Ivan Kireevskij. Alle drei beschäftigen sich mit dem Zauber, der von der jungen Karolina Jaenisch ausgeht, mit ihrer vielseitigen Begabung.

So heißt es in dem Gedicht Petr Andreevic Vjazemskijs :

Ihr Geist, seine Studien sind mir bekannt,

Denen sich dieser glühende Zögling der Wissenschaften

In wăhlerischer Umarmung öffnete,

Ein Mitbürger der Musen mehrerer Völker,

Ein Priester an den Altären, die ihren (der Musen)

Glaubensulberzeugungen im gleichen Maße geweiht sind,

Ein Freund bedeutender Gedanken und wohlgestalteter Gesănge.

Trotz ihrer Jugend habe sie sich nicht in Nichtigkeiten verloren, sondern sei zu einer besseren Welt vorgedrungen, zur Welt des Gefühls und des Verstandes. Was anderen undurchdringliche Finsternis verhülle, sei ihr vertraut, sel ihr angeboren.

Auch Stepan Petrovic S̉ evy r ev hat in seinem schwärmerischen Widmungsgedicht ${ }^{120}$ diese Ander sartigkeit in den Mittelpunkt gestellt, die Fähigkeit, den ruhelosen Menschen, der sich im mühselig-alltăglichen Kleinkram aufreibt, wenigstens für eine kurze Zeitspanne aus diesem Dunstkreis in klare Höhen zu erheben:

118

119

"Posvjascenie E.A. Baratynskomu" (K. Pavlova 1964, S. 308).

"S stesnen'em cuvstvo smotrju na vas al'bom"; in: Ztschr.f. slav. Phil. , 1959 - XXVII, S. 36f. Als Entstehungsdatum geben Rapgof (S. 7) und Kovarskij (Einleitung zur Ausgabe 1964, S. VI) übereinstimmend 1830 an.

"Kogda-to russkoj seljanin...", datiert vom 7./19.2.1828; in: Ztschr. f. slav. Phil., 1959 - XXVII, S. $37 f$. 
Im Taumel vielf âtiger Nichtigkeiten,

Umringt von langweilig-unnützen Kümmernissen,

Ward ich betăubt und matt;

Aber Sie haben, wie der lichte Gott des Gesangs, In den leidenschaftlichen Minuten des Abschieds, Sie haben die meiner Seele vertrauten Klänge

Zu neuem Leben erweckt.

Durch die Zauberkraft threr Augen

Schlugen Sie meine Inspiration in Ihren Bann,

Wenigstens für einen kurzen Augenblick

Verflog der quálende Rausch,

Und in einem traurig-kummervollen Leben

War dieser flüchtige Augenblick der Begeisterung

Ein göttliches Geschenk threr Blicke.

Nach diesen begeisterten, aber doch reichlich verschwommenen Versen nimmt sich das Zeugnis Ivan Vasil'evic Kireevskijs sehr viel nüchterner aus; nicht nur, weil es in Prosa geschrieben wurde, sondern auch, weil der Ansatzpunkt sehr viel konkreter ist: in einem Brief an Anna Petrovna Zontag ${ }^{121}$ beschätigt sich Kireevskij mit dem soeben erschienenen "Nordlicht". Auch er geht auf die ausgeprägte Doppelbegabung ein. Dieses junge Mădchen sei "mit den mannigfaltigsten und außergewöhnlichsten Talenten begabt. Soweit ich urteilen kann, übertreffen diese Übersetzungen alle bisher bekannten aus dem Russischen - in welche Sprachen auch immer, davon ist weder der allzu hoch geschäzte Bowring, noch der so wenig gewürdigte von der Borg ausgenommen" ${ }^{122}$. Die dem "Nordlicht" hinzugefügten Originale seien "voller Poesie und bemerkenswert gerade durch das, was man bei unseren jungen Mădchen seltener als alles andere antrifft: Originalităt und Kraft der Phantasie" ${ }^{123}$. Mit Ungeduld erwarte er das Echo in Deutschland, vor allem das Urteil des ăußerst geistreichen Wolfgang Menzel, dem die russische Literatur zum ersten Mal auf dem gegenwärtigen Niveau prăsentiert werde.

121 "Pis'mo k Anne Petrovne Zontag", vom 10./22.12.1833; in: I. V. Kireevskij, Polnoe sobranie socinenij, Bd. 2, S. $73 \mathrm{f}$.

ib., S. $73 f$.

ib., S. 74 . 
Aber eines hălt er Karolina Jaenisch vor, bei aller Bewunderung ihrer Leistung: Wenn eine junge Russin den deutschen Vers so vollkommen beherrsche, und den französischen vielleicht in noch größerem Maße, dann sei es um so verdrießlicher, daß sie nur an der Sprache ihres Vaterlandes ihre $\mathrm{Kräfte}$ nicht messen wolle.

Solch sachliches Urteil sucht man bei Nikolaj Michajlovic J a z y kov vergebens. Da die meisten Zeugnisse über den ersten Lebensabschnitt der Dichterin gerade von ihm stammen - zwischen 1829 und 1833 hat er ihr sieben Gedichte gewidmet ${ }^{124}$ - und er auch damals von allen Bekannten den engsten Umgang mit ihr plegte, man al so von seiner Seite auch am ehesten Auf schlüsse über Karolina Jaenisch hätte erwarten können, ist dieser Mangel um so bedauerlicher. Aus seinen Worten spricht grenzenlose Bewunderung, das tief verehrte Mädchen wird zu einem unerreichbaren, uberirdischen Wesen stilisiert, dessen Seele "göttliche Offenbarungen" 125 zuteil werden. Sie lebt in einer anderen Welt, hat ihre Jugend "zum Ruhme der Musen. . erhabenen Aufgaben geweiht" 126 .

Tief empfundene, innige Grüße,

Prächtige Tråumereien

Bringen Dichter -Jünglinge Ihnen, Der Vollendung des Schönen, dar!

Ihre Lieder sind klangvoll und wunderbar,

Die Herzen leidenschaftlich - aber ach!

Weder wollüstige Inspirationen, Noch die Phantasie eines Verliebten Sind thnen lieb! Die Liebe zum Leben Einer anderen Welt und die Poesie Haben Sie sich zum Abgott gemacht,

124 Von diesen sieben Gedichten sind drei an "K. K. Janis" adressiert, die vier weiteren sind jedoch mit Sicherheit ebenfalls an sie gerichtet. Es handelt sich um folgende, in dem "Polnoe sobranie stichotvor enij" Jazykovs wiedergegebenen Gedichte:

1) "K..." - "Zivye, neźnye privety..." (S. 329f.);

2) "Vy skoro i legko menja ocarovali..." (S. 330);

3) "Na prazdnik vas prines ja dva priveta..." (S. 330f.);

4) "Uvencannyj i pristyzennyj vami..." (S. 331).

125 "K. K. Janiš" (Vy, c’ej duše vo cvete lučsich let....), 1831, ib. , S. 308. 126 "Na prazdnik vas prines ja dva priveta..." , zwischen 1829 und 1833; ib. , S. 330 . 
Der jenen unerreichbar bleibt.

Sie müssen vor Thnen stehen

Stumm und still, verwirrt

Und voll körperloser Träume,

Gleichsam in heiligem Er schrecken.

Was hier über das Verhältnis zwischen Karolina Jaenisch und ihren Altersgenossen allgemein ausgesagt wird, gilt auch für das zwischen ihr und Jazykov: es ist merkwürdig unirdisch. Die Ursachen dafür liegen nicht nur in seiner schwärmerischen Veranlagung, sondern auch - und vor allem - in ihrem Selbstverständnis. Den Bruch mit Mickiewicz, der ja aus recht trivialen Gründen erfolgt war, hatte sie zur göttlichen Fügung umgedeutet; sie war nicht verlassen worden, sondern hatte aus kindlichem Gehorsam Verzicht geleistet. Dieses frühe Leid hatte sie, in ihrer eigenen Deutung, über jene erhoben, die - wie Jazykov von sich selbst sagt - sich "im Kreise der Freunde kühn von der Muse der Gesănge ... das belebende und liebliche El ixier ausgelassener Reden und lustiger Einfälle" nahmen ${ }^{128}$. Von dem selbst geschaffenen Podest aus warf sie sich zur unbestechlichen Richter in und Herrscherin auf. Diese Doppelrolle wird von Jazykov allzu bereitwillig akzeptiert.

Früher, da ich weder die Furcht vor Tadel

Noch den Zauber strengen Lobes kannte,

Stand mein stolzer Vers feierlich da,

Ein Sohn freier Gedanken und lichter Eindrücke.

Jetzt, umgeben von großen Namen,

Zittert er, stürzt vor Ihnen nieder.

Vom Marktplatz der Eitelkeiten entrückt

Vor den Altar der prächtigen Kathedrale,

Erbebt die Seele, geheimnisvoll erfüllt

Von der Gegenwart Gottes, der alle geladen hat.

Auch den 'Herrschaftsanspruch' Karolina Jaenischs legitimiert Jazykov; um die Rechtmäßigkeit sinnfälig zu machen, verwendet er das Bild des frei gewählten Kosakenhetmans. Er m eint, nicht nur im eigenen Namen, sondern

"K..." (Żivye, nežnye privety... ), zwischen 1829 und 1833; in:

N. M. Jazykov, Polnoe sobranie stichotvorenij, S. $329 \mathrm{f}$.

"K. K. Janis" (V bylye dni ot muzy pesnopenij...) ), 1829; ib., S. 276. ib. 
für seine Generation sprechen zu dürfen.

Zierde und Ehre für die alte Hauptstadt Moskau,

Thnen haben die Jünglinge des eigenen freien Kosakendorfes

Den mächtigen Hetmansstab überreicht.

Und gerne beuge ich vor Ihrem Rang

Meinen Kosakenkopf,

Den mir der liebenswerte Ataman verdreht hat.

Das Bild wird in einem ander en Gedicht wieder aufgenommen:

Aber ich - Ihr Kosak - werde auf ewig nicht yergessen,

Wie mein Ataman mit mir gescherzt hat. 131

Die Richterin und Herrscher in Karolina Jaenisch wurde mit dem Symbol der Macht, dem Hetmansstab, ausgezeichnet; die Dichter in und Über setzerin wird mit den Attributen geschmückt, die dieser Funktion angemessen sind:

Und zwei Kränze, einer schöner als der andere,

Winden sich um das junge Haupt,

Der grüne Lorbeer fremder Poesie

Und Brillanten Ihrer eignen Muse.

Den Kontrapunkt zu diesen Huldigungen bildet ein Epigramm von

S. Sobolevskij, in dem die erste Begegnung Alexander von Humboldts mit der jungen Karolina Jaenisch glossiert wird. Humboldt befand sich 1829 auf einer Forschungsreise in den Ural und nahm auf der Hin- und Rückr eise jeweils für einige Tage in Moskau Aufenthalt. Als er mit der Professorentochter bekannt wurde, war er sowohl von deren persönlicher Ausstrahlung ${ }^{133}$ als auch von ihrer vielschichtigen Begabung tief beeindruckt. Er

130 "Na prazdnik vas prines ja dva priveta...", zwischen 1829 und 1833; ib., S. 331.

"Uvenčannyj i pristyžennyj vami... ", zwischen 1829 und 1833; ib.., S. 331 .

"K. K. Janiš (Vy, c’ej duše vo cvete lư̌šich let..."), 1831; ib., S. 308.

Fast dref Jahrzehnte liegen zwischen dieser Begegnung und der năchsten, letzten. 1858, also ein Jahr vor dem Tode Humboldts, besucht K. Pavlova ihn in Berlin. Er soll sie mit den Worten empfangen haben: "Geben Sie zu, gnädige Frau, daß ich liebenswürdig bin: ich habe dreißig Jahre auf Sie gewartet; ein anderer an meiner Stelle wäre lăngst gestorben" (zitiert aus: Tatevskij sbornik S. A. Račinskogo, S. 109 
bestärkte sie in ihrem Vorhaben, russische Literatur nach West-Europa zu vermitteln.

Karolina Jaenisch fand an dieser Bewunderung kein Genügen; ihr Geltungsbedürfnis trieb sie, sich vor anderen der Anerkennung, die der berühmte Gelehrte ihr gezollt hatte, zu rühmen ${ }^{134}$. Sie soll sogar verbreitet haben, er habe den Abstecher nach Moskau nur ihretwegen gemacht, da er ihre deutschen Verse gekannt habe ${ }^{135}$. Diese Prahlerei gab den Anlaß zu Sobolev skijs Spottgedicht:

Der Himmel schenkt dem Menschen

Einen Ausgleich für Tränen und wiederholtes Leid:

Glückselig ist der Moslem, hat er Mekka geschaut Auf seine alten, kummervollen Tage.

Wie sehr sie diese Begegnung beeindruckt hat, zeigen die folgenden uberschwenglichen Verse (in deutscher Sprache):

An A. v. $\mathrm{H}(\mathrm{u}) \mathrm{mb}(\mathrm{ol}) \mathrm{dt}$

Mir ward ein Kranz von leuchtenden Sekunden, Ein Sonnenlicht fiel in mein stilles Leben; Doch kaum wagte ich das Auge zu erheben, So war es schon vergangen und verschwunden.

Im dunkeln Dasein gibt es helle Stunden, Die, schönen Wundern gleich, hernieder schweben;

Sie sind uns als ein ewig Gut gegeben, Denn nimmer welket, was wir dann empfunden.

Doch wenn der Strahlenaugenblick verglommen, Dann fühlen doppelt wir des Lebens Leere, Gemeiner dann erscheinet uns die Menge:

Denn als entzückt Căcilie vernommen Die Harmonien der sel'gen Engelchöre, Verletzten sie die irdischen Gesănge.

K. Pavlova 1964, S. 488.

Vgl. Sobolevskij, Épigrammy i èksprompty, S. 122. Deutsche Gedichte, die zu dieser Zeit bereits veröffentlicht waren, ließen sich nicht feststellen. Es ist die Frage, ob es solche überhaupt gibt oder ob die Behauptung aus der Luft gegriffen ist. 
Aber der ist glücklicher, Karolina,

Der, Welt und Wohlleben liebend,

Berlin verläßt einzig mit der Absicht,

Dich kennenzulernen.

Dieser ironische Kommentar fand Anklang in Moskau; in Abschriften ging er von Hand zu Hand, immer wieder varijert und erweitert. Als Autoren wurden, neben Sobolevskij, auch A. A. Elagin und I. V. Kireevskij genannt ${ }^{137}$.

136 Die ersten vier Zeilen wurden Puskkins "Bachcisarajskij fontan" entnommen ("Tatarskaja pesnja", erste Strophe).

S. Sobolevskij, Épigrammy i èksprompty, S. 43.

137 Ungeachtet zahlreicher Detallvarianten, sei hier nur auf die folgende, stark veränderte und erweiterte Variante verwiesen, deren Verfasser (1t. Tatevskij sbornik Racinskogo, S. 109) Ivan Kireevskij sein soll:

Der Himmel schenkt dem Menschen

Einen Ausgleich für Tränen und wiederholtes Leid:

Glïcklich, wer sich eine Bibliothek

Einrichten konnte auf seine alten Tage!

Glücklich, wer in die geheimnisvolle Gebirgskette

Des wilden Ural vorgedrungen ist:

Sein Kabinett erstrahlt

Im Feuer des Topas und des Opals.

Aber der ist glücklicher, Karolina,

Der, Brillanten liebend,

Inretwegen aus Berlin abreiste

Und hier in Moskau dich fand!

(Tatevskij sbornik Racinskogo, S.' $108 \mathrm{f}$.

Ohne die mittlere Strophe, nur aus Strophe eins und drei bestehend, ist das Gedicht, das von P. Bartenev A.A. Elagin zugeschrieben wird (Russkij archiv, 1893, Nr. 3, S. 317). Hier kann eine Verwechslung vorliegen, da das Epigramm vermutlich an Elagin gerichtet war (sh. Sobolevskij, Epigrammy i èksprompty, S. 123). 


\section{Mittlere Jahre}

Nach ihrer Heirat trat Karolina Pavlova aus ihrem bisherigen eng begrenzten Bereich heraus; ihr Mann pflegte schon in dieser Zeit mannigfache Beziehungen zu Schriftstellern, Journalisten und Wissenschaftlern. Aber ein Teil dieses Bekanntenkreises schenkte ihr offenbar nur wenig Beachtung, jedenfalls fehlen von einigen langjahrigen Freunden schriftliche Urteile fast völlig. Herzen hat sich nur einmal und nur vorläufig über die Pavlova geăußert: "... ihre Stimme ist unangenehm, ihr Aussehen ist auch absolut nicht vorteilhaft, aber Geist und Talente unterliegen keinem Zweifel. Mehr kann ich nach der ersten Begegnung nicht sagen" ${ }^{138}$. Mehr ist von ihm, obgleich die Verbindung bis weit in die sechziger Jahre hinein andauerte, nicht überliefert worden. - Von Gogol', einem häufigen Gast der Pavlovs, liegen leider auch keine Äußerungen vor. Selbst Pogodin und Tjutcev, die auf Grund ihrer slavophilen Grundhaltung am ehesten auf die Pavlova hătten eingehen können, begnügten sich mit allgemeinen Phrasen ${ }^{139}$. Das gleiche gilt für Aleksej Ivanovič Turgenev, der in Paris die Veröffentlichung ihrer Übersetzungen ins Französische betreute. Ivan Sergeevic Turgenev gab ein unfreundliches, indirektes Urteil ab: "... die Gedichte šcerbinas sind noch weniger nach meinem Geschmack als die Verse der Pavlova oder der Rostopcina..." 140 .

Relativ groß ist die Zahl der Pauschalurteile auch aus dieser Zeit; mit erstaunlicher Vor eingenommenheit wurde in Bausch und Bogen gelobt und getadelt. Meinten die einen, wer so Wertvolles schaffe, sei auch menschlich über allen Zweifel erhaben, so vertraten die anderen die Ansicht, wer so ausgeprägte Charakterschwächen habe, könne auch künstlerisch nichts Nennenswertes hervorbringen. Für die bedingungslosen Bewunderer seien

Brief vom 14./26.2.1843; in: Gercen, Sobranie sočinenij, Bd. 2, S. 342 .

139 Vgl. M. P. Pogodin, Pis'ma...; in: Sbornik otdel enija russkogo jazyka..., S. 45, $126 \mathrm{f}$. - F. I. Tjutcev, Lettres; in: Starina i Novizna, S. $123 \mathrm{f}$.

Brief an S. T. Aksakov vom 22.1./3.2.1853; in: Vestnik Evropy, 1894, Bd. 1, S. 342 . 
hier stellvertretend nur die Aksakovs und Jazykov genannt; auch die Brüder Kireevskij und Afanasij Fet gehören dazu. Besorgt wird darüber gewacht, daß Karolina Pavlova nicht vom Piedestal ihrer Erhabenheit herabsteige in die Niederungen weltlicher Nichtigkeiten. So steht ihr - nach den Vorstellungen Ivan Sergeevic Aksakovs - beispielsweise die Teilnahme an Tanzvergnügen nicht an, da sonst vielleicht der Eindruck entstehen könnte, sie năhme ihren Beruf nicht ernst genug ${ }^{141}$. Als die Dichterin Ende der vierziger Jahre, in einer künstlerischen Krise, an der Vernünftigkeit ihrer Tätigkeit zweifelt, beschwört er seine Familie in einem Brief: "Sagt ihr, was Ihr wollt, - sie soll nur, um Gottes willen, nicht aufhören zu schreiben! Ich liebe ihre Verse, sie sind lebendig und wärmend: von meinen eigenen friert es mich" 142 . Für ihn ist ihre Dichtung wie ein Genesung bringendes Rezept ${ }^{143}$.

In welchem Maße auch Sergej Timofeevic und Konstantin Sergeevic Aksakov für die Pavlova Partei ergriffen, sollen zwei Begebenheiten er lăutern. 1848 hatte die Dichter in den Roman "Dvojnaja żizn" veröffentlicht. Daraufhin brachte der "Moskvitjanin" eine sehr sachliche Rezension von S̉evyrev ${ }^{144}$; objektiv wog er Vorzüge und Măngel dieses Werkes ab. Diese Nüchternheit der Analyse emporrte Vater und Sohn Aksakov zutiefst, sie brachen einen Streit mit dem Rezensenten vom Zaun, indem sie ihm Böswilligkeit, Ungerechtigkeit usw. unter stellten. Sie machten dem Herausgeber des "Moskvitjanin", M. P. Pogodin, schwere Vorwürfe, diese Besprechung überhaupt gedruckt $\mathrm{zu}$ haben und forderten von ihm eine scharfe $\mathrm{Zu}$ rechtweisung Š̉evyrevs. Der Feldzug gegen den Kritiker wurde so geführt, daß Pogodin, der übrigens stets seine ironisch-distanzierte Haltung beibehielt, in seinem Tagebuch notierte: "Sie krakeelen so gegen S̉evyrev, daß

Vgl. I. S. Aksakovs Brief an die Familie vom 8./20.2.1844; in:

I. S. Aksakov v ego pis'mach, Bd. 1, S. $72 f$.

(Siehe dazu auch Anm. 85).

142 Brief vom 13./25.11.1850; ib., Bd. 2, S. 359.

143 Brief vom 24.6./6.7.1844; ib., Bd. 1, S. 159.

144 Moskvitjanin, 1848, Teil 2, Nr. 3, Abt. III, S. 1-19. 
es widerwärtig ist zuzuhör en" ${ }^{145}$. - Den zweiten Beweis kritikloser Bewunderung liefert S. T. Aksakov in seinem Brief vom Januar 1854 an Pogodin. Nikolaj Pavlov war vier Wochen zuvor aus Perm' heimgekehrt. Ohne zu bedenken, welche unrühmliche Rolle Karolina Pavlova bei der Verbannung ihres Mannes gespielt hatte, maß er alle Schuld Pavlov zu und entrüstete sich: "Warum empfangen alle Pavlov wie früher ?" 146

Der Dichterin treu ergeben wie die Aksakovs blieb auch Nikolaj Michajlovic J a y kov. Fünf Gedichte aus den Jahren 1840 bis 1846 belegen, daß trotz der räumlichen Entfernung - Jazykov mußte aus gesundheitlichen Gründen jahrelang in Westeuropa leben - die Verbindung nie abgerissen ist. Der Einfluß der Pavlova, unter dem einst seine Gedichte "kraftvoll und wohlklingend" 147 wurden, blieb uneingeschränkt erhalten: in der Ferne war es ihr Vers, "klar wie Kristall; / Wie Gold so licht; so hart wie Stahl" ${ }^{148}$, der ihn zeitweise sein Leid vergessen ließ. Für ihn, dem die Schönheiten Italiens, Südfrankreichs, der Schweiz und der Rheinlandschaft nichts bedeuteten, da ihn übermächtiges Heimweh quảte, war Karolina Pavlova ein Stück Heimat, fast ein Symbol des geliebten Moskau. In eben dem Maße, wie Jazykov sich zum reaktionaren Slavophilen entwickelte - was sicher zum Teil durch den erzwungenen langen Auf enthalt im 'morschen' Westeuropa und durch die dar aus folgende Idealisierung Rußlands bedingt war - , wurde die Dichter in für ihn zum Symbol:

Ich preise Sie dafür, daß Sie

Für uns singen, nicht wie andere,

Daß Ihnen Rußland das Vaterland ist,

Innen - der berühmten Tochter Moskaus!

$\mathrm{Da}$ sich Ihnen unsere wunderbare Sprache erschloß,

145 Eintragung vom 6./18.3.1848; in: Barsukov, Žizn' i trudy M.P. Pogodina, Bd. 9, S. 455.

146 Ohne Quellenangabe zitiert bei V. Brjusov, K. Pavlova; in: Ežemesjačnye socinenija, S. 286.

Vgl. das Gedicht "K. K. Pavlovoj" (V te dni, kogda...) vom März 1841; in: N.M. Jazykov, Polnoe sobranie stichotvorenij, S. $372 \mathrm{f}$.

Vgl. das Gedicht "K. K. Pavlovoj" (Togda, kogda Zestoko bolen...) vom 18./30.4.1844; ib. , S. $382 \mathrm{f}$. 
Unsere metallische, tönende, von selbst dröhnende, Zügellose, treffende Sprache!

Doch nicht jeder vermag sie zu beherrschen!

Und den werten Ver ehrerinnen

Fremdsprachiger Gedanken und Bücher

Ist sie nicht zugänglich. Und sie kennen

Sie nicht - sie brabbeln

In einer anderen, nicht in der russischen Sprache

Ihre Träume und Eindrücke daher, -

Und auf ihnen liegt kein Segen.

Sie sind nie und nimmer Kinder Gottes. 149

Jazykovs reaktionäre Einstellung radikal isierte sich in den folgenden zwei Jahren so, daß er nicht einmal vor übel sten Beschimpfungen seiner Gegner haltmachte ${ }^{150}$. Dabei richteten sich seine Angriffe nicht nur gegen Mănner wie Herzen und Čaadaev, sondern auch gegen Granovskij, der sich ernsthaft um einen Ausgleich zwischen Westlertum und Slavophilie bemühte, und gegen Konstantin Aksakov, an dessen slavophiler Ausrichtung wohl kein Zweifel bestand, nur, weil er mit 'Verrätern' wie Granovskij verkehrte. Als Folge dieser Verbohrtheit wurde Karol ina Pavlovas Freundschaft zu Jazykov brüchig. Wie aus dem letzten ihr gewidmeten, im April 1846 entstandenen Gedicht ${ }^{151}$ hervorgeht, ubte sie scharfe Kritik an seiner Haltung. Zunächst beschwört er die Harmonie vergangener Jahre, um die Disharmonie der Gegenwart wirkungsvoll dagegen absetzen zu können. Jetzt sei er plötzlich in "Ungnade" ${ }^{152}$ gefallen, er, der Wehrlose, werde von ihr mit unerhörter Feindschaft verfolgt. Und alles nur, weil er gegen Lumpen und Feinde des Vaterlandes aufgestanden sel, weil er das wahre, das vorpetrinische Rußland liebe. Trotz der tiefen Enttäuschung bleibe er aber aufrichtiger Bewunderer und treuer Ritter der Dichterin.

149 "K. K. Pavlovoj" (Chvalju ja vas za to...) vom 21.4./3.5.1844; ib. , S. 385.

Vgl. die Gedichte "K nenašim..." (ib., S. 394 f. ), "Konstantinu Aksakovu" (ib., S. 396f.), "K Caadaevu" (ib. , S. 397f.). Sie entstanden alle im Dezember 1844.

151 "K. K. Pavlovoj" (V dostopamjatnye gody... ) vom 28.4./10.5.1846; ib. , S. $410 f$.

152 Bezeichnend ist die Wortwahl: in 'opala' (S. 411) klingt das Motiv der Abhängigkeit des Kosaken von seinem Hetman wieder an, hier abgewandelt zum Motiv vom Ritter und seiner Dame. 
Indes, der Riß war nicht mehr zu kitten. Karol ina Pavlova erteilte ihm eine eindeutige Absage, weil er sich uberhaupt in die Polemik eingelassen und damit die Idee des wahren Dichtertums verraten habe.

An N.M. Ja(zykov)

What is wright is wright.

(Byron)

Nein! ich konnte nicht, wie stets,

Auf die Herausforderung der Leier antworten;

Diese Leier wurde mir jetzt

Unbegreiflich und fremd.

Ich erkenne ihre Weise nicht,

Sie fesselte in jenen Tagen nicht mein Ohr;

In ihr (der Weise) ist ein Schrei heidnischer Wut,

In ihr erwachte ein böser Geist zu neuem Leben.

Ich finde in meiner Seele keine Anerkennung

Fur Taten des Hochmuts und der Schuld,

Auf Verdammungen und Schimpfworte

Ist kein Antwort-Vers in mir.

In mir ist kein Gefüh, außer Kummer,

Wenn die vertraute Stimme des Săngers,

Indem sie blinde Leidenschaften gottlos wiederholt,

$\mathrm{Ha}$ in die Herzen gießt.

Und ich bin zutief st empört,

Wenn der, dessen Lied rein war,

Die heilige Muse auf den Marktplatz schickt,

Nachdem er inr Schimpfworte in den Mund gelegt hat,

Qualvoll und trostlos ist es für mich zu wissen,

Wie er von leidenschaftlicher Feindschaft durchdrungen ist,

Uner săttlich einen fremden Gedanken strafend

Und in einem fremden Gewissen herumwuihlend.

Ich schäme mich für ihn, es ist mir schmerzlich;

Und statt der Lieder, wie einst,

Entringen sich unwillkürlich

Nur bittere Worte dem Herzen.

Jazykov starb im Dezember 1846.

Die erklärten Gegner der Pavlova haben bei ihrer Wertung in unzulässiger Weise persönliche Antipathie mit der Ablehnung des künstlerischen Schaffens vermengt. Ein Beispiel geben die Erinnerungen von Dmitrij Vasil'evic Grigorovič:

K. Pavlova 1964, S. $133 f$. 
"In ihn (Pavlov), so sagt man, verliebte sich das außer st exaltierte Frăulein Jaenisch und trug ihm selbst Herz und Hand an; sie hatte eine Leidenschaft fürs Verseschreiben, aber was für N. F. Pavlov noch besser war, sie hatte ein bedeutendes Vermögen... Man stellte mich der Dame des Hauses vor, einer Dame von hohem Wuchs, mager, mit einem Gesicht, das eher an das Gesicht eines energischen Mannes als an das einer Frau erinnerte. Noch war keine halbe Stunde nach den üblichen Liebenswürdigkeiten vergangen, da las sie schon mir und zwei-drei dort sitzenden Leuten thre Gedichte vor, die sich mehr durch schöne Harmonien der Wörter auszeichneten als durch poetischen Gehalt. Sie las in singendem Tonfall, wobei sie unverändert eine melancholische Pose beibehielt, aber an besonders wichtigen Stellen richtete sie sich unerwartet auf und schüttelte krampfhaft den Kopf. Sie war aufrichtig davon überzeugt, daß erhabene, ungewöhnlich begabte Naturen, zu denen sie sich selbst zählte, nicht lange lebten, und oft erinnerte sie an ihr nahes Ende. Es wird erzăhlt, daß Granovskij, der es überdrüssig war, solche Art von Gejammer anzuhören, ihr einmal gesagt habe: "Karolina Karlovna, wann sterben Sie denn endlich?"..."154

Von Timofej Nikolaevic Granovskij stammen überhaupt die boshaftesten Worte, die über den Menschen Karolina Pavlova geschrieben wurden. 1852, noch vor der Klage gegen ihren Mann, heißt es:

"Was Madame betrifft - sie verleumdet. Das ist alles, was sie tut, glaube ich, aber sie setzt dabei ein unbestreitbares Talent ein, mehr Phantasie und Eifer als in ihrer Poesie. Sie verleumdet alles bis hin zu den Kindern, die noch in der Wiege liegen. Ein sanftes und rührendes Geschöpf, das ich sehr wenig sehe, das aber hartnăckig darauf besteht, mich als seinen Freund zu bezeichnen" 155 .

Nach der Verhaftung Pavlovs urteilt er: "Seine Frau spielt in dieser ganzen Geschichte eine infame Rolle... Seine Frau ist ein Ungeheuer (monstre)" 156. Und an anderer Stelle: "Das ist eine Frau ohne Herz, ohne Ehre, ohne Scham"; sie sei bereit, ihren Mann Hungers sterben zu lassen ${ }^{157}$.

S.A. Sobolevskij, der ja schon die vergleichsweise harmlose Prah-

D.V. Grigorovic, Literaturnye vospominanija..., S. $193 \mathrm{f}$. Brief an E. B. Ċičerina, 1852; in: T.N. Granovskij i ego perepiska, Bd. 2, S. 314.

ib. 
lerei Karolina Jaenischs anlåłich des Humboldt-Besuchs in Moskau so bissig kommentiert hatte, verfaßte wiederum ein Epigramm:

Ach, wohin du auch blickst,

Alles ist ein Grab der Liebe!...

Mamsell Janis steckte

Ihren Mann ins Gefängnis.

Diese Dame bittet flehentlich,

Bittet alle flehentlich wegen ihres Mannes:

"Daß inm dieses Gefängnis doch

Noch schmaler, schlechter, enger wäre"...

"Haltet inn darin fest

Jahrelang, wenn möglich,

Wenigstens an die zehn Jahre,

Und dann mit einer Anweisung für Postpferde

Weg mit ihm, wenigstens nach Vjatka,

Wenn er nicht nach Kamcatka kann" 158.

Die selbstgewählte Absonderung, die Flucht in eine häufig theatralische Erhabenheit hatten in der Pavlova die Făhigkeit zu echten Bindungen verkümmern lassen. Da sie sich selbst als außergewöhnlichen Menschen begriff, handelte sie stets so, wie sie dieser Rolle für angemessen hielt und war dann selbst für einen großen Teil der Feindseligkeit und des Spottes verantwortlich, mit denen man ihr begegnete. Besonders deutlich wird das in ihrem Streit mit Ivan Ivanovic Pa na ev, in dessen Zeitschrift "Sovremennik" eine schlechte Kritik ihres "Razgovor v Kremle" erschienen war $^{159}$.Der Rezensent vertrat die Ansicht, daß es selbst einem starken Talent nicht gelingen könne, einen so umfangreichen Stoff (einen Streifzug durch die Geschichte Englands, Frankreichs und Rußlands!) in den allzu engen Rahmen von zwanzig Druckseiten zu zwängen. Karolina Pavlova hielt fảlschlicherweise Panaev für den Verfasser dieser Besprechung, die übrigens vollkommen sachlich das Werk analysierte, ohne jeden Angr iff

S. Sobol evskij, Ėpigrammy i èksprompty, S. 47. $\mathrm{Da} \beta$ auch dieses Gedicht eine weite Verbreitung fand, beweist die Vielzahl der Varianten. In einer Handschriftensammlung ist das variierte Gedicht überschrieben: "Na K. K. Pavlovu (urožd. Janiš), kogda ona prosila Zakrevskogo arestovat' ee muža, tak kak on razorjaet ee kartocnoju igroju" (Sobol evskij, S. 126). Eine weitere, stark abgewandelte Form bringt Berg in: Russkaja starina, Bd. LXIX, 1891 (Febr.), S. 269.

Sovr emennik, Bd. XLVII, 1854, Nr. 9, S. 34-38. 
gegen die Person. Trotzdem war die Dichter in zutiefst gekränkt und schrieb zu ihrer Verteidigung einen Brief an Panaev ${ }^{160}$. Nach dem legitimen Versuch künstlerischer Rechtfertigung nimmt das Schreiben eine typische Wendung: es wird in peinlicher Weise per sönlich.

"Ihren Tadel meiner Dichtung konnte ich hinnehmen, indem ich allen Mut zusammennahm; aber Ihre Mißachtung gegenuber meiner Person konnte ich nicht ohne Schmerz erfahren. Ich mußte die bittere Wahrheit erkennen und mich uberzeugen, daß jener Tag, an den ich so viele angenehme und lebendige Erinnerungen bewahre, völlig aus Ihrer Erinnerung gelöscht ist, - ein herrlicher Julitag, den Sie bei mir auf der Daca in der Umgebung von Moskau verbracht haben. Ich bin gezwungen, ach! Sie daran zu erinnern, wie wir miteinander durch die Lindenalleen gingen, uns an der Natur begeisternd, über Poesie sprechend, und wie ich Innen damals eben diese Verse 161 vorlas, die ich zum Scherz geschrieben hatte, und wie Sie entzückt waren von dieser Parodie und sie sich von mir ausbaten. Und das ist alles vergessen, jetzt richten Sie meine eigene Waffe, die thnen von mir gegeben wurde, gegen mich!... Nachdem ich thnen das so aufrichtig gesagt habe, füge ich noch hinzu, daß ich Ihnen, Ivan Ivanovič, größtmögliche Berühmtheit wünsche und höchst erfolgreiche kritische Abhandlungen, wenn auch auf meine Kosten" 162.

Sof'ja Vladimirovna Éngel'gardt kommentierte:

"Sich zum Anwalt seiner eigenen Werke zu machen, ist ein Gewaltakt... und auf diese Weise einem Menschen eine Waffe in die Hănde zu geben, der nichts anderes tun kann als sich ihrer zu bedienen, - das ist ein Fehlen weiblichen Taktes, das die fragliche Autorin immer charakterisiert hat" 163.

Was anderes als unverhohlenen Spott durfte die Pavlova nach dieser Entgleisung erwarten: Die Antwort Panaevs ${ }^{164}$ begann denn auch entsprechend:

160 Brief vom 12./24.10.1854; in: Sovremennik, Bd. XIVIII, 1854, Nr. 11, S. 130-136.

161

Gemeint ist das Gedicht "Vezde i vsegda" (K. Pavlova 1964, S. 127f.), das unter anderen vom Rezensenten als Beispiel für ihre Vorliebe für ausgefallene Reime zitiert worden war.

162 Sh. Anm. 160, hier: S. 134-136.

163 Brief (franz.) vom 10./22.1.1855 an Druzinin; in: Letopisi, Buch 9, S. 368 .

164 Die Antwort wurde gleichzeitig mit dem Schreiben K. Pavlovas ver öffentlicht; in: Sovremennik, Bd. XUVIII, 1854, Nr. 11, S. $136 \mathrm{f}$. 


\begin{abstract}
"Gestatten Sie mir zuerst, Ihnen für das wahrhafte Vergnügen zu danken, das $\mathrm{mir}$ Ihr liebenswürdiger, wohlgesetzter und geistreicher Brief ber eitet hat, der in mir so viele angenehme Erinnerungen wachrief. Da ich die Unmöglichkeit fühle, Ihnen auf Thre demütigen Zeilen, wie Sie sich ausdrücken, ebenso liebenswürdig, wohlgesetzt und geistreich zu antworten, werde ich mich bemühen, wenigstens kurz zu sein, da ich auch nicht für eine einzige überflüssige Sekunde thre Auf merksamkeit von Thren poetischen Ideen, Arbeiten und Träumen ablenken möchte" 165 ... "Ganz unbegründet werfen Sie mir vor, daß der herr liche Jul itag aus meinem Gedăchtnis gelöscht sei, den ich mit thnen auf der Daca bei Moskau verbracht habe... Nein, ich erinnere mich lebhaft an ihn, in allen Einzelheiten: sowohl an die Lindenalleen als auch an thre bewundernswerten Verse, die Sie so vortrefflich deklamieren, wobei Sie ihnen durch dieses Deklamieren noch mehr Schönheit und Kraft verleihen, sofern das überhaupt möglich ist. Einen ganzen Tag in Ihrer Gesellschaft zu verbringen und dabei thre Verse anzuhören - das ist ein solch hoher Genuß, den man nicht so schnell ver gessen kann..."166.
\end{abstract}

Dieses (von seiten der Pavlova) kleinliche und nicht eben geistreiche Gezänk bot Ekaterina Petrovna Rost op $\mathcal{C}$ in a Gelegenheit zur Revanche für ein Gedicht, in dem sie Jahre zuvor von Karolina Karlovna in übler Weise angegr if fen worden war ${ }^{167}$. Übrigens waren sich die beiden Dichterinnen nie persönlich begegnet; dennoch hegten sie tiefe Abneigung gegeneinander.

Lied, anlaßßich des Briefwechsels eines gelehrten

Mannes mit einer nicht minder gelehrten Frau

Allee dicht belaubter Linden (lipok),

Du bist voller Bedeutung für die Welt !

Erglühend im Feuer der Begeisterung,

Stand sie dort vor ih $\mathrm{m}$.

Und stolz den Kopf zurückgeworfen, Majestätisch mit der Hand winkend, Traktierte sie den Neva-Lord
Mit Maskerade und Doppellebe ${ }^{168}$.

Und sie las von einem finnischen Poem Inre Übersetzung daraus ins Sanskrit...

\title{
165 \\ ib. , S. 136 . \\ ib. , S. 137.
}

"My sovremennicy, grafinja..." , Januar 1847; K. Pavlova 1964, S. $134 \mathrm{f}$.

Anspielung auf die Poeme "Kadril" und "Dvojnaja zlzn". 
(In Chinesisch oder gar in Japanisch

Veröffentlicht diese Dame Verse!)

Betăubt starrte er sie an, -

Und er traute seinen Ohren nicht;

Und er zischte durch die Zăhne Verwünschungen

Gegen alle Korinnas ${ }^{169}$, gegen alle Blaustrümpfe...

Die Zeit verging: Bosheit löste die Freundschaft ab -

Ein schwarzer Kater lief zwischen den Freunden hindurch;

Der Treulose hat vergessen, was gewesen ist

In jener Allee, wo er gezecht hat!!!!!!!!!

Er veröffentlichte in seiner Zeitschrift

Eine böse Kritik an Korinna;

Und sie kratzte mit erzürnter Feder

Einen donnernden Artikel zusammen.

Allee dicht belaubter Linden,

Du bist voller Bedeutung für die Welt!

In gegenseitiger Feindschaft entbr ennend
Erzürnen er und sie sich jetzt $1 . . .170$

Sowohl die positiven als auch die negativen Pauschalurteile sind zwar aufschlußreich für das Verhătnis der Zeitgenossen zu Karolina Pavlova, aber beide Gruppen vermitteln ein völlig überzeichnetes Bild, - ein Bild, in dem die Proportionen nicht stimmen. Um der Pavlova gerecht zu werden, bedarf es einer differ enzier enden Betrachtungsweise, wie sie sich beispielhaft bei Boris Nikolaevic $\dot{C} i c$ e $r$ in findet:

"Karolina Karlovna Pavlova ist übrigens durchaus keine alltăgliche Frau. Bei einer auffalligen Käle des Herzens hatte sie auch einige glänzende Eigenschaften. Sie war gescheit, bemerkenswert gebildet, beherrschte viele Sprachen und besaß selbst ein außergewöhnliches literarisches Talent. Eine poetische Saite im eigentlichen Sinne hatte sie nicht: dafür mangelte es an innerem Feuer; aber den Vers beherrschte sie ausgezeichnet, sie über setzte hervorragend, und manchmal gelang es ihr, einen Gedanken treffend und elegant in poetischer Form auszudrücken. Aber sie war von maßloser Eitelkeit, und Takt hatte sie ganz und gar nicht. Sie liebte es, ob es paßte oder nicht,

\section{9}

Unter Anspielung auf Germaine de Staels "Corinne ou l'Italie" nennt E. P. Rostopcina thre Rival in eine "neue Korinna" (Brief an A.V. Druzinin vom 24.11./6.12.1854; in: Letopisi, Buch 9, S. 278).

"Pesnja, po povodu perepiski učenogo muža s ne menee učenoj zenoju", beigefügt dem in Anm. 169 genannten Brief; ib., S. $279 \mathrm{f}$. 
mit ihrem literarischen Talent zu prunken und von dem Eindruck zu erzăhlen, den sie hervorrief. Stăndig las sie laut Gedichte, sowohl eigene als auch fremde, in singendem Tonfall und in irgend so einer seltsamen Selbstvergessenheit, die später von Sobol evskij in einem lustigen Epigramm gerühmt wurde" 171.

In der Schilderung der weiteren Entwicklung in den späten vierziger und frühen fünfziger Jahren schwingt bei allem Unverständnis aufrichtiges Bedauern über das Scheitern ihrer Ehe mit.

An den immer deutlicher hervortretenden negativen Charaktermerkmalen nahmen auch Chomjakov und S̉evyrev Anstoß, ohne jedoch gleichzeitig die Dichterin Pavlova abzuqualifizieren. So schreibt Aleksej Stepanovic Chomjakov an Jazykov:

"Thre Tátigkeit erfreut uns, und es ist nur unangenehm, daß sie sich, wie man es auch drehen mag, trotzdem immer als Deutsche erweist. Außer lyrischen Stücken schreibt sie ein kleines Poem. Junge Damen, die sich auf einem Ball begegnet sind, erzählen einander ihre Geschichte. Dieses Thema ist, wie Du siehst, nicht leicht und wird vortrefflich ausgeführt. Im Vers sind, bei echter Poesie, Leichtigkeit und Ungezwungenheit der Unterhaltung zwischen Damen der Gesellschaft eingefangen, und das ist mit einer solchen Meister schaft geschehen, auf die auch Puskin oft nicht verzichtet hätte" 172 .

Ähnlich lobende Worte findet Stepan Petrovic Š evyrev für das verstechnische Können der Pavlova; gleichzeitig weist er aber auch auf die Gefahr einer Überbetonung des formalen zuungunsten des inhaltlichen Aspekts hin. Seine Rezension des Poems "Dvojnaja zizn'" ist ein Beispiel für sachliche, abgewogene Kritik. Wesentlich engagierter ist sein Urteil über den Menschen Pavlova. 1853 stellte er sich entschieden auf die Seite Nikolaj Filippovičs und tat alles in seinen Kräften Stehende. Als er von dem trau-

B. N. Čicerin, Vospominanija, S. 4.

A.S. Chomjakov, Polnoe sobranie socinenij, Bd. 8, S. $112 \mathrm{f}$. Als Entstehungsdatum des Briefes hat der Herausgeber 1842 ermittelt; das ist falsch. Ebenso unzutreffend ist die Anmerkung 1 auf Seite 113, Chomjakov spreche von "Dvojnaja žizn"'; dieses Werk der Pavlova ist nämlich weder ein 'kleines Poem' noch erzählen sich darin junge Frauen gegenseitig ihre Lebensgeschichte. Chomjakov kann nur das Poem "Kadril" gemeint haben, an dem die Dichter in seit 1843 arbeitete. Folglich ist der Brief frühestens 1843 und spătestens Anfang 1844 geschrieben worden, da er noch ins Ausland geschicktpwurde, Jazykov aber im Frühjahr 1844 nach Rußland zurückkehrte 
rigen Ende des Professors Jaenisch erfuhr, schrieb er Pogodin: "Seine Tochter ist wie ein moralisch mißgestaltetes Geschöpf. Vom Vater hatte sie alles bekommen - und nach seinem Tode hat sie sich grauenvoll betragen $^{\text {173. }}$.

Michail Aleksandrovic Dmitr iev schätzte das Gespräch, die geistige Auseinandersetzung mit der Dichterin sehr. Dennoch betrachtete auch er, wie Šlevyrev, ihre Überbewertung der Form mit Besorgnis. Das zeigt ein Widmungsgedicht ${ }^{174}$ aus dem Jahre 1843; dar in kennzeichnet er eingangs ihrenVers als gegossenes Metall, das zu tönen beginne, als Stahl, der seine federnde Biegsamkeit nicht verlor en habe.

Aber glaube nicht, daß die Idee dem Dichter Nicht notwendig und nicht naturgemäß wäre! Eine Idee ohne Klang ver sinkt im Fluß Lethe; Aber ein Klang ohne Idee - ist eine Woge.

Sie blitzt auf - und jagt voruber;

Und eine andere folgt ihr und

Ergießt sich

In den Glanz der Sonnenstrahlen!

Das ist der Irrtum der Lügenlehre

Unserer heutigen Diskussionen!

Schrecklich lärmend, geschwätzig,

Bleibt thr keine Muße zum Nachdenken!

Das ist der Widerhall der unter Aeols Hănden Harmonisch tönenden Harfe, Und er ist es nicht wert, Musikalisches Spiel genannt zu werden!

Wessen Zunge überliefert

Die Kănge des antiken Dichters? ...

Das Instrument haben die Jahre zerstört, Mit seinem Geist hat er die Jahrhunderte durchdrungen!

Farben des Gedankens, der Empindung Klănge:

Das ist der Dichter! - ...

173 Ohne Quellenangabe zitiert in: Bar sukov, Žizn'i trudy Pogodina, Bd. 12, S. 441.

174 "Ne smotrja na stich moj skromnyj..."; in: Ztschr. f. slav. Phil., XXVII - 1959, S. 41 f. 
Man muß in diesem Gedicht wohl mehr sehen als nur eine "freundliche Kritik" ${ }^{175}$, wie Max Vasmer es nennt: es ist eine ernsthafte Mahnung, sich nicht im Formalen zu erschöpfen; "Farben des Gedankens, der Empfindung Klănge" müssen eine harmonische Verbindung eingehen, um wahre Poesie zu werden.

In den Jahren nach dem Skandal, den die Klage gegen Nikolaj Pavlov ausgelöst hatte, führte Karolina Karlovna ein unstetes Leben ${ }^{176}$. Dadurch wurden auch die noch gebliebenen spärlichen Verbindungen brüchig. Mit der Übersiedlung nach Deutschland begann ein völlig neuer Abschnitt; die Dichterin mußte sich erst wieder einen Bekannten- und Freundeskreis schaffen.

175

ib. , S. 42 .

Um einen Begriff ihrer Rastlosigkeit zu geben, hier ein kurzer Überblick über ihre Reisen in den Jahren 1853 bis 1858 :

1853 - Peter sburg - Dorpat.

1854 - Dorpat - Petersburg (bis Nov. 1855), Abreise nach Italien.

1856 - Rom - Rundreise durch Italien - Konstantinopel.

1857 - Konstantinopel (Jan.) - Interlaken (Febr.) - Weimar (Juni) Dresden (Sept.).

1858 - Berlin (Mai/Juni) - Moskau (Juni - Aug.) - Petersburg (Sept.)Dresden (ab Nov.). 


\section{Späte Jahre}

Für die totale Abkehr von ihrer bisherigen Heimat waren drei Faktoren bestimmend. Der Gedanke an eventuelles eigenes Verschulden war ihr stets fremd gewesen ${ }^{177}$; so mußte sie sich auch jetzt mißver standen ${ }^{178}$, ganz zu unrecht gekränkt und verleumdet fühlen. - Außerdem konnte sie sich der bitteren Erkenntnis nicht ganz verschließen, daß ihr Sohn Ippol it eindeutig auf seiten des Vaters stand. - Und schließlich darf auch die Bedeutung ihrer katastrophalen materiellen Situation nicht unter schätzt werden ${ }^{179}$.

Die völlige Verdrăngung Moskaus aus ihrem Leben mußte ausgerechnet der treueste Anhänger aus vergangenen Jahren, Ivan Sergeevic Aksakov, erfahren. Im Januar 1860 hatte er Karolina Pavlova in Dresden besucht und berichtete seiner Mutter und seinen Schwestern:

"Sie freute sich natürlich außerordentlich über mich, aber nach zehn Minuten oder noch weniger las sie mir schon ihre Gedichte vor... Sie ist vollkommen munter, heiter, froh, im höchsten Maße zufrieden mit sich selbst und nur mit sich selbst beschäftigt... Man sollte meinen, die Katastrophe, die sie getroffen hat, das Unglück, das wahrhaftige Unglück, das sie erfahren hat, - die Trennung von ihrem Sohn, der Verlust von Stellung, Namen und Vermögen, die Armut und die Notwendigkeit, von einer Arbeit zu leben, das alles, sollte man meinen, muß einen Menschen schwer erschüttern, muß in ihm tiefe Spuren hinterlassen... Überhaupt nicht,

177 In einem Brief an N.A. Mel'gunov vom 18.5.1860 nennt sie sich ausdrücklich eine "zenšcina nepovinnaja"; in: B. Rapgof, K. Pavlova. Materialy..., S. 70.

178 Dazu eine Passage aus einem Brief Sof 'ja Éngel'gardts an A.V. DruZinin vom 5./17.5.1854: "Wir haben hier Frau Pavlov, eine entthronte Korinna, und, a propos, man hat gerade einen Brief von ihr erhalten, in dem sie erklärt, daß sie, da sie in Dorpat nicht ver sta nde $n$ worden sei, ihren Wohnsitz nach Petersburg verlegt habe. Wenn Sie davon irgendetwas begreifen, werde ich Innen mein Kompliment sagen"; in: Letopisi, Bd. 9, S. 362.

179 Ihre Armut und vor allem auch die völlige Ungewißheit, wovon sie in Zukunft leben sollte, spiegeln sich wider in zwei Briefen an N.A. Mel'gunov vom 22.4. und 18.5.1860; in: B. Rapgof, K. Pavlova. Materialy..., S. 70-73; und in einem Brief an O.A. Kireeva vom 22.7.1860; ib., S. $73 f$. 
sie ist vollkommen dieselbe, die sie war, sie hat sich in nichts geändert, ist nur gealtert, und alles Gehörte diente ihr nur als Anlaß und Material für Gedichte... So sagt sie thnen, daß sie nicht mehr an menschliche Freundschaft glaube, - und alles sei Unsinn, und fünf Minuten später rühmt sie sich in den Gedichten eben, und in ausgezeichneten Gedichten, daß sie den Glauben an die Freundschaft und an die Menschen bewahrt habe. Das ist er staunlich! In dieser Frau voller Talente ist alles ungereimt, ist nichts Ernsthaftes, Herzliches, Tiefes, Wahrhaftiges und Aufrichtiges, - dort auf dem Grund ist eine schreckliche Herzlosigkeit, irgendeine Stumpf heit und seelische Unentwickeltheit, Auf richtigkeit hat sie nur in der künstlerischen Vor stellung, sie gibt sich ganz der Poesie, den Versen hin statt den Gefühlen - eine gewisse äußerliche Exaltation. Sie fühlen, aber dessen ist sie sich natürlich selbst nicht bewußt, daß sie niemanden liebt, daß es für sie nichts Liebes, Teures, Heiliges gibt. Man kann nicht sagen, daß sie eine theoretische Natur wäre, daß bei ihr das Gefühl nur im Kopf säße, nein; aber ihre geistige Tătigkeit trăgt eben nicht die Anzeichen von Fleisch und Blut eines verinnerlichten Menschen an sich. Fott weiß, woher das kommt, nur nicht aus der Tiefe. In ihr ist nicht die abstrakte, rein verstandesmäßige Erkenntnis entwickelt, - sondern ganz all ein die rein künstlerische Erkenntnis; das ist es, was man über sie sagen muß: daß sie sich mit der Kunst völlig vergiftet hat, und daß darum kein einziges, lebendiges, gesundes Fleckchen in ihr geblieben ist, keine einzige freie, menschliche Regung,... In Karolina Karlovna war niemals auch nur ein russischer Charakterzug, - sie ist vollkommen deutsch... und ist jetzt gleichsam nach Hause zurückgekehrt ${ }^{180}$, sie paßte in eben dem Maße zu Deutschland wie Deutschland zu ihr. Keine Trauer um die Heimat, nicht einmal Interesse, etwas von ihr zu

Das ist allerdings eine Mißdeutung; Karolina Pavlova war in Deutschland nicht zu Hause. Sie hatte sich, je nach den Bedürfnissen, mal als Russin und mal als Deutsche bekannt. Ging es um ihre Übersetzungen in westeuropäische Sprachen oder um Originale in ebendiesen Sprachen, so betonte sie ihre russische Herkunft, um die Bewunderung für die Meisterschaft, mit der sie sich in diesen fremden Sprachen bewegte, zu steigern (Vgl. I. V. Kir eevskij, O russkich pisatel'nicach; in: Polnoe sobranie socinenij, Bd. 2, S. 74.) - Um aber ihren russischen Gedichten die gebührende Anerkennung zu sichern, gab sie sich deutsch. So schreibt E.A. Stakenšnejder 1856: "Aber das Bemerkenswerteste an ihr ist, daß sie überhaupt keine Russin ist und erst vor ganz kurzer Zeit russisch gelernt hat (!), und sie beherrschte die russische Rede und den russischen Vers hervorragend" (E. A. Stakenšnejder, Dnevnik i zapiski, S. $124 \mathrm{f}$.). - Karolina Pavlova selbst bezeichnet sich in einem Brief aus Dresden an Mel'gunov vom 22.4.1860 als "Ženščina, odna, bez pomošci, v cužoj zemle" (B. Rapgof, K. Pavlova. Materialy..., S. 71). 
erfahren, was sich in Rußland tut und wie, nicht einmal Erinnerungen, außer vielleicht in Ver sen" 181 .

Etwa drei Wochen spăter resümiert Aksakov: " Dresden ist durch Karolina Karlovnas Schuld für mich so gut wie verloren" ${ }^{182}$.

Hatte Karolina Pavlova mit Aksakov den letzten treuen Anhänger aus der Moskauer Zeit verloren, so gewann sie schon bald einen neuen aufrichtigen Bewunderer und Freund in Aleksej Konstantinovic Tol stoj . Die Bekanntschaft wurde Ende 1860 oder zu Beginn des Jahres 1861 geschlossen ${ }^{183}$. Zahlreiche Briefe wurden gewechselt ${ }^{184}$, die zum Teil natürlich ihrer beider Arbeit zum Thema haben, zum Teil aber auch einen lebendigen Eindruck ihrer per sönlichen Beziehungen geben.

"Sie können sich nicht vorstellen, was für eine Freude es für mich ist, Briefe von thnen zu bekommen. Ich sage ohne jede Schmeichelei, daß einer der angenehmsten Abschnitte in meinem Leben die Zeit war, als wir, Sie und ich, uns gegenseitig kontrollierten, und ich denke mit Freude an die Zeit, in der Sie mir den "Wallenstein" vorlesen werden, aber ich werde rasen, wenn ich mit Ihnen über das deutsche Original streite" 185 .

181

Brief vom 23.1./4.2.1860; in: I. S. Aksakov v ego pis'mach, Bd. 3, S. 353-355.

182

Brief vom 13./25.2.1860; ib., S. 369.

183 Als Anhaltspunkte dienen zwei Briefe Tolstojs. Der erste wurde am 23.11.1860 in London an F. U. Tjutcev geschrieben; dar in wird der Adressat gebeten, seinen năchsten $\mathrm{Br}$ ief nach Dresden zu schicken (vgl. A.K. Tolstoj, Sobranie socinenij, Bd. 4, S. 123 f.). - Der zweite entstand am 21.3./2.4.1861 in Krasnyj Rog, dem Gut Tolstojs. Dar in berichtet der Graf seinem Freund B.M. Markevic, daß er in Dresden die Bekanntschaft der Pavlova gemacht habe; ihre Übersetzungen seien die besten, die er je in irgendeiner Sprache gelesen habe (ib. , S. 127-129). - Aus Krasnyj Rog stammt aber auch schon ein Schreiben vom 12./24.3.1861. Die Bekanntschaft fallt also in die Zeitspanne zwischen November 1860 und Februar 1861.

Leider standen mir nur Tolstojs Briefe an die Pavlova zur Verfügung. 15 Briefe der Pavlova an thn liegen, wie eingangs erwăhnt, in der Handschriftenabteilung der Akademija Nauk SSSR. Trotz aller Bemühungen blieben mir diese-Dokumente unzugänglich.

Brief vom 3./15.4.1864 aus Rom (aus dem Franz. ins Russ. übersetzt); in: A. K. Tolstoj, Sobranie socinenij, Bd. 4, S. 162. 
Wie hoch Tolstoj den Umgang mit der Pavlova schätzte, geht auch aus einem etwas später geschriebenen Brief hervor:

"Ich găbe viel darum, jetzt bei Innen zu sein (hier fährt er deutsch fort!) und mir von Innen einen Schwung geben zu lassen. Die Produktionskraft ist da, und ist auch nicht müßig, aber Sie sollten mich anregen und begrenzen" 186 .

Jahre später drăngte er: "Sie müssen mir das ver sprochene Sujet für ein Drama geben..." 187. - Sein Verhăltnis zu Karolina Pavlova brachte Tolstoj auf die kurze Formel: "...jeden Tag überzeuge ich mich davon, daß der beste Ort für die Arbeit - Dresden ist, und der beste St imulant (dtsch.) sind Sie" ${ }^{188}$.

Diese Verbindung erschöpfte sich nicht im geistigen Bereich - in enger Zusammenarbeit und wechselseitiger Anregung -, sondern bewähr te sich auch an den Fragen des täglichen Lebens. Sobald Tolstoj erkannt hatte, daß Karolina Pavlovas Zukunft finanziell in keiner Weise gesichert war, nahm er sich dieses Problems tatkrätig an. Als Freund und Hofbeamter Alexanders I. war es ihm tatsächlich möglich zu helfen: im Sommer 1863 trug er in Karlsbad der Großfurstin Elena Pavlovna die Bitte vor, der in Armut lebenden Dichter in eine Pension auszusetzen. Ende des Jahres fragte er bei der Pavlova an: "...lassen Sie mich wissen, ob die Großfür stin Elena irgendetwas unternommen hat?" ${ }^{189}$ - Es dauerte allerdings noch volle drei Jahre, bis er mitteilen konnte: "Sieg! Die Großfürstin hat für Sie eine lebenslängliche Pension festgesetzt. Das wurde sofort nach ihrer Rückkehr vorber eitet, aber erst heute entschieden" ${ }^{190}$. In der Zwischenzeit half er in den Grenzen, die sein Taktgefühl ihm setzte:

"Was die Über setzung des "Don Żuan" anbelangt, so habe ich sie immer unbedingt als $\mathrm{thr}$ Werk angesehen und in olgedes sen a uch als Ihr Eigentum. Wenn ich in Dresden nicht auf die-

186

Brief vom 12./24.1.1865 aus Krasnyj Rog (franz., in russ. Übers.); ib., S. 166.

Brief vom 5./17.7.1870 (franz., in russ. Übers.); ib., S. 345. Brief vom 27.3./8.4.1866 (franz., in russ. Übers.); ib., S. 177.

Brief vom 13./25.12.1863 (franz., in russ. Übers.); ib., S. 160. Brief vom 25. 8./6.9.1866 (franz., in russ. Übers.); ib. , S. 185. 
sem Standpunkt beharrt habe, dann deshalb, weil ich Sie $\mathrm{für} \mathrm{ch}$ t e te. Gestatten Sie mir aber jetzt, Ihnen dafür zu danken, daß Sie mir die Möglichkeit gegeben haben, ein ehrenhafter Mensch zu bleiben und daß Sie nicht von mir verlangt haben, mir fremdes Hab und Gut anzueignen. "Don Žuan" gehört Ihnen, gnädige Frau, und ich wăre glücklich, wenn ich Gelegenheit hätte, Ihnen auf indirekte Weise nützlich zu sein" 191 .

Tolstojs Vermittlung war es auch zuzuschreiben, daB Karolina Pavlova 1863 erstmals eine Sammlung ihrer Arbeiten in Rußland veröffentlichen konnte. Er hatte 1861 Aksakov die Gedichte verkauft - für 96 Rubel!

Erinnert man sich des negativen Bildes, das Ivan Aksakov von ihr gegeben hatte, so stellt sich die Frage, wie Tolstoj mit ebendieser Frau Freundschaft schließen konnte. Die Antwort hat er selbst gegeben. Karolina Pavlova hatte seine beidenWerke "Don Żuan" und "Knjaz' Serebrjanyj" noch vor der Veröffentlichung kennengelernt und über schüttete den Dichter mit Lob. Er schildert das in einem Brief an B. M. Markevic so:

"... Frau Pavlov sowie einige deutsche Literaten, denen sie ihre Übersetzung 192 vorlas,... haben mir Dinge gesagt, die zu wiederholen ich nicht wage, aber sogar nach Abzug aller Übertreibungen und unter Berücksichtigung ihrer ganzen Nachsicht - kann ich sagen - bleibt noch genug übrig, um mich glücklich zu fühlen und getrostet zu sein nach dem großen Fiasko das meine Lesung bei der Groffürstin Marija erdulden mußte"193. ... "Was Frau Pavlov betrifft, so steht ihre Meinung über "Serebrjanyj" nicht hinter dem zurück, was sie über "Don Zuan" sagte, und meine Zunge străubt sich, das zu wiederholen" 194 .

Diese Bewunderung tat dem verletzten Selbstgefuihl des Dichters außerordentlich wohl. Aber abgesehen von diesem aktuellen AnlaB, mag wohl das allgemeine Empfinden beider Autoren, bei den maßgebenden Literaturkritikern nicht gefragt zu sein, von vornherein eine Verbindung begünstigt haben.

Aleksej Tolstoj war der einzige Freund in der Dresdener Periode. Andere Bekanntschaften, die für die Pavlova hätten fruchtbar werden können, endeten sehr bald durch den Tod der kaum gewonnenen Freunde. So

Brief vom 25.10./7.11.1861 (franz., in russ. Utbers.); ib., S. 142. Prolog und weitere Teile des"Don Zuan".

Brief vom 21.3./2.4.1861 (franz., in russ. Übers.); ib., S. 128. ib. , S. 129. 
starben Alexander von Humboldt und Varnhagen von Ense, die ihr beide mit Hochachtung begegnet waren, innerhalb von sieben Monaten ${ }^{195}$, kaum daß die Beziehungen aufgefrischt beziehungsweise neu geknüpt worden waren. Auch die Verbindung zu dem Maler Aleksandr Andreevic Iv a n ov brach bereits nach einem Jahr ab; Ivanov starb 1858 .

Sein Tod lieferte ihr den Vorwand, 'abzurechnen' mit den Zeitgenossen, die wahrhaft berufene Künstler wie Ivanov ${ }^{196}$ (und natürlich wie sie selbst!) nicht mehr zu würdigen wissen:

"In unserem Jahrhundert vergißt man Tote und Lebendige schnell. ...Werden seine Landsleute das tun, was sie noch tun können, nicht um seinetwillen, das ist zu spät, sondern um ihrer selbst willen? Werden sie, die den Lebenden vergessen hatten, sich des Entschlafenen erinnern?...Werden die Tadel am Grabe des Künstlers nicht unwillkürlich verstummen? Aber wenn das auch nicht geschieht, so ist das nichts Neues. So ist das Schicksal aller dieser Märtyrer einer Idee. Für sie gibt es keine Gnade. Mögen sie rastlos arbeiten, mögen sie denen den Weg bahnen, die mit Steinen nach ihnen werfen, mögen sie ihre große Tat mit dem Blut ihrer Adern vollenden, mit dem Mark ihrer Knochen, mögen sie Elend und Not erdulden, Verleumdungen, Schmăhungen, Verrat und, was noch unerträglicher ist, allgemeine Gleichgültigkeit, und wenn sie durch all dieses sterben, was dann? Vile damnum! - Ja, mögen sie das alles erdulden! ihre Leiden und Schmerzen werden nicht vergeblich sein, ... kein einziger von ihnen, der verlassen und einsam stirbt, stirbt ohne großen und wunderbaren Nutzen. Es gibt auf der ganzen Gotteswelt nichts Höheres als den Widerstand des Geistes gegen alles irdische Elend und allen Gram; es gibt nichts Erhabeneres als einen Menschen, der sich auf den Kampf mit dem erbarmungslosen Engel des Leidens einläßt und, immer aufs neue zu Fall gebracht von seinem unsterblichen Feind, immer aufs neue sich erhebt und den todbringenden Kamp fortsetzt. Und darin besteht der Beweis unserer göttlichen Bestimmung, daß dieser Anblick uns nicht er drückt, sondern erhebt, daß der Tod des Märtyrers andere Märty rer schafft und daß wir, wenn wir diese geistigen Laokoons betrachten, die, zerrissen, dennoch alle ihre letzten $\mathrm{Kr}$ äfte zusammenraffen, kein Bedauern empfinden, sondern eine unermeßliche, heilige Freude" 197.

\section{5}

196

Varnhagen starb am 10.10.1858, Humboldt am 6.5.1859.

Dazu ist anzumerken, daß sie nie auch nur ein Bild von Ivanov gesehen hat.

K. Pavlova, Vospominanija ob Ivanove; in: Russkij vestnik, 1858, Bd. 16, Buch 15, S. $297 \mathrm{ff}$. 
Durch Wilhelm Wolfsohn, den Karolina Pavlova schon in den vierziger Jahren in Moskau kennengelernt hatte und in dessen "Russischer Revue" sie ihre Arbeiten veröffentlichte, wurde sie mit Berthold Auerbach bekannt. Er zeigte sich sehr interessiert, durch sie seine Werke auch dem russischen Publikum zugänglich zu machen. Als er jedoch nach längerer Zeit und nach etlichen Anfragen beiWolfsohn erkennen mußte, daß die Pavlova die versprochene Über setzung seines "Preiselspeter" noch gar nicht in Angr iff genommen hatte, zog er sich verärgert zurück.

Mit dem Tode Tolstojs reißen die Zeugnisse über sie völlig ab. Über die Jahre bis 1893 ist nichts bekannt außer der bereits erwähnten MickiewiczÜbersetzung ${ }^{198}$ und dem ebenfalls schon genannten Brief an Władyslaw Mickiewicz $^{199}$.

Als Karolina Pavlova gestorben war, brachten fünf russische Zeitschriften einen Nachruf; es waren Nekrologe auf eine Unbekannte ${ }^{200}$. Drei Artikel - in "Novoe vremja", "Russkie vedomosti" und "Istor iCeskij vestnik" enthielten den gleichen Wortlaut, nur die "Russkie vedomosti" hatten den zweiten Absatz des ohnehin dürftigen Textes noch fortgelassen. Der anonyme Verfasser dieser Notizen, anders kann man die wenigen Zeilen kaum nennen, hatte sich mit einigen allgemeinen Floskeln über die Verstorbene und mit der Aufzählung einiger weniger Werke beholfen.

Ausführlicher, aber auch unverbindlich gehalten, ist das Gedenken von D. Ja. (Jazykov?) in den "Moskovskie vedomosti". Mit Recht geht der Autor davon aus, daß er die Leserschaft der neunziger Jahre erst mit Karolina Pavlo va bekanntmachen muß. Er tut das, indem er in gedrängter Form einen Abriß ihres Lebens und Werkes gibt.

Die einzige Würdigung, die wohl nicht nur als journalistische Pnichtübung geschrieben wurde, stammt von Petr Bartenev, dem Herausgeber des
198
sh. Anm. 26.
200
sh. Anm. 58.
sh. Anm. 4. 
"Russkij archiv", der in Moskau im Hause der Dichterin verkehrt hatte. Er geht auch verhältnismäßig ausführlich auf ihre Beziehungen zu Zeitgenossen ein. Zu den Höhepunkten ihres Schaffens gehört für ihn, außer dem Roman "Dvojnaja zizn" , das Gedicht "Razgovor v Kremle": "Wer hat kraftvoller und klangvoller über unseren Kreml geschrieben?... Allein für diese Verse darf Moskau Karolina Karlovna Pavlova nicht vergessen" 201.

Als sich ihr Todestag zum ersten Mal jährte, erschienen zwei Zeitschriftenartikel, beide von ihrem Enkel Dmitrij Ippolitovid geschrieben 202 . Dar in wird übereinstimmend das Bild einer zu Unrecht Vergessenen gemalt. Bis zuletzt habe sie mit allen $\mathrm{Kr}$ äften ihrer 'russkaja dusa' und ihres 'russkoe serdce $e^{\prime}$ an der Heimat gehangen; dort aber habe man ihren Tod kaum bemerkt. In "Russkoe obozrenie" wird dem Leser im Anschluß an einen knappen Abriß von Leben und Werk das Poem "Fantasmagorii" vorgestellt. - Der zweite Auf satz, in den "Moskovskie vedomosti", verherrlicht die Pavlova als eine Dichterin, die allein aus innerem Zwang geschrieben habe, unbekümmert darum, was aus ihren Arbeiten werde, ob sie gedruckt werden oder nicht; Lobeswor te haben ihr nicht geschmeichelt, jeglicher Stolz sei ihr fremd gewesen. Pu blikum und Kritik seien stets begeistert gewesen, sowohl von ihren Übersetzungen als auch von ihren eigenen Dichtungen. Auch in den letzten Jahren habe sie, obgleich nichts mehr veröffentlicht worden sei, nicht aufgehört zu schreiben ${ }^{203}$. Pavlov schließt:

"Wir haben nicht so viele Dichter, als daß wir nicht die durch Druck ausgezeichneten Werke einer wahrhaft poetischen Begabung zu schätzen wüßten. Solche Werke, von wem und wann auch immer sie ge-

201

P. Bartenev, K. K. Pavlova; in: Russkij archiv, 1894, Buch 1, S. 123.

a) D. I. Pavlov, K. K. Pavlova; in: Russkoe obozrenie, 1894, Nr. 12, S. $961-970$.

b) D. Pavlov, Zabytyj poèt. Pamjati K.K. Pavlovoj; in: Moskovskie vedomosti, 1894, Nr. 331 (2./14.12.).

Über den Verbleib dieser unveröffentlichten Arbeiten macht Pavlov leider keine weiteren Angaben. 
schrieben wurden, verlieren niemals ihre Bedeutung, ihre bezaubernde Kraft.

Was glänzt ist für den Augenblick geboren,

Das Echte bleibt der Nachwelt unverloren!" 204

Eben diese Differenzierung ist Gegenstand dieser Arbeit.

204 Sh. Anm. 202 b); hier: letzte Sparte (Faust-Zitat deutsch). 
for

(5)

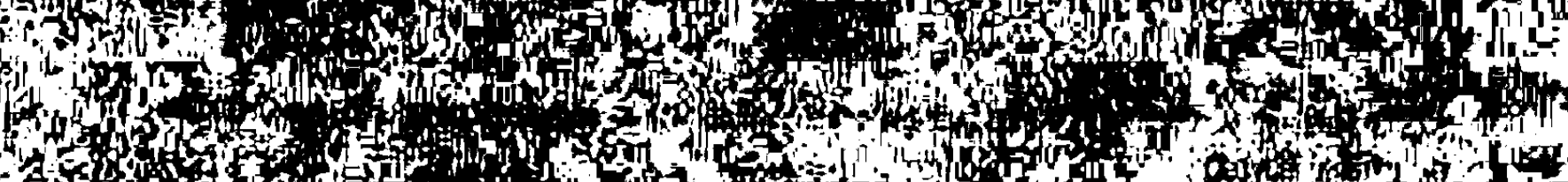

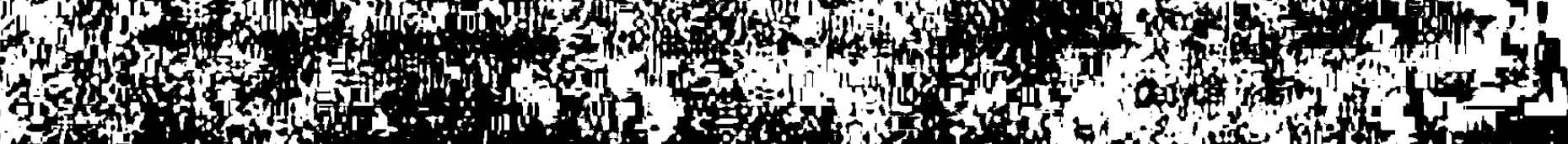
(n)

in

$3^{4}$

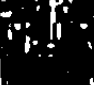

A.

:

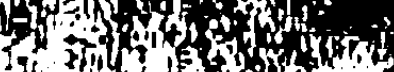

If

然 to Lis ifing 17. Hong

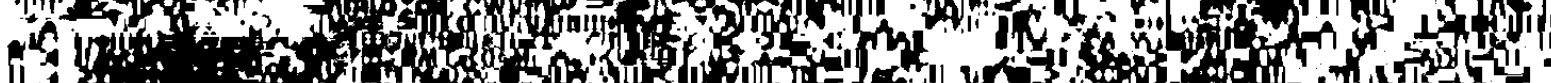

(1) 120
S. Wh if

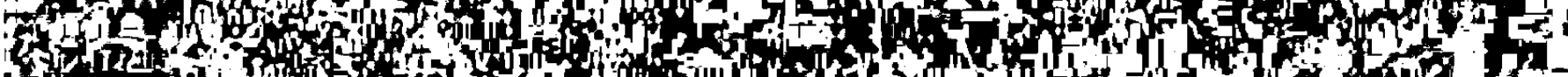

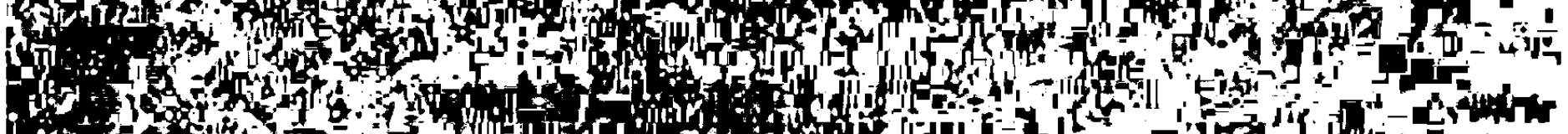

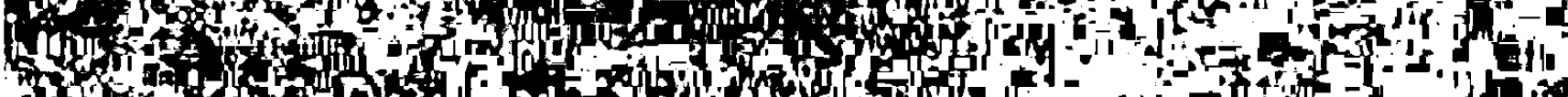
and

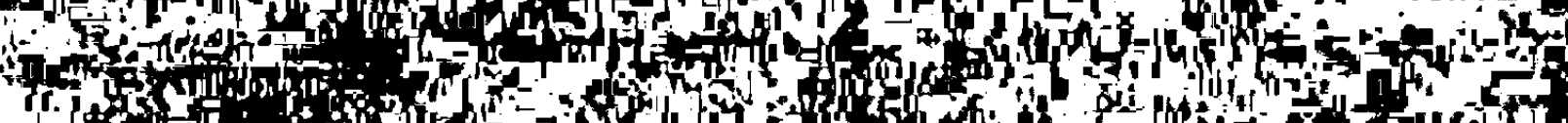

r. P4s

Hete (19)

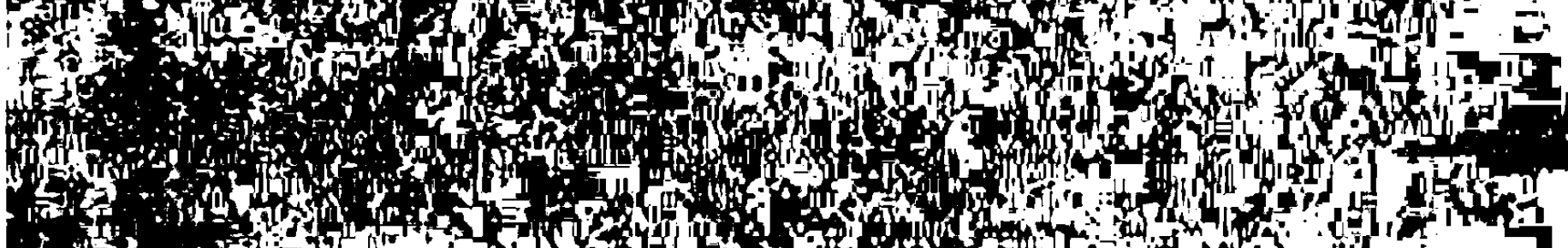

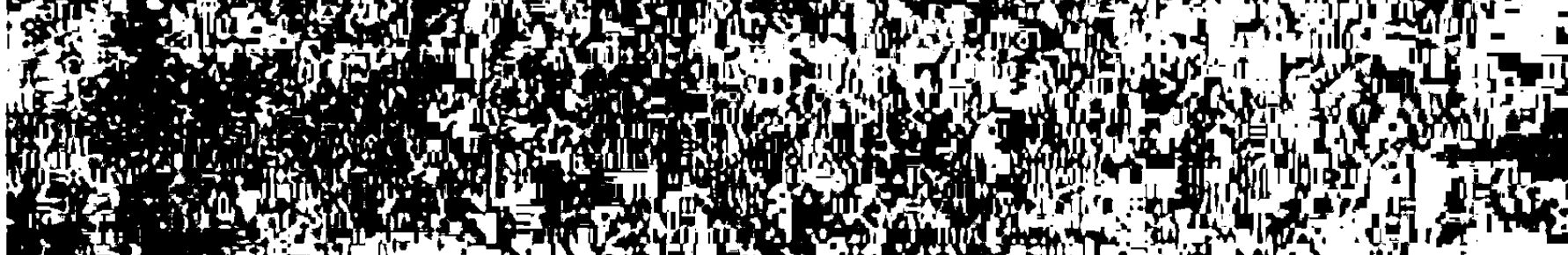

Hof

Aif

(5) if and

IN 20 ,

(1)

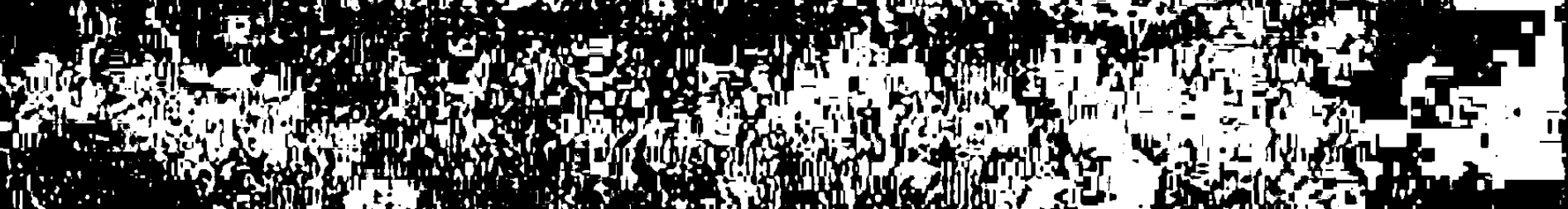

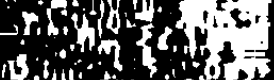
ay S.5. 


\section{ZWEITER TEIL}

Werk

Die Biographie Karolina Pavlovas vermittelt das Bild eines erstaunlich früh entfalteten Talents. Als ob sie sich in dieser raschen Vollendung gleichsam verausgabt hătte, verharrt sie auf der erreichten Höhe, scheint nicht mehr die Kraft zur Fortsetzung des steilen Auf stiegs zu haben. So wie ihr Leben ohne rechtes Ziel, ohne echte Entwicklung verlief, fehlt auch threr Dichtung der Gewinn neuer Gegenstände, die Vertiefung der in der Jugend erlangten Perspektive. Die Dichterin kreist um einmal gestellte Themen, um einmal aufgeworfene Fragen in wechselnder Entfernung, ohne sich aber einkreisend treffenderen Antworten wesentlich zu năhern. Dieser Mangel wird oft kunstvoll verdeckt.

Eine gewisse Vordergründigkeit wird auch durch einen Blick auf das Übersetzungswerk bestätigt. Der Vorwurf, daß statt wirklicher Literaturvermittlung eher ein modischer Streifzug durch die Weltliteratur geboten wird, kann mit dem Einwand, daß es sich vorwiegend um erlesene Dichtungen und im großen und ganzen um gute Übersetzungen handelt, mehr erhärtet als entkräftet werden. 
4

(1)

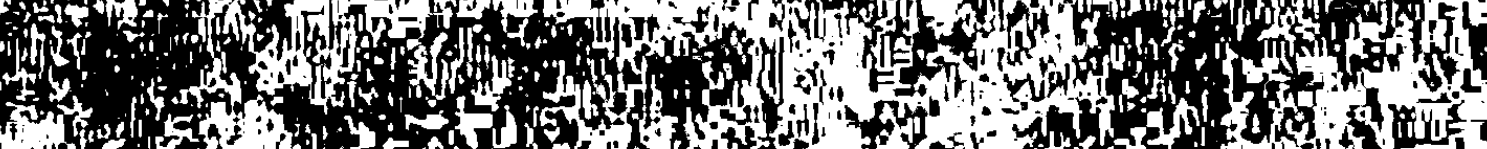

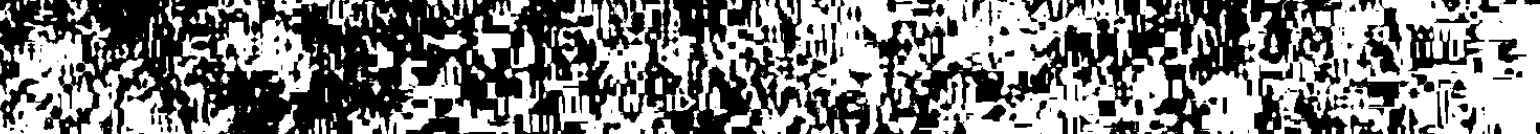

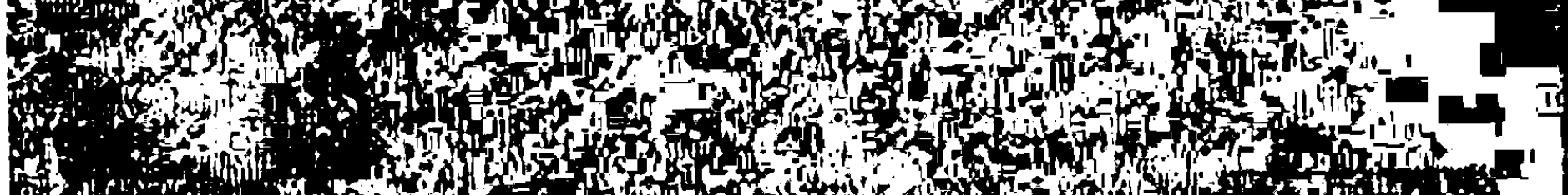

is

Hon

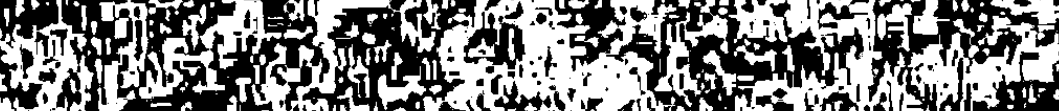

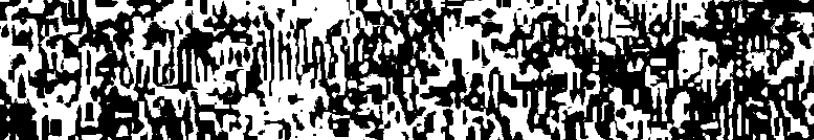

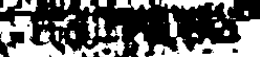

ASt A noth

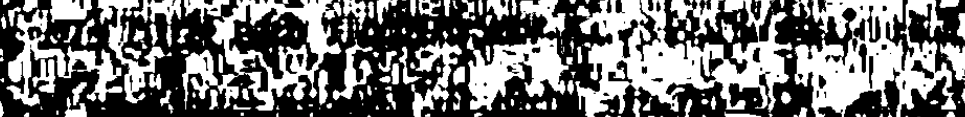

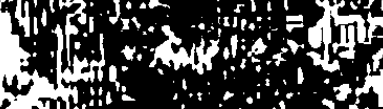

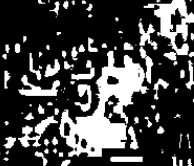

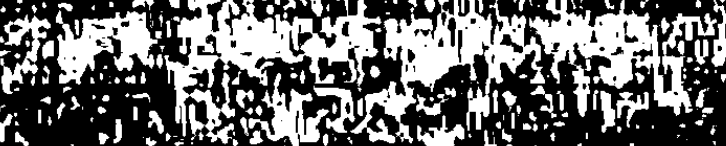

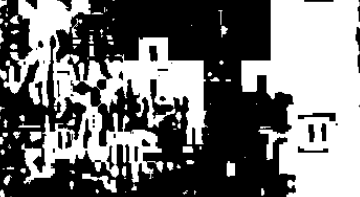

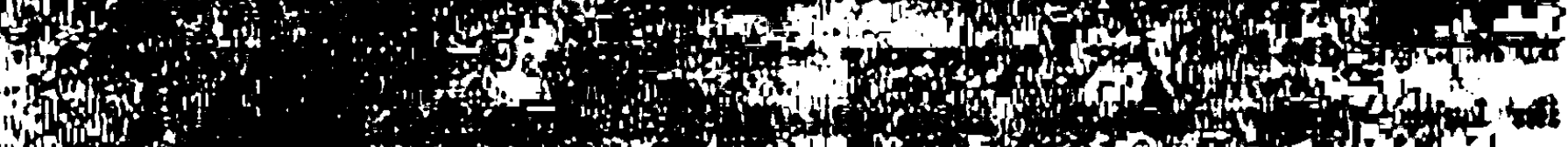

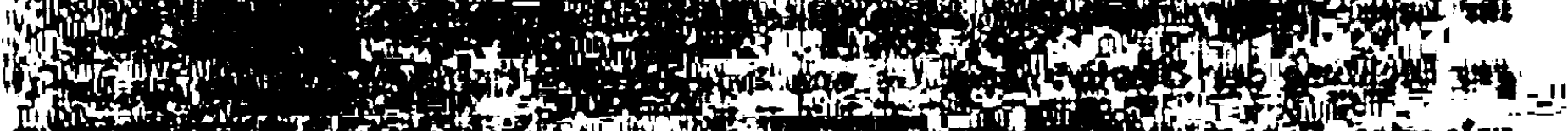

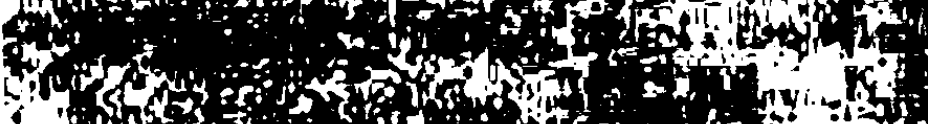

sith

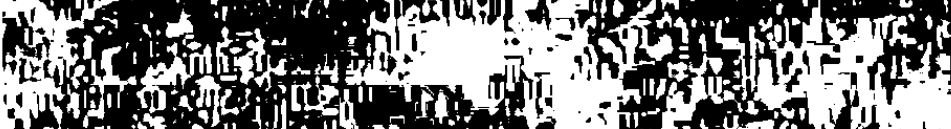

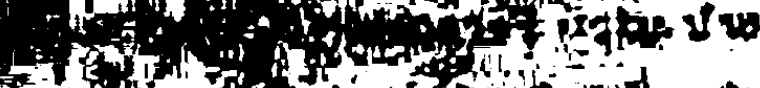

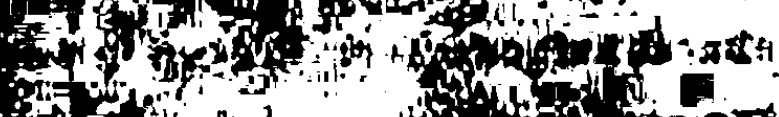

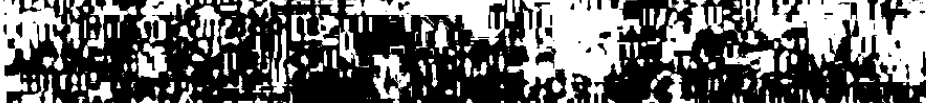

19y and

an $A$

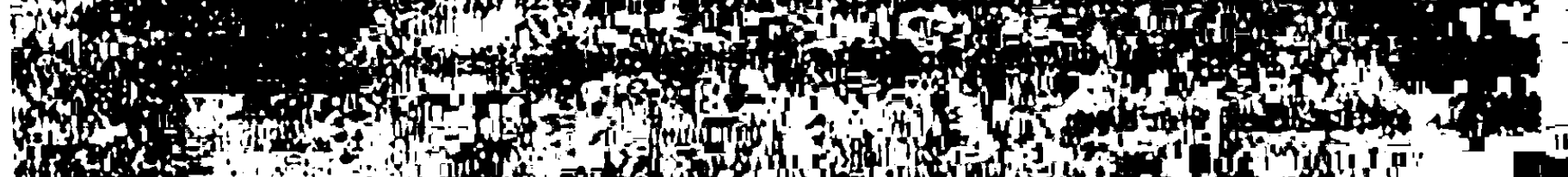
f. En

(1)

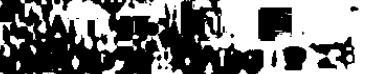

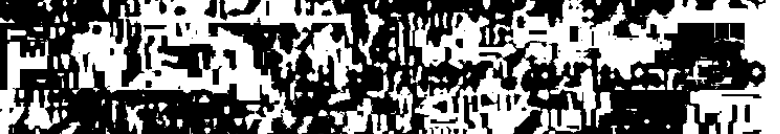
(1) SW

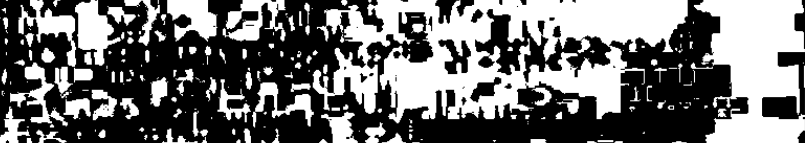
for

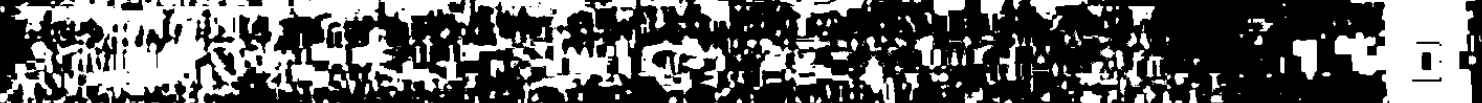
Si

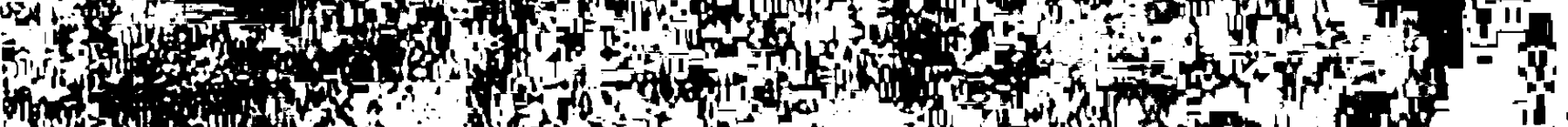

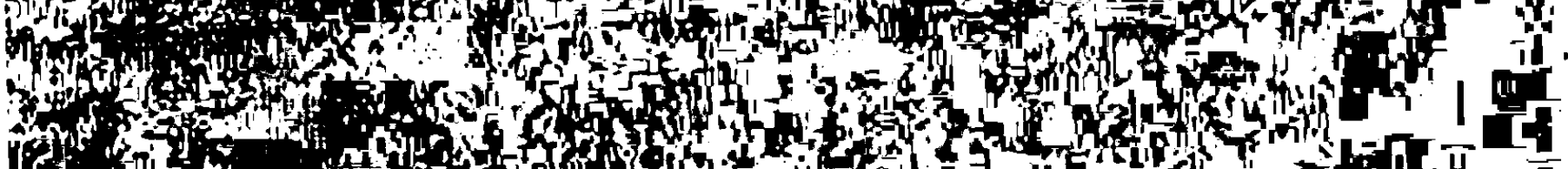

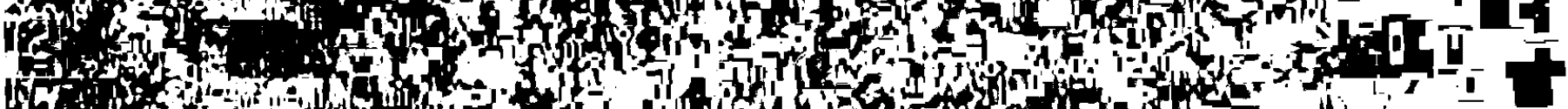
150 of 皮, =

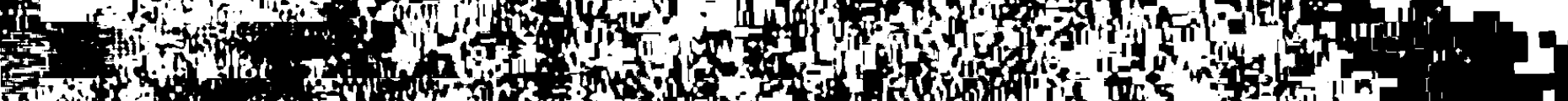

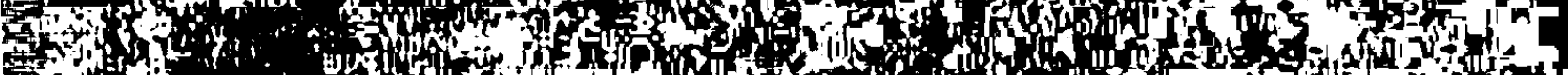

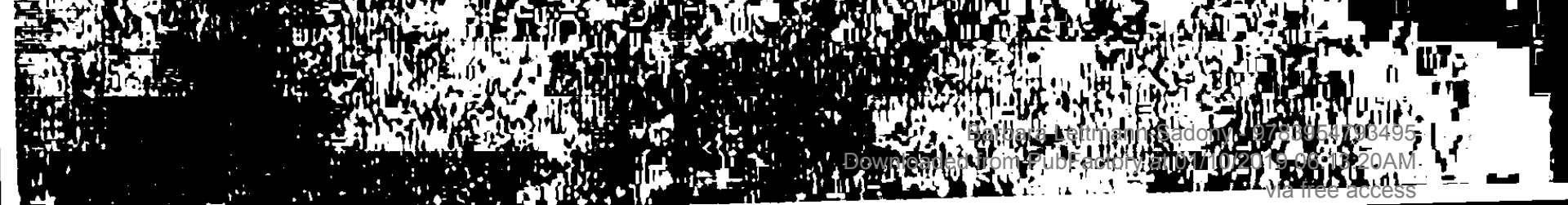




\section{Kapitel}

\section{Eigene Dichtungen}

Das Originalwerk Karolina Pavlovas ist zum größten Tell lyrisch. Selbst wenn sich die Dichterin in anderen Grundformen versucht, schlăgt hăufig das lyrische Element durch. Mit dieser Verwischung der Grenzen steht sie eindeutig in der romantischen Tradition.

Die größte thematisch geschlossene Gruppe der Gedichte hat den Dichter selbst zum Gegenstand, seine Berufung, seine Stellung in der Welt. In einer Zeit, die dem Dichter, wie die Pavlova inn verstand, den Platz mehr und mehr streitig machte, war die Selbstreflexion als Akt der Selbstbehauptung notwendig. So ist es nicht verwunderlich, daß Karolina Pavlova in den vier künstlerisch fruchtbarsten Jahrzehnten (etwa vom Beginn der dreißiger Jahre bis 1870) mit einer lückenlosen Kette derartiger Gedichte ihren poetischen Freiheitsraum abzusichern versuchte. In dieser Umfriedung beschäftigte sie sich vorwiegend mit den traditionellen Themen der Romantik und Nachromantik. Auffallig ist jedoch ein starkes Mißverhältnis zwischen dem Aufwand, Stellung und Aufgaben des Dichters zu ergründen, und dem tatsăchlichen Ertrag ihres Schaffens. Für das Übergewicht dieser Fragestellung bieten sich noch weitere Erklärungen an. Einmal könnte die Pavlova auch aus Mangel an Einfällen auf diesen zeitlosen und doch stets aktuellen Gegenstand gerne zurückgegriffen haben; diese Gedichtgruppe wăre also ein 'Notbehelf', eine Art sprachlichen MüBiggangs. Zum anderen aber - und das scheint mir wahrscheinlicher zu sein könnte der Grund in ihrer ausgeprägten Selbstbezogenheit zu suchen sein. Immer wieder setzte sie sich mit der Frage auseinander, weshalb ihr Erfolg in keinem ausgewogenen Verhảltnis zu der dichterischen Bedeutung stand, die sie sich selbst beimaß. Da der Dichter schon auf Grund seines Berufs oder seiner Berufung, wie sie es für selbstverständlich hielt, dem profanen Zugr iff der Kritik entrückt war ${ }^{205}$, sind der Pavlova offensichtlich nur selten Zwei-

In einem Brief an I. I. Panaev erklärte sie es als ihr "Prinzip, keine einzige Besprechung meiner nicht allzu vielen Werke zu lesen, absolut nichts über irgendwelche Zeitungsmeinungen zu wissen... "; in: Sovr emennik, S. -Peterburg 1854 - Bd. XIVII, Nr. 11, S. 130. 
fel an ihrem Können, an ihrer Aussage gekommen. Es konnte nur an der Engstirnigkeit der Umwelt liegen, daß sie ohne nachhaltiges Echo blieb; folglich mußte sie sich verkannt fühlen. Es ist ihr tragischer Irrtum, nie begr iffen $z u$ haben, daß so unerhört das von ihr Verkündete nicht war. Das ständige Um-sich-selbst-Kreisen machte sie weitgehend unempfindlich, unempfänglich für Fragen, die außerhalb ihrer selbst lagen.

Etliche Gedichte erwecken den Verdacht, nur um der virtuosen Spielerei mit den künstlerischen Mitteln willen geschrieben worden zu sein, aus Freude an der Artistik; ihre Inhalte drohen auseinanderzufließen und werden manchmal nur notdürftig von der brillanten Form zusammengehalten. Diese Überbetonung des Formalen gegenüber dem Gehalt läßt dann zweckfreie Kunst leicht zur zwecklosen werden. Eine gewisse inhaltliche Erschöpfung ist ja überhaupt kennzeichnend für die Erben Puskins; zu der gut gelernten Form fand auch Karolina Pavlova kaum neue Inhalte.

Wollte man so etwas wie ein formal typisches Gedicht der Pavlova konstruieren, so trüge es folgende Merkmale: es wäre jambisch mit kreuzweiser Reimbindung geschrieben; jede der regelmåßig gebauten Strophen bestünde aus vier Versen. Zur Verdeutlichung einige statistische Anmerkungen über Versmaß, Strophenbau und Reimschema:

Der Jambus wird in ungefähr zwei Dritteln der 115 russischen Gedichte angewandt. Über 50 dieser rund 80 jambischen Dichtungen sind vierhebig; mit Abstand folgen fünfhebige (15 Gedichte). Zwei-, Drei- und Sechshebigkeit sind selten.

Der Trochăus wird, beinahe ausschließlich vierhebig, in 13 Stücken verwandt; der Daktylus fast ebensooft (12mal, häufig mit von Vers zu Vers wechselnder Hebungszahl). Der Anapäst begegnet nur einmal.

Zweimal wird die Form der Sapphischen Ode, je einmal die der ChevyChase-Strophe und des Rondeaus nachempfunden ${ }^{206}$, nur ein Gedicht ist in Sonett-Form geschrieben.

Die Sapphische Ode wurde nachgeahmt in: "Plovec" (K. Pavlova, S. 186f.) "Eto bylo blestjasceee more..." (ib. , S. $208 \mathrm{ff}$.); die Chevy-Chase-Strophe in: "K. S. A(ksakovu)" (ib. , S. 136); die Form des Rondeaus in: "Serenada" (ib., S. 150f.). 
Knapp vier Fünftel aller lyrischen Stücke sind in absolut ebenmäßig gebaute Strophen gegliedert. Bei 78 von diesen 89 Gedichten ist auch die Zahl der Hebungen je Vers konstant; bei den übrigen 11 variiert sie nach einem festen Schema. - Die verbleibenden 26 Dichtungen weisen ver schiedenartige Abweichungen von dieser Regelmåßigkeit auf. Bei 6 von ihnen ist nur die Anzahl der Verse pro Strophe identisch; Versmaß und Hebungszahl wechseln jedoch. 9 Gedichte sind in unregelmäßige Abschnitte unterteilt. 11 haben keinerlei Einschnitt (es handelt sich bei dieser letzten Gruppe übrigens fast durchweg um Widmungen).

62 der insgesamt 95 regelmäßig gegliederten Dichtungen haben vier zeilige Strophen, 8 haben achtzeilige; das überrascht bei der Bevorzugung des Kreuzreims nicht sonderlich. Mit großem Abstand (13mal) folgt der künstlerisch interessante Fünfzeiler. Nach dem Muster $a b a$ a $b$ wurde 11 mal gereimt, nach dem Schema $a \mathrm{a} b \mathrm{a} b$ einmal. Hinzu kommt die einmalige eigenwillige Variante $a b b b a$. Und schließlich werden zweimal zwei Möglichkeiten der Reimbindung kombiniert: die erste Strophe reimt $a b b a b$, die zweite $a b a a b$ beziehungsweise in umgekehrter Reihenfolge.

Paarreim und umarmender Reim treten fast nie auf. Die Kadenz ist beinahe ohne Ausnahme wechselnd.

Die Vorliebe für bestimmte Gedichtformen darf keineswegs zum Vor urteil der Einseitigkeit führen. Es ist der Dichter in in hohem Maße gelungen, das 'Kategor ische' eines Versmaßes rhythmisch zu über spielen. Stark variierte Akzentintensităt ist dabei ein ebenso geeignetes Kunstmittel, die Verse vor dem 'Klappern' zu bewahren wie Pausenzeichen und Enjambements. Von dieser Möglichkeit, mehrere Zeilen, ja sogar zwei, drei Strophen in einen großen Bogen einzuspannen, macht Karolina Pavlova reichlich Gebrauch. Kaum ein Gedicht, in dem der Zeilensprung nicht angewandt worden wäre.

Der souveränen Handhabung formaler Mittel entspricht die Fähigkeit zu kor rekten Reimbindungen. Einige Unreinheiten sind mit der Anpassung an die moderne Orthographie zu erklären, andere werden nur vom Leser, nicht aber vom Hörer empfunden (-oj: -yj oder -ij). Echte Unreinheiten sind selten (Beispiele: dorogoju : vinoju : sudieju; besedu ja : bytija; um auf bab'e , star'e moẽ etc. zu reimen, wird mehrmals aus byt' $e$ und bytie die Form bytié er- 
mischt). - Nur åußerst selten tut der Akzent eines Reimwortes der natür lichen Betonung des anderen Gewalt an (Beispiele: gorda : zidá; vstréca : izdaléça; izdaleká : vostoká; dy mú : t’mu).

Sicher ist ein technisch einwandfreies Gedicht nicht schon ein gutes. So wie der Inhaltskomplex der formalen Struktur adăquat sein sollte, so muß im besonderen das gewählte Wort in doppelter Hinsicht angemessen sein: seine Bedeutung soll dem intendierten Inhalt entsprechen, seine Lautgestalt sich der Form fügen. Ganz ohne Konzessionen an die eine oder andere Seite geht es gewiß nicht; uber den Wert einer Dichtung entscheidet dann letztlich die Nähe zum Ideal der völlig kompromißlosen Wortwahl.

Betrachtet man zunächst nur die Reimwörter, so ist bei Karolina Pavlova das Bemühen um Originalităt unverkennbar. Banale, durch hăufige Verwendung abgegriffene Reimbindungen sind selten (Beispiele: pevcy : vency; nocej : solovej; sna : luna; vesny : sny; sada : serenada : vzgljada).

Groß ist die Gruppe der Wortpaare, die in logischem Zusammenhang stehen und oft sogar demselben Bedeutungsfeld angehören. Für diese Spezies scheint mir der Begriff 'assoziativer Reim' angebracht. Hier einige Beispiele: pelenoj : nocnoj; mglistoj : volnistyj; slab : rab; chiter : vor; lačuzku : starušku; vlast' : klast'; scita : kresta; zabavoj : cirk krovavyj.

Die 'interpretierenden Reime' geben schlaglichtartig Auf schlüsse über das Verständnis der Dichterin von der Welt, dem Leben, von Staat und Volk und schließlich auch vom Dichter. Zu den einzelnen Themenkreisen seien jeweils nur wenige Wortpaare angeführt:

zemnoj : gluchoj; zloj : zemlej; mir : pir; mir : kumir; zlatom : razvratom; puciny : čuzbiny;

vremja : bremja; raja : vospominaja; neba : chleba; svetila : sila; krest : protest; stuzu : muzu; cerdake : bednjake;

slavoj : krovavoj; slava : pava; krovavyj : der Zavoj;

pochod : narod : vpered; nepogod : narod; svoboda : naroda;

rassveta : poèta; predskazan`ju : mectan`ju : dan`ju.

Mit sehr viel mehr Dynamik aufgeladen sind die 'antithetischen Reime'; hier werden Begriffe zusammengeklammert, die im Grunde auseinander str eben: 
tvar': car'; proroka : poroka; chrama : srama; loz'ju : bož'ju; prezrennyj : blagoslovennyj; prach : nebesach; Vodan : christian; nebosklona : zemnogol ona; bezdnoj : ty sjacezvezdnyj; siloj : mogiloj; lom : snom; nežnoj : mjateźnoj; lad : chlad; grechi : stichi; serdcem cist : kommunist.

Auf der Suche nach ausgefallenen Reimen verwendet Karolina Pavlova häufig Fremawörter und Eigennamen. Solche Bindungen können recht originell sein (Beispiele: uzy : francuzy; ubora : toreadora; otrad : aromat). Tatsächlich aber wird hierbei in sehr vielen Fällen die Grenze zwischen Kunst und Artistik über schritten ${ }^{207}$. So wird beispiel sweise in dem Gedicht "Razgovor v Kremle" die Vorliebe fast schon zur Manier; im Durchschnitt ist jedes fünfte Reimwort ein Name oder Fremdwort. Zum Beleg eine kleine Auswahl: Uspenskij, Ninevija, Rodos, Erusalim, Kolumb, Rafaila, Śekspir, Rasinu, Versal', Saavedra, Stratforda, Makbeta, Sardama.

"Razgovor v Kremle" war Anlaß zu einem Briefwechsel zwischen Karolina Pavlova und dem Herausgeber des "Sovremennik", I. I. Panaev, den sie irrtümlich für den Verfasser einer in seiner Zeitschrift erschienenen Rezension 208 dieses Gedichts gehalten hatte.

An dieser Stelle sei auf ein Unikum unter den Gedichten hingewiesen, auf "Vezde i vsegda" (K. Pavlova 1964, S. 127f.). Es besteht aus elf je vierzeiligen Strophen und nur zwei Sătzen. Der erste Satz umfaßt die ersten vier Verse, der zweite erstreckt sich über vierzig Verse! Die Reime machen das Gedicht zum Monstrum. Ein Kritiker, der 1854 "Razgovor v Kremle" rezensierte, ging noch nachträglich auf dieses Erzeugnis ein: "Niemand wird bestreiten, daß dieses Gedicht im Hinblick auf Reichtum, Original ität und Neuheit der Reime nicht seinesgleichen hat. . . Aber was für einen Eindruck ruft es hervor? ist in ihm Poesie? und wor in besteht sein Wert? Es kann einen zum Lachen bringen wie ein gelungener Scherz, aber von Poesie ist auch nicht ein Schimmer darin, und sein ganzer Wert besteht denn auch darin, daß es zeigt, wie leicht es ist, eine Vielzahl reicher und ungewöhnlicher Reime zusammenzusuchen, die übrigens noch keine Poesie ausmachen..." (Sovremennik, 1854 - Bd. XLVII, Nr. 9, Abt. IV, S. 37). - K. Pavlova führte in einem Brief an Panaev aus, da $\beta$ dieses Gedicht nur als Spaß gedacht gewesen sei (vgl. dazu S. 69 dieser Arbeit). Es läßt sich nicht entscheiden, ob das zutrifft oder ob sie sich nachtrăglich von ihrem Produkt distanzieren wollte.

Sovremennik, 1854 - Bd. XIVII, Nr. 9, Abt. IV, S. 34-38. 
Es hatte darin geheißen, daß eine derartige Hăufung ungewöhnlicher Reime nicht gerade für die Meisterschaft eines Dichters spreche. In ihrem Rechtfertigungsschreiben 209 verteidigte sich die Verfasser in damit, daß sie sich mit ihrer Vorliebe in so erlesener Gesell schaft wie der Puskins befände. Sie wollte sich zwar nicht mit ihm vergleichen, "aber bei allem Bewußtsein seiner Größe kann man nicht umhin, zu bekennen, daß es schwieriger war, wenn vom Zorn des Sultans die Rede ist, auf Tul' $\mathrm{Ci}^{\prime} \mathrm{zu}$ stoßen, als auf Stratford, wenn von Sekspir die Rede ist... "210. Panaev parierte: "Ich kenne die Verse Puskins fast auswendig, aber in allen seinen Werken sind, zusammengenommen, kaum so viele glänzende, ausgesuchte und or iginelle Reime wie in einem von Ihnen. Der große Dichter gestattete seinem Reim nicht, sich allzu groß zu tun; ungeachtet seiner Liebe zu ihm, hielt er ihn in gebührenden Grenzen: bei ihm ordnete sich der Reim stets dem Gedanken unter und nicht der Gedanke dem Reim" 211 .

Nach diesem Exkurs zum Abschluß noch einige Proben ausgefallener Reime aus anderen Gedichten:

cholere : Kossid'ere : chimere; fimiam : mectam; zorz-zandistka : artistka; nacij : émancipacij; trata : Sokrata; ruke : per ché; fruttí di mare : gitare; in dem Gedicht "Gondola" wird allein viermal auf 'gondol'era' ger eimt: pera, chimera, sero, vera!

Viele Reime werden auch mehrfach wieder aufgenommen. Das muß nicht immer Mangel an dichterischer Făhigkeit sein, sondern ist häufig bewußtes Anknüpfen an vorausgegangene Gedichte, kann die Funktion der Zyklenbildung haben. Hier einige dieser 'programmatischen', wiederkehrenden Wortpaare:

ljubov' : vnov' (7); cudes : nebes (auch die davon abgeleiteten Adjektive, 6); siloj : mogiloj (5); mir : pir ; ljubov' : krov'; strastno : neprasno; vremja : bremja; neba : chleba; sveta : poèta; privet : poèt.

Das Bemühen um Originalităt und die Vorliebe für einen gehobenen Wortschatz lassen sich bei Karolina Pavlova nicht nur im besonderen Falle der Reimbindung feststellen, sondern gelten für ihre Wortwahl im allgemeinen. Bieten sich zum Ausdruck eines Gedankens mehrere Wörter an, so

Datiert vom 12./24.10.1854; in: Sovremennik, 1854 - Bd. XLVIII, Nr. 11, S. 130-136.

ib., S. $136 \mathrm{f}$; ; hier: S. 137. 
wird die Dichterin in den meisten Fallen das 'gewăhltere' Wort wăhlen, da ihre Themen vorwiegend auf einer höheren Ebene angesiedelt sind. Diese Tendenz kann man auch beobachten, wenn es um die Entscheidung zwischen der geläufigen vollvokalisierten und der feierlicheren kirchenslavischen Form eines Wortes geht.

Eindrucksvollstes Beispiel für die konsequente Unterscheidung der Stilhöhen ist die Dichtung "Dvojnaja żizn". Das alltăgliche Leben der Gesellschaft mit Empfängen, Bällen, Ausflügen etc. wird in Prosa geschildert; in diesen Passagen werden ausnahmslos die Vollformen 'golos', 'molodoj', 'golova' etc. angewandt. - Das Leben der Seele aber kann sich erst in der Nacht, in der Stille, im Traum entfalten; es findet in Versen seinen Ausdruck. In diesen Teilen werden, dem Inhalt angemessen, kirchenslavische Formen benutzt, mit nur vier Ausnahmen: dreimal taucht die vollvokalisierte Form in Naturschilderungen auf, die jeweils am Anfang eines Abschnitts in Versen stehen und den Übergang zwischen Tag- und Nacht-Leben schaffen. Die vierte Abweichung findet sich in den letzten Versen des Werks: dem Entschluß Cecilijas, sich dem oberflächlichen, konformen Tag-Leben zu bequemen, entspricht der Gebrauch der Form 'molodye'; gleichsam als Kontrapunkt, als Echo eines letztlich absichtsvoll überhörten Rufs folgt darauf noch einmal das kirchenslavische 'glas'.

In den Gedichten Karolina Pavlovas läßt sich das gleiche Bemühen um eine Trennung der Stilebenen feststellen, wenn die Dichterin sich hier auch der Idealvorstellung, die sie in "Dvojnaja żizn" so kompromißlos hatte verwirklichen können, nur weitgehend annähern konnte. Die archaischen Formen überwiegen gegenüber den vollvokalisierten im Verhảntnis drei zu zwei. Auch so feierliche Formen wie 'slovesa', 'rek' und 'rekla' sowie 'glagol' werden verwendet.

So wie sich im Überwiegen der Wörter des erhabenen Stils die Bevorzugung hoher Inhalte zu erkennen gibt, so zeigt sich die weltanschauliche Grundhaltung der Dichterin in der großen Zahl der Wörter aus dem Umkreis des Irrationalen. An der Spitze stehen die Begriffe 'Seele', 'Herz' etc. ('duša', 'serdce', 'grud"*). Allein in den rund vierzig Gedichten, die den Dichter zum 
Gegenstand haben, werden sie etwa $60 \mathrm{mal}$ benutzt; über $30 \mathrm{mal}$ ist von 'Traum' die Rede ('mecta', 'mectan'e', 'son', 'greza', 'bredni'). 'Begeisterung' und 'Eingebung' ('vdochnovenie', 'poryv', auch umschrieben mit 'zar', 'volnenie') werden $20 \mathrm{mal}$ genannt, etwa $25 \mathrm{mal}$ Wörter für die vorherrschende Stimmung 'Trauer' ('grust" bzw. 'grustnyj", 'toska', 'pecal", auch eingefangen in 'slezy'). Mehr als 20mal werden Bezeichnungen der 'Düsternis' verwandt ('mrak', 'mgla', 't'ma', 'dym', 'ten"', 'noc'"). 


\section{Gedichte über den Dichter}

Der Dichter war für Karolina Pavlova zeitlebens Außenseiter, und zwar in dem doppelten Sinn von Vertreibung und Selbstisolation. Allerdings kann man sich oft nicht des Eindrucks erwehren, daß die entschieden vorgetragene Sonderstellung und der Abbruch aller Bindungen zum Alltäglichen eine selbsttåuschende Verbrämung der Tatsache war, daß nur wenige etwas von dieser Dichter in wissen wollten.

Daß es dem Dichter gegeben war, den sprachlosen Kosmos und die verschlüsselte Natur zu verstehen, entsprach durchaus dem Selbstverständnis des romantischen Dichters. In der Verdolmetschung oder auch nur in der Mitteilung des Geheimnisses dem gegenüber, der von sich aus nicht fähig ist, es zu ahnen oder gar zu verstehen, sah die Pavlova bereits die Zerstörung eben dieses Geheimnisses. Sie wollte allenfalls für Eingeweihte schreiben, die Kluft zum gemeinen Publikum schien ihr unüberbrückbar zu sein.

Die Heimat des Dichters - das heißt sowohl Lebensraum hic et nunc als auch Herkunftsland - sei nicht diese begrenzte Erde, sondern vielmehr der unendliche Kosmos.

On vselennoj gost', emu vsjudu pir,

Vsjudu kraj cudes;

Emu dan v udel ves ${ }^{\circ}$ podlunnyj mir, Ves ${ }^{\circ}$ ob-em nebes; ..

Der Dichter hat den Sinn für das Wunderbare; es durchdringt ihn und schlägt sich - beinahe unr eflektiert - im Gedicht nieder. In diesen relativ frühen Versen $^{212}$ sieht Karolina Pavlova die dichterische Existenz weitgehend problemlos, sieht sie 'naiv'.

Vsẽ żivit ego, emu vsẽ krugom

Dlja mecty magnit:

Zazurcit rucej - vot i v chor s ruc'em

Ego stich zurcit;

Zarevet li les pri bor'be s grozoj,

Kak serdityj tigr, -

Emu buri voj lis predmet zivoj

Sladkozvučnych igr.

"Poèt" (1839); K. Pavlova 1964, S. 77 f. 
Kosmos und Natur zentrieren sich um das Ego des Dichters. Das Außergewöhnliche seiner Position wird durch die Hăufung von Personalpronomen sinnfălig gemacht. Im ersten Vers der zweiten Strophe wirken die aufeinanderstoßenden Pronomen ". ego, emu ..." wie ein Gravitationskern.

Noch weitaus prononcierter ist die Aussage in einem Gedicht, das in demselben Jahr entstand. Die letzte Strophe lautet:

Ne dlja pol'zy ze narodov

Vsja priroda rascvela:

Est' almaz podzemnych svodov,

Reki est' bez parochodov

Ljudi est' bez remesla. 213

Schon der Klang dieser Verse ist spröder. Die Härte des Trochăus wird durch Inversionen noch gesteigert. Die Dichterin markiert die Antithese durch geschickte Ausnutzung der dem Trochăus eigenen fallenden Bewegung: kategorisch stehen "ne" und "est'" am Anfang des Verses. Das rhetor ische Vorziehen der negativen Aussage bringt den Ton einer fast trotzigen Verteidigung in das Gedicht. Diese Strophe ist das Resümee einer Erörterung der Position der Dichter in der Gesellschaft. Innen sei, wie jedem anderen, eine Aufgabe mit eigenen Schwierigkeiten und Problemen gestellt; ihnen sei die Zeit der Eingebung nicht untertan, die Zeit, da "ihre Träne hell erglänzt, / Ihre Wange heiß erglüht". Karolina Pavlova erwartet von der Menge kein Verständnis dieses besonder en Auftrags, aber Toleranz, "einen Winkel, wo der Lärm verstummt, / Wo die Mittagssonne wärmt, / Wo der Mond von den Himmeln blickt".

In diesem Gedicht sind bereits die Grenzen abgesteckt, innerhalb derer das Dichter - Thema varilert wird. Die unproblematisch-idyllische Darstellung aus "Poèt" wiederholt sich nicht. Anhand der Metaphern läßt sich nachzeichnen, in welchem Maße und in welcher Richtung sich im Laufe der Jahre und Jahrzehnte das Bild Karolina Pavlovas vom Dichter ver schoben hat.

In den relativ frühen Gedichten - etwa bis an die Schwelle der vierziger Jahre - überwiegt die Vorstellung vom außer-menschlichen Wesen. 
Allerdings ist es nicht mehr nur die mediale Göttlichkeit der eingangs zitierten Verse, das passive, bloß verkündende Durch-sich-hindurch- und Aus-sich-herausströmen-Lassen, sondern mehr und mehr kommt die Mühe des Vordringens zum Transzendenten zur Sprache.

Ce n'est pas le bonheur qui mur it le poète:

II lui faut la tempête, il lui faut les tourments!

Ce n'est pas dans la paix de ses plus doux moments,

Dans un cercle d'amis, dans les bras d'une épouse

Que grandit son génie et sa palme jalouse;

Oh! que de maux sans nom dans cette ame de feu!

Que cet homme a souffert pour devenir un dieu! 214

Der Gedanke, daß der Dichter sich erst zum Göttlichen emporringen muß, findet sich auch in dem programmatischen Gedicht "Motylek" 215.

Motylek

Ċego tvoja chocet pričuda?

Kuda, motylek molodoj, Prirody blestjašcee cudo, Vzvilsja ty k lazuri rodnoj ?

Ne znal svoego naznacen'ja,

Byl dolgo ty pracha zulec;

No vremja vtorogo rozden'ja

Prišlo dlja tebja nakonec. Upejsja ze cistym éfirom, Guljaj ze v nebesnoj dali, Porchaj ozivlennym sapirom, Żivi, ne kasajas' zemlí. -

Ne to li sbylos i s toboju?

Ne tak li, chudožnik, i ty

Byl skovan żitejskoju mgloju,

Byl cervem zemnoj tesnoty?

Sred' grustnogo tak ze bessil 'ja

Nastal cas urocnyj cudes:

"Fragment" (1834 ?); K. Pavlova 1964, S. 495.

"Motylek" (1840); K. Pavlova 1964, S. 83 f.

Das Bild des Schmetterlings wurde auch schon von Žukovskij ver wandt (vgl. "Motylek i cvety", 1824). Er stellt Schmetterling und Blumen gegenüber: der Falter nicht erdgebunden, frei, mit der Erinnerung an reine, himmlische Schönheit - die Blumen bis zum Tode der Erde verhaftet, ohne Ver ständnis für die Stimme des Gefühls. K. Pavlova hat das Bild stark verengt. 


\begin{abstract}
Vnezapno rasširil ty kryl'ja,
Uznal sebja synom nebes.

Pokin' '̇e zemnuju obitel'

I ucast' primi motylka;

Svobodnyj, kak on, nebozitel',

Na zemlju gljadi s vysoka!
\end{abstract}

In diesen Versen wird jegliche soziale Funktion des Dichters rundweg ver neint; die Erde mit ihrer Enge und ihrem Nebel ist ihm eine schwere Fessel. Zur festgesetzten Zeit aber vollzieht sich das Wunder der Verwandlung; der Künstler wird sich dessen bewußt, ein Sohn der Himmel zu sein. Frei und unbekümmert schwingt er sich empor aus dem irdischen Gefängnis. Von der Sonnenseite her schaut er aus angemessener Entfernung hinab auf die Erde. Das Bild des Schmetterlings ist nicht sehr glücklich gewählt. Karolina Pavlova war es zweifellos nur um die Metamorphose vom ohnmächtigen Wurm zum ungebundenen Himmel sbewohner gegangen. Jedoch beinhaltet diese Metapher unausweichlich auch das Element des Flatterhaf ten, des Geistlos-Hübschen. So gesehen gewinnt das Gedicht - von der Autorin völlig unbeabsichtigt - eine wenig schmeichelhafte Nebenbedeutung.

Saltykov-Šcedrin qual ifiziert in seiner Rezension der Werkausgabe von 1863 die Poesie dieser Dichter in pauschal als "motyl'kovaja poezija" ab, wobei er nur den taumelnden Flug des Falters im Sinn hat: "Schmetterlings-Poesie heißt sie nach dem Namen des Schmet terlings, des mutwilligsten, aber zugleich auch leichtgläubigsten der Insekten, und sie stammt in direkter Linie vom berühmten Lied vom Zeisig ab, dann führt sie über Fürst Šalikov 216 und Herrn Sevyrev weiter und endet bei Frau Pavlov. Diese ganze Poesie ist nichts anderes als eine in Versen geschriebene Anwendung gefälliger Manieren auf zufällig begegnende Gegenstände" 217.

Gemeint ist der sentimentale Dichter und Herausgeber des "Damskij zurnal" (1828-1 833) P. Salikov (1768-1852).

N. Ščedr in (M.E. Saltykov): O literature,. S. 161.

Sein Spott wendet sich auch gegen die zahlreichen Widmungsgedichte, eine gesellschaftliche Pflichtübung: "Begegnet Frau Pavlov zum Beispiel einem Dichter - schreibt sie dem Dichter eine Epistel, hat sie I.S. Aksakov getroffen - schreibt sie I.S. Aksakov eine Epistel, erblickt sie irgendein Lämpchen aus Pompeji - läßt sie auch das nicht ohne ein feierliches Lied. Ihr ist es völlig gleichgültig, an wen sie sich wendet, was sie singt, weil nicht die Gegenstände der Außenwelt sie beeindrucken, sondern weil sie die Gegenstände der Außenwelt durch die Galanterie ihr er Hinwendung beeindruckt" (ib., S. 161 f. - vgl. auch dazu das Gedicht K. Pavlovas "Lampada iz Pompei", K. Pavlova 1964 , S. 146f.). 
Karolina Pavlova war sich aber durchaus dessen bewußt, daß das Emporgehoben-Sein oder das Sich-Erheben über die irdische Enge nicht nur Freiheit bedeutet, sondern auch Gefahr und unter Umständen sogar Tod. In einem Gedicht aus dem Jahr $1842^{218}$ trägt sie Baratynskij ihr gebrochenes Selbstverständnis vor. Sie beneidet ihn um seine noch helle Auffassung vom Dichtersein, um seine unversehrte Schaffenskraft. Die Klage kulminiert in der achten Strophe in dem Ausruf, daß die heilige Leier schwer geworden sei. Mit dem unvermittelt angehängten Bild vom stürzenden Phaethon steigert sie die Aussage noch.

No tjažela svjataja lira!

Bessmertnym plamenem spalen, Nadmennyj duch $s$ vysot éf ira

Padet, bezumnyj Faéton!

Die zweite Metapher ist zwar sehr plastisch und der formale Nachvollzug des Sturzes mit den Mitteln des Enjambements und der sinkenden Intonation in der letzten Zeile künstlerisch geglückt, aber die Einfügung dieser mythologischen Lesefrucht ist etwas gewaltsam. Und sie ist insofern unangebracht, als die Aussage des ersten Verses das folgende Blld totaler Vernichtung aus Mutwillen überhaupt nicht erwarten läßt.

Bezeichnenderweise ist der Sturz des Phaethon die letzte Metapher, die den Dichter als göttlich darstellt. Dieser Bewußtseinswandel ist sicherlich auch durch die privaten Erlebnisse dieser Zeit gefördert worden. Karolina Pavlova hatte sich wohl bisher in ihren Jedichten als überirdisches Wesen stilisiert, jedoch blieb sie sowenig wie jeder andere Mensch von irdischen Schwierigkeiten und Problemen, von ganz vordergründigen Nöten wie beispielsweise Vermögensfragen usw. verschont. Die sich bereits abzeichnende Ehekrise mußte sie ahnen lassen, daß auch sie in der Welt verstrickt war, daß auch sie sich nicht ständig 'profanen' Dingen entziehen konnte. Sie nahm diesen Konflikt nicht frei an, sondern verdrängte die Notwendigkeit, mit ihm leben zu müssen, so weit wie möglich. Die Unfähigkeit der Pavlova, solche Anstöße wirklich aufzuarbeiten und in Erkenntnisse umzusetzen, ist bereits im biographischen Teil dieser Arbeit dargelegt worden . 
Die Erschütterungen der vierziger Jahre führten zwar dazu, daß die Dichterin in der Folgezeit 'menschlichere' Metaphern für den Künstler verwandte, aber sie betonte nach wie vor seine Sonder stellung. Er war nicht mehr Angehöriger einer anderen, höheren Welt; er war ein außergewöhnlicher Mensch. Damit wandte sich Karolina Pavlova eigentlich erst jetzt der typisch romantischen Vorstellung vom asketischen Dichter zu.

In dem knappen Jahr zwischen Juni 1843 und Mai 1844 schrieb die Dichterin allein vier Gedichte unter dem Titel "Duma", was man als Zeichen für eine innere Einkehr deuten darf. Das Bild des Wanderers, der auf halbem Wege stehenbleibt und Atem holt, kann als typisch für diese Zeit angesehen werden. Er hält inne und projiziert in die ihn umgebende Leere eine traumhafte Wirklichkeit. Um den Gedanken Raum zu geben, fehlt in diesen fast zyklisch aneinandergerückten Gedichten entweder die Darstellung einer Umgebung völlig oder aber die Landschaft ist so unkonturiert, daß sie bloß Umschreibung für Abgeschiedenheit ist. Wie sehr die Schilderung der Außenwelt ihre Funktion als zeitliche und răumliche Fixierung zugunsten einer Metapher für die Leere aufgegeben hat, wird in "Duma (Chotja ustalaja, dosla ja...)" 219 offensichtlich. Weil die gleiche Seelenlandschaft gemeint ist, empfindet man es kaum als Bruch, daß in der vierten Strophe der Vergleich mit einer "friedlichen Ebene", einem "stillen Mittag" gezogen wird, später dann aber von "tiefer Dunkelheit" die Rede ist, in der als hoffnungsvolles, "vertrautes Licht" allein der Polarstern strahlt. - In dem Zyklus herrscht mit wechselndem Akzent eine Stimmung zwischen Resignation und Zuversicht, einer Zuversicht, die eben aus der Fähigkeit schöpft, das Dunkel traumhaft, das heißt poetisch zu erhellen:

No $s$ každoj mgloj nevedomaja sila

Tainstvenno vstaet $v$ grudi moej, Kak tam blestjat nebesnye svetila Jasnee vsẽ, cem noc’ krugom temnej. 220

219 220

"Duma (Chotja ustalaja, došla ja. .)" (Okt. 1843); K. Pavlova 1964 , S. $115 \mathrm{f}$.

"Duma (Ne raz sebja ja voprošaju strogo. .)" (Mai 1844); ib., S. 119. 
Dieser Gedanke begegnet uns auch in der Nachdichtung eines Gedichts von Georg Philipp Schmidt ${ }^{221}$. Die Pavlova hat die Vorlage durch nur wenige Verånderungen ${ }^{222}$ so sehr ihrer derzeitigen Stimmungslage angepaßt, daß die Über setzung fast wie ein eigenes Werk anmutet ${ }^{223}$. Ein năheres Eingehen scheint mir auch deshalb gerechtfertigt zu sein, weil in "Strannik" die innere Verfassung der Dichterin in der Objektivierung eines geschlossenen Bildes besonders anschaulich gemacht werden kann.

In dieser Dichtung korrespondieren zwei Ebenen. Das Ich des Dichters erlebt in der Gestalt des Wanderers die Realităt einer Landschaft, die langsam in der Dămmerung versinkt. Seinem Blick öffnet sich die Tiefe des Raumes. In ihm steigt das diffuse Gefühl der eigenen Nichtigkeit und Verlassenheit auf; er wird auf sich selbst zurückgeworfen. In einer typisch romantischen Wendung hellt sich in dem Maße, wie die realen Konturen verblassen, in ihm gleichsam eine Seelenlandschaft auf, in die Leere hinein kann ein neues

221

"Strannik" (Originaltitel: "Des Fremdlings Abendlied"). Die Übersetzung entstand im November 1843; ib. , S. 117.

Georg Philipp Schmidt von Lübeck (1766-1849) war ein Dichter der Spătromantik.

222

Vgl. dazu D. Gerhardt, der sich mit dieser Übersetzung befaßt hat und dem das Auffinden des Originals zu danken ist. Zu den Veränderungen heißt es: "Ein leiser Zug rationaler Gründlichkeit weht aus ihrer Ausdrucksweise, ein teleologisches "kuda" hat das dimensionslose "wo" in den Zeilen 16 abgelöst, statt des unfrohen Wanderers, der nicht weiß, wo er geht, spricht bei ihr der obdachlose, getriebene, der nicht weiß, wohin (Z. 4 und 10 beider seits). So schließen auch die letzten Zeilen nicht mit einer Antwort voll verschwimmender Resignation, sondern mit einer Lehre voll hohnlachender Härte. Auch in den Einzelheiten zeigt sich dergleichen: die antithetischen Glieder in den Zeilen 7-8 sind klarer zusammengestellt, Z. 21-22 zielen deutlicher auf das gelobte Land hin als im Deutschen..." ( $\mathrm{Zu}$ den russischen Über setzungen der Karolina Pavlova, S. 318).

In der Werkausgabe von 1915 stand unter dem Titel "S nemeckogo". Wie der Anmerkung der Ausgabe von 1964 (S. 555) zu entnehmen ist, trägt auch die Handschrift den Zusatz "Perevod", allerdings von fremder Hand; das Original sei jedoch unbekannt. Die Herausgeber waren offensichtlich der Ansicht, es handele sich doch um ein eigenes Gedicht $K$. Pavlovas (was vom Inhalt her ja auch durchaus möglich wäre), und reihten es daher in die eigenen Werke und nicht in die Über setzungen ein. 
Bild entworfen werden. Die Hinwendung zur Innenwelt ist schon rein äußer lich leicht am Gedicht abzulesen: immer weniger Verse der einzelnen Strophen schildern die Außenwelt. In der fünten Strophe wird die Introversion vollendet:

Mracna mne neba sineva, Vesna stara, i zizn' mertva, I ich privety - zvuk pustoj:

Ja vsem prişlec, ja vsem cužoj!

Diese Verse sind die Achse des Gedichts, sie bringen die Absage an die 'normale' Welt, die charakterisiert ist durch Himmelsblăue, Frühling, Leben. Durch das Stilmittel des Oxymorons wird die radikale Verneinung gestaltet; Parallelismus, im zweiten Vers noch unterstützt durch einen Binnenreim, verstärkt die Intensităt der Aussage. Die sechste und siebente Strophe verdichten das Gegenbild und statten die zunăchst nur vage skizzierte Welt mit immer mehr konkreten Merkmalen aus.

Gde ty, mnoj zdannaja odna,

Obetovannaja strana!

Moj kraj ljubvi i krasoty -

Mir, gde cretut moi cvety,

Predel, gde sny moi zivut,

Gde mertvye moi vstajut,

Gde sly \$itsja rodnoj jazyk,

Gde vsẽ, cego ja ne dostig!

Die Steigerung des Bildes, seine zunehmende Verdichtung geschehen durch anaphorischen Druck.

Aber so schnell die Vision des Landes aufgebaut wurde, so jäh zerfließs sie im Nebel. Der Wanderer erwacht aus dem kurzen Traum, um die Erkenntnis reicher, daß sich diese andere, ideale Welt wohl nur ahnen, aber nicht erreichen läßt. So müßte er ein ewig Suchender bleiben.

Gljažu v grjadušcuju ja t'mu,

Vopros odin sepcu v semu;

"Blaženstvo tam, - zvucit otvet, -

Tam, gde tebja, bezumec, net!"

Die Schlußstrophe ist jedoch zweideutig. Es bleibt ungeklärt, ob das verheiBene Land tatsăchlich, aber dem Dichter für immer unerreichbar, existiert oder ob er ruhelos einem Trugbild nachwandert. 
Dieses Thema findet seine Fortsetzung in dem Gedicht "Zovet nas Zizn': idem. ." 224 . Es beginnt fast zögernd, in mehreren Stuf en. Zunächst wird es durch ein Motto vorbereitet; eine allgemeine Betrachtung über die retardier enden Augenblicke im Menschenleben stimmt den Leser ein. Erst dann wird er in die poetische Wirklichkeit geführt.

Zovet nas żizn': idem, mužajas', vse my;

No v kratkij cas, gde stichnet grom nevzgod,

I strasti spjat, i spory serdca nemy, -

Dochnet dusa sredi mir skich zabot,

I vdrug mel'knut dalekie édemy,

I dumy vlast' opjat' svoe beret.

Dann setzt die Rahmenhandlung ein, in der das Bild vom Wanderer wieder aufgenommen wird. Er legt eine Rast ein, bleibt auf halbem Wege stehen:

Za nim cvety i majskij den' $v$ doline,

A pered nim - granit i zimnij chlad.

Die Handlung wird, im Unterschied zu "Strannik", bis zum beginnenden Morgen fortgeführt. Das Bild des fernen Paradleses, des gelobten Landes, das dort nur mit wenigen Strichen skizziert worden war, wird hier im breiteren fünfhebigen Jambus ausgemalt.

Tam mnogo est', cego ne vstretit' snova;

Prelestna tam i radost' i beda;

Tam mnogo est' ljubimogo, svjatogo,

Razbitogo sud'boju nav segda.

Uželi vsě duša zabyt' gotova?

Użeli vse prochodit bez sleda?

Uzel' vy mne - bezżiznennye teni,

Vy, vzjavšie s menja, $v$ moej vesne,

Dan' Zarkich slez i gor estnych borenij,

Pogibšie! užel vy cuźdy mne

I pomnites', sredi serdečnoj leni,

Liš izredka i têmno, kak vo sne?

Zunächst ist es nur eine alles verklärende Rückschau, eindringlich gestaltet durch die Anapher "tam mnogo est"". Dann jedoch wird der beschauliche Rückblick gestört durch bohrende, zweifelnde Fragen; dle Beschwörung der Vergangenheit bekommt durch das viermalige "uzeli" bzw. "užel" etwas ungemein

"Zovet nas Żizn": idem.." (Juli 1846); K. Pavlova 1964, S. 128-131. 


\section{Drăngendes.}

War das ersehnte Land in "Strannik" die Heimat des Dichters schlechthin, so trägt sein Bild hier, der Eigenart Karolina Pavlovas entsprechend, ganz private Züge. Wie in den "Duma" -Gedichten ist hier die Problematik wieder stărker eigenbezogen: das Ich ist weiblich ${ }^{225}$. Alle Aussagen sind viel direkter und unsymbolischer. So sind auch die auf die Geleitverse und einleitenden drei Strophen folgenden zehn Strophen eine liebevolle Ausmalung eines einzigen Verses aus der vorigen Arbeit: "Predel, ... / Gde mertvye moi vstajut". Hier erstehen noch einmal alle jene, die ihr als Mensch oder als Künstler in etwas bedeutet haben und längst gestorben sind. Da ist zunăchst die Jugendfr eundin, die dem geliebten Manne einem Dekabristen offensichtlich - in die Verbannung folgte; da sind Daszkiewicz und Baratynskij; und schließlich Puskin und Lermontov, beide Opfer eines Duells.

Aber durch die Konkretisierung wird das Bild auch zeitlich ganz deutlich als Vergangenheit fixiert; je mehr Gestalt es erhält, desto klarer wird, daß es nicht mehr wirklich ist. Eine seltsam gegenlăufige Bewegung findet statt: je plastischer die Figuren hervortreten, desto fühlbarer wird deren Abwesenheit.

Die Dichter in erkennt diesen Vorgang und zieht daraus die Konsequenz, daß es nicht ihre Aufgabe sei, verlorene Paradiese zu beschwören und ihnen nachzutrauern, sondern daß sie sich der Gegenwart stellen müsse. - Wie das Bild durch Fragen eingeleitet wurde, so wird es auch fragend wieder zurückgenommen und mit der Aufforderung "Ostav" menja!" gleichsam hinweggef egt.

Die Umwandlung wird gleich in der ersten Strophe ganz deutlich vollzogen:

Ostanovjas' gory na polovine,

Prišlec poroj krugom brosaet vzgljad:

Kak on, vpered gljazu ja reże nyne,

I bolee gljazu uze nazad. 
Uvy! zacem blestjat skvoz' mrak bescvetnyj

Byvalych cuvstv bludjašcie ogni?

Zacem poryv i nemočnyj, i tšcetnyj?

Kto vyzval vas, moi mladye dni?

Cto, blednyj lik, vperjaes`izdaléka

I ty $v$ menja svoj nepodvižnyj vzor?

Spokojna ja; sli gody bez nameka;

$\mathrm{K}$ cemu ty zdes', uśedsij s davnich por?

Ostav' menja! - beleet den's vostoka,

Pust ${ }^{\circ}$ prizrakov isceznet grustnyj chor.

In der letzten Strophe dämmert der Morgen herauf. Die Dichter in nimmt seine Aufforderung zu Taten an und kehrt sich ab von der Nacht mit ihren Trugbildern. Dieser Tag ist zwar ein neuer Anfang, aber ein illusionsloser Aufbruch in eine nüchterne Welt.

Beleet den', zvezd gasit roj almaznyj,

Zovet $k$ trudu i trebuet dela;

Pora sver sat' svoj put' odnoobraznyj,

I vse zabyt', eto zizn' prevozmogla,

I otrezvet ot chmelja dumy prazdnoj,

I sled mecty opjat' strjachnut ${ }^{\circ}$ s cela.

Im unmittelbar anschließenden Gedicht, das Ivan Sergeevic Aksakov zugeeignet ist ${ }^{227}$, stellt Karolina Pavlova der gerade geschilderten versunkenen geistigen Heimat und deren Vertretern die jetzt heranreifende Generation "leidenschaftlicher Ignoranten" gegenüber. Zwar kann sie ihnen nicht starke Überzeugung, Willen und Hoffnungen absprechen, aber von ihrem erhabenen Standort aus muß sie deren Realismus als vordergründig schärfstens ablehnen. Die Verurteilung dieser Jugend, die ihren Blick nur auf das Naheliegende richte, gipfelt in dem Begriff "Kurzsichtigkeit" (den sie sicher nicht

Gemeint ist Mickiewicz, der zwar als einziger aus der Reihe der beschwor enen Gestalten noch lebt, aber für $K$. Pavlova doch für immer verloren ist. Sie vermag es trotzdem nicht, ihn völlig aus ihren jedanken zu verbannen. 1848, nach der Februarrevolution in Frankreich, wo sich Mickiewicz damals aufhielt, gedenkt sie seiner daher noch einmal mit einem Gedicht: "Sredi sobytij ezeçasnych" (K. Pavlova 1964 , S. 136).

"I. S. Ak(sako)vu" (Aug. 1846); ib., S. $131 \mathrm{f}$. 
zuf ăllig auf "Wissenschaft" reimt!): alles, was außerhalb des eng begrenzten Gesichtskr eises liege, werde von der neuen Generation für nicht existent erklärt. Die Kritik an der zeitgenössischen realistischen, prosaischen Dichtung wird erweitert zur Kritik des wissenschaftlichen Zeitalters überhaupt.

Est' mnogo tjazkich predvešcanij,

Cholodnych mnogo est' umov,

Kotorych mysl', v nas vek soznanij,

Ne priznaet svjatych alkanij,

Uprjamych ver i detskich snov,

I, podavlen zemnoj naukoj,

$V$ nich dar božestvennyj iscez;

I vzor ich, nyne blizorukoj,

Dlja nich dostatoćnoj porukoj,

Ćto gasnut zvezdy sred' nebes.

Der Pavlova ist der entschleiernde Rationalismus wesensfremd. Sie will über die Dinge hinweg weiterhin den Blick "auf die Sterne des Himmels" richten.

No my gljadim na zvezdy neba,

Na mira većnogo ob-em,

No $v$ nas ziva svjataja treba,

I ne zitej skogo lis' chleba

Dlja zizni my ot boga zdem.

In den antithetischen Reimwörtern "...zvezdy neba : ... svjataja treba : ...zitejskogo lis' chleba" spielt sie die Symbole der unter schiedlichen Blickrichtungen gegeneinander aus. Unversöhnlich, ohne den Versuch einer Synthese, konfrontiert sie die gegensätzlichen Standorte. Im Bild des Samens, von Gott auf einen Boden von Sand und Stein geworfen, prophezeit sie der jungen Generation Erfolglosigkeit (dritte Strophe); die Frucht werden andere einsammeln. In einigen Reimbindungen konkr etisiert die Dichterin den Gegensatz. In der zitierten vierten Strophe zum Beispiel (Est' mnogo...) sind alle Reime antithetisch: die Verse eins und vier zu drei, Vers zwei zu fünf.

Trotz der bitteren Erkenntnis, daß ihr persönlich und den wenigen noch verbliebenen Weggefährten ebenfalls die Ernte versagt sein werde, bleibt die Überzeugung, daß eines fernen Tages ihresgleichen Anerkennung finden wird. Die letzten beiden Verse dieses Gedichts drücken unmittelbar das aus, was im vorangegangenen mit dem Aufbruch in die wüste Gebirgs- 
welt umschrieben wurde.

Da budet vera - nase delo, Stradan'e - naša blagodat'.

Die Analysen der Situation des Dichters enden jeweils mit einem Ausblick auf eine trostlose Zukunft der eigenen dichterischen Existenz. Aber dieses ausweglose Schicksal wird mit dem Blick auf einen fernen, der Pavlova und ihresgleichen nicht erreichbar en Hoffnungsschimmer immer wieder angenommen.

Mit dieser Bitterkeit, die sicherlich nicht ganz frei war von der Süße der Exklusivität, ließ sich leichter leben, solange gleichgesinnte Freunde da waren, solange sie wußte, daß es Menschen gab, die sie verstanden, die eingeweiht waren. In mehreren Gedichten hat Karolina Pavlova die Bedeutung solcher Bindungen betont. Lebenszeichen der Gefährten sind ihr heimatliche Grüße in der Fremde. Eine Nachricht von Baratynskij erfreut sie so, wie den Wanderer im fernen Land der unerwartete Anblick einer altvertrauten Blume 228 .

Es geht in all diesen Aussagen um die Empfindung der Geborgenheit inmitten der abweisenden Umwelt des Dichters. Der Weg ist dann weniger beschwerlich zu gehen, das Los ist leichter zu tragen:

Puskaj ze putniki poroj

Usly šat gde-to glas privetnyj,

"Au" znakomyj za goroj! 229

Oder auch, wenn sich - "V cas svetlych dum i strojnych del" - der Dichter des Dichters erinnert:

Perenosjasja v kraj iz kraja,

Crez gory, bezdny, glus' i step',

Da s-edinit ich pesn' Zivaja,

Kak èlektríceskaja cep' ! 230

Nicht immer bedient sich Karolina Pavlova solch metaphorischer Umschreibungen. Die Wirkung einiger Worte der Anerkennung von S. A.

228 Vgl. "E. A. Baratynskomu" (Juli 1842); K. Pavlova 1964, S. 112 f.

229 Vgl. "N. M. Jazykovu" (1842); ib., S. 113f., hier S. 114.

230 ib., S. 114. 
Račinskij ${ }^{231}$ schildert sie ganz konkret:

I probudili dva-tri slova

V grudi poryv byvalyj snova

I na ustach byvalyj stich. 232

Karolina Pavlova hielt an dem Entschluß fest, allen Widrigkeiten zum Trotz den einmal eingeschlagenen Weg zu Ende zu gehen. Aber in der zweiten Hảlfte der vierziger Jahre kam es auf Grund verschiedener Faktoren zu einer Krise, die erst zu Beginn der fünfziger Jahre endete. Die Fronten der ver schiedenen geistigen Lager hatten sich verhärtet, die gegenseitigen Angr iffe waren schärfer geworden. Wer sich nicht auf diese Auseinandersetzungen einließ, geriet nur zu leicht an die Peripherie der literarischen Welt. - Viele Freunde Karolina Pavlovas waren gestorben; Beziehungen waren abgebrochen, einerseits wegen der weltanschaulichen Polarisierung, ander er seits wegen der unerquicklich gewordenen Atmosphäre im Pavlovschen Hause.

Die lange Zeit nur poetisch wirkliche Vereinsamung wird jetzt zur Realităt. Die Dichterin ist mit sich selbst allein und wird sich selbst fragwürdig. Es folgen einige sehr per sönliche Gedichte, in denen sie auf symbolische Objektivierung und Verallgemeinerung zum dichterischen Schicksal schlechthin verzichtet. Verglichen mit den grandiosen Bildern, die sie vorher verwandt hat, knüpt sie hier an eher kleine, ganz persönliche Begebenheiten an. Waren die vorangegangenen Gedichte in gewissem Sinne dynamisch gewesen, so werden sie jetzt von statischen abgelöst; der Wanderer wird er setzt durch einen eher ratlos auf der Stelle tretenden Menschen.

In dem bereits ausführlich besprochenen Antwortgedicht an Jazykov aus dem Jahre $1846^{233}$ trägt Karolina Pavlova ihm noch einmal aufs ent-

Sergej Aleksandrovic Racinskij (1836-?), Botaniker, literarisch sehr interessiert, Herausgeber des "Tatevskij sbornik".

Vgl. "Molcala duma rokovaja..." (Dez. 1852); K. Pavlova 1964, S. $151 \mathrm{f}$. , hier S. 151.

"N. M. Ja(zykov)u" (1846); ib., S. $133 f$.

Vgl. hierzu auch S. 66 dieser Arbeit. 
schiedendste vor, daß der Dichter sich aus dem Tagesgeschehen heraushalten müsse. Sie wirft ihm vor, sich auf "Verwünschungen und Gezänk" eingelassen zu haben; seine Handlungsweise sei "dem Hochmut und der Sünde" entsprungen. Mit Bitterkeit konstatiert sie, daß auch er, dem sie jahrelang verbunden war, ihr völlig fremd geworden sei:

Mne stala nyne lira èta

I neponjatna, i cuźda.

Ne priznaju ee napeva,

Sie ereifert sich nicht etwa über die Borniertheit seiner Denkweise, womit sie zweifellos recht gehabt hätte, sondern verurteilt die Tatsache an sich, daß er sich in die ideologischen Richtungskämpfe verstrickt hat. Statt über den Dingen zu stehen, habe er sich mit der Menge gemein gemacht; sein Verhalten sei "heidnisch" und "gottlos".

Der Vorwurf, in die Niederungen des Alltags abgeglitten zu sein, wird in dem unmittelbar anschließenden Gedicht an E. P. Rostopcina 234 wieder aufgenommen. Obgleich die Verse in erster Linie in der Absicht geschrieben wurden, mit der Rostopcina 'abzurechnen', wobei selbst der Gegensatz Moskau - Petersburg dazu herhalten mußte, die kleinl iche Mißgunst der Pavlova ideologisch zu verbrämen, sind sie in diesem Zusammenhang sehr aufschlußreich. Gerade in dieser Überzeichnung erhäl ihr Wunschbild vom Dichter besonders deutliche Konturen. Die Rostopcina wird scharf getadelt, weil sie - "Sklavin der Nichtigkeiten (Eitelkeiten)" - die Vaterstadt Moskau vergessen und sich dem lärmenden Leben der Residenz ergeben habe, das tue, wonach ihr gerade der Sinn stehe und sich selbst keine Schranken setze. Wirkungsvoll setzt Karolina Pavlova dieses mondäne Leben ab gegen die eigene Idylle. In enger, vertrauter Umgebung, fast nie über die Stadtgrenzen Moskaus hinausgekommen, ohne jede Kenntnis Petersburgs und des Auslands, tue sie ihre bescheidene Arbeit.

Noch aus einem anderen Grunde zitiere ich dieses Gedicht. Es scheint mir ein Beispiel für die bewußte oder unbewußte Selbsttäuschung Karol ina Pavlı

"My sovremennicy, grafinja..." (Jan. 1847); K. Pavlova 1964, S. 134 f.

Vgl. hierzu auch S. 70f. dieser Arbeit. 
vas zu sein, für eine gewisse Stilisierung des 'Schmollwinkels' zur Eremitenklause; insofern muß man solchen Aussagen mit Skepsis begegnen.

Die Abneigung, ja man muß wohl schon sagen Feindseligkeit der Dichter in gegenüber dem Zeitgeschehen gipfelt in einem Gedicht, das an eine nicht identifizierbare Person mit den Initialen S. K. N. gerichtet ist $^{235}$. Es entstand im Sommer 1848, zu einem Zeitpunkt al so, da sich Westeuropa im Umbruch befand. In diese Situation hinein stellt Karolina Pavlova noch einmal ihre Auffassung mit einer geradezu engstirnigen Radikalität. Den Tadel des Adressaten wegen ihres langen Schweigens nimmt sie zum Anlaß, ihre Meinung über Briefwechsel zu sagen: sie seien nur Ge schwätz, sagten entweder allzu viel oder gar nichts. Zudem habe sie sich mit der Prosa gănzlich entzweit, Verse seien ihr einziges Medium, sich auszudrücken. Aber worüber solle man in diesen Zeiten überhaupt schreiben?

Izvest'ja l' zdete vy? - Kakogo?

'Cego boites' ne uznat', Kogda vsẽ plocho to, cto novo?

Kogda neznan'e - blagodat' ${ }^{236}$

Sie wolle nichts hören und nichts sehen, weder von den Ereignissen im Ausland - die Revolution in Italien ist in ihren Augen ein "kindisches Aufbrausen" - noch von den Problemen in Rußland selbst. Der Mensch befinde sich mit seiner hektischen Unruhe im tiefen Wider spruch zur Natur, die sich unverändert nach ihren eigenen harmonischen Gesetzen.vollziehe. In der Hoff nung, diese Wirrnisse seien befristet, bleibe dem Dichter als einziger Ausweg die absolute Zurückgezogenheit in sich selbst, eine vita contemplativa.

Našedši ugolok ujutnyj,

Gde moźno grezam dat' prostor,

Godiny ètoj mnogosmutnoj

Chocu ne slusat' kr ik i spor;

"K S. K. N." (Aug. 1848); K. Pavlova 1964, S. $137 f$.

Es ist schon verschiedentlich die Rede von der Unfähigkeit der Dichter in zu echter innerer Entwicklung gewesen. Die Verse sind daher besonders auf schlußreich. Einem Menschen, dem alles Neue, nur weil es neu ist, schon verdächtig erscheint, fällt die Răumung einmal eingenommener Positionen sehr schwer. 
Chocu ja nyne zit' neveźdoj,

I, stavja pomyslam Certu, Dalekoj tesit'sja nadezdoj, Chranit ' ljubimuju mectu;

.......

Chocu gljadet' na bezdnu neba, Skakat' verchom, citat' stichi.

Bereits in einem früheren Gedicht, das anläßlich eines Besuchs in Gireevo entstanden war ${ }^{237}$, hatte sich Karolina Pavlova die doppelte Frage gestellt, ob sie letztlich die Kraft haben werde und ob es überhaupt sinnvoll sei, noch zu dichten. Gerade hier, an einem Ort angenehmster Erinnerungen an Zusammenkünfte mit Freunden wie Jazykov und Baratynskij, wurde sie sich der Leere ringsum und des schmerzlichen Mangels an Gleichgesinnten besonders deutlich bewußt.

Der Verdacht der Unaufrichtigkeit, der Verdacht, daß sie diese Zeiten anklagt, weil sie ihr das Publikum nehmen, verstärkt sich. Nach diesen Gedichten kann man ihr das Beglückende des Dichtens an und für sich nicht mehr so recht glauben. Sie brauchte, allen anders lautenden Beteuerungen zum Trotz, ein Echo.

Die vertraute Umgebung Gireevos belebt Träume von einst, ruft eine Fülle von "Gedanken und Inspirationen" hervor; aber die völlige Abgeschiedenheit der Dichterin - teils selbstgewählt, teils jetzt auch durch äußere Umstände ihr aufgezwungen - läßt sie an sich selbst zweifeln.

Sversu li ich? Pojdu li smelo,

Kuda mne bog sudil idti?

Uvy! okrestnost' opustela,

Otzyvy smolkli na puti.

Ne vovremja stichov pričuda, Izcez poètov chorovod, I veter russkij niotkuda

Volsebnych zvukov ne neset.

"Dumy" (Juni 1847); ib., S. 135.

Um nur ein Beispiel zu nennen: "Net, ne im tvoj dar..." (ib., S. 80f.) Das Gedicht entstand vermutlich im Jahr 1840. 
Einige Jahre spăter - 1850 - nimmt Karolina Pavlova in dem Gedicht "Laterna magica" 239 die Frage nach dem Sinn des Dichtens in dieser Zeit wieder auf. Ihre völlige Isolierung gibt ihr zwar eine absolute, aber eben deswegen fragwürdige dichterische Freiheit. Diese wird in einer kleinen Episode ad absurdum geführt. Die Dichter in sitzt über einem Blatt Papier und denkt über die "beißende Kritik" an ihren Versen nach:

Cern' svetskaja, s svoim cholodnym tolkom,

Opasnyj nam i strogij sudija.

In einer Welt der bloßen ratio gebe es "Trauer der Seele" und "lichte Paradiese" wohl nur noch in den Gesprăchen der Kinder und des "Weibervolks"; alle Themen seien offensichtlich abgegriffen. Sie läßt ihren Gedanken freien Lauf, eine Reihe unscharfer Vor stellungen stellt sich ein, sie verschwinden wieder. Dann erfolgt, um im Bulde des Titels zu bleiben, eine Scharfeinstel lung. Über Dächer hinweg steuern die Gedanken auf ein Haus zu, ein Fenster, - dringen zu einem jungen Mådchen vor, das traurig um Verständnis bittet. Die Dichter in lăßt sich mit einem achselzuckenden "Izvol" auf dieses Einzel schicksal zutreiben.

Izvol'; vstuplju ja v novoe znakomstvo,

Vstuplju s toboj $\mathrm{v}$ dusevnoe rodstvo;

Ljubvi li zertva ty, i1' verolomstva,

$I^{*}$ prosto lis' mectan'ja svoego, -

Vsê ob-jasnju: pišu ne dlja potomstva,

Ne dlja tolpy, a tak, dlja nikogo.

Die Erfahrung dieses willkürlichen Gedankenflugs faßt Karolina Pavlova in der Schlußstrophe zusammen, die von tiefer Resignation zeugt:

Znat', suźdeno inym uź svyse èto,

I pisano im, vidno, na rodu,

Predat ${ }^{\circ}$ svoi bescennejşie leta

Nenuźnomu i glupomu trudu;

Nosit' $v$ duse bezumnyj zar poèta

Sebe samim i procim na bedu.

$\mathrm{Zu}$ verstummen wäre konsequent ${ }^{240}$, aber das Schicksal will es anders, es

239

"Laterna magica" (Sept. 1850); ib., S. 147f. - Das Gedicht trägt den Untertitel "Vstuplenie" und war (1t. Anm. S. 563) als Vorspann zu einem geplanten, aber nicht verwirklichten Zyklus gedacht.

Von hier aus betrachtet, erscheint es auch verstăndlich, daß der Gedichtzyklus ungeschrieben blieb. 
zwingt sie, mit dieser $\mathrm{Z}$ iel - und Zwecklosigkeit irgendwie fertigzuwerden. Der in diesem Gedicht vorgeführten dichterischen Freiheit fehlt das Korrelat der Notwendigkeit, die Verpflichtung auf ein sinnvolles Objekt, das die Dichterin in sich nicht mehr finden konnte und in ihrer Umwelt nicht zu finden glaubte.

Im Grunde durchlebte Karolina Pavlova in diesen Jahren eben die Krise ihrer literarischen Generation, die aus der Ausschöpfung der formalen Möglichkeiten und einer Erschöpfung der überkommenen Inhalte resultierte. Erst im Symbolismus sollte es dem L'art pour 1'art-Dichter gelingen, sich neue Erlebnisschichten, neue Quellen der Inspiration zu erschließen.

Das verzweifelte Mißtrauen der Dichterin mußte von außen durchstoBen werden. Es war Racinskij, der mit den bereits erwăhnten "zwei-drei Worten" den früheren Schwung in ihr wiederbelebte. Sie überwand die innere und außere Stagnation, brach in doppeltem Sinne auf, tat eben das, was sie der Rostopcina einige Jahre zuvor vorgeworfen hatte: sie wandte sich der Welt zu, durchstreifte ruhelos Europa. Die mannigfachen Anregungen, die sie auf diesen Reisen empfing, setzte sie in eine lange Zeit ungekannte dichterische Produktivităt um. Es folgt zwar keine Periode himmelstürmender Hoffnungen, zu denen die Lebensumstände wahrhaftig keinen Anlaß gaben; sie knüpit an die früheren Sedichte um das Wanderermotiv an. Der Weg scheint noch gangbar zu sein. Die Dichter in ist sich ihrer Situation wohl bewußt, hat aber die Kraft, ihr ein kategorisches "Dennoch" entgegenzusetzen.

Ne raz v duse poznavsi smelo

Razvrata temnye dela,

Svjatoe cuvstvo ucelelo

Odno, sred' ljutosti i zla;

Kak stolb razrušennogo chrama,

Gde proneslosja bujstvo bitv,

Stoit odin, glasja sred' srama

$O$ meste very i molitv. 241

1846 hatte Karolina Pavlova beklagt, daß ihr Leitstern erloschen sei und daß es ihr kaum leid tue, ohne ihn leben zu müssen ${ }^{242}$. Jetzt

"Ne raz v duse..." (1852); K. Pavlova 1964, S. $152 \mathrm{f}$. 
aber ist der Himmel nicht mehr verfinstert und sternlos, der Horizont hat sich wieder geweitet.

Esce blestjat peredo mnoju

Svetila pravdy i dobra;

Esce ne stynu ja dusoju;

Truda pokinut' ne pora. 243

Die Krise wird nicht bewaltigt, sondern vertagt. In den er sten Dresdener Jahren bricht sie unter vergleichbaren außeren Gegebenheiten wieder hervor. Und wieder genügt der Anstoß von außen, die $Z$ weifel vergessen $z u$ machen. Es war Aleksej Tolstoj, der ihr mit der Bitte, seinen "Don Żuan" zu übersetzen, das Selbstvertrauen zurückgab. Geradezu über schwenglich dankt sie ihm in einem Gedicht ${ }^{244}$. Alles, was ihrer Meinung nach zur poetischen Existenz gehört, habe er wieder in ihr erweckt. Der hier gebotene Katalog dessen, was den Dichter ausmacht, ist derselbe wie eh und je.

Damit bricht die Reihe der um den Dichter kreisenden Gedichte ab. Das Thema tritt in den Hintergrund, weil Karolina Pavlova sich wieder fast ausschließlich der Über setzertătigkeit zuwendet. 1870 schreibt sie noch einmal ein betuliches Gedicht dieser Art in deutscher Sprache ${ }^{245}$, spricht ohne Gespür für die Banalităt - noch einmal vom erwählten Verkünder "der Menschenseele Glück und Schmerz".

"Ne pora!" (Juni 1858); ib., S. 197.

"Gr. A.K. T(olsto)mu" (1862 ?); ib., S. 223.

"Genug des Wortschwalls, des sich reihenden. .." (Aug. 1870); ib. , S. 489.
} 


\section{Gedichte zu anderen Themen}

Das Bild, das sich in den bisher besprochenen Gedichten von dem Menschen und von der Dichterin Karolina Pavlova abzeichnete, könnte auch aus anderen Werken er schlossen werden; aber so wenig verhüllt tritt es nicht wieder hervor. Die Hauptquelle der Inspiration - die eigene, tragisch empfundene Existenz - ist als ein Grundstrom der Klage in sehr vielen Arbeiten zu spüren. Es ist die Klage über eine ganz persönliche Not, die Not einer Generation, einer Gesinnungsgemeinschaft; und aft gelingt der Dichter in die Objektivierung des subjektiven Schicksals zu einer exemplarischen Menschenklage. Manchmal allerdings durchdringt ein lamentierender Ton an sich gute Gedichte, verhindert deren Loslösung vom Künstler, deren Eigenstăndigkeit.

Die Gliederung des Werkes bereitet einige Schwierigkeiten, und zwar aus folgenden Gründen:

1) Bei romantischer Dichtung ist das $\mathrm{Kriterium} \mathrm{der} \mathrm{Grundformen} \mathrm{und}$ Gattungen - im Sinne der Gedichtarten - wenig tauglich. Die Pavlova macht von der Möglichkeit der Überschreitung der Grenzen gern Gebrauch.

2) Nach Motiven und Stoffen - soweit der Begriff 'Stoff' in der Lyrik anwendbar ist - zu ordnen, verbietet sich wegen der Vielfalt in diesem nicht sehr umfangreichen Werk.

Naheliegend ist daher eine Gruppierung nach Themen. Da die Gedichte Karolina Pavlovas meistens mehrschichtig sind, erfolgt die Zuordnung auf Grund der jeweils vorherrschenden Aussage. Die Gedichte $z$ ăhlen zu ihren besten, in denen sich die Dichter in thematisch beschränkt; sie sollen darum in den Mittelpunkt der einzelnen Gruppen gestellt werden. In Querverweisen sollen sowohl formale Besonderheiten als auch Stoffe, Motive, Metaphern usw. verfolgt werden.

So extensiv Karolina Pavlova die formalen Mittel eingesetzt hat, so sehr hat sie auch die Möglichkeiten der Einkleidung ihrer Anliegen in Stoffe und Motive ausgeschöpt. Als ein Beispiel hierfür sei die weitgespannte zeitliche und räumliche Verankerung ihrer Gedichte in der Realität angeführt. Manchmal sind Ort und Zeit nur Hintergrund, mehr oder weniger zuf alliger Schauplatz; manchmal aber sind sie auch mit starkem Symbolgehalt wesentlich an der Aussage beteiligt. Die Dichtungen sind in dem Dreieck Orient - 
Westeuropa - Rußland angesiedelt. Stark vertreten ist der Mittelmeerraum: Spanien, Sudfrankreich und vor allem Italien mit den Städten Neapel, Venedig und - hăufig - Rom. Deutschland begegnet relativ selten im Werk Karolina Pavlovas. Selbstver ständlich sind die meisten lokalisierbaren Gedichte an die russische Landschaft, an russische Stadte gebunden. Wenn die Gedichte uberhaupt einen klaren Zeitbezug haben, dann - außer zur Gegenwart - vor allem zur alten Geschichte, selten auch zum abendländischen Mittelalter. Der Geschichte des alten Rußland ist kaum eine Strophe gewidmet.

Mit der Aufzăhlung der Orte und Zeiten sind zugleich einige für das Denken der Pavlova wichtige Symbole, einige wesentliche Antinomien genannt. Breiten Raum nimmt das Thema Rußland - Europa ein, manchmal reduziert auf den Gegensatz Moskau - Petersburg. Rom ist zum einen Zeichen für das Heidnische in Absetzung vom Christlichen, zum anderen aber auch Zeichen für das Lateinisch-Katholische gegenüber dem Griechisch-Orthodoxen und schließlich Symbol des Verfalls als Folge des Bruchs mit den tradierten Werten; in diesem Sinne will die Dichterin Rom als Mahnung an Moskau verstanden wissen.

Das Ausspielen von Antinomien kann als ein wesentliches Merkmal ihres Schaffens betrachtet und in engem Zusammenhang mit der erwăhnten Grundströmung der Klage gesehen werden.

Das Menschenbild Karolina Pavlovas ist aus ihren Bewertungen der rationalen und irrationalen $\mathrm{Kr}$ äfte zu erschließen. In ihrem Denken korrespondieren die Begriff spaare Geist - Seele und Schuld - Unschuld. In der Einschătzung der intellektuellen Seite des Menschen ist das Bewußtsein des Kausalzusammenhangs zwischen Erkenntnis und Vertreibung aus dem Paradies spuirbar; die Seele vermag ein Stiuck dieses Paradieses zu bewahren. Die Dichter in verkennt nicht die Notwendigkeit dieser Spannung, aber in ihren Arbeiten schwingt oft die Frage mit, ob das geistige Fortschreiten den Preis wachsender Verstrickung in Schuld wert sei. In diesem Ver ständnis ist der Geist nicht Ordnungsfaktor, vielmehr verwirrt er, stiftet Unordnung. Die Situation des Menschen ist insofern tragisch, als er aus diesem Streben seines Geistes nicht ausbrechen kann und seine Seele dabei Schaden nimmt. Dem Dichter bleibt der Ausweg ins Irreale und damit aus der menschlichen 
Gesellschaft heraus, der Weg der dann einsamen Seele in Traum und Erinnerung.

Oft sind die Gedanken Karolina Pavlovas rückwärts gewandt. In der Welt des Kindes sieht sie eines der letzten Paradiese. In einem Sonett aus dem Jahre 1839 hat sie wohl die schönsten Worte dafür gefunden.

Sonet 246

Ne daj ty potusknet' duse zerkal'no cistoj

Ot ich dychanija, nevinnyj angel moj!

Kak v detstve, otrazaj igroj ee srebristoj

Vse skazki cudnye, dar stariny svjatoj.

Divisja chitrostjam rusalki golosistoj,

Pust' cuditsja tebe kosmatyj domovoj;

Vol sebnych tech cvetov chrani venok dusistyj,

Te sueverija - narjad ljubvi mladoj.

Ver', deva milaja, predanijam starinnym,

$V$ serdečnoj prostote vnimaj rasskazam dlinnym;

Pust' ljudi mudrye ich slusajut sutja,

No ty pugajsja ich vecerneju poroju;

Moej dusi tvoja chotela byt' sestroju,

Bespecnyj ze poèt vsegda dusoj ditja.

Karolina Pavlova hat in dieses Gedicht den Ton einer Anbetung getragen. Die langen sechshebigen Verse dämpfen die Stimme des Sprechers. Die beide Quartette übergreifende gleichlautende Reimbindung, ausklingend im Reimpaar des ersten Terzetts, ebnet die Lautung der Strophen ein. Diese formale Ausgeglichenheit ist der Harmonie der dargestellten Welt adäquat. Die wechselnde Kadenz und einige Enjambements verhindern, daß der verhaltene Klang in Litanei umschlägt. Das Maß der Entrückung und Verklärung wird in den Anreden "nevinnyj angel moj" und "deva milaja" deutlich; an dieses Gegenüber ergeht die Aufforderung zu naivem Verhalten: "divisja", "ver" ", "pugajsja". Heiliges - "svjataja starina", "cistaja dusa", "serdecnaja prostota", "sueverie" - und Märchenhaftes - "golosistaja rusalka", "kosmatyj domovoj", "volsebnye cvety" - sind miteinander verflochten. Es ist von "wunderbaren Märchen", "alten Sagen" und "langen Erzählungen" die Rede.

"Sonet" (1839 ?); K. Pavlova 1964, S. 76. 
Im zweiten Terzett faßt die Dichter in den Inhalt der vorangegangenen Verse in der Sentenz zusammen, daß der unbekümmerte, der naive Dichter immer die Seele eines Kindes habe. Mahnung und Anbetung, tiberlegenheit und Unterlegenheit kennzeichnen die Haltung des Sprechers in diesem Gedicht; es ist die Haltung des sentimentalischen Dichters.

Sehr viel schlichter in der Aussage ist eine "Serenada" aus dem Jahre 1851. Schon der Titel weist darauf hin, daß dieses Gedicht vertont werden sollte ${ }^{247}$. Es kann mit Fug und Recht eine vollkommene Nachahmung eines Volksliedes genannt werden. Selbst ein so harter Kritiker Karolina Pavlovas wie Pereverzev hat für die "Serenada" sehr anerkennende Worte gefunden 248. Form und Inhalt sind von ergreifender Einfachheit: Eine Mutter singt ihr Kind in den Schlaf und macht sich die Kraft bewußt, die ihr aus dem Dasein dieses unschuldigen Geschöpfes erwăchst; die Freude wird von Strophe zu Strophe größer. Obgleich das Gedicht von der Form her ohne Anfang und ohne Ende ist - der dritte Vers einer jeden Strophe ist jeweils die erste Zeile der fol genden, der Kehrreim verstärkt die unendlich wiegende Bewegung noch -, ist es inhaltlich doch geschlossen. Es beginnt mit einer allgemeinen Liebeserklărung:

Ty vsee, cto serdcu milo,

S cem ja sžilsja umom;

Ty mne ljubov' i sila, -

Spi bezmjateźnym snom!

Die Bilder werden immer konkreter, immer großartiger. Im dritten Vers der sechsten Strophe kündigt sich - die Dichterin wechselt hier in den Konjunktiv über - gleichsam eine Apotheose an:

"Serenada" (Okt. 1851); ib., S. 150f. Die Dichter in wies in einem Brief an Pogodin, den Herausgeber des "Moskvitjanin", darauf hin, daß "diese Verse mehr für Musik geschrieben" seien (aus der Handschrift zitiert nach: K. Pavlova 1964, S. 564).

Pereverzev schreibt: "Unter den Gedichten der Pavlova gibt es eines, das nicht ohne Grazie und Innigkeit ist und das seine Entstehung dem Muttergefühl verdankt. Es heißt "Serenade" und ist ein echtes Wiegenlied, das sanfte Ruhe ausbreitet sowohl über das Kind als auch über die Mutter, die "ihre Liebe und ihre Kraft" in den Schlaf singt. Wenn die innige Saite im Werk der Dichter in öfter zum Klingen gekommen wäre, hătten wir wahrscheinlich eine Reihe sehr schöner Verse gehabt" (Salonnaja poètessa; in: Sovr emennyj mir, S. 187). 
Kak burja b ni grozila, -

Spi bezmjateznym snom!

Kak burja b ni grozila,

Chotja b skvoz' vichr' i grom

Neslos' moe vetrilo, -

Spi bezmjateznym snom!

Das schon in dem Sonett verarbeitete Motiv der heiligen Unschuld des Kindes wird in zwei Balladen um den christlichen Gedanken der Erlösung ausgeweitet. Im "Nocleg Vitikinda" 249 wird die historische Auseinander setzung zwischen Heidentum und Christentum, zwischen Widukind und Karl dem Großen in einer Episode veranschaulicht und zugunsten des Christentums entschieden. Und es ist bezeichnenderweise ein Kind, durch das sich die Überlegenheit der neuen Lehre offenbart. In ihm ist der unerschütterliche Glaube symbolisiert. Der Knabe erlöst durch sein zwar unreflektiertes, aber um so beherzteres Eintreten seine Eltern und rührt den erbitterten Gegner des Christentums an.

Ostanovilsja vozd' serdityj, Pritich, na mal'cika smotrja;

Lozil sja otblesk dumy skrytoj

Na groznyj lik bogatyrja.

"Net! - vygovor il on i zvonko

Mec zazvenel, v nožny skol'zja. -

Net, Gunnar! ètogo rebenka

Gubit' ne sleduet, nel' zja".

Der "Rudokop" 250 ist sicher eine der inhaltlich vielschichtigsten und romantischsten Arbeiten Karolina Pavlovas und kann von dem hier behandelten Thema her nicht ausgeschöpt werden. Aber in dieser Ballade oder besser: in dieser Novelle in Versen - ist das Motiv der im Kind verkörperten Unschuld, die den Menschen zur Besinnung bringt, mit einem sehr deutlichen Bezug zur christlichen Heilslehre ausgestattet. Die Seele

"Nočleg Vitikinda" (1 858); K. Pavlova 1964, S. 204-208.

"Rudokop" (Juli 1841); ib., S. 97-103. 
des Bergmanns wird aus dem Bann der magischen Natur erlöst und von der Nachtseite zum Licht gezogen. Die Heilung wird dadurch veranschaulicht, daß sich ihm die Sinne für die Schönheiten der Gotteswelt wieder öffnen. Der "Leichnam seines Herzens", das über der ausschließlichen Anspannung des Geistes "lăngst erkaltet" war, erzittert wieder.

Sel rudokop crez dol rosistyj,

I, podchodja $\mathrm{k}$ nemym skalam,

Vpival vsej grud'ju vetr dusistyj,

Zemli vesennij fimiam.

I sverchu vzor on brosil jasnyj

$V$ gluchoe, smradnoe zerlo:

$\mathrm{Da}$, on otvergnet dar naprasnyj ,

Pokinet mraka remeslo!

Voskresnet vol'noju dušoju,

Vor diesem Hintergrund wird sein leiblicher Tod bedeutungslos. Er ist nicht verloren, er gewinnt die Unschuld des Kindes auf einer höheren Ebene, in der Gotteskindschaft wieder.

Als Frage nur und ohne die tröstende Verheißung der letztlichen Heimkehr hatte Karolina Pavlova den Gedanken, daß der Mensch mit jedem weiteren Schritt ins Leben sich der unversehrten Natur entfremde, bereits in dem früheren Gedicht "Nebo blescet..." 251 gestaltet. In der ewig jungen Welt, in der alles lebendig, alles heil sei ("vse zivo, ... vse celo"), altere allein die Seele, weil das Herz es nicht verstanden habe, seine Trăume zu bewahren.

Der Mensch erinnere sich an sich selbst wie an etwas Fremdes, heißt es in der Dichtung "Da, mnogo bylo nas..." 252.

In dem Gedicht "Byla ty s nami..." 253 vergleicht die Pavlova das "friedlich-trauliche Land" mit einer "wunderbaren Insel jenseits der dunklen Weite des Meeres". Aber diese Idylle wird zerstört in dem Augenblick, da "der verhängnisvolle Becher der Erkenntnis" die Lippen berührt:

"Nebo blescet birjuzoju..." (Febr. 1840); ib., S. 84.

"Da, mnogo bylo nas, mladenceskich podrug;.. "(Dez. 1839); ib. , S. 80.

"Byla ty s nami nerazlućna..." (Juni 1842); ib., S. $105 \mathrm{f}$. 


\section{Zabudes' tajnu vdochnovenij \\ $\mathrm{V}$ bor 'bach zemnogo bytija; \\ $V$ ogne stradanij i volnenij \\ Peregorit duša tvoja.}

Bis hierhin ist das Gedicht nicht mehr als eine Variante zum Thema 'der Geist als Wider sacher der Seele'. Aber dieser These wird eine Antithese entgegengesetzt, der Idylle wird eine Absage erteilt:

Net! ne prav vas ropot tajnyj!

Ne mečtanij sladki chmel',

Ne dusi pokoj slucajnyj

Ej naznacennaja cel'.

Das Verhängnis der Erkenntnis wird umgewertet zum notwendigen Anstoß, in fruchtbare Unruhe aufzubrechen. Dieser Aufbruch wird schon durch die graphische Anordnung sinnfálig gemacht: die ersten fünf Strophen sind ohne Absatz zu einem Block zusammengefügt. Ihm stehen im zweiten Teil fünf klar voneinander abgesetzte Strophen gegenüber. Auf die gefälligen jambischen Verse des ersten Teils folgen spröde Trochăen; dem glatten Redefluß folgen Sătze von apodiktischer Hărte. Eine Reihung von elementaren Bildern (Wasser, Feuer, Luft) suggeriert Lebendigkeit. Mit einem einprăgsamen Chiasmus endet das Gedicht:

Ċto umom togda vladelo,

Tem vladeet nyne um.

Diese positive Bewertung des Geistes, die Hinwendung zum Leben und zum Lebenskamp findet sich nur selten im Werk Karolina Pavlovas 254.

Viel hăufiger sind die elegischen Gedichte, die unmittelbaren $\mathrm{Kla}$ gen, die :veitgehend auf symbolische Verschleierung verzichten und nicht mehr zu einer Aussage über die menschliche Not schlechthin objektiviert sind $^{255}$. Die Grundstimmung ist Resignation, manchmal Bitterkeit, manch-

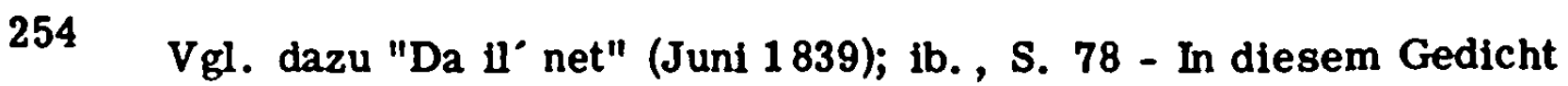
wird sehr viel verhaltener das Leben bejaht, so wie es ist.

Als Beispiele seien hier nur folgende Gedichte genannt:

"Mladych nadeźd i ubeźdenij..." (Dez. 1852); ib. , S. 152, "Ljublju ja vas, mladye devy;..." (1855 ?); ib. , S. 170f., "Da, sli my zitejskoj dorogoj,..." (zwischen Juni und Sept. 1858); ib. , S. $202 f$. , "Kogda vstrecajus' ja slucajno..." (?); ib. , S. 226. 
mal aber auch Gelassenheit. Bezeichnend für diesen Fatalismus ist die letzte Strophe eines kleinen Gedichts aus dem Jahr $1858^{256}$ :

Priucena grozoj vsecasnoj

Ja verit' $v$ blizkuju bedu;

Smotrja na svod éfira jasnyj,

Ja gromonosnoj tuci żu.

Auch ein großer Teil der Liebesgedichte Karolina Pavlovas leidet an einem zu starken Erlebnisbezug; sie sind nicht übertragbar. So enthalt zum Beispiel der ganze Komplex der Utin-Gedichte so viele Anspielungen auf diese einmalige Episode, daß die Verse im Persönlichen befangen bleiben und nicht die Höhe einer allgemeingültigen Aussage erreichen.

Aus der Zeit der Verbindung mit Mickiewicz liegen keine Dichtungen vor. Erst mehr als zehn Jahre spăter hat die Dichterin diese Begegnung in Versen verarbeitet. Obgleich die beiden Gedichte ${ }^{257}$ im Titel an ein konkretes Ereignis anknüpen - den 10./22. November 1826 - , ist hier die Liebe doch von den zufalligen Einzelheiten der Episode abgelöst, das Bleibende herausgearbeitet und als zeitlose Aussage gestaltet worden. Daß die Liebe zu Mickiewicz 'idealer' war, erleichterte gewiß die Objektivierung.

Karolina Pavlova hat dann thr Bestes geleistet, wenn sie eine Empfindung, einen Gedanken nicht nur von der persönlichen Erfahrung abgehoben, sondern im Gewand eines ganz anderen Stoffes verfremdet hat. Dann hat sie Kunstwerke von hohem Rang geschaffen. Leider ist ihr diese Distanzierung zu selten gelungen, um ihr den Platz unter den Dichtern ihrer Zeit zu sichern, der ihr auf Grund dieser Gedichte zugekommen wäre.

\footnotetext{
256 "Starat'sja otdochnut" dušoju..." (1858?); ib., S. $196 \mathrm{f}$.

257 "10 nojabrja 1840" (1840); ib., S. 90 ,

"Na 10 nojabrja" (1841 ?); ib., S. 93 f.
} 
Donna Inezil' ja 258

On znaet to, cto ja tait' dolźna:

Kogda vcera, po ulicam Madrita, Surovyj brat so mnoju sel serdito, Pred prislecom, mantil'eju pokryta, Vzdochnula ja, nemoj toski polna.

On znaet to, cto ja tait' dolźna: $\mathrm{V}$ noc' lunnuju, kogda iz mraka sada Ego ko mne neslasja serenada, Ot zorkogo ego ne skrylos' vzgljada, Kak sevelilsja zanaves okna.

On znaet to, cto ja tait' dolžna:

Kogda, v krase bogatogo ubora,

Vosel on v cirk, $\mathbf{s}$ mečom toreadora, -

On ponjal luc ispugannogo vzora,

I pocemu sidela ja bledna.

On znaet to, čto ja tait' dolźna:

On molca żet, predvidja den' nagrady,

Ctoby ljubov' rastorgla vse pregrady,

Kak tajnyj ogn' zavešennoj lampady,

Kak sil'naja, stesnennaja volna!

Dieses Gedicht greift das Motiv der Liebenden auf, die nicht zusammenkommen können. Drei kleine Szenen offenbaren die Liebe in nur den beiden verständlichen Zeichen: in einem Seufzer, der Bewegung einer Gardine, in einem erschrockenen Blick. In diesen flüchtigen Begebenheiten wird zwischen den Liebenden ein beinahe quâlendes Spannungsf eld aufgebaut. Die Form ist mit dem Inhalt vollkommen kongruent. Die Dichterin wăhlt eine fünzeilige Strophe mit fünfhebig jambischen Versen, also eine sehr dynamische Gedichtform, die sowohl nach Beschwerung der Strophe als auch des Verses drängt. Das Reimschema a bbba steigert die Spannung. Zwei gegenläufige Bewegungen sind unverkennbar: die drei b-Verse sprengen das a-Zeilenpaar, gleichzeitig aber streben die a-Ver se zueinander; sie kommen zusammen, weil die er ste Zeile des Gedichts in jeder Strophe wieder aufgenommen wird. Die Strophen werden durch diesen Paarreim aneinandergezogen, der Paarreim selbst wird durch den Stropheneinschnitt aber wieder gespalten. Die durchgängige Umklammerung der drei mittleren Zei- 
len durch die a-Verse beschleunigt das ohnehin schon durch Dreierreim und weibliche Kadenz gesteigerte Tempo in der Strophenmitte. Besser als durch diesen Wechsel von Năhe und Ferne, Vereinigung und Trennung hătte die unterdrückte Leidenschaft nicht dargestellt werden können.

Der fünthebige Jambus fordert eine rhythmische Akzentuierung, neigt zur Zăsurbildung. So wie das Paar aus der jeweils fünften und ersten Zeile als retardier endes Moment dem Fluß des Gedichts Einhalt gebietet, so halten die Beschwerung der Zeilenmitte und die männliche Kadenz den Lauf der a-Verse auf. Mit den Mitteln der Betonung und der Lautangleichung erreicht die Dichter in einen der spanischen Folklore ăhnlichen Klang. Nicht nur die Alliterationen und Assonanzen - etwa die Hăufung der Sibilanten im fünften Vers der zweiten Strophe, die weitverbreitete a-Assonanz - zeigen die star ke Anlehnung an romanische Lyrik, sondern auch der Wechsel rezitativer und melodiöser Passagen.

Die Überzeugung, daß er wisse, was sie verheimlichen muß, wăchst von Zeichen zu Zeichen, von Beweis zu Beweis zur Gewißheit heran. In der vierten Strophe hat sich Inezll'ja so in ihn hineinver setzt, daß sie sagen kann, was er denkt; sie nennt die Liebe zum ersten Mal beim Namen. In den Metaphern der beiden letzten Verse wird die Macht dieser Leidenschaft gebannt.

Sehr eigenwillige Einkleidungen hat das Thema Liebe in den beiden folgenden Gedichten erfahren. Innerhalb weniger Wochen schrieb Karolina Pavlova zwei balladische Dichtungen, in denen von einer Leidenschaft die Rede ist, die den Menschen zu Grunde richtet. Sowohl in "Doc" zida" 259 als auch in "Starucha" 260 wird das Motiv mit märchenhaften Zügen ausgestattet. Das Geschehen beider Gedichte ist nicht restlos aufzuklären, aber gerade das macht ihren besonderen Reiz aus. Die Dichterin macht sich hier wie dort die Möglichkeiten des Trochăus geschickt zunutze. Oft bindet sie zwei vierhebige Verse zu einer Langzeile. Da die Kadenz wechselt, können je nachdem, ob die erste und zweite, die dritte und vierte Zeile gebunden

"Doc' Zida" (Jan. 1840); ib., S. $82 \mathrm{f}$.

"Starucha" (Febr. 1840); ib. , S. 85-88. - Vgl. dazu auch F. W. Neumann, Geschichte der russischen Ballade, S. 192. 
werden oder die zweite und dritte - entweder flüssige achthebige Einheiten oder kulminier ende Langverse entstehen. Für die Kollision zweier Hebungen findet sich in der dritten Strophe der "Doc' Zida" ein gelungenes Beispiel:

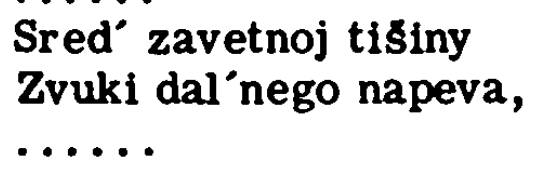

Das Zusammentreffen von "Stille" und "Kănge" wird hier im Nebeneinander zweier Hebungen sinnfallig gemacht. Die Dichterin nutzt darüber hinaus in diesem Beispiel den Klang der konfrontierten Wörter aus: auf das helle "tisiny" folgt das dunkle "zvuki". In diesem Gedicht finden sich geradezu Musterbeispiele für Klangzauber. Beinahe spiegelbildlich sind die Laute des dritten und vierten Verses der vierten Strophe angeordnet und symbolisieren das Gegenüber der Liebenden vollkommen:

\section{Żdet mogucego èmira \\ $\overline{\text { Doc }} c^{\circ}$ edinaja żida.}

Den magischen $\mathrm{K}$ ang des $\mathrm{u}$-Lautes verwendet $\mathrm{K}$. Pavlova in der vorletzten Strophe: das Unheil kündigt sich an.

I uznaet on nemuju

Dumu tajnuju moju

Tichim vzdochom ocaruju,

Vzorom strastnym upoju.

In beiden Gedichten tritt ein Erzăhler auf; er kommentiert die Handlung nicht nur von außen, sondern kommt auch mit den Titelgestalten ins Gespräch. Hier wie dort sind die Agierenden Frauen; hier wie dort fált ihnen ein Mann zum Opfer.

In "Doc' zida" ist die eigentliche Handlung, auch von der Wirklichkeit des Gedichts her gesehen, irreal, in das Innere der Heldin verlegt. Die Liebe des im Harem gefangenen Mădchens ist dämonisch, dem Haß unmittelbar benachbart. In den Antworten auf die Fragen des Erzählers war nur deutlich geworden, daß das Verhalten dem Emir gegenüber anders sein, sichnicht in Gesang und Tanz erschöpfen würde. Die letzte Strophe, buchstäblich das letzte Wort bringt das Unerhörte:

I, sklonjas' s ulybkoj nežnoj

$\mathrm{K}$ povelitelju licom, Žar grudi ego mjateźnoj

Usmirju moim nozom. 
Auch in der Wirklichkeit des Gedichts "Starucha" wird Unwirkliches dargestellt. Die Dichterin greift auf die heimische Märchen- und Sagenwelt zurück. Ein junger Mann - auch er verhăl sich 'anders' - wird von einer Alten behext. Er muß einem Phantom nachjagen, verzehrt sich im Verlangen nach der unerreichbaren "deva-čudo", in deren Bann ihn die Alte schlägt. Der Held wird also gleichermaßen an das Schöne und an das Håßliche gefesselt. Karolina Pavlova verwendet hier verschiedenartige Elemente der Volksdichtung: Intensitătssteigerung durch Doppelung des Ausdrucks (z. B. "užv narode chodjat sluchi, / Sluchi strannye o tom. ."), durch Wiederholung ganzer Strophen (Teil zwei, Strophe fünf und elf) oder auch durch Parataxen. Sie setzt das Stilmittel der Lautmalerei hăufig ein, um das Beschwörende in den Worten der Alten zu unterstreichen:

Obol'scaja, vozmuscaja,

Nacinaet rec' septat'.

oder:

Soblaznitel'no starucha

Śpcet, sepcet svoj rasskaz.

Karolina Pavlova versteht die Natur einerseits als Abglanz des Ewigen, als paradiesische Harmonie in Unschuld, andererseits aber auch als dämonische, als numinose Natur, als Herausforderung an den Menschen, an der er wächst, der er aber oft auch nicht gewachsen ist. Die drei folgenden Gedichte sind jewells von einer Elementarkraft beherrscht.

Eine Hymne an die mitreißende Vitalităt des Meeres ist die Dichtung "Port Marsel'skij" 261 aus dem Jahre 1861. Die Wellenbewegung wird formal auf verschiedene Weise nachgeahmt. Die Daktylen entsprechen dem steilen Aufbăumen und langsamen Verlaufen der Wogen. Auch die sechszeilige Strophe gibt diese Bewegung wieder: mit einem kraftvollen Paarreim beginnt sie und lăuft in zwei Kreuzreimen aus. Der dritte Vers findet im fünften ungebrochenen Widerhall, der vierte im sechsten nur noch eine halbe Antwort,

"Port Marsel'skij" (Sept. 1861); K. Pavlova 1964, S. 220. 
von den vier Hebungen der vorangegangenen Zeilen tauchen ledigilich zwei auf. Parataxen und Alliterationen schmiegen sich dem Dargestellten an. In der zweiten Strophe schöpft die Dichter in die formalen Mittel bis hart an die Grenze zum Artistischen aus. Archaische Stabreime und das Vorherrschen des weiten Vokals a in den ersten beiden Versen bezeichnen das Anschwellen der Wogen, Alliteration der Sibilanten im Verein mit hellen i-Lauten das Flüstern der kleinen, auslaufenden Wellen.

Vam ja vverjajus', valy okeana!

Vam, svoenravnym, buntujušcim $r$ 'jano,

$\mathrm{Na}$ bereg chlescusccim sumnoj dugoj!

Mcite że, dikie sily pučiny,

Mcite menja vy $k$ cužbine drugoj

Ot ètoj cuźbiny.

In diesem Gedicht ist die Empfindung der sinnlichen Befreiung mit einer gewissen Lust am Untergang gepaart.

Sehr viel beklemmender sind Faszinosum und Tremendum in der Ballade "Ogon" 262 verschmolzen. Ein Knabe, der von seiner Mutter zur Bewachung des Feuers in einer einsamen Hütte zurückgelassen worden ist, wird von dem Spiel der Flammen gefangengenommen und kann sich deren hypnotischer Macht nicht entziehen. Das Feuer breitet sich aus. Der endgültige Durchbruch wird durch den Wechsel des Versmaßes nach der zwölften Strophe nachvollzogen: Die Sprache der Flammen war bis dahin dem durchgehenden vierhebigen Trochăus angepaßt; die um eine Hebung verkürzten, nun durchweg männlich endenden Verse erinnern an Beschwörungsformeln und Zaubersprüche und kündigen die Katastrophe an. In der folgenden Strophe sind Laut und Sache magisch vereint:
Ryscet v pecke, svišcet, rdeja,
Chlešcet on kirpicnyj svod,
Zašipit sipen'em zmeja,
Voem volka zarevet.

Dem Feuer fallen der Knabe und seine schlafende Schwester zum Opfer.

262

"Ogon'" (Juni 1841); tb., S. 94-97.

Vgl. dazu auch F.W. Neumann, Geschichte der russischen Ballade, S. $189 \mathrm{f}$. 
Nur wenige Wochen spăter entstand "Rudokop" 263 . Dieses Gedicht ist ein später und meines Wissens der einzige Nachhall des Bergmann-Motivs der deutschen Hochromantik. Karolina Pavlova muß Tieck, Novalis und E. Th. A. Hoffmann gekannt haben. Die Goldsuche als Symbol für die Einlassung mit dem Bösen könnte Tiecks "Runenberg" entnommen sein. Der "Rudokop" liest sich wie eine Paraphrase zu den folgenden Sătzen aus "Heinrich von Ofterdingen" von Novalis:

"Die Natur will nicht der ausschließliche Besitz eines einzigen sein. Als Eigentum verwandelt sie sich in ein böses Gift, was die Ruhe verscheucht und die verderbliche Lust, alles in diesen Kreis des Besitzers zu ziehn, mit einem Gefolge von unendlichen Sorgen und wilden Leidenschaften herbeilockt. So untergräbt sie heimlich den Grund des Eigentümers und begrabbt ihn bald in den einbrechenden Abgrund, . . ."264.

Der Schluß ist dem der "Bergwerke zu Falun" von E. Th. A. Hoffmann sehr ăhnlich. Während dort die Bindung an ein Mädchen den Zwang, der ihn 'nach innen' treibt, löst, ist es bei Karolina Pavlova die Unschuld des Kindes. In beiden Fällen kommt die Erlösung zu spät. Das Element Erde, verkörpert im Erdgeist, nimmt sich sein Opfer. Im "Rudokop" ist die dämonische Natur der göttlichen gegenübergestellt, das Uralte dem Ewigjungen, das Unerlöste dem Erlösten.

In der Schilderung der friedlichen, freien Natur, auch - bei der Pavlova sehr hăufig - der Stadtlandschaft, gelingt ihr nicht die Dichte der Darstel lung, die von sich aus, das heißt ohne ausgesprochenen Hinweis des Autors, ihren Symbolcharakter offenbart. Die Dichterin muß der Assoziationssteuerung durch unmittelbaren verbalen Eingr iff nachhelfen. Zum Beispiel zählt sie in dem Gedicht "Gondola" 265 das, was ihr beim Anblick Venedigs einfanlt, wörtlich auf, weil das gezeichnete Bild zu schwach ist, um im Hörer diese Gedankenkette hervorzurufen. Eine Landschaft wird also in diesem Falle nur als interessanter 'Aufhänger' genommen; die Beziehung zur wesentlichen Aus-

"Rudokop" (Juli 1841); K. Pavlova 1964, S. 97-103. Vgl. dazu auch D. Tschizewskij, Zu zwei Gedichten von Karolina Pavlova, S. $113 \mathrm{ff}$. Novalis, Schriften, Bd. 1, S. 245.

"Gondola" (Juni 1858); K. Pavlova 1964, S. 214-216. 
sage ist so schwach, daß die Anknüpfung unmotiviert erscheint.

Der Zyklus "Fantasmagorii", der in vielen Zügen an empfindsame Reisebeschreibungen er innert und in dem sich ein so hervorragendes Gedicht wie "Port Marsel'skij" befindet, vermittelt zuweilen den Eindruck, daß Karolina Pavlova mit ihrer Weitgereistheit und mit ihrer Bildung prunken wollte. Diese Dichtungen sind zum Teil formal vorzüglich, gehen aber an ihrer Überladenheit unter. Zum Beispiel überfrachtet die Dichterin die Venedig-Gedichte "Venecija" 266 und das bereits genannte "Gondola" mit Anspielungen auf die miteinander verknüpte Geschichte der Städte Byzanz und Venedig, betrachtet deren Machtverfall mit den Augen einer Bürger in des 'dritten Rom'. Bei dieser Fülle erdrücken sich die Motive gegenseitig.

Die Blässe der bildlichen Darstellung, das Klischeehafte des gewăhlten Naturausschnitts mindern auch den Wert solcher Gedichte, in denen wie beispielsweise in "Sputnica feja" 267 - die Natur Seelenvorgänge spiegelt. Wenn jedoch jegliche Korrespondenz fehlt, also weder das Bild von sich aus eine Parallele nahelegt noch die Autorin den Leser darauf stößt, sinken die Gedichte aus Mangel an innerer Spannung ins Idyllische ab. Als Beispiel für solche belanglosen Schilderungen sei nur "Ozero Valen" 268 genannt.

Sobald Karolina Pavlova aber eine antinomische Spannung schafft, die Natur gleichsam als Kontrapunkt der Innerlichkeit entgegensetzt, geraten die Dichtungen besser.

In "Pil'nic" 269 relativiert sie mit der Frage der letzten beiden Verse einer jeden Strophe die geschilderte Abendstimmung. Das Gedicht ist lebendig durch den Kontrast zwischen äßßerem Frieden und innerer Unruhe.

\footnotetext{
266

"Venecija" (Juli 1858); ib. , S. 213 f.

"Sputnica feja" (Aug. 1858); ib., S. 198-202.

"Ozero Valen" (Okt. 1861); ib., S. 219.

"Pil'nic" (Okt. 1861); ib., S. $218 \mathrm{f}$.
} 


\section{Pil'nic}

V svoe osennee ubranstvo

Ves' les torźestvenno odet;

Roskošno na ego prostranstvo

Zakata l'etsja jarkij svet;

Blestjat vse vetvi zolotye

Pod neba zolotym lucom...

Zacem mne pomnitsja Rossija

$\mathrm{S}$ svoim surovym oktjabrem?

I ticho gasnet blesk ëfirnyj,

Strany tainstvennej Certy.

Kak dume predavajas' mirnoj,

Stojat lesnye vysoty!

Derev cut' dvižetsja lis' temja,

Ruc'ja vnizu cut' sep'et tok...

Kak mne na um prichodit vremja

Zlych vozmuscenij i trevog?

In den folgenden Gedichten reflektiert Karolina Pavlova ihren w el t a nschaulichen Standort. Es ist so reizvoll wie bedenklich, am einzelnen Menschen erfahrene Antinomien ins Menschheitliche und Historische zu verlängern. Bei einer derartigen Polarisierung können dann zum Beispiel Begriffe zusammenrücken wie Unschuld - Seele - Glaube - Moskau - Rußland Orthodoxes - Bewahrendes einerseits und andererseits Schuld - ratio - Wissen - Rom bzw. Petersburg - Westeuropa - Lateinisches - Verfall. Dieser gewisse Schematismus im Denken ist sicher kein spezifisches Merkmal der Pavlova; aber wie sehr durch ihn Dichtungen belastet werden können, läßt sich an ihrem Werk gut zeigen.

"Razgovor v Kremle" 270 ist der umfangreiche Beitrag Karolina Pavlovas zum Thema Rußland - Europa. Sie versucht darin eine chiliastische Deutung der Geschichte, in der Rußland als Mărtyrer erscheint, der für das Abendland das Kreuz auf sich genommen hat ${ }^{271}$. Trotz seiner 43 achtzeiligen Stro-

"Razgovor v Kremle" (10./22.4.1854); ib. , S. 158-168.

Diese messianistischen Züge bezog $K$. Pavlova in den Gedichten "Citala Casto s grust'ju detskoj.." (April 1842; ib. , S. 106f.) und "Ne gordoju voz'mem bor'boju. ." (1862 ?; ib. , S. 222f.) zwar nur auf ihre Generation, aber insofern auch auf Rußland, als sie sich und ihresgleichen als Bewahrer des wahren Rußland verstand. 
phen ist dieser gereimte historische Abriß überladen. Zwar sind der Dichterin in dieser Arbeit auch hervorragende Verse gelungen und Strophen, die von großem Einfühlungsvermögen und Verständnis zeugen, aber in dem Geflecht aller möglichen Antinomien geht die große Linie verloren ${ }^{272}$. Im Stoff liegt die Tendenz zum Versepos. Mit der Konstruktion der Gesprächsrunde hat die Dichterin aber ein dramatisches Element hineingetragen. Diese nicht überzeugende Mischform bietet allerdings die Möglichkeit, eine enorme Stofffülle in die Dichtung einzubringen. "Razgovor $\mathrm{v}$ Kremle" ist ein Beispiel für Weitschweifigkeit: das Gedicht erstickt im eigenen Überangebot. Es ist darüber hinaus ein Beispiel dafür, daß der Pavlova manchmal der sichere Blick für das 'Angemessene' fehlte.

In der Arbeit "Rim" 273 aus dem Jahre 1857 begegnet die Dichterin der Gefahr der Ausuferung des Stoffs mit Erfolg, ohne daß dabei die Aussage an Tiefe verliert. Sie schildert den Anblick Roms, wie er sich dem Ankommenden an einem truben Tag bietet; aber durch gelungene Überzeichnung wird die Realităt dieser kurzen Zeitspanne symbolisch verdichtet. Rom wird in einer apokalyptischen Landschaft gesehen.

My edem poljanoju goloj, Ne vstretjas' s żivoju dušoj;

Vdali, iz-pod tuci tjaželoj, Vidneetsja gorod bol' šoj.

I, budto b ego nazyvaja,

Crez mertvoj pustyni predel

Ot neba stemnevšego kraja

Otryvistyj grom progremel.

Diese Weltgerichtsstimmung zieht die Personifizierung Roms fast zwangsläufig nach sich; die Stadt steht - verkörpert im "mnogogrešnyj vladyka" - vor dem Gericht Gottes. Im Bild des Entthronten, des schutzlosen und kranken Riesen sind Glanz und Elend Roms eingefangen; der Hinweise der fünften Strophe auf die Geschichte bedarf es kaum mehr.

So bemängelte auch der Rezensent dieses Gedichts, daß der Rahmen zu eng und der Stoff zu umfangreich sei; beides müsse zu Lasten von "jasnost" und "prostota" gehen, den unabdingbaren Voraussetzungen für ein literarisches Erzeugnis (in: Sovr emennik 1854 - Bd. XLVII, Nr. 9, Abt. IV, S. 34-38, hier S. 35).

"Rim" (März 1857); K. Pavlova 1964, S. 212 f. 
Gde vesti, i kazn', i zakony

Goncy ego miru nesli,

Gde tesnye sli legiony,

Gde bili Celom koroli.

Die letzte Strophe kündigt den Untergang an:

On smotret, kak veter poljany

Pesok po pustyni metet,

I serye vschodjat tumany

Iz topi tletvornych bolot.

Dieses Gedicht zăhlt zu den gelungenen der hier besprochenen Gruppe, weil die Dichterin von der ersten bis zur letzten Zeile im Bilde bleibt und nicht kommentierend und reflektierend ausbricht.

In dem sehr viel früheren Gedicht "Moskva" 274 hat Karol ina Pavlova eine ganz ăhnliche Rahmenhandlung entworfen. Auch hier sieht sie die Stadt vor sich liegen, aber in einer grandiosen Abendstimmung.

Vzgljanula ja prostor dolin: pylaja,

Kasalos' ich uze svetilo dnja.

I gorod tam palatnyj i sobornyj,

Raskinuvsis' siroko $v$ sirine,

Blistal vnizu, kak by nerukotvornyj,

An dieser Stelle entfernt sich die Dichterin aus dem Bild und verliert sich in Meditationen. Das Symbol deutet sich nicht selbst, sondern muß von der Autorin interpretiert werden.

Rom ist für Karolina Pavlova Kristallisationspunkt aller negativen Züge des Westens. Nur so ist es zum Beispiel zu verstehen, daß sie die russische Niederlage im Krimkrieg als "Prazdnik Rima" ${ }^{275}$ deutet. Mit dieser In-eins-Setzung Europas mit Rom ist die Prophezeiung des Untergangs verknüpft.

Viele Verse widmet die Dichterin der römischen Christenverfolgung. Mit dem Gegensatz Heiden - Christen spielt sie zugleich den Gegensatz zwi-

"Moskva" (1844); ib. , S. $122 \mathrm{f}$.

"Prazdnik Rima" (Jan. 1855); ib. , S. 171-173. 
schen dem abgefallenen Westen und dem helligen Rußland aus 276 .

Karolina Pavlova hat aber durchaus nicht alles Russische kritiklos bewundert. Anlaßlich des verlorenen Krimkriegs weist sie in dem Gedicht "Plovec" 277 auf die russische Sorglosigkeit und Trägheit hin. Sie sieht auch die Fragwürdigkeit der ungenügend vorbereiteten Bauernbefreiung in der Arbeit "Na osvoboždenie krest'jan" 278 .

Vgl. dazu nur folgende Gedichte:

"Prazdnik Rima",

"Użin Polliona" (12./24.Jan. 1857); ib. , S. 190-196,

"Na osvoboždenie krest'jan" (1862); ib. , S. 223-225.

"Plovec" (1855); ib., S. $186 \mathrm{f}$.

Vgl. Anm. 276. 


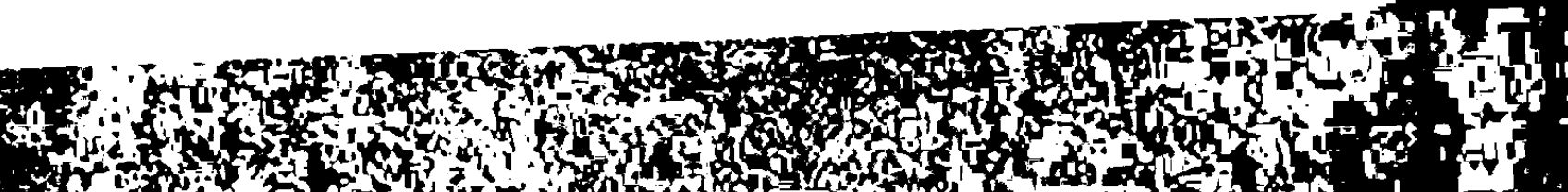

H.

(1)

W $x$ is

(n)

H.

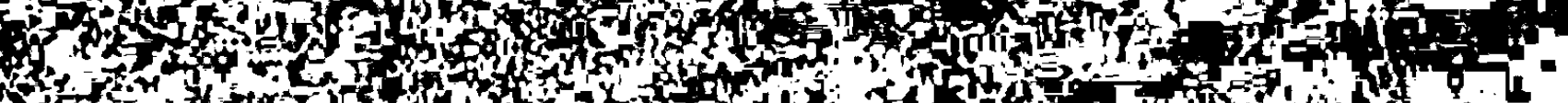

(5t)

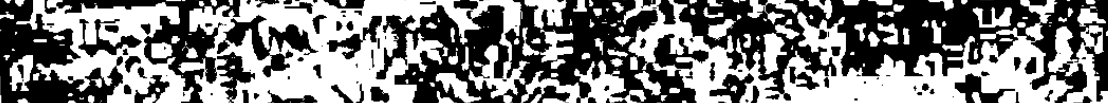

of

Th

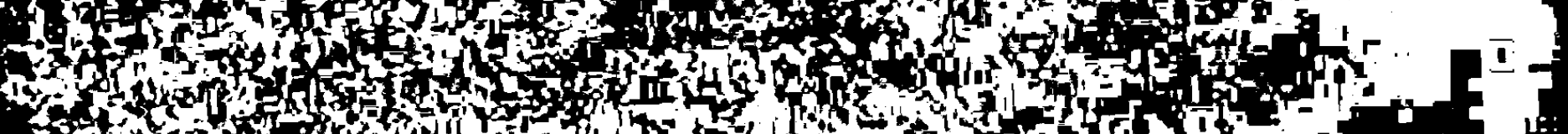
a 4f

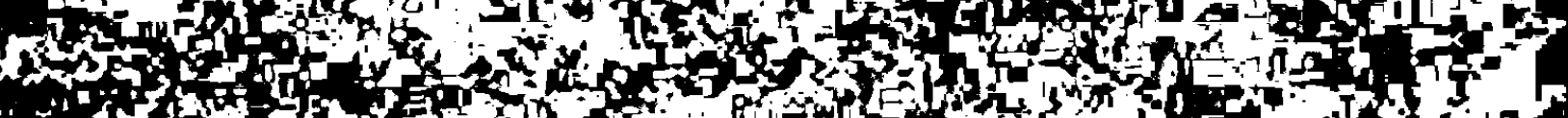
-

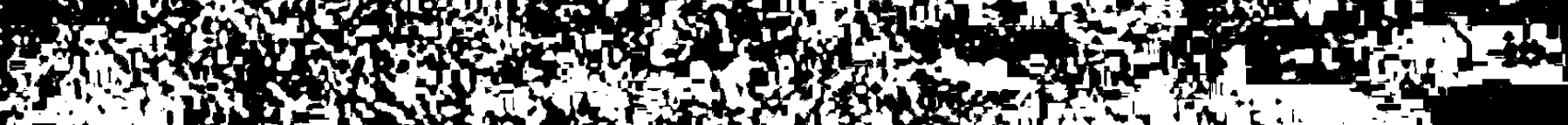
(1) and

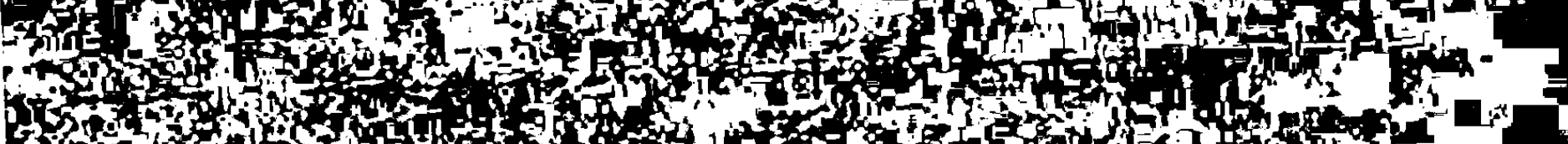
S.jor 19for

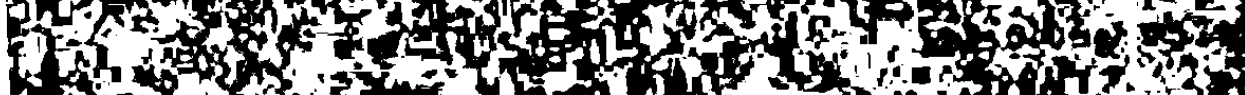
a

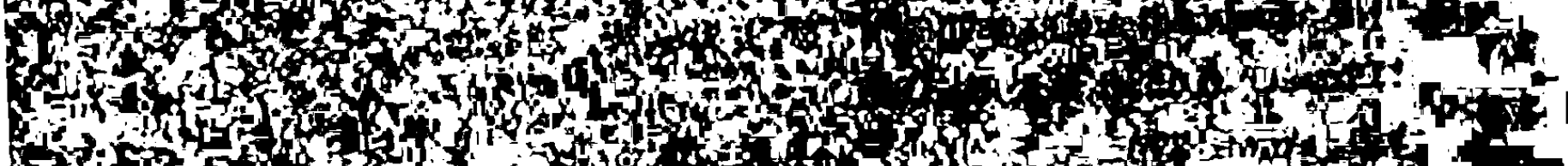

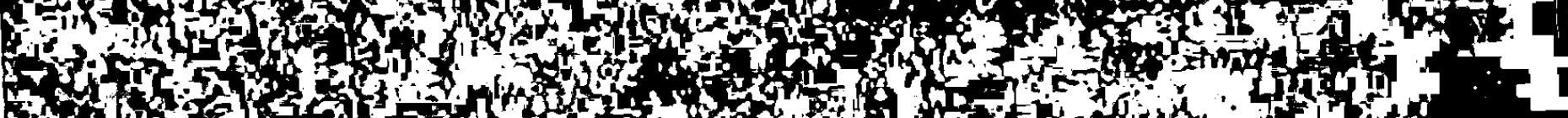

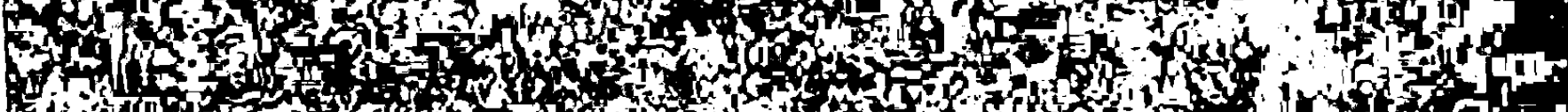

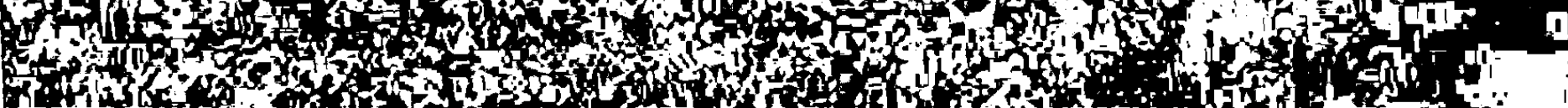

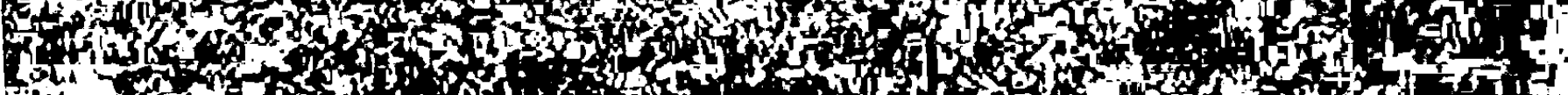
nis 


\section{Erzählungen in Versen und in Prosa}

Auch die herrschenden gesellschaftlichen Zustände nahm Karolina Pavlova nicht vorbehaltlos hin. In drei größeren Arbeiten hat sie versucht, die Schwächen der Oberschicht freizulegen. Zu Beginn der vierziger Jahre nahm sie die Arbeit an den Poemen "Dvojnaja żzn" und "Kadril" auf. "Dvojnaja Zizn'" erschien ber eits 1848, wăhrend "Kadril "l erst 1859 veröffentlicht wur de. Im selben Jahr legte die Dichter in auch die thematisch verwandte Prosaerzăhlung "Za cajnym stolom" vor. Diese Dichtungen bestătigen zum einen, daß die große Dichtform nicht die Stärke Karolina Pavlovas war, zum anderen, daß sie sich mit diesen Ver suchen engagierter Literatur auf ein ihr im Grunde wesensfremdes Gebiet wagte. In der stofflichen Fulle hat sich die Aussage verloren. Die Schilderungen sind zu breit, werden oft zum Selbstzweck und rücken diese Arbeiten manchmal in die Năhe bloßer 'Enthüllungen' . Die Dichterin verzeichnet zwar die Behinderung der individuellen Entfaltung durch die gesellschaftlichen Konventionen, zeigt das Verlogene, die Doppelbödigkeit der Moral auf, aber in jedem Falle arrangieren sich die Heldinnen schließlich mit den geltenden Spielregeln.

Am besten ist noch "Dvojnaja zizn" 279 gelungen. Formal ist diese Arbeit dem typischen zweidimensionalen romantischen Roman angenähert. Außenwelt und Innenwelt, Tag und Nacht sind als ungebundene und gebundene Rede voneinander geschieden. Es wurde schon darauf hingewiesen, daß Karolina Pavlova die Stilebenen săuberlich getrennt hat ${ }^{280}$. Über das Herz siegt letztlich der Verstand, die Gesellschaftsraison macht die Träume zunichte. Den inneren Monolog Cecilijas hat die Dichterin als nächtliches Zwiegespräch mit einem Unbekannten gestaltet, von dessen frühem Tod das Mädchen am Tage erfahren hatte. Diese innere Stimme weckt in Cecilija Zweifel; sie macht ihr klar, daß das Tag-Leben nicht das ganze Leben sel, daß die Seele die ihr auferlegten Fesseln abstreifen müsse. In den nächtlichen Gesprächen werden dem Mădchen die Măngel der Tag-Welt immer deutlicher, aber zugleich wird ihm

"Dvojnaja Żizn’" (1844-1847); K. Pavlova 1964, S. 231 -307.

Vgl. dazu S. 93 dieser Arbeit. 
klar, daß es mit ihnen leben muß. Cecilija versucht, ein doppeltes Leben zu führen, erkennt aber nach einiger Zeit, daß sie von dieser Bewußtseinsspaltung überfordert ist und sich für die eine oder andere Seite entscheiden muß. Sie wendet sich der Tag-Welt zu, weil es ihr unertrăglich erscheint, "nur das zu lieben, was unmöglich ist, / Nur an das zu glauben, was fern ist" $^{281}$.

Die Kritiken dieser Arbeit waren sehr unterschiedlich. Hier seien nur zwei herausgegriffen, die die gegensătzlichen Betrachtensweisen umreißen sollen.

Im ersten Falle handelt es sich um das Vorwort zu einem Auszug aus "Dvojnaja zizn"", der ein Jahr vor der Veröffentlichung des ganzen Poems erschienen war ${ }^{282}$. Dort wird hervorgehoben, daß Inhalt und Form einander in idealer Weise entsprechen. Weiter heißt es:

"Dieses Werk ist höchst zeitgemäß und, neben seiner allgemeinen Bedeutung, zugleich vollkommen national. Indem es die Geheimnisse der menschlichen Seele aufdeckt, spiegelt es unser Leben wider, seine gegenwärtige Spaltung, Nichtigkeit und Abgeschmacktheit, die quallende Leere und die Konvention außerlicher Formen, die von unser er Gesellschaft angenommen wurden, und zugleich stellt es die Făhigkeit eben dieses Lebens dar, bei all seiner Abgeschmacktheit, bei all seiner sichtbaren und wirklichen Entfremdung vom allgemeinen Leben - wenn auch in den geheimsten Winkeln der Seele, wenn auch nur im Traum -, eine solche Geistigkeit aufzudecken, einen solch bedeutsamen Kampf, eine solche Wahrheit und Liebe, von denen die Seele der Heldin unbewußt, in ihren Trăumen, angefüllt ist" 283.

Die zweite Rezension erschien 1848, als das ganze Poem vorlag, im "Syn otecestva" $^{284}$. Sie unter scheidet sich grundsätzlich von der ersten.

"Dvojnaja žizn', 7. Abschnitt; K. Pavlova 1964, S. 287.

"Dvojnaja żizn", socinenie K.K. Pavlovoj"; in: Moskov skij literaturnyj i ucenyj sbornik na 1847 god. Moskva 1847, S. 691-696 (Vorwort, das von P. Bartenev im "Russkij archiv" 1894, Nr. 1, S. 123 einem der Aksakov-Brüder zugeschrieben wurde) und S. 697-700 (Auszug aus dem 5. Kapitel).

284 E. Rozen, Dvojnaja zizn; in: Syn otecestva, 1848, Buch 5, Abt. VI, S. 1-19. 
"Wenn man ein neues Buch liest, über das man einen kritischen Aufsatz schreiben will, muß man sich vor allem darum bemühen, seine Grundidee und das, was der Autor gerade wollte, herauszufinden; das ist absolut nicht leicht für den Fall, daß die Grundidee dem Autor selbst nicht klar ist, daß sie in Mystizismus ubergeht und in magnetischen Visionen der Seele umherirrt. .." 285.

Weiter unten heißt es:

"Offen gestanden, die scheinbare Spaltung, Nichtigkeit und $A b g e s c h m a c k t h e i t$ unserer Lebenswe ise und die Ent fremdung vom allgeme inen $L$ eben, die stark nach Slavophilie riechen, stoßen auf einigen $\mathrm{Zweifel;}$ aber wir erwarten, daß das Talent und noch mehr der vornehme Takt einer klugen, gebildeten Dame es ver stünde, sich über solche engen Begriffe zu erheben, ohne die Schule zu kränken, die sich so von Herzen für sie (die Pavlova) begeistert. Unsere Erwartungen wurden nicht erfüllt;..." 286.

Für den Rezensenten ist die Seele gemeinsame Quelle für Denken und Fühlen. Die Spannung $\mathbf{z w i s c h e n ~ d i e s e n ~ b e i d e n ~ e n t g e g e n g e s e t z t e n ~} \mathbf{K r}$ äften müsse fruchtbar gemacht werden; erst der Mensch, der den ganzen Raum seiner Seele durchmesse, gelange zu einem vollkommenen Bewußtsein seiner selbst. Dieses Ideal sei aber nie absolut, sondern nur annăhernd zu erreichen. Und das sei gut so, weil sonst der Bewegung der Seele, und damit dem Leben, das Ende drohe. Die Notwendigkeit der Zweiteilung als unabänderliche Lebensbedingung werde aber von der Moskauer Schule (d. h. von den Slavophilen) nicht anerkannt 287.

Karolina Pavlova weiß keinen anderen Ausweg als die Flucht in die Innerlichkeit. Aber dieser Möglichkeit ist keine der Heldinnen aller drei Arbeiten gewachsen.

In "Kadril" 288 wirft die Dichterin die Frage auf, ob nicht die gegenwärtigen gesellschaftlichen Zustände Ergebnis des falschen Verhaltens der Frau seien und ob die Frau etwas zur Verănderung beitragen könne. Die Pavlova variiert in vier Erzathlungen das Thema der bewußten oder unbe-

$\begin{array}{ll}285 & \text { ib. , S. } 1 . \\ 286 & \text { ib. , S. } 2 . \\ 287 & \text { ib. , S. } 3 .\end{array}$

288 "Kadril""; K. Pavlova 1964, S. 308-372.

Vgl. hierzu auch die Äußerungen Chomjakovs über dieses Poem (S. 72 dieser Arbeit). 
wußten Anpassung an die gesellschaftlichen Normen, ohne aber, wie in "Dvojnaja zizn", ein Gegenbild zu entwerfen. Die einzige, die die Gesellschaft durchschaut, die junge Gräfin Polina, weiß zum Abschluß dieses Gedankenaustauschs nichts anderes zu sagen, als daß es an der Zeit sei, zum Ball zu gehen!

Zwei Stellungnahmen liegen zu "Kadril" vor, wie sie gegensätzlicher kaum gedacht werden könnten. 1851 war ein Ausschnitt aus dem Poem veröffentlicht worden ${ }^{289}$. Daraufhin erschien im "Moskvitjanin" eine Besprechung ${ }^{290}$. Der Rezensent gab an, bereits das ganze Werk zu kennen.

"Diese Erzăhlungen sind alle von gleichem Wert: in allen wird wahre Meisterschaft sichtbar; aber ihre Verschiedenartigke it und Gegensätzlichke it verleihen ihnen noch mehr Wirkung, wecken noch mehr Interesse, was im einzelnen Ausschnitt verlorengeht. Außerdem wurde für jede der vier Erzählungen ein besonderes Versmaß gewählt: das ist eine strahlende Symphonie in Versen, mit meisterhaften Übergängen aus einer Tonart in die andere... R a s $s k a z L i z y$ ist im fünhebigen Trochäus geschrieben, in dem bei uns fast noch keiner geschrieben hat. .. Die Ver schiedenartigkeit der Versmaße, die Frau Pavlov verwendet, ist eine wirkliche Bereicherung unserer dichterischen Sprache: nur sie (die Pavlova) und Zukovskij haben alle Möglichkeiten unserer reichen Prosodie erprobt; selbst Puskin begnügte sich hauptsächlich mit dem vierhebigen Jambus; Ausnahmen sind sehr selten" 291.

Außer diesen formalen Făhigkeiten wird auch die scharfe Beobachtungsgabe der Dichter in hervorgehoben, ihr Vermögen, Charaktere zu erfassen und lebendig darzustellen 292 .

Von beißendem Spott durchtränkt ist die Kritik, die 1859, nach dem Erscheinen des ganzen Poems ${ }^{293}$, in der satirischen Zeitschrift "Iskra" er-

289 "Rasskaz Lizy"; in: Raut. Literaturnyj sbornik. .., Moskva 1851 , Buch 1, S. 313-327.

290 Moskvitjanin 1851, Nr. 9-10 (Mai), Abt. "Kritika i bibliografija", S. $157 \mathrm{f}$.

ib., S. 157.

ib. , S. 158.

"Kadril" "; in: Russkij vestnik, 1859, Januar, Buch 1, S. 181 -196;

Buch 2, S. 337-349; Februar, Buch 1, S. 501-514; Buch 2, S. $691-708$. 
schien 294 . In einer fingierten Leserzuschrift "aus der Provinz" wurde "Kadril'" 'in Grund und Boden gelobt' als eine "erfreuliche Erscheinung, die natürlich schon von ganz Rußland auswendig gelernt" worden sei.

"Nein, Sie (d.h. die Herausgeber) haben sich einfach in den Schmutz und die Nichtigkeit der entlarvenden Literatur hineingedrängt und haben das Gespür für die erhabensten Schönheiten der Poesie verloren. Schande, Schande über Sie wegen dieser Gleichgültigkeit gegenüber der vaterländischen Literatur! Die bedeutendste Probe der Poesie, der Aristokratie, der Feinfühligkeit und der Vornehmheit der Empfindungen geht unbeachtet an thnen vorbei, aber der Tod (durch Ertrinken in einem See) irgendeines Polizeihauptmanns vom Lande findet in Threr Zeitschrift eine wohlgesetzte und sogar poetische Beschreibung. So haben sich Ihre Begr iffe verzerrt! Aber ich muß dieser Sittenverderbnis ein Ende setzen, ich fühle, da $\beta$ ich dazu berufen bin... Die Hefte des "Russkij vestnik", in denen das Poem veröffentlicht wurde, treibt man bei uns nicht mehr auf, für welchen Preis auch immer. .." 295 .

In diesem Stil geht es fort.

Auch in der Erzählung "Za cajnym stolom" 296 wird besonders die Situation der Frau beleuchtet. Die Meinung, daß die Frau sui generis nichts anderes als ein "hübsches Spielzeug" sei, daß sie von Natur aus nur eine passive Rolle spielen könne, steht der Auffassung entgegen, daß die untergeordnete Stellung der Frau Produkt ihrer Erziehung sei, daß eine andere Ausbildung auch ihre Rolle verändern würde. Es sei die gesellschaftliche Voreingenommenheit, der Frau nur Gefühl und dem Mann nur Verstand zuzubilligen. Das Wortgefecht geht unentschieden aus, am Schluß bleibt alles offen.

Die in diesen Arbeiten von Karolina Pavlova kritisch entworfenen Bilder aus der Gesellschaft decken zwar das Fragwürdige dieser Ordnung auf, bieten aber keinen gangbaren Ausweg, auf die Frage "Was tun?" weiß die Dichter in keine Antwort.

\footnotetext{
294 (M. G. ), Novoe kapital'noe priobretenie russkoj slovesnosti; in: Iskra, 1859, Nr. 24 (26.6./8.7.), S. 233-235.

ib., S. 234.

"Za cajnym stolom"; K. Pavlova 1915, S. 335-412.
} 


\section{are.}

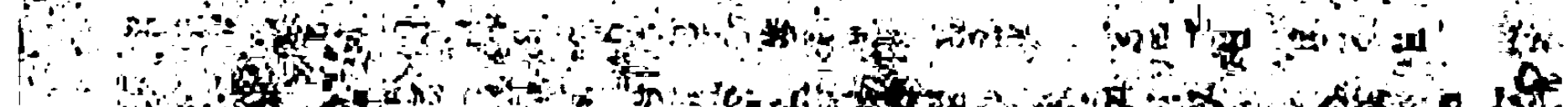

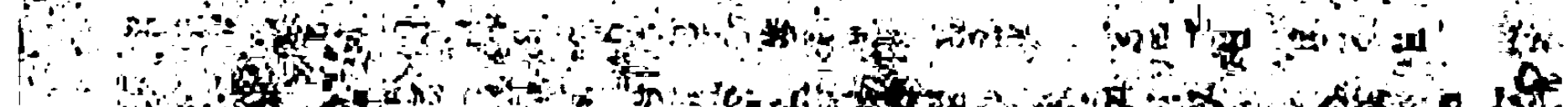
Da

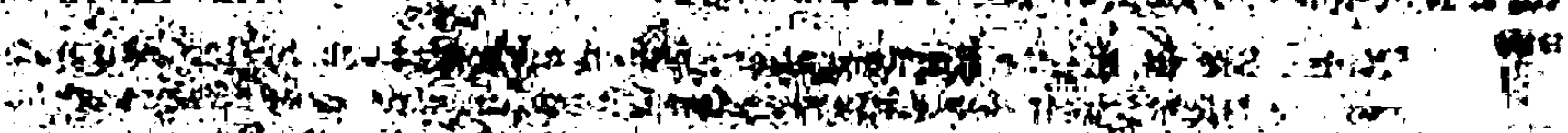

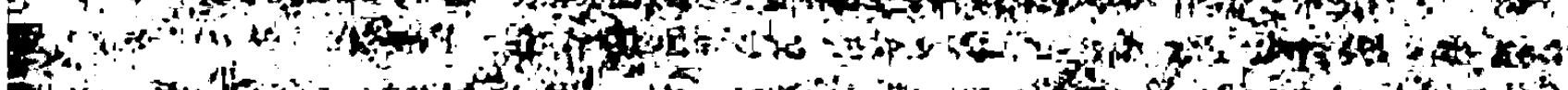
(6)

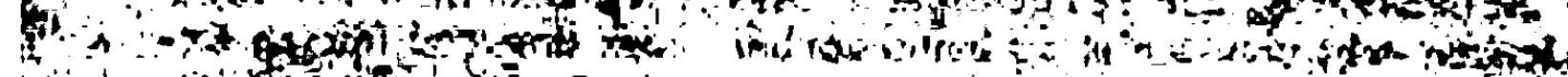

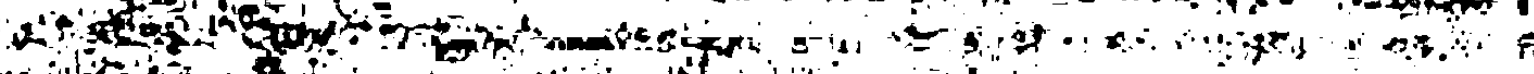

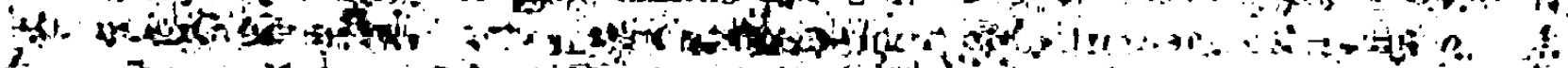

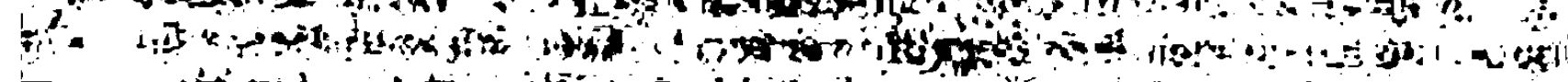
For a 3.

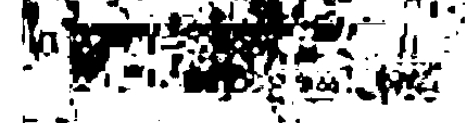
and

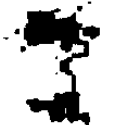

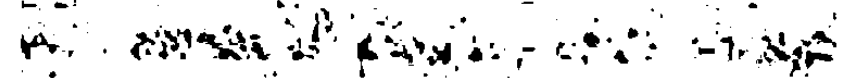

$\therefore$ is 3)

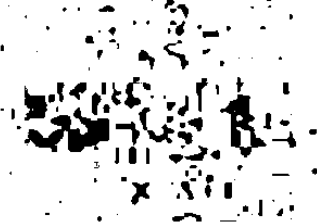

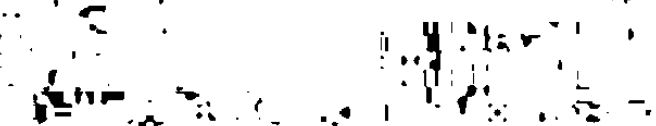 $\therefore \therefore$

.

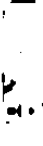
Ha 1 is

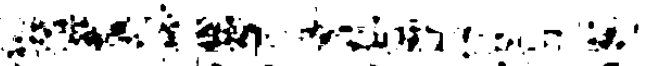

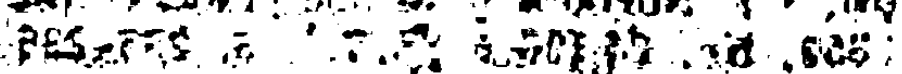

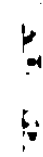

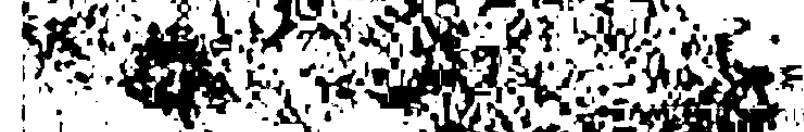

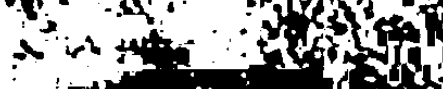




\section{Fremdsprachige Gedichte}

Bis Ende der dreißiger Jahre hat Karolina Pavlova ihre eigenen Dichtungen vorwiegend in deutscher und französischer Sprache abgefaßt und zum größten Teil im "Nordlicht" beziehungsweise in dem französischen 'Pendant' "Les préludes" veröffentlicht. Ihre deutschen Gedichte hat sie offensichtlich ebenfalls als "Proben der neueren russischen Literatur" betrachtet.

Wenn Tschižewskij und Gerhardt meinen, daß diese Arbeiten eher ein Beitrag zur deutschen als zur russischen Romantik seien ${ }^{297}$, trifft das insofern zu, als einige Stoffe und Motive der damaligen deutschen Literatur entlehnt zu sein scheinen. So ist zum Beispiel "Die Geisterstunde" Goethes "Erlkönig" verwandt, in der "Nixe" sind Ähnlichkeiten mit Goethes "Fischer" festzustellen. Aber auf der anderen Seite sind diese Themen romantisches Allgemeingut gewesen. Und die Form verrăt schon deutlich die Merkmale der späteren, russischen Dichtung Karol ina Pavlovas. Die Dichterin zeigt in diesen Arbeiten bereits ihre Souverănităt im Umgang mit den lyrischen Stilmitteln, ihre Formulierfreude. Sie wechselt beinahe von Gedicht zu Gedicht Versmaß und Strophenbau.

So unterscheidet sie zum Beispiel in der ersten ihrer drei Balladen "Die Geister stunde" 298 - die Stimmen mit Hilfe der Zeilenlănge. Die Stropheneinschnitte richten sich nach der Handlung. Die Form unterwirft sich dem Inhalt. - Dagegen ist die Ballade "Alvar der Talador" 299 streng invierhebige Trochäen, in vierzeilige Strophen gefaßt; der Stoff beugt sich der Form. - Das Motiv von der Nixe und dem Knaben ${ }^{300}$ in drei Sonetten abzuhandeln, ist künstlerisch kaum zu rechtfertigen. Hier arbeitet die Sonett-Form dem Inhalt insofern entgegen, als ihre Strenge das Naturmagische domestiziert.

\footnotetext{
297 Vgl. D. Tschizewskij und D. Gerhardt, Deutsche Puskkin-Übersetzungen von Karolina Pavlova; in: Germanoslavica 1937, H. 1-2, S. 39. "Die Geisterstunde"; K. Pavlova 1964, S. 470-477.
"Alvar der Talador"; ib., S. 477-480.

"Die Nixe"; ib., S. $485 f$.
} 
"Man wird finden, daß ich mehrere unăchte Reime gebraucht habe, allein bei der Armuth der deutschen Sprache anvollkommen reinen Reimen glaube ich, daß das Beispiel Schiller's und Göthe's diese Freiheit genugsam rechtfertigt, und sich ihrer unbedenklich zu bedienen erlaubt", heißt es im Vorwort zum "Nordlicht" 301.

Diese Freiheit wird man einem Übersetzer, der sich um größtmögliche Treue zum Original bemüht, in höherem Maße zubilligen als dem Dichter. Aber Karolina Pavlova, der man insgesamt große Sicherheit im Reimen bescheinigen muß, hat in ihren deutschen Gedichten allzu unbedenklich gereimt. Bindungen wie $\mathfrak{i}: \ddot{u}, \ddot{a}: \ddot{b} / e$, ei : äu/eu sind in der deutschen Dichtung durchaus möglich, aber nur solange sie Ausnahmen bleiben. Störend sind Wörter, die ihrer Reimentsprechung eine unzulăssige Länge oder Kür ze auf zwingen: büßen : müssen, Grüße : Küsse, müssen : schließen, Liebesgeflüster : düster.

Die Vorliebe für Reime auf Fremdwörter und Namen zeigt sich am deutlichsten in "Alvar der Talador" ${ }^{302}$. Allein fünf verschiedene Wörter hängt die Dichterin an "Mondecar", vier an "Doña Flor" usw. - In dem Gedicht "Flucht und Rückkehr" ${ }^{303}$ reimen Pyrenäen : umsteh'n, Pomeranze : Romanze, Myrten : verirrten.

Zwischen 1860 und 1870 hat Karolina Pavlova noch einige Dichtungen in deutscher Sprache geschrieben, vorwiegend kurze gereimte Grüße.

301 "Das Nordlicht", Vorwort S. XIf.

302 Vgl. dazu die Zusammenstellung von D. Tschižewskij und D. Gerhardt, Deutsche Puškin-Übersetzungen...; in: Germanoslavica 1937, H. 1-2, S. 39.

303 "Flucht und Rückkehr"; K. Pavlova 1964, S. $481-483$. 


\section{Kapitel}

\section{Über setzungen}

Das Werk Karolina Pavlovas besteht zum überwiegenden Teil aus Übersetzungen aller poetischen Grundformen und ist den umfangreichen Sprachkenntnissen entsprechend breit gefächert. Der Schwerpunkt liegt auf der Literaturvermittlung zwischen Rußland und Deutschland.

1823 hatte K. F. von der Borg in einer reichhaltigen Anthologie dem deutschen Publikum einen repräsentativen Querschnitt durch die russische Literatur von der Mitte des 18. bis zu Beginn des 19. Jahrhunderts vorgelegt 304 . "Das Nordlicht" kann insofern als Ergănzung dieser Sammlung aufgefaßt werden, als Karol ina Jaenisch vor allem die seinerzeit neueste Literatur übertrug. Von der Borg veröffentlichte u.a. erstmals Arbeiten von I. I. Dmitriev, K.N. Batjuškov und V.A. Zukovskij. In den folgenden Jahren erschienen dann auch verstreut die ersten Puskin-Übersetzungen 305. Die deutsche Leser schaft schenkte jedoch der zweitrangigen russischen Literatur, den Übertragungen von Geschichts- und Sittenromanen nach dem Muster Walter Scotts ${ }^{306}$ oder den Erzeugnissen eines Bulgarin, Grec und Senkovskij ${ }^{307}$ weitaus mehr Auf merksamkeit. Um so höher ist die Absicht Karolina Jaenischs zu bewerten, Autoren wie Baratynskij, Jazykov, Del'vig und Venevitinov in Deutschland bekannt zu machen und die Dichter Zukovskij und Puskin wieder in Erinnerung zu bringen. Leider war das Echo auf das

K. F. von der Borg, Poetische Erzeugnisse der Russen. Ein Versuch. 2 Bde. (355 und 415 Seiten), Riga und Dorpat 1823.

Vgl. dazu A. Rammelmeyer, Russische Literatur in Deutschland; in: Deutsche Philologie im Aufriß, Bd. 3, Sp. $447 \mathrm{f}$. ib. , Sp. 447.

Faddej Venediktovic Bulgarin (1789-1859);

Nikolaj Ivanovic Gree (1787-1867); Osip Kvanovic Senkov skij (1800-1858).

Bulgarin und Grec waren Herausgeber der "Severnaja pcela"; Senkovskij gab die "Biblioteka dlja ctenija" heraus. Alle drei galten in Rußland als Reaktionăre und kăufliche Journalisten.

Vgl. dazu Rammelmeyer, ib. , Sp. 447. 
"Nordlicht" trotz lobender Rezensionen offenbar so schwach ${ }^{308}$, daß die im Vorwort angekündigten weiter en Lieferungen nicht folgten.

Erst nach ihrer Übersiedlung nach Dresden übersetzte Karolina Pavlova wieder russische Literatur ins Deutsche, vor allem die Arbeiten ihres Freundes Aleksej Konstantinovic Tolstoj, aber auch einige Gedichte von Chomjakov und Lermontov.

Die meisten deutschen Dichter, aus deren Werken sie ins Russische übersetzte, waren hauptsächlich durch V. A. Źukovskij und F. I. Tjutčev bereits in Rußland bekannt: Chamisso und Rückert durch Żukovskij, Heine durch Tjutcev. Dagegen wurden, soweit ich feststellen konnte, Freiligrath sowie Julius Hammer und Ernst Schulze erstmals von Karol ina Pavlova ins Russische übertragen. Hier muß jedoch angemerkt werden, daß die Vorlagen nicht gerade zu den besten Stücken der damaligen deutschen Literatur gehörten. Als Vermittlerin russischer Literatur nach Deutschland war die Pavlova zweifellos bedeutender.

Auch mit den Übersetzungen der englischen Romantiker Scott, Campbell, Moore und Byron ${ }^{309}$ folgte sie dem großen Vorbild Źukovskij.

In dem Sammelband "Les préludes" hat Karolina Pavlova die französischen Leser mit den zeitgenössischen Autoren Zukovskij, Puškin, Benediktov, Jazykov und Chomjakov bekannt gemacht. Vereinzelt - und das erst

308 Tschižewskij und Gerhardt vermuten, daß Karolina Pavlova eventuell das Buch selbst zurückgezogen habe, weil sie sich durch spätere Über setzer (wie Opitz und Bodenstedt) überflügelt glaubte (Deutsche Puskin-Über setzungen...; in: Germanoslavica 1937, H. 1-2, S. 46). Diese Annahme scheint mir nicht sehr wahrscheinlich zu sein. Auch Rammelmeyer spricht von dem geringen Erfolg beim Publikum (vgl. Anm. 305 dieser Arbeit, ib., Sp. 448). Dafür spricht, daß "Das Nordlicht" heute offensichtlich nur noch in einem Exemplar in Deutschland vorhanden ist, in der "Öffentlichen Bibliothek zu Detmold".

309 Walter Scott (1771-1832);

Thomas Campbell (1777-1844);

Thomas Moore (1779-1852);

George Noel Gordon Byron (1 788-1 824). 
Ende der fünfziger Jahre - hat sie auch französische Dichtungen ins Russische übertragen; aber die Dichter Molière, André Chénier und Victor Hugo waren zu dieser Zeit in Rußland hinlänglich bekannt.

Um das Bild von der Literaturvermittlung zwischen Rußland und anderen europäischen Lăndern zu vervollstăndigen, sei noch erwăhnt, daß je einmal Aischylos, Adam Gottlob Oehlenschlăger und Aleksander Chodzko ins Russische übertragen wurden.

Karolina Pavlova hat sich nicht darauf beschränkt, aus dem Russischen in andere Sprachen beziehungsweise aus anderen Sprachen ins Russische zu übersetzen. Die Anthologie "Les préludes" ist ein Beispiel für ihre Vielseitigkeit als Über setzerin. In diese "Huldigung" an das Französische - so der Herausgeber Ronchaud im Vorwort - hat die Dichterin außer den schon genannten Proben der russischen Literatur auch Werke englischer, deutscher, polnischer und italienischer Autoren auf genommen. Wenn auf 86 Seiten ein Streifzug durch fün Literaturen anhand von 16 Dichtern aus verschiedenen Jahrhunderten geboten wird, dann dient dieses Büchlein eher der Selbstdarstellung eines unbestreitbar bewunderungswürdigen Sprachtalents als der Literaturvermittlung. "Les préludes" lassen ein Konzept, wie es im "Nordlicht" verwirklicht worden war, vermissen. Diesen Mangel hat der Herausgeber, L. de Ronchaud. wohl auch gemeint, wenn er, bei aller Anerkennung der hohen Qualităt sämtlicher Über setzungen, sein Bedauern über die allzu kleinen Ausschnitte aus russischer und polnischer Literatur ausdrückt. Ronchaud vertröstet den Leser auf eine geplante Sammlung nur russischer Autoren 310 .

Aber auch in diesem Falle unterblieb die angekündigte Fortsetzung, wohl wegen des geringen Erfolgs der Anthologie 311 .

310 K. Pavlova selbst habe in einem Brief an Aleksandr Turgenev davon gesprochen, einen solchen Band, der als Entsprechung zum "Nordlicht" gedacht sei, schon vorzubereiten (vgl. Ronchaud im Vorwort zu "Les préludes", S. IXf.).

311

Sie ist nur in ganz wenigen französischen Bibliotheken vorhanden. Das Exemplar, das mir die "Bibliotheque de l'Ar senal" (Paris) zur Verfügung stellte, war noch nicht einmal aufgeschnitten! 
Auf die Frage nach den Gründen für die Ubersetzung dieses oder jenes Dichters in diese oder jene Sprache laßst sich nicht eindeutig antworten. Allgemein kann man die Ubersetzertătigkeit mit dem verbreiteten philologischen Interesse der Romantik erklăren. Im Einzelfall werden persönliche Neigung, auch Bekanntschaft mit dem Autor, gelegentlich auch die zuf allige Begegnung mit einem Gedicht den Anstoß zur Übertragung gegeben haben. Nicht auszuschließen ist bei Karolina Pavlova sicher auch die Absicht, ihre universale Bildung zu demonstrieren 312 .

Es ist müßig zu fragen, ob sie bei der Auswahl immer sehr geschickt vorging, ob sie den für eine literarische Strömung charakteristischen Dichter, ob sie die für einen Autor jeweils charakteristische Arbeit ausgewăhlt hat. Eine Antwort müßte - abgesehen davon, daß man über das 'Typische' hăufig geteilter Meinung sein kann - den heute nur schwer wägbaren Zeitgeschmack berücksichtigen. Unbestritten ist jedoch, daß Karolina Pavlova zu den besten Übersetzern ihrer Zeit gehört und in eine Reihe mit Zukovskij und Tjutcev gestellt werden kann.

Was die sprachliche Vielfalt betrifft, so steht sie wohl einzig da. Die folgende Übersicht zeigt das ganze Ausmaß ihrer Möglichkeiten.

1. Aus dem Russischen

a) ins Deutsche Lyrische Dichtungen:

A. K. Tol stoj (12 Gedichte); Puskkin (6); Baratynskij (5); Jazykov (5); Chomjakov (4); Źukovskij (3); Del'vig (3); Venevitinov (3); Lermontov (2) - Volkslieder (9).

Dramatische Dichtungen:

A. K. Tol stoj (3); Puškin (1).

Erzăhlungen:

Puskinin (1); Somov (1); Anonymus (1).

Das gilt auch für die Motti, die sie ihren Dichtungen voranstellte: am hăuf igsten sind Byron-Zitate; es werden aber auch Zitate aus Cicero, Petrarca, Goethe, Musset, Sainte-Beuve (Pseudonym: Delorme) und Puskkin sowie aus der spanischen Literatur verwandt. 
b) ins Französische Lyrische Dichtungen:

Žukov skij (1); Puškin (1); Benediktov (1); Jazykov (1); Chomjakov (1).

2. Aus dem Deutschen

a) ins Russische

Lyrische Dichtungen:

J. Hammer (3); Freiligrath (2); Heine (1); Rlickert (1); Chamisso (1);

E. Schulze (1); Anonymus (1).

Dramatische Dichtungen:

Schiller (2).

b) ins Französische

Lyr ische Dichtungen:

Goethe (2); Ruckert (1); Schiller (1).

Dramatische Dichtungen:

Schiller (1); Grillparzer (1).

3. Aus dem Englischen

a) ins Russische

Lyrische Dichtungen:

Scott (7); Byron (4); Moore (1); Campbell (1); Anonymus (1).

b) ins Französische

Lyrische Dichtungen:

Moore (2); Scott (2); Campbell (1).

4. Aus dem Polnischen

a) ins Französische

Lyrische Dichtungen:

Mickiewicz (3); A. Chodzko (1).

b) ins Deutsche

Lyrische Dichtungen:

Mickiewicz (2). 
c) ins Russische

Lyrische Dichtung:

A. Chodzko (1).

5. Aus dem Französischen

ins $R$ ussische

Lyrische Dichtungen:

V. Hugo (1); A. Chénier (1).

Dramatische Dichtung:

Molière (1).

6. Aus dem Griechischen ins $R$ ussische

Dramatische Dichtung:

Aischylos (1).

7. Aus dem It alienischen ins Französische

Lyrische Dichtungen:

Dante (2); Petrarca (2).

8. Aus dem $D a ̈ n i s c h e n$ ins $R$ ussische

Dramatische Dichtung:

A. G. Oehlenschläger (1). 


\section{Lyrik}

Das Über setzungswerk Karol ina Pavlovas zeigt einen dem originalen Schaffen vergleichbaren Reichtum der Inhalte und Formen. Auch hier uberwiegt das Lyrische, auch hier sind alle Gedichtarten vertreten, sind die formalen Möglichkeiten weitgehend ausgeschöpt worden. Die Skala der Themen und Stoffe ist noch breiter und kaum uberschaubar.

Da sich die Qualität eines Über setzers besonders am Lyrischen er weist, stehen im Mittelpunkt des folgenden Abschnitts die Gedichtübertragungen und zwar ausschließlich aus dem Russischen ins Deutsche und aus dem Deutschen ins Russische. Bevorzugt werden die Arbeiten bis dahin in Deutschland beziehungsweise in Rußland unbekannter Dichter; die anderen Über setzungen sollen nur am Rande behandelt werden ${ }^{313}$, da sie in ihrer

K. Pavlova ist als Ubersetzer in mehrfach gewürdigt worden. Zu den folgenden Übertragungen liegen Besprechungen vor:

Puskkin:

"Prorok" - Tschizewskij und Gerhardt, Deutsche Puškin-Uber setzungen..., S. $44 \mathrm{f}$.

Scobel, Karolina von Jaenisch. .., S. 30 f.

Zastrow, Puschkin-Gedichte..., Seitenangabe nicht möglich, da die Arbeit nach formalen Kriterien, nicht nach Titeln gegliedert ist.

"Ty i vy" - Tschizewskij und Gerhardt, ib., S. 45. Scobel, ib., S. 31.

"Pesnja" (Kogda vzojdet...) - Tschižewskij und Gerhardt, ib., S. 45. Scobel, ib., S. 32.

"Cerkesskaja pesnja" - TschiŽewskij und Gerhardt, ib., S. 45. Scobel, ib., S. 31.

"Écho" - Tschiźewskij und Gerhardt, ib. , S. 46.

Scobel, ib., S. 32.

"K..." (Ja pomnju cudnoe...) - Zastrow, ib.

aus "Boris Godunov" - Scobel, ib., S. 27.

"Metel'" - Scobel, ib., S. $34 \mathrm{ff}$.

Scott:

aus "The Lay of the Last Minstrel" - F.W. Neumann, Geschichte der russischen Ballade, S. 184.

"Nora's vow" - ib., S. 199.

(Forts. S. 150) 
Mehrzahl lediglich bereits vorhandene Kenntnisse von den jewelligen Autoren ergänzten. Damit wird weder die Berechtigung noch der Wert dieser Übersetzungen in Frage gestellt. Diese Beschränkung hinsichtlich der Sprachen, Autoren und Werke ist nicht frei von einer gewissen Willkir, aber meines Erachtens insofern statthaft, als mehr Beispiele nicht mehr Charakteristika der Ubersetzungskunst Karolina Pavlovas zutage fördern würden.

Im Vorwort zum "Nordlicht" schreibt K. Jaenisch: "Ich schmeichle mir, ...daß ich in keinem (Gedicht) mich auch nur im geringsten von den Originalen entfernte, und daß keines sein Kolor it und seinen eigenthümlichen Charakter in der Ubersetzung eingebüßt hat" ${ }^{314}$. Mag diese Behauptung auch etwas übertrieben sein, so war die Pavlova zweifellos die korrekteste thersetzerin ihrer Zeit. Hervorzuheben ist, daß thr Bemühen um weitgehende Anschmiegung an die Vorlage nur selten deren poetische Schönheit beeintrăchtigte.

Der Unter schied zwischen freier Nachdichtung und getreuer Übertragung kann an folgendem Kuriosum verdeutlicht werden. In das "Nordlicht" nahm Karolina Jaenisch thre deutsche Fassung eines vermeintlichen Originalgedichts von Zukov skij auf: "Voskresnoe utro v derevne" - "Der Sonntagmorgen im Dorfe" 315. Tatsăchlich handelt es sich bei der Vorlage um die Ubersetzung des Gedichts "Sonntagsfrühe" von Johann Peter Hebel (1760-1826), in alemannischer Mundart geschrieben. Zum Vergleich werden hier die jeweils ersten Verse des Originals, der Übersetzung und der Rückibersetzung angeführt:

\footnotetext{
"Jock of Hazeldean" - ib. , S. 198. aus "Rokeby" - ib., S. 200.
}

Schmidt:

"Des Fremdlings Abendlied" - Gerhardt, Zu den russischen Über setzungen. .., S. 315-318.

Anonymus:

"Ballada" - F.W. Neumann, Geschichte der russischen Ballade, S. 221.

"Edward" - Gerhardt, Zu den russischen Über setzungen. .., s. 307-314.

314 Vorwort zum "Nordlicht", S. XI.

315 Diesen Irrtum haben Boehme und Luther aufgedeckt; vgl.: Frühe deutsche Über setzungen... I ; in: Die neue Gesellschaft, 1948, H. 5/6, S. 38. 


\section{Hebel}

Der Samstig het zum Sunntig gseit:

"Jez hani alli schlofe gleit;

Si sin vom Schaffe her und hi

Gar sölli muled und schlofrig gsi,

Und 's goht mer schier gar selber so,

I cha fast uf ke Bei me stoh." 316

\section{Żukov skij}

"Slusaj, družok! (govorit Voskresen'ju Subbota) derevnja

Vsja uź zasnula davno; v okrestnosti vse uź pokojno;

Vremja i mne na pokoj: menja odolela dremota;

Polnoc' blizko!. ." I tol'ko uspela Subbota promolvit': 317

\section{Pavlova}

"Höre, Freund! (spricht zum Sonntag der Sonnabend) längst schon entschlafen

Ist das ganze Dorf, und umher ist alles schon ruhig; Ruhen muß ich nun auch, der Schlummer erfaßt mich, es nahet Mitternacht bald" - und kaum hatte der Sonnabend Zeit, es zu sprechen: 318

Zukov skij verzichtet auf eine Stropheneintellung und gibt den Inhalt der elf sechszeiligen Strophen sehr frei in 43 Hexametern wieder. Karolina Pavlova braucht für die Rückubertragung zwar fünf Verse mehr, aber nur, um einige gedrängtere syntaktische Konstruktionen des Russischen aufzulösen. Im übrigen übersetzt sie fast wörtlich, wie das Beispiel zeigt; selbst die Mängel - so z. B. die für eine Dichtung in Hexametern zahlreichen Zeilensprünge - wurden übernommen.

Die folgenden vier Übersetzungen russischer Gedichte zeichnen sich ebenfalls durch hohe Originaltreue aus; Versmaß, Reimschema, Kadenzen und Strophenbau entsprechen völlig der Vorlage.

316 J. P. Hebel, "Sonntagsfrühe"; in: Alemannische Gedichte, S. $79 \mathrm{f}$. 317 V.A. Žukovskij, "Voskresnoe utro v derevne"; in: Polnoe sobranie socinenij, Bd. 3, S. 88.

K. Jaenisch, "Der Sonntagmorgen im Dorfe"; in: Das Nordlicht, S. 15 . 
Die strenge Komposition des Gedichts "Pesnja" von B a r a t y n 8 k i j 319 das im Jahre 1827 entstanden war, bereitet der Übertragung einige Schwierigkeiten. Die zweite Halfte der achtzeiligen Strophen hat formal Refraincharakter. Die Verse 5 und 7 sind durchweg durch das Reimpaar "sladost": radost'" gebunden; die Verse 6 und 8 sind klangidentisch: "tvoej : v nej" (1. und 2. Strophe), "moej : ej" (3. und 4. Strophe). Der Gleichklang verschleiert, daß aus der Ungewißheit (1. und 2. Strophe) Gewitheit geworden ist (3. und 4. Strophe). Frage und Antwort stehen sich nicht kraß gegenüber, sondern gehen durch diesen Kunstgriff ine inander über. Karolina Pavlova hat mit großem Geschick versucht, diese Frage und Antwort verschmelzende Form belzubehaiten. Sie hat die 7. Ver se so ubersetzt, daß "Entzücken" durchweg am Zellenende steht; in den 5. Versen wechselt der Ausdruck. Diese Abweichung von der Vorlage wird dadurch ausgeglichen, daß ihr in den Zellen 6 und 8 die durchgangige Reimbindung "mir : ihr" gelungen ist.

In seinem Auf satz zu einigen tbertragungen Karol ina Pavlovas spricht D. Gerhardt von der "maßigenden Technik", die ihr Uber setzungswerk auszeichne ${ }^{320}$. In der Tat ist die Tendenz, starke Worter durch schwächere wieder zugeben, starke Spannungen zu muldern, fast in jeder Arbeit feststellbar. Zum Beispiel verzichtet die Pavlova auf die Inversionen in den Versen 6 bis 8 der er sten zwei Strophen. Durch den völligen Verzicht auf den dramatischen Eingang der 3. Strophe - Baratynskij: "Strada ja!" - und die Abschwăchung des russischen "protiven" zu "trüb" verliert diese Strophe erheblich an Leidenschaftlichkeit.

Zum Schluß sei noch auf einige stilistische Unebenheiten hingewiesen, die jedoch die Qualităt der Übersetzung nicht wesentlich mindern:die Wortfolge in Vers 1 der 1. Strophe sowie in Vers 7 der 4. Strophe entspricht eher den Regeln der russischen als der deutschen Syntax:

319

E.A. Baratynskij, "Pesnja" (1827); in: Polnce sobranie stichotvorenij, S. $125 f$.

320 D. Gerhardt, Zu den russischen Utber setzungen der Karolina Pavlova; in: Ztschr. f. slav. Phill., 1939, S. 312. 
Wenn sich die Sonne golden hebt und glühend,...

Was einst der Seele Lust gab und Entzücken, ...

Obgleich auch in der tbersetzung einer Elegie von Venevit 1nov 321 manches farbigere Wort des Originals durch ein blasseres wiedergegeben, mancher intensivere Ausdruck im Deutschen geschwăcht wird, kann man auch diese Übersetzung kongenial nennen. Karolina Pavlova übersetzt zum Beispiel "upilasja" mit "du trankst", "mertvit" mit "verzehrt", sie wăhlt für den Vers "I ètot ogn' tomitel'nyj, mjateznoj" den matteren Ausdruck "Doch diese Glut ist düster und voll Qualen". Die Steigerungen durch Wiederholungen von Wörtern oder Wortgruppen übernimmt sie nicht:

Na cvet nebes ty dolgo nagljadelas'

I cvet nebes $\mathrm{v}$ ocach nam prinesla.

Des Himmels Blau, zu dem dein Blick sich wandte, Hast du in deinen Augen uns gebracht;

Ebenso fehlt die Wiedergabe des doppelten "ogn"" der Vorlage (Vers 12 und 13).

Sehr geschickt ist dagegen Vers 15 übertragen:

Net! on i zzet, i mucit, i mertvit,...

Nein, nein! sie sengt, sie martert, sie verzehrt;...

Die stark bindende und steigernde Wirkung des "i..i... i" erreicht die Übersetzerin durch das doppelte "nein" und die konjunktionslose Reihung der Verben.

Das komplizierte Reimschema der Vorlage wird von Karolina Pavlova verändert:

$$
\begin{aligned}
& \text { V.: a b a bcddcefefgghihijkjk } \\
& \text { P.: a b b a cdcdefefgghhijjikllk }
\end{aligned}
$$

Die Beschwerung der Verse 15/16, 18/19 und 22/23 durch zusătzliche Paarreime ist unerheblich. Die Ausdehnung von 22 auf 24 Verse geht auf Kosten

D. V. Venevitinov, "Élegija" (1826); in: Polnoe sobranie socinenij, S. 90 .

Über setzung: "Elegie"; in: Das Nordlicht, S. 92. 
der Prägnanz:

(14) On ne gor it ljubor'ju tichoj, neźnoj, -

(14) Nicht kann sie still und mild erwärmend strahlen,

(15) Von einer zarten Liebe sanft verklärt;

(17) To stichnet vdrug, to burno zakipit,

(18) Zuweilen scheinet plotzlich sie gestillt,

(19) Und lodert dann auf's neue heiß und wild,...

Derartige Dehnungen sind oft die Folge eines interpretierenden Eingr iff s; die Uber setzer in will sich manchmal deutlicher ausdrücken als der Dichter.

Das Gedicht "Kon'" von Jaz y k ov ${ }^{322}$ aus dem Jahre 1831 gewinnt seinen besonderen Reiz aus dem unmittelbaren sprachlichen Nachvollzug der Bewegung des Pferdes. Die rhythmische tberspielung des vierhebigen Trochăus und das kunstvolle Spiel mit Vokalen und Konsonanten stellen den Ubersetzer vor eine schwierige Aufgabe. Es liegt nahe, eine solche Vorlage in einer freien Nachdichtung wiederzugeben. Vokalbögen, Assonanzen, Alliterationen können in einer eng an das Original angelehnten Übertragung. nur schwer nachgeahmt werden. Karolina Pavlova hat versucht, der Vorla ge möglichst dicht zu folgen und zugleich den klanglichen Zauber auch in der deutschen Fassung zu erhalten.

Versmaß und Reimschema sind auch hier beibehalten worden, ebenso der Wechsel von zwölf - und sechszeiligen Strophen, der den 'Rösselsprung' auf den ersten Blick erkennen läßt.

Der über Vers 3 und 4 gespannte Satz

Sizyj par kipit i pyset

Iz pylajuscich nozdrej.

wird von der Pavlova so wiedergegeben:

Aus den heißen Nüstern hebet

Dampfend sich der blaue Duft.

Von der Lautmalerei Jazykovs, die das Schnauben durch die Häufung der gestoßenen p- und der hellen 1-Laute vorzügdich nachahmt, ist in den ent-

N. M. Jazykov, "Kon'" (1831); in: Polnoe sobranie stichotvorenij, S. $313 f$.

Über setzung: "Das Roß"; in: Das Nordlicht, S. 188-190. 
sprechenden Versen der Über setzung nur noch ein schwacher Nachklang in den Konsonanten b, $d, p f$, bewahrt. Uberhaupt fehlt der deutschen Fassung die Lebhaftigkeit; es fehlen der plotzliche Tempuswechsel (z. B. in den Versen 8 und 9: ... poskakal! / Skacet. . . - Sprengt's. . . / Sprengt) und die Fragen der zweiten Strophe. Die Ellipsen "Skoro, skoro pod zamok!" oder "Snova v delo, kon' retivyj" sind in Sătze aufgelöst worden.

Die tiber setzung verliert auch durch die relativ große Zahl sprachlicher Ungeschicklichkeiten und unreiner Reimbindungen. Verunglückt ist zum Beispiel die Wiedergabe der Wendung "potok klubitsja" durch "Rollt der Regenstrom vorüber" oder "Strojno-vernymi sagami" durch "Stattlich, wie es sich gebuihret". Die Reimbindungen "Freude : Heide", "an ihm : ungestüm", "schön : geh'n", "Überfluß : Fuß" wirken bei relativer Hăufigkeit störend.

Die Übersetzung der folgenden Romanze von $\mathrm{Del}^{\prime} \mathrm{v}^{\mathrm{ig}}{ }^{323}$ zeigt, daß Karolina Pavlova auch mit einer Langzeile umzugehen weiß. Allerdings sind die deutschen Verse etwas zu glatt geraten; in thnen fehlen einige retardierende Elemente der Vorlage. Der Lauf der Worter wird bei Del'vig durch einige vom Versmaß erzwungene Pausen aufgehalten:

$\times \times \times \times \times 8 \times \times \times \times 8 \times$.

Karolina Pavlova begnügt sich mit einer Klimax im Vers (mit Ausnahme der 3. Zeile), verlegt einen zweiten Gipfel ans Zeilenende, indem sie die durchweg weiblichen Kadenzen des Originals in männliche umwandelt:

×x $8 \times 8 \times 8 \times \times 8 \times 8$.

Der Rhythmus der deutschen Fassung ist schwächer, die Aufgipfelung in der Mitte und am Ende des Verses hat eine stark trennende Wirkung, während die asymmetrische Akzentsetzung des Originals den Redefluß mehr zusammenhălt. Die Zusammenfassung zweier zweizeiliger Strophen zu einem Vierzeller kann als Versuch der Übersetzerin angesehen werden, dem Auseinanderfallen der Verse entgegenzuwirken.

A. A. Del'vig, "Romans" (1821 oder 1822); in: Polnoe sobranie stichotvorenij, S. 160.

Über setzung: "Romanze"; in: Das Nordlicht, S. $200 \mathrm{f}$. 
Die Anklănge an die Volksdichtung gibt Karolina Pavlova nur ungenügend wieder:

Kon' moj, kon', vernyj kon', ...

... treues RoB ...

V mulyj kraj, strašnyj kraj kak strela pustilsja.

Flog der Ritterjüngling hin wie ein rascher Pfeil. Dagegen hat die Übersetzer in in die 3. Zeile durch die Formel "Gras so grün" einen volksliedhaften Ton gebracht:

Svezich trav ne scipal kon' ego unylyj,

Unberührt ließ sein Roß stehn das Gras so grün.

Für die auffallige Milderung des Ausdrucks noch ein Beispiel:

... sil'nej vitjaz' vozmutilsja,

... in banger Eil ${ }^{\circ} \ldots$ der Ritterjüngling ...

Ausgesprochen verunglückt ist die Wiedergabe der Wendung "Ne $k$ dobru. ." am Anfang der 5., 6. und 7. Zeile durch dreifaches "Nicht vergebens.."!

Mehr als drei Jahrzehnte nach dem Erscheinen des "Nordlichts" brachte Karolina Pavlova ein Băndchen mit Gedichten Aleksej Tol st oj s heraus, die sie ins Deutsche übertragen hatte ${ }^{324}$. Die großen Vorzüge und kleinen Mängel ihrer Übersetzungskunst sind im Grunde dieselben geblieben, wie das folgende Beispiel zeigt:

Ne ver ${ }^{\circ}$ me, drug, kogda, $v$ izbytke gorja,

Ja govorju, cto razljubil tebja,

V otliva cas ne ver ${ }^{\prime}$ izmene morja,

Ono k zemle vorotitsja, ljubja.

Už ja toskuju, preźnej strasti polnyj,

Moju svobodu vnov' tebe otdam,

I uź begut $s$ obratnym sumom volny

Izdaleka $k$ ljubimym beregam! 325

Zwölf Gedichte von Alexis Grafen Tolstoy. Aus dem Russischen uber setzt im Versmaß des Originals von Caroline von Pawloff. Dresden 1868.

A.K. Tolstoj, "Ne ver' mne, drug, kogda. ." (1856); in: Sobranie socinenij, Bd. 1, S. 119. 
Glaub Du mir nicht, wenn Du aus meinem Munde

Das Wort vernimmst: Ich liebe Dich nicht mehr! -

Dem Flieh'n der See in ihrer Ebbestunde,

Glaub nimmer Du; harr' ihrer Wiederkehr.

Schon schwillt das Herz in Lieb= und Schmerzensgluthen,

Ich fuhle mich auf's neu an Dich gebannt; -

Und brausend rollen die entwich'nen Fluten

Zurücke schon zu dem geliebten Strand. 326

Das zögernde Tropfen der Worte in den ersten beiden Versen des Originals verwandelt sich in einen glatteren Redefluß; ringt sich dort der Sprecher jedes Wort mühsam ab, so gehen inm hier die Worte sehr viel leichter über die Lippen; der Wegfall der Wendung "v izbytke gorja" ist insofern folgerichtig. Die Metapher des 3. und 4. Verses der 1. Strophe ist in der Vorlage dichter.

Die bisher besprochenen Ubersetzungen verraten eine hervorragende Kenntnis des Deutschen. Aber die 'Raffinesse' der Wortwahl,wie sie in einigen russischen Gedichten Karolina Pavlovas anzutreffen ist, sucht man in den Übertragungen ebenso vergeblich wie auch in ihren deutschen Originalgedichten. Der 1. Vers der 2. Strophe der Tol stoj-Übertragung "Schon schwill das Herz in Lieb= und Schmerzensgluthen" ist nicht nur metaphorisch verunglückt; ein Wort wie 'Liebgluthen' ist schlecht erfunden. Auch für "izdaleka" hătte sich gewiß eine bessere Entsprechung als "zurücke" finden lassen.

Daß Karolina Pavlova mit der russischen Sprache letztlich doch vertrauter war als mit der deutschen, zeigen auch die Über setzungen deutscher Literatur ins Russische. Zum Beispiel hat die Übertragung des Gedichts "Der Biwak" von Freiligrath ${ }^{327}$ einige Unebenheiten der Vorlage ausgeglichen. So stehen den zahlreichen kontrahierten Formen (Feu'r, ruh'nd, sand ${ }^{\prime}-$

326 Über setzung: "Glaub Du mir nicht,..."; in: Zwölf Gedichte... (vgl. Anm. 324), S. 10.

327 F. Freiligrath, "Der Biwak" (vor 1838); in: Samtliche Werke, Bd. 1, S. 65-67.

Über setzung: "Bivak"; in: K. Pavlova 1964, S. $400 \mathrm{f}$. 
gem, blut'ger, glüh'nde) keine vergleichbaren Mängel in der Über setzung gegenüber. Auch hat die Pavlova tadellos gereimt, wăhrend Freiligrath manche Reimbindung gewaltsam herbeiführt (Beispiele: Verhack : -bivouac, Lafette : Muskete, Meder : Răder, gărt : Schwert, tausendkehlig : măhlig).

Den Mar schrhythmus des hier verwendeten dreihebigen Jambus, unter stützt durch die harten Verschlußlaute $p, t, k$ hat Karolina Pavlova durch die reichliche Verwendung der Konsonanten $c h, k, t$ ausgezeichnet nachgeahmt.

Die leichten Verănderungen und Ergănzungen überspielen manche Schwăche der Vorlage, zum Beispiel:

(13) Sie wehn um eine Stirne,

In der es kocht und gärt.

Der Held, als ob er zürne,

Tief atmend făhrt ans Schwert.

Pred burnoj golovoju

Nesetsja divnyj stroj,

Serditoju rukoju

Schvatil svoj mec geroj.

oder:

(15) Es jauchzt thm tausendkehlig

Der gluh'nde Orient;

Derweil die Flamme măhlig

Verglimmend niederbrennt.

I każdogo uź kraja

Sud'ba v ego ruke,

A plamja, dorogaja,

Dymitsja na peske.

Karolina Pavlova hat als erste das berühmte Gedicht "Lorelei" des in Rußland sehr geschätzten Heinrich $\mathrm{He}$ in $\mathrm{e}^{328}$ ins Russische ubersetzt. Diese Übertragung ist eines der wenigen Beispiele für eine verhảltnismăBig große Entfernung von der Vorlage. Die Pavlova hat die auch im Russischen gut nachzuahmende dreihebige Volksliedstrophe nicht beibehalten;

H. Heine, "Ich weiß nicht, was soll es bedeuten" (1823); in: Sămtliche Werke, Bd. 1, S. 106.

Über setzung: "Loreleja"; in: K. Pavlova 1964, S. 399. 
die vierhebigen Trochăen erschienen ihr offenbar dem balladischen Inhalt angemessener. Das Original ist leichter, liedhafter; die Über setze$r$ in nimmt das Märchen fast ein wenig zu ernst. Die ersten Verse der russischen Fassung sind sehr viel schwerer durch den doppelten Vokalbogen i-o-u-a und die Reihung der beinahe synonymen Gerundien "gorjuja" und "toskuja". Derartige intensitătssteigernde Wiederholungen sind ja besonders charakteristisch für die russische Volksdichtung. Es spricht für das hervorragende Gespür Karolina Pavlovas für poetische Feinheiten, daß sie auch die Stilmittel überträgt.

(3)

Ihr goldnes Geschmeide blitzet, Sie kămmt ihr goldenes Haar.

(4) Sie kämmt es mit goldenem Kamme Und singt ein Lied dabei; Das hat eine wundersame, Gewaltige Melodei.
…..
Ceset kosu zolotuju, Ceset grebnem zolotym.
Ceset kosu zolotuju I poet pri bleske vod Pesnju, slovno nezemnuju, Pesnju divnuju poet.

Diese sechs Verse übertreffen an Dichte die Vorlage. Mit den ersten drei Versen dieses Auszugs gerät die Übersetzerin hart an die Grenze der Übertreibung. Der Chiasmus der anschließenden drei Zeilen im Verein mit der p-Alliteration wirkt unmittelbar beschwörend; die Pavlova betreibt eine gewisse Wortmagie. Es gibt sicher getreuere Übertragungen, aber nur wenige, die solch eine innige Aneignung durchscheinen lassen.

Die Lyrik fordert den Übersetzer am stärksten. Die Übertragung anderer poetischer Grundformen erfordert im allgemeinen nicht ein solch hohes Maß an gleichzeitiger Rücksichtnahme auf Inhalt und Form. Die Auswahl der sprachlichen und stilistischen Mittel ist wesentlich größer. 


\section{Dramatik}

Es ist er staunlich, daß Karolina Pavlova die 'leichtere' Aufgabe, Episches und Dramatisches zu über setzen, nicht so gut gelang. Diese Übersetzungen leiden vor allem darunter, daß die Pavlova den Unterschieden der jeweiligen Syntax nicht hinreichend Rechnung getragen hat. Den im Vergleich zu einem lyrischen Stück meist komplizierteren Satzbau eines Prosatextes wußte sie manchmal nicht den Stilregeln der anderen Sprache anzupassen.

In einer Analyse der Übertragung von Puskins "Metel" bemängelt G. Scobel vor allem, daß die zahlreichen Partizipialkonstruktionen fast immer wörtlich übernommen worden seien, daß die Wiedergabe der Aktionsarten und Aspekte oft mißglückt sei ${ }^{329}$.

Auch die Dramenubersetzungen verletzen manchmal das Stilempfinden. Aber man verspirt in den deutschen Fassungen der TolstojDramen mehr Vertrautheit mit der Sprache. In den sechziger Jahren unterlaufen Karolina Pavlova bei der Wiedergabe der russischen Verben zum Beispiel nur noch selten Fehler. Dagegen begegnen auch hier noch allzu hăufig unaufgelöste Partizipien und Gerundien, wie der folgende Auszug aus "Smert' Ioanna Groznogo" (I. Akt, 2. Szene) zeigt:

Von fruher Jugend auf die Ruh nicht kennend, Im Felde bald, umsaust von Feindesspeeren, Der Heiden Schaar besiegend, bald daheim

Bekămpfend Meutereien und Verrath, Seh' ich, rückblickend, eine lange Reihe Schlafloser Năchte nur und stürm'scher Tage! - 330

329

Das Bemühen um möglichst wörtliche Wiedergabe habe häufig eine grobe Verletzung des deutschen Stils zur Folge. Vgl. G. Scobel, Karoline von Jaenisch und die russische Literatur, S. $34 \mathrm{ff}$.

A.K. Tolstoj, "Smert' Ioanna Groznogo"; in: Sobranie socinenij, Bd. 2, S. $121-260$, hier S. 143.

Über setzung: hier zitiert nach dem Vorabdruck "Der Tod Iwan's des Schrecklichen"; in: Russische Revue, Bd. 2, 1863, S. 347382 , hier S. 368. 
In diesen späten Übersetzungen geht Karolina Pavlova mit der Vorlage recht großzügig um; aber die Straffungen und Dehnungen entstellen die Aussage nicht.

Den fünfhebigen Blankvers handhabt sie im Deutschen zwar so flüssig wie im Russischen; aber die Übertragung eines Abschnitts aus Schille r 8 "Demetrius" - Fragment bestătigt den Eindruck, daß die Über setzungen ins Russische an sprachlicher Schönheit vergleichbare gegenläufige übertreffen.

Die folgende Rede der Marfa aus der 1. Szene des 2. Aufzugs kann besser wohl kaum übertragen werden. Jede Wendung, jede Stilfigur, jede Sinnbeschwerung findet eine kongeniale Entsprechung.

Ich hab um inn getrauert sechzehn Jahr, Doch seine Asche sah ich nie. Ich glaubte

Der allgemeinen Stimme seinen Tod

Und meine mSchmerz. Der allgemeinen Stimme

Und meiner Hoffnung glaub ich jetzt sein Leben.

Es wäre ruchlos, mit verwegnem $Z$ weifel

Der höchsten Allmacht Grenzen setzen wollen.

Doch war er auch nicht meines Herzens Sohn,

Er soll der Sohn doch meiner Rache sein:

Ich nehm inn an und auf an Kindes Statt,

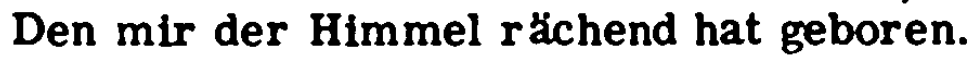
331

Sestnadcat' let o nem lila ja slezy,

No grob ego ja ne otkryla. Glasu

Vseobšcemu i gorju moemu

Ja verila; vseobscemu ze glasu

$\mathrm{Ja}$ verju nyne $i$ moej nadezde.

Prestupno bylo by, somnen'em derzkim

Postavit' gran' nepostizimoj vlasti.

No serdca moego ne bud' on synom, -

On budet synom mscen'ja moego!

Ego otsel usynovljaju ja,

Rozdennogo mne pravosudny m nebom.

331 F. Schiller, "Demetrius"; in: Sămtliche Werke, Bd. 3, S. 9-51, hier S. 45.

332 Über setzung: "Scena iz poslednej neokoncennoj tragedii Ṡlllera "Dmitrij Samozvanec" "; in: K. Pavlova 1964, S. 381 -387, hier S. $386 \mathrm{f}$.

Der Übersetzerin lag offensichtlich eine komplettierte deutsche Fassung vor. 
Es ist bedauerlich, daß Karolina Pavlova hăufig nur Bruchstücke übersetzt hat. Betrachtet man ihr Uber setzungswerk als Ganzes, dann ist - bei aller Qualităt der einzelnen Ubertragungen - sein Hauptmangel die Zuf ălligheit, das Sich-Verlieren in der Vielzahl der Sprachen, Autoren und Werke. 


\section{ZUSAMMENFASSUNG}

Es scheint mir wenig sinnvoll zu sein, am Schluß dieser Arbeit den Versuch zu unternehmen, den Platz Karolina Pavlovas in der russischen Literaturgeschichte des 19. Jahrhunderts neu zu bestimmen. Wie in der Einleitung vermutet, entzieht sich die Dichterin einer Einstufung auf Grund einer summarischen Bewertung. Daß sie die bedeutendste Dichter in ihrer Zeit war, besagt nicht viel; der Dichter war auch in ihrem Ver ständnis ein Wesen sui generis. Kaum eine Zeile in threm Werk, die nicht auch von einem Mann hätte geschrieben werden können; kaum ein Thema, das spezifisch 'weiblich' wäre. Allenfalls von einigen Übersetzungen könnte man sagen, daß die Vorlage durch ein weibliches Temperament gesehen worden ist; allenfalls in "Dvojnaja zizn" ist das Anliegen der Frauenemanzipation zu verspüren.

Karolina Pavlova hat einige Gedichte geschrieben, die in eine Reihe mit den besten Schöpfungen der russischen Literatur gehören. Daß thr Werk als Ganzes sie in der Rangfolge dann doch wieder zurückstuft, ist weniger der einen oder anderen mittelmăßigen Arbeit zuzuschreiben als vielmehr dem Mangel an Geschlossenheit, an Konzentration des poetischen Vermögens. Karolina Pavlova hat sich in zu vielem versucht, statt sich auf die Bereiche zu beschränken, in denen sie ihr Bestes geben konnte, die sie dann tiefer hätte ausloten können. Das Originalwerk, so wie es ist, mehrt das Puskin-Erbe nicht, verlängert den Nachklang der Romantik bis in eine Zeit, die ihn nicht mehr hören wollte.

In einer Geschichte der russischen Über setzer năhme die Pavlova einen hervorragenden Platz ein. Ihre Übertragungen sind zum größten Teil auch heute noch lesenswert und halten dem Vergleich mit späteren stand. So bewußte Literaturvermittlung wie im "Nordlicht" und in den TolstojÜbersetzungen wurde jedoch mit der großen Zahl der anderen Übertragungen nicht geleistet. 
Der Vorwurf einer gewissen Ziellosigkeit trifft Karolina Pavlova als Mensch, als Dichterin und als Übersetzerin. Aber man muß ihr zugute halten, daß sie in einer Zeit der Übergănge lebte und wirkte, in einer Zeit, in der alte Orientierungslinien ungültig wurden und neue noch nicht gesichert waren, in der es schwer war, sich zu behaupten und einen eigenen Weg zu finden.

In seinem Auf satz "Karolina Jaenisch (Pavlova) and Adam Mickiewicz" (The Polish Review, Vol. XIV, No. 3, Summer 1969, S. 68-78) gibt Munir Sendich an, daß seine Studie "The Life and Works of Karolina Pavlova" bereits im Oktober 1968 als Dissertation von der Graduate School of Arts and Science, New York Univer sity angenommen worden sei. Meine mehrfachen Bemühungen, sie schon vor der Veröffentlichung einzusehen, sind leider erfolglos geblieben. Ich hoffe jedoch, nach Erscheinen des Buches zu Sendichs Ergebnissen in toto Stellung nehmen zu können.

In dem kurz vor der Drucklegung erschienenen Auf satz von Anthony D. Briggs "'Twofold Life': a Mirror of Karolina Pavlova's Shortcomings and Achievement" (The Slavonic and East European Review, Vol. XLIX, No. 114 - January 1971, S.1-17) kommt der Verfasser anhand der Besprechung vor allem des Poems "Dvojnaja żizn" zu Schlussen auf den Menschen und die Dichterin Karolina Pavlova, die sich weitgehend mit den hier erarbeiteten decken. Briggs beklagt ebenfalls die Diskrepanz zwischen formaler Meisterschaft und zuweilen kargem Inhalt und konstatiert den Mangel an einer klaren Linie und das Fehlen einer gewissen Selbstzucht. Er kreidet der Pavlova an, daß sie zu viel unverarbeitetes Leben in ihr Werk habe fließen lassen. Auch er bemerkt, daß die Vielfalt letztlich die Schwäche der Pavlova gewesen sei. Sein Fazit: ". sie war unfähig, ihr eigenes Talent zu beherrschen oder ihm zu gestatten, sie zu beherrschen" (ib., S. 2). 


\section{LITERATURVERZEICHNIS}

\section{Primărliteratur}

(Weröffentlichungen der Werke chronologisch, Briefe alphabetisch nach Adressiaten, Über setzungen alphabetisch nach Verfassern der Vorlagen geordnet)

\section{Gesammelte Werke}

Das Nordlicht. Proben der neueren russischen Litteratur von Karoline von Jaenisch. Erste Lieferung. Dresden und Leipzig 1833.

Les préludes, par Mme Caroline Pavlof, née Jaenisch. Paris 1839.

Stichotvorenija K. Pavlovoj. Moskva 1863.

Zwölf Gedichte von Alexis Grafen Tolstoy. Aus dem Russischen ubersetzt im Versmaß des Originals von Caroline von Pawloff. Dresden 1868.

Sobranie socinenij. Redakcija i materialy dlja biografii K. Pavlovoj Valerija Brjusova. 2 Bde., Moskva 1915.

Polnoe sobranie stichotvorenij. Leningrad 1939.

Polnoe sobranie stichotvorenij. Moskva / Leningrad 1964.

\section{Separate Veröffentlichungen einzelner Werke}

Jeanne d'Arc, tragedie de Schiller, traduite en vers français, par Mme Caroline Pavlof, nee Jaenisch. Paris 1839.

Les pleurs des femmes. Romance. Paroles de madame Caroline Pavloff. Musique de Fr. List, dedié a madame Caroline Pavloff. Moskva 1844.

Dvojnaja zizn'. Ocerk K. Pavlovoj. Moskva 1848.

Razgovor v Kremle. Stichotvorenie K. Pavlovoj. S. -Peterburg 1854.

Der Tod Iwan's des Furchtbaren. Trauer spiel in fün Aufzügen von Alexis Grafen Tolstoy. Deutsch von Caroline von Pawloff. Dresden 1868.

Zar Fedor Iwanowitsch. Trauerspiel in fünf Auf zügen von Alexis Grafen Tolstoy. Aus dem Russischen über setzt von Caroline von Pawloff. - Den Bühnen gegenüber als Manuscript gedruckt. Dresden 1869. 
3. In Zeitschriften, Anthologien etc. erschienene und in keiner der vorgenannten Ausgaben enthaltene Werke

a) eigene Arbeiten

Sotlandskaja melodija (Pseudonym: "Magnol ia"); in: Otecestvennye zapiski, S. -Peterburg 1840, Bd. 9, S. 211.

Sil'sfil'd; in: Moskvitjanin, 1849, Bd. 2 (Febr.), Nr. 4, Abt. 2, S. $101-128$.

Das Nachtmahl Sever's; in: Russische Revue, St. Petersburg und Leipzig, Bd. 2, 1863, H. 6, S. 419-426.

Menschenklage; in: Julius Hammer (Hrsg.), Leben und Heimat in Gott. 13. Aufl. Leipzig (1896).

b) Briefe

an Berthold Auerbach (dtsch., Februar oder Mărz 1863); in: HansJürgen zum Winkel, Die Briefe russischer Dichter und Journalisten an Berthold Auerbach, Zeitschrift für slavische Philologie, 1963, Bd. XXXI, S. $135 \mathrm{f}$.

an Ottilie von Goethe (dtsch., 15./27.10.1829); in: R. Fischer P. Kirchner - R. Ziemann (Hr sgg.), Fahrten nach Weimar. Slavische Gäste bei Goethe. Weimar 1958, S. 79.

an Ol'ga Alekseevna Kireeva (russ./franz., 10./22.7.1860); in: Bor is Rapgof, K. Pavlova. Materialy dlja izucenija zizni i tvorcestva. Petrograd 1916, S. 73f. (Bellage zu dem Brief auf S. 76).

an Nikolaj Aleksandrovic Mel'gunov (russ., 18.5.1860); ib., S. 70. an Nikolaj Aleksandrovic $\mathrm{Mel}^{\circ}$ gunov (russ., 22.4.1860?); ib., S. 71-73. an Adam Mickiewicz (franz., 19.2./3.3.1829); in: Włady slaw Mickiewicz, Żywot Adama Mickiewicza. Poznan, Bd. 1, 1890, S. XLIV-XLV. an Adam Mickiewicz (dtsch., 5./17.4.1829); ib., Bd. 1, S. XLV-XLVI. an Włady glaw Mickiewicz (poln. Übers., 20.4.1890); ib. , Bd. 1, S. 269-273.

an Ivan Ivanovic Panaev (russ., 1854); in: Sovremennik, S. - Peterburg 1854, Bd. XLVIII, Nr. 11, S. 130-136.

an Sergej Aleksandrovic Racinskij (franz., 30.1./11.2.1859); in: Ju. N. Verchovskij, E. A. Boratynskij. Materialy k ego biografii. Petrograd 1916, S. 117.

an Sergej Aleksandrovic Racinskij (franz. 
an Stepan Petrovic Sevyrev (russ., 1853 ?); in: Boris Rapgof, K. Pavlova. Materialy dlja izucenija zizni i tvorcestva. Petrograd 1916, S. 68 f.

an Stepan Petrovic Sevyrev (franz., ohne Datum); ib., S. 69.

an Michail Matveevic Stasjulevic (russ., 11./23.6.1868); in: M. M. Stasjulevic i ego sovremenniki v ich perepiske. Pod redakciej M.K. Lemke. S. -Peterburg, Bd. 2, 1912 , S. 455.

an Unbekannt (russ. Übers., Orig. dtsch., 4.10.18? ?); in: Boris Rapgof, K. Pavlova. Mater ialy dlja izucenija żizni i tvorcestva. Petrograd 1916, S. 76f.

c) Über setzungen

aus Chomjakov

Sterne I und II (Zvezdy); in: Alexander Tschernow, Aus russischen Dichtern (Lyrisches, Episches, Dramatisches) in deutschen Übertragungen. Halle a.d. Saale o.J. (um 1893), S. 145.

Das Tagewerk (Truženik); in: Russische Revue, Bd. 1, St. Petersburg und Leipzig 1863, H. 2, S. 119 f.

Groß ist die That eines steten... (Podvig est' i v srazen'e...); ib., Bd. 3, 1864, H. 1 (Jan.), S. 244.

Unabsehbar, Wog' auf Wogen... (Siroka, neobozrima...); ib., S. $245 \mathrm{f}$.

aus Lermontov

Unbekümmert (aus "Demon"); in: Alexander Tschernow, Aus russischen Dichtern (Lyrisches, Episches, Dramatisches) in deutschen Übertragungen. Halle a.d. Saale o.J. (um 1893), S. 125.

Mein Vaterland (Rodina); ib., S. 126.

aus Mickiewicz

Baktschisarai (Bakczysaraj); in: Russische Revue, Bd. 3, Leipzig 1864 , H. 1 (Jan.), S. 423.

Die drei Söhne des Lithauers Budris (Trzech Budry sów). Ueber setzt von Karoline v. Pawl off im 81. Jahre ihres Lebens; in: Feuilleton der Deutschen Roman-Zeitung, Berlin 1890, Sp. 57.

aus Schiller

Smert' Vallenštejna. Tragedija v pjati dejstvijach. (Šillera); in:Vestnik Evropy, S. -Peterburg 1868, Bd. IV, Buch 7 (Juli), S. 5-120; Buch 8 (Aug.), S. 463-538. 
aus Oehlenschläger, Adam Gottlob

Garrik vo Francii (Orig. unbek.); in: Moskvitjanin, 1852, Teil I, Buch 2, Abt. I, S. 169-212.

aus Tolstoj, Aleksej Konstantinovic

Don Juan. Dramatisches Gedicht von Alexis Grafen Tolstoy. (Don Zuan); in: Russische Revue, Bd. 1, St. Petersburg und Leipzig 1863 , H. 3, S. 256-275.

\section{Volkslieder}

Brautwahl (Ueber'm Meere da hielt der Goldfink Haus. . Orig. unbek.); in: Johannes Scherr, Bildersaal der Weltliteratur, Stuttgart o.J. , Bd. 3, 10. Buch, S. 372 .

Der schwarze Rabe (O, du Ebene, weites Blachgefild!.., Orig. unbek.); ib. , S. 372 .

d) Über setzungen ihrer eigenen Werke

Im Türkis er strahlt der Himmel (Nebo blescet birjuzoju);

An Seele und an Leib gekettet (Ne raz v duse poznavsi smelo);

In ungestilltem Trauern ( $\mathrm{K}$ mogile toj zavetnoj);

Die Sphinx (Sfinks);

Das Tagewerk (Trud ezednevnyj, trud upornyj!);

in: Friedrich Fiedler (Hrsg.), Russische Dichterinnen. Ausgewählte Dichtungen übertragen und mit biographischen Notizen versehen.

Leipzig 0.J. (um 1907), S. 5-7.

Ans Verlorne, an das was geendet ( $O$ bylom, o pogibsem, o starom); Als Răcher kühn sich wider setzend (Kogda karatelem vel ikim); in: Dein Lächeln noch unbekannt gestern. Verse russischer Frauen. Übertragen und herausgegeben sowie mit einem Nachwort versehen von Johannes von Guenther. Heidelberg 1958, S. $7 \mathrm{f}$.

Die Werke der Pavlova werden durchweg nach der Ausgabe Moskva / Leningrad 1964 zitiert; bei Arbeiten, die darin nicht enthalten sind, wird jeweils die Erstveröffentlichung herangezogen.

Sekundărliteratur

(Aksakov, Ivan Sergeevic): Ivan Sergeevic Aksakov v ego pis'mach. 4 Bde. , Moskva 1888-1896.

Aksakov, Konstantin Sergeevic: Pis'mo G.S. i I. S. Aksakovym; in: Literaturnoe nasledstvo, Moskva 1952, Bd. 58, S. 564.

Aksakov, Sergej Timofeevič: Istorija moego znakomstva s Gogolem. Moskva 1960. 
--- Sobranie socinenij. 4 Bde., Moskva 1955-1956.

A k s a kova, V. Sergeevna: Briefe; in: Literaturnoe nasledstvo, Moskva 1952, Bd. 58, S. 576 ff. (passim).

(Annenkov, Pavel Vasil'evic): P.V. Annenkov i ego druz'ja. Literaturnye vospominanija i perepiska 1835-1885 godov. S. -Peterburg 1892.

A r onson, M. und S. Rejser: Literaturnye kruzki 1 salony. Leningrad 1929. Arseniew, Nicolas von: Die russische Literatur der Neuzeit und Gegenwart in thren geistigen Zusammenhängen. Mainz 1929.

A suk in, Nikolaj: Karolina Pavlova; in: Put', 0. O. 1914, Nr. 1, S. 29-37. (A uerbach, Berthold): Berthold Auerbachs Briefe an Wilhelm Wolfsohn; in: Nord und Sud, Breslau 1887, Bd. 42, H. 125 (Aug.), S. 288-298; H. 126 (Sept.), S. 419-436.

Baratynskij, Evgenij Abramovic: Polnoe sobranie socinenij v dvuch tomach. S. - Peterburg 1894.

Bar suk ov, Nikolaj: Żizn' i trudy M. P. Pogodina. 22 Bde., S. -Peterburg 1888-1910.

Bartenev, Petr: Avdot'ja Petrovna Elagina; in: Russkij archiv, Moskva 1877, Nr. 8, S. 493.

--- (Hrsg. ): Iz pisem k N. F. Pavlovu ego prijatelej (1853); in: Russkij archiv, Moskva 1894, Nr. 2, S. 214-219.

--- K. K. Pavlova; In: Russkij archiv, Moskva 1894, Nr. 1, S. 119-123.

Bekker, I. I. : Mickevič v Peterburge. Leningrad 1955.

Beleckij, A.I.: Novoe izdanie socinenij K. K. Pavlovoj; in: Izvestija otdelenija russkogo jazyka i slovesnosti russijskoj akademii nauk, Petrograd 1917, Bd. XXI, Buch 2, S. 200-220.

Belinskij, Vissarion Grigor'evic: Polnoe sobranie socinenij. 13 Bde., Moskva 1953-1959.

Bely j, Andrej: Simvolizm. Kniga statej. Moskva 1910.

Ber g, N. V. : Zapiski; in: Russkaja starina, S. -Peterburg 1891, Bd. LXXX (Febr.), S. 262-270 und (März) S. $598 f$.

Bill ip, Witold: Mickiewicz w oczach wspolczesnych. Dzieje recepcji na ziemiach pol skich w latach 181 8-1 830. Wrocław / Warszawa / Krakơw 1962.

B oe hme, W.E. und A. Luther: Frühe deutsche Über setzungen aus dem Russischen; in: Philobiblon. Eine Zeitschrift für Bücherliebhaber. A Magazine for Book-Collectors. Wien 1933, S. 277-286 und S. 349-363.

Frühe deutsche tbersetzungen aus dem Russischen (II); in: Die neue Gesellschaft. Monatszeitschr ift der Gesell schaft zum Studium der Kultur der Sowjetunion, 1948, H. 5/6, S. 37-47. 
Botkin, Vasilij Petrovic: Brief an Aleksandr Vasil'evic Družinin (20.3.1860); in: Letopisi. Gosudar stvennyj literaturnyj muzej, Buch 9 - Pis'ma k A.V. Družininu (1850-1863), Moskva 1948, S. $59 \mathrm{f}$.

Briggs, Anthony D.: "Twofold Life": a Mirror of Karolina Pavlova's Shortcomings and Achievement; in: The Slavonic and East European Review, Vol. XILX, No. 114 - January 1971, S. 1-17.

Brjusov, Valerij Jakovlevic: Karolina Pavlova; in: Ezemesjačnye socinenija, o. O. 1903, Nr. 11/12, S. 273-290.

-.- Zapisi prošlogo. Vospominanija i pis'ma. Pod redakciej S.V. Bachrušina i M. A. Cjavlov skogo. Moskva 1927-1928.

Brodskij, N.L. (Hrsg. ): Literaturnye salony i kružki. Pervaja polovina XIX veka. Moskva / Leningrad 1930.

-.- , Gladkov, Golovecenko und Gudzij (Hrsgg. ): Gercen v vospominanijach sovremennikov. Moskva 1956.

(C a adaev, Petr Jakovleviđ): Socinenija i pis'ma P.Ja. Caadaeva. 2 Bde. , Moskva 1913.

¿ erny §evskij, Nikolaj Gavrilovic: Polnoe sobranie socinenij. 25 Bde., Moskva 1939-1953.

Chmiel ow ski, Piotr: Adam Mickiewicz. Zarys biograficzno-literacki. 2 Bde. Warszawa / Kraków 1886.

Chodzko, Aleksander: "Zejda lata - wszak tyle zeszło i nie wraca,..."; in: Max Vasmer, Russische und polnische Gedichte im Nachlaß von Karolina Pavlova, Zeitschrift für slavische Philologie, 1959, Bd. XXVII, S. 47.

Chomjakov, Aleksej Stepanovic: Brief an N.F. Pavlov (28.5./9.6.1853); in: Russkij archiv, Moskva 1894, Nr. 2, S. 216-218.

-.- Brief an S. P. Śevyrev (1847); in: Russkij archiv, Moskva 1878, Nr. 5, S. 61 .

(--- ) Polnoe sobranie socinenij Alekseja Stepanoviča Chomjakova. 8 Bde., Moskva 1900-1907.

Chomjakova, Ekaterina Michajlovna: Brief an N. M. Jazykov; in: Polnoe sobranie socinenij A. St. Chomjakova, Bd. 8, Moskva 1900, S. $105 \mathrm{f}$.

Chra nevic , Konstantin E.: Mickevic i Karolina Janis; in: Istoriceskij vestnik, S. -Peterburg 1897, Bd. LXVII, Buch 3 (März), S. 1080 -1086 .

(C icerin, Boris Nikolaevic): Vospominanija Borisa Nikolaevica Cicerina. Moskva sor okovych godov. Moskva 1929.

Danilevskij, Grigorij Petrovic: Brief an A.V. Druzinin (22.11./4.12. 1862); in: Letopisi. Gosudar stvennyj literaturnyj muzej, Buch 9 Pis'ma k A. V. Druźininu (1850-1863), Moskva 1948, S. 113-117. 
(---) Socinenija G. P. Danilevskogo. (24 Bde.) Bd. 1, 8. Aufl. S. -Peterburg 1901 .

Daszkiewicz, Cyprian: "Dwa duchy w oblokach" / "Muhammed przed Allahiem i Gabriel"; in: Max Vasmer, Russische und polnische Gedichte im Nachlaß von Karolina Pavlova, Zeitschrift für slavische Philologie, 1959, Bd. XXVII, S. $47 \mathrm{f}$.

Dmitriev, Michail Aleksandrovic: Brief an K.K. Pavlova (18./30.1.1843); in: Ju. N. Verchovskij, E. A. Boratynskij. Materialy k ego biografii. Petrograd 1916 , S. 89 f.

-.. "Ne smotrja na stich moj skromnyj... "; in: Max Vasmer, Russische und polnische Gedichte im Nachlaß von Karolina Pavlova, Zeitschrift für slavische Philologie, 1959, Bd. XXVII, S. $41 \mathrm{f}$.

Dobroljubov, Nikolaj Aleksandrovic: Sobranie socinenij v devjati tomach. Moskva / Leningrad, Bd. 6, 1963 und Bd. 7, 1963.

Duryl in, S.: Russkie pisateli u Gete v Vejmare; in: Literaturnoe nasledstvo, Moskva 1932, Bd. 4-6, S. 287-323.

E ngel'gardt, Sof'ja Vladimirorna: Brief an A.V. Druzinin (5./17.5. 1854); in: Letopisi. Gosudar stvennyj literaturnyj muzej, Buch 9 Pis'ma k A. V. Drużininu (1850-1863), Moskva 1948, S. $362 \mathrm{f}$.

--- Brief an A.V. Druzinin (10./22.1.1855); ib., S. $367 \mathrm{f}$.

Érnst, Sergej: Karolina Pavlova i grafinja Evdokija Rostopcina; in: Russkij bibliofil, S. -Peterburg 1916, Nr. 6, S. 5-35.

Fet, Afanasij Afanas'evic: Rannie gody moej zizni. Moskva 1893.

(Fiedle r, Friedrich): Russische Dichterinnen. Ausgewăhlte Dichtungen ubertragen und mit biographischen Notizen versehen von Friedrich Fiedler. Leipzig 0.J. (um 1907).

Fischer, Rudolf - Peter Kirchner - Rüdiger Ziemann (Hrsgg.): Fahrten nach Weimar. Slawische Gäste bel Goethe. Weimar 1958.

Frank, S.: Goethe in Rußland; in: Germanoslavica, Brün / Prag / Leipzig / Wien, 2. Jg. - 1932/33, S. 55-60.

Franzos, Karl Emil: Nikolaj Pawlow (1875); in: Franzos, Aus HalbAsien. Culturbilder aus Galizien, der Bukowina, Suidrussland und Rumänien. 3. umgearbeitete und vermehrte Auflage. Stuttgart 1889 , Bd. 1, S. $331-353$.

Gajde nkov, N.M. (Hrsg.): Russkie poetty XXX veka. Chrestomatija. Izd. 3-e, dopolnennoe i pererabotannoe. Moskva 1964, S. 510-514.

Gennadi, G. N.: Perevody socinenij Puskina; in: Bibliograficeskie zapiski, periodiceskoe izdanie 1859 goda. Moskva 1859, Bd. II, Nr. 2.

Gerbel', Nikolaj Vasil'evic(Hrsg.): Christomatija dlja vsech. Russkie poéty $v$ biografijach $i$ obrazcach. S. -Peterburg 1873, S. 414-419. 
Gercen, Aleksandr Ivanovic: Sobranie socinenij v tridcati tomach. Moskva 1965.

Gerhardt, Dietrich: Zu den russischen Übersetzungen der Karolina Pavlova; in: Zeitschrift für slavische Philologie, 1939, Bd. 16, S. 306-319.

Gogol', Nikolaj Vasil'evic: Polnoe sobranie socinenij. 14 Bde., Moskva / Leningrad 1937-1952.

Golicy n, N. N.: Bibliograficeskij slovar' russkich pisatel'nic. S. -Peterburg 1889, S. 189-192.

(Gol ova Ceva (Panaeva), A.Ja.): Vospominanija A.Ja. Golovačevoj (Panaevoj); in: IstoriCeskij vestnik, S. - Peterburg 1889, Bd. XXXV, Buch 2 (Febr.), S. 291 -333 und Buch 3 (März), S. 505-576.

Gomolicki, Leon: Mickiewicz wśód Rosjan. Warszawa 1950.

Granovskij, Timofej Nikolaevic: Brief an N.F. Pavlov (1853);

in: Russkij archiv, Moskva 1894, Nr. 2, S. $215 f$.

(--) T.N. Granovskij i ego perepiska. 2 Bde., 2. Aufl. Moskva 1897.

Grekov, N.P.: "Posmotrel by ja na more sumnoe..."; in: Max Vasmer, Russische und polnische Gedichte im Nachlaß von Karol ina Pavlova, Zeitschr ift für slavische Philologie, 1959, Bd. XXVII, S. $42 \mathrm{f}$.

Grif c ov, B.: Karolina Pavlova; in: Russkaja mysl' ${ }^{\circ}$ Moskva 1915, Nr. 11, Abt. III, S. 11-16.

Grigor'ev, Apollon Aleksandrovic: Vospominanija. Moskva / Lenin$\operatorname{grad} 1930$.

Grigor ovic, Dmitrij Vasil'evic: Literaturnye vospominanija s priloZeniem polnogo teksta vospominanij P.M. Kovalevskogo. Leningrad 1928.

H a m mer, Julius (Hrsg.): Leben und Heimat in Gott. Eine Sammlung Lieder zu frommer Erbauung und sittlicher Veredlung. 13. Aufl. Leipzig 0.J. (um 1896).

(H u m boldt, Alexander von): Pis'mo Aleksandra Gumbol'dta k K. K. Pavlovoj (19.6.1858); in: Tatevskij sbornik S.A. Racinskogo, S. - Peterburg 1899 , S. $112 f$.

J a godit s ch, R.: Goethe und seine russischen Zeitgenossen; in: Germanoslavica, Brünn-Prag-Leipzig-Wien, 1. Jg. - 1931/32, H. 3, S. $347-381$.

Ja strun, Mieczy sław: Mickiewicz. 2 Bde., Kraków 1951.

(J a zy kov, Dmitrij D. ): Pavlov, Ippolit Nikolaevic; in: Obzor zizni i trudov pokojnych russkich pistelej D.D. Jazykova. S. - Peterburg 1885 , 2. Folge, S. $38 \mathrm{f}$. 
-.- Pavlova, Karolina Karlovna. - Obzor zizni i trudov russkich pisatelej i pisatel'nic, 13. Folge; in: Sbornik otdelenija russkogo jazyka i slovesnosti imperator skoj akademil nauk, Petrograd 1916, S. 178$184,306$.

J a z y kov, Nikolaj Michajlovic: Pis'ma A. M. Jazykovu; in: Literaturnoe nasledstvo, Moskva 1952, Bd. 58, S. 651.

-.- Polnoe sobranie stichotvorenij. Moskva-Leningrad 1964.

$\mathrm{Kahle}$, Erika: Die russische Literatur in Deutschland in der 1. Háfte des 19. Jahrhunderts. Phil. Diss., Masch. -schr., Würzburg 1950.

$\mathrm{Ka}$ i s e $\mathrm{r}$, Bruno: Über Beziehungen der deutschen und russischen Literatur im 19. Jh., Berlin 1948.

Kall e nbach, Józef: Adam Mickiewicz. 2 Bde., Kraków 1897.

Karlinsky, Simon: Marina Cvetaeva. Her Life and Art. Berkeley und Los Angeles 1966.

Kar pele s, Gustav: Goethe in Polen. Ein Beitrag zur allgemeinen Litteraturgeschichte. Berlin 1890.

Ka si in, N. : Esce o "Socinenijach Karoliny Pavlovoj"; in: Kniga i revoljucija, Petrograd 1921, Nr. 8-9, S. $121 \mathrm{f}$.

Kaveli n, Konstantin Dmitrievic: Sobranie socinenij. 4 Bde., S. -Peterburg 1904.

Kire evskij, Ivan Vasil'evic: "Daruet nebo Celoveku. . "; in: Tatevskij sbornik S. A. Raçinskogo. S. -Peterburg 1899, S. $108 \mathrm{f}$.

-.- O stichotvorenijach g. Jazykova; in: Teleskop, Moskva 1834, Teil XIX, Nr. III, S. $163-165$.

-.- Polnoe sobranie socinenij v dvuch tomach. Moskva 1911.

Koenig, Heinrich (Hrsg. ): Literarische Bilder aus Rußland. Stuttgart und Tubingen 1837.

Kose lev, Aleksandr lvanovic: Brief an N.F. Pavlov (1853); in Russkij archiv, Moskva 1894, Nr. 2, S. 219.

Kostylev, A.N.: Pis'mo P.I. Bartenevu (9./21.3.1852); in: Literaturnoe nasledstvo, Moskva 1952, Bd. 58, S. 752.

Kov or in, V. : Neizvestnyj sonet N. M. Jazykova; in: Russkaja literatura, Leningrad 1961, Nr. 4, S. 131-133.

Kühne, F. G. : Karolina v. Jaenisch, Das Nordlicht. Erste Lieferung; in: Jahrbücher für wissenschaftliche Kritik, Berlin 1834, H. 115 (Juni), Sp. 966-968.

Kuła k ow ski , Sergjusz: Adam Mickiewicz i Karolina Jaenisch-Pawłowa; in: Wiadomosci literackie. Tygodnik. Warszawa, Niedziela 8 wrzesnia 1929 r. , Nr. 36 (297). 
Kurtzmann, L.: Die polnische Literatur in Deutschland bibliographisch zusammengestellt. Posen 1881.

Lé ouz on, Louis Antoine Le Duc: La Russie contemporaine. Paris 1853.

Lerner, Nikolaj Osipovic: Trudy i dni Puskina. 2-e, ispravlennoe i dopolnennoe izd., S. - Peterburg 1910.

L e wa k, Adam: Katalog rekopisów muzeum Adama Mickiewicza w Paryżu. Krakbw 1931.

Lir ondelle, André: Le poete Alexis Tolstoi l'homme et l'œuvre. Paris 1912.

L o ma n, N.L.: "On ne ljubil ešce. ." (1860); in: Russkaja stichotvornaja parodija (XVIII - nacalo XX v.). Leningrad 1960, S. 419.

Luther, Arthur (Hrsg.): Solange Dichter leben. Puskkin-Studien. Krefeld 1949.

--- Russische Literatur in Deutschland; in: Russische Rundschau. Monatshefte für die neue russische Literatur, Berlin 1925, H. 1 (Okt.), S. 64-70.

-.- Russkie pisateli 18 - 19 vv. v nemeckich perevodach; in: Vremennik obšcestva druzej russkoj knigi, Paris 1938, IV, S. 113-128.

-.- Puskin und die deutsche Sprache und Dichtung; in: Pouchkine Revue de Littérature comparée, Paris 1937 - 17, S. 108-116.

Ma uguin, François: Brief an K.S. Aksakov (18./30.7.1840); in: Russkij archiv, Moskva 1880, Buch 2, S. 269 f.

Mel'gunov, Nikolaj Aleksandrovič: Brief an A. I. Koselev (9./21.5.1860); in: Bor is Rapgof, K. Pavlova. Materialy dlja izucenija Zizni i tvorcestva. Petrograd 1916, S. 70-73.

-.. Brief an I. N. Pavlov (16./28.1.1859); in: Ju. N. Verchovskij, E. A. Boratynskij. - Materialy k ego biografii. Petrograd 1916, S. 106-108.

..- Pis'ma Gercenu; in: Literaturnoe nasledstvo, Moskva 1955, Bd. 62, S. 356 - 384 passim.

Mickie wicz, Adam: Dzieła. 16 Bde., Warszawa 1955.

Mickiewicz, Ladislas (Włady slaw): Adam Mickiewicz, sa vie et son cuvre. Paris 1888.

-.- Żywot Adama Mickiewicza. 2 Bde., Poznan 1890-1892.

Mil'keev, Evgenij Lukic: "Vaš stolik"; in: Max Vasmer, Russische und polnische Gedichte im Nachlaß von Karolina Pavlova, Ztschr.f. slav. Phil., 1959, Bd. XXVII, S. $40 \mathrm{f}$.

N. N . : "Dlja molodogo pokolen'ja. . "; in: Max Vasmer, Russische und polnische Gedichte im Nachlaß von Karolina Pavlova, Ztschr.f. slav. Phil., 1959, Bd. XXVII, S. 39. 
Iz zapisnoj knižki "Russkogo archiva"; in: Russkij archiv, Moskva 1893 , Nr. 3, S. 316-318.

K biografii professora N. I. Nadeżdina; in: Russkij archiv, Moskva $1885, \mathrm{Nr} .8$, S. $573 \mathrm{ff}$.

K "Sočinenijam" K. K. Pavlovoj; in: Kniga i revoljucija, Petrograd 1920, Nr. 3-4, S. 93.

"Mickevicu (Cto, zavist' 1' vostorg. .)"; in: Max Vasmer, Russische und polnische Gedichte im Nachlaß von Karolina Pavlova, Ztschr. f. slav. Phil., 1959, Bd. XXVII, S. 43-45.

"Mickeviču (Tvoich gerœev, - ja ne znaju. .)"; ib., S. 45. "Ne Chloja èto socinjala. ."; ib., S. 45.

Nekrolog I (auf K. K. Pavlova); in: Novoe vremja, S. -Peterburg 1893, Nr. 6386 (7./19.12.1893).

Das Nordlicht. Proben der neueren russischen Literatur von Karol ine von Jaenisch. (Rezension); in: Blätter für literarische Unterhaltung, Leipzig 1834, Bd. 1 (Jan. -Juni), S. 239 f.

Literaturnaja zametka (Rezension des "Nordlichts"); in: Molva, Moskva 1834, Nr. 15, S. 227-230.

ohne Titel (Nekrolog auf K. K. Pavlova); in: Istor iCeskij vestnik, S. Peterburg 1894, Bd. LV (Febr.), S. 584-585 ("Smes"n).

(F.B.), ohne Titel (Rezension des "Razgovor v Kremle"); in: Sever naja pcela, o. O. 1854, Nr. 226 (9./21. Okt.), S. 1079 (PCelka zurnal'naja vsjakaja vsjacina).

(Dm. Jaz. S.), Pamjati K. K. Pavlovoj; in: Moskovskie vedomosti, 1903, Nr. 330 .

K. K. Pavlova (Nekrolog); in: Russkie vedomosti, Moskva 1893, Nr. 339.

(D. Ja.), Karolina Karlovna Pavlova, urożdennaja Janis. - Nekrolog, in: Moskov skie vedomosti, 1893, Nr. 335 (5./17. Dez.), S. 5.

Karol ina Pavlova; in: Russkie poetty. Antologija v cetyrech tomach, Bd. 2, Moskva 1966, S. 459-472.

Russkaja poėzija 1840-1850-ch godov. 3. Aufl., Moskva-Leningrad1962, S. $38 \mathrm{ff} ., 261 \mathrm{ff}$.

Les préludes, par Mme Caroline Pavlof, née Jaenisch. (Rezension); in: Otece stvennye zapiski, S. - Peterburg 1839, Bd. IV, Abt.VII ("Sovremennaja bibl iograficeskaja chronika"), S. 162-166.

(M.G.), Novoe kapital'noe priobretenie russkoj slovesnosti. (Pis'mo iz provincii); in: Iskra. SatiriCeskij zurnal s karrikaturami. S. -Peterburg 1859, Nr. 24 (26.6./8.7.), S. 233-235. 
-.- Raut, Literaturnyj sbornik. Izdanie N. V. Suškova. Moskva 1851; in: Moskvitjanin 1851, Nr. 9-10 ("Kritika ibibliografija"), S. $151 \mathrm{ff}$.

(V.A.), Razgovor v Kremle. Stichotvorenie K. Pavlovoj. (Rezension); in: Moskvitjanin 1854, Bd. V, Abt. IV, Nr. 17 ("Kritika i bibliografija), S. 1-7).

Razgovor v Kremle. Stichotvorenie K. Pavlovoj (Rezension); in: Sovremennik, S. -Peterburg 1854, Bd. LXVII, Nr. 9, Abt. IV, S. 34-38.

Stichotvorenija K. Pavlovoj (Rezension); in : Biblioteka dlja ctenija, o. O., 1863, Nr. 8 ("Bibliografija"), S. 80-86.

Dvojnaja Zizn'. Ocerk K. Pavlovoj; in: Biblioteka dlja ctenija, o. O. 1848 - 87, Nr. 3, Abt. IV ("Literaturnaja letopis' - Fevral' 1848: Novye knigi"), S. 1-17.

Dvojnaja żizn', socinenie K. K. Pavlovoj; in: Moskovskij literaturnyj i ucebnyj sbornik na 1847 god. Moskva 1847, S. 691-696.

Dvojnaja Zizn'. Ocerk K. Pavlovoj; in: Sovremennik, S. -Peterburg 1848, Bd. VII, Nr. 3, Abt. III, S. 47-60.

Dvojnaja zizn'. Ocerk K. Pavlovoj; in: Otecestvennye zapiski, S. Peterburg 1848, Nr. 5-6, Abt. VI, S. 4-9.

Nekra sov, Nikolaj Alekseevic: "Moe razocarovanie. Poema." (1 851); in: Russkaja stichotvornaja parodija (XVIII - nacalo XX. v.). Leningrad 1960 , S. 477-479.

Neumann, Friedrich Wilhelm: Geschichte der russischen Ballade. Königsberg 1937.

Noval is: Schriften. Die Werke Friedrich von Hardenbergs in 4 Bănden.

2. Aufl. Darmstadt 1960.

Obscestvo ljubitelej Rossijskoj Slovesnosti pri Moskovskom Universitete. Istoriceskaja zapiska i mater ialy za sto let. Moskva 1867.

Ody nie c, Antoni Edward: Listy z podróży. 2 Bde., Warszawa 1961.

Ogarev, Nikolaj Platonovič: Pis'mo k Annenkovu (21.12.1854/2.1.1855);

in: P.V. Annenkov i ego druz'ja. S. - Peterburg 1892, S. $646 \mathrm{f}$.

Panaev, Ivan Ivanovic: Brief an K.K. Pavlova(1854); in: Sovremennik, S. - Peterburg 1854, Bd. XLVIII, Nr. 11, S. $136 \mathrm{f}$.

-.. "Poét" (1 851); in: Russkaja stichotvornaja parodija (XVIII - nacalo $X X$ v. ). Leningrad 1960, S. $479 \mathrm{f}$.

-.- Literaturnye vospominanija. Leningrad 1950.

P(avlov), $D$ (mitrij Ippolitovic): K. K. Pavlova i neizdannyj ocerk ee "Fantasmagorija"; in: Russkoe obozrenie, Moskva 1894, Bd. 30, Nr. 12, S. $961-970$ ("Materialy dlja charakteristiki russkich pisatelej, chudoźnikov i obšcestvennych dejatelej"). 
-.- Zabytyj poèt. Pamjati K. K. Pavlovoj; in: Moskovskie vedomosti, 1894, Nr. 331 (2./14.12.), S. 3 f.

(Pavlov, Nikolaj Filippovic): Pis'ma N. F. Pavlova k A. A. Kraevskomu; in: Otcet imperator skoj publicnoj biblioteki za 1892 god. S. - Peterburg 1895, S. 84-116.

(--) Pis'ma N. F. Pavlova k S. P. Śevyrevu; ib., S. 117-158.

(---) Stichi N. F. Pavlova vo vremja zakljucenija za dolgi (1852); in:

Russkij archiv, Moskva 1885, Nr. 1, S. 142.

"Vy, s vasej muzoj Evropejskoj. ." (1836); in: Max Vasmer, Russische und polnische Gedichte im Nachlaß von Karol ina Pavlova, Ztschr. f. slav. Phil., 1959, Bd. XXVII, S. $39 \mathrm{f}$.

Pereverzev, V.: Salonnaja poètessa. (Po povodu sobranija socinenij K. Pavlovoj); in: Sovremennyj mir, S. -Peterburg 1915, Nr. 12, Abt. II, S. 185-188.

Pogodin, A.: Goethe in Rußland; in: Germanoslavica, Brün-Prag-Leipzig-Wien, 1. Jg. - 1931/32, H. 3, S. 333-347.

Pogodin, Aleksandr L'vovic: Adam Mickevic. Ego żizn'i tvorcestvo. Bd. 2, Moskva 1912.

(Pogodin, Michail Petrovic): Pis'ma M.P. Pogodina k M.A. Maksimovicu; in: Sbornik otdelenija russkogo jazyka i slovesnosti imperatorskoj akademii nauk. S. - Peterburg 1883, Bd. XXXI, Nr. 2, S. 1-143.

Polonskij, Jakov Petrovic: "Osen" (1842); in: Max Vasmer, Russische und polnische Gedichte im Nachlaß von Karolina Pavlova, Ztschr. f. slav. Phil., 1959, Bd. XXVII, S. $38 \mathrm{f}$.

--- Moi studenceskie vospominanija; in: Niva. Ezemesjacnye literaturnye priloženija. S. -Peterburg 1898, Nr. 12, S. 641-688.

Ponomarev, S. I. : Nikolaj Filippovic Pavlov (1805-1864); in: Sbornik otdelenija russkogo jazyka i slovesnosti imperatorskoj akademii nauk, S. -Peterburg 1889, Bd. XLVI, Nr. 3, S. 2-19 ("Materialy dlja istoril russkoj literatury").

--- Nasi pisatel'nicy; ib., 1891, Bd. LII, Nr. 7, S. 1-22.

Puskin, Aleksandr Sergeevic: Polnoe sobranie socinenij v desjati tomach. Moskva 1962-1966.

R a a b , Harald: Die Lyrik Puskins in Deutschland (1820-1870). Berlin 1964.

R a C in skij , Sergej Aleksandrovic: Stichotvorenija Karoliny Karlowny Pavlovoj i vospominanija o nej; in: Tatevskij sbornik S.A. Racinskogo, S. - Peterburg 1899, S. 106-111.

(Raevskaja , E.I. ): Iz vospominanij E. I. Raevskoj; in: Russkij archiv, Moskva 1896, Nr. 2, S. $220 \mathrm{ff}$. 
R a m mel me yer, Alfred: Russische Literatur in Deutschland; in: Deutsche Philologie im Aufriß, Bd. 3, Berlin 1962, Sp. 439-480.

R a pg of , Boris: K. Pavlova. Materialy dlja izucenija zizni i tvorcestva. Petrograd 1916.

Re is s ner, Eberhard: Die Aufnahme und Bewertung russischen Literaturgutes in Deutschland in der ersten Hălfte des 19. Jahrhunderts. Habil. -Schr., Masch. -schr., Berlin 1962.

Rostopcina, Evdokija Petrovna: Brief an A.V. Druzinin (24.11./6.12. 1854); in: Letopisi. Gosudar stvennyj literaturnyj muzej, Buch 9 Pis'ma k A.V. Druz ininu (1850-1863). Moskva 1948, S. 278-280.

Rozen, E. : Dvojnaja zizn'. Ocerk K. Pavlovoj; in: Syn otecestva, o. O. 1848, Buch 5, Abt. VI, S. 1-19.

(Sabinina, Marfa Stepanovna): Iz zapisok Marfy Stepanovny Sabininoj; in: Russkij archiv, Moskva 1901, Nr. 8, S. 576 ff.; Nr. 9, S. 49 ff.

Sadovskoj, Boris: K. K. Pavlova; in: ders. : Ledochod. Stat'i i zametki. Petrograd 1916, S. 119-121.

Sal'nikov, A.N.: K. K. Pavlova; in: ders. : Russkie poéty za sto let (s puškinskoj épochi do našich dnej) v portretach, biografijach i obrazcach. S. - Peterburg 1901, S. 165-168.

(Sa marin, Jurij Fedorovic): Socinenija Jurija Fedorovica Samarina. 12 Bde., Moskva 1877-1911.

Ścedrin, N. (M.E. Saltykov): Stichotvorenija K. Pavlovoj (Moskva 1863); in: der s.: O literature. Moskva 1952, S. 161-167.

Scher $\mathbf{r}$, Johannes: Bildersaal der Weltliteratur. Dritte neu bearbeitete und stark vermehrte Auflage. Bd. 3, Stuttgart o.J.

Sc obel, Gabriele: Karoline von Jaenisch (Karolina Karlovna Pavlova) und die russische Literatur. Hausarbeit der Humboldt-Universität Berlin, phil. Fak., Masch. -schr., 1960.

Se ndi ch, Munir: Karolina Jaenisch (Pavlova) and Adam Mickiewicz; in: The Polish Review, Vol. XIV, No. 3, Summer 1969, S. 68-78.

Ševyrev, Stepan Petrovic: Brief an N. F. Pavlov (1853); in: Russkij archiv, Moskva 1894, Nr. 2, S. $218 \mathrm{f}$.

--- Dvojnaja Zizn'. Ocerk K. Pavlovoj. Moskva 1848; in: Moskvitjanin 1848, Teil II, Nr. 3, Abt. III, S. 1-19.

"Kogda-to russkoj seljanin. ."; in: Max Vasmer, Russische und polnische Gedichte im Nachlaß von Karol ina Pavlova, Ztschr.f. slav. Phil., 1959, Bd. XXVI, S. $37 \mathrm{f}$.

Russkij biograficeskij slovar ${ }^{\circ}$, Bd. XIII, S. -Peterburg 1902 (Reprint New York 1962). 
Polski słownik biograficzny, Bd. III, Kraków 1937.

Smir en skij, Boris: Zabytyj romans Lista; in: Smena, Moskva 1957, Jg. $34, \mathrm{Nr} .13$, S. 24.

Smol janikov, I. B. : Karolina Pavlova; in: Novoe vremja, Beograd 1915, Nr. 14233, 14250.

Sobolev skij, Sergej Aleksandrovic: Épigrammy i èksprompty. Moskva 1912.

St ake n snejder, Elena Andreevna: Dnevnik i zapiski (1854-1886). Moskva-Leningrad 1934.

(Sta sjul evic, Michall Matveevic): M. M. Stasjulevic i ego sovremenniki v ich perepiske. 2. Bd., S. -Peterburg 1912.

Störig, Hans Joachim (hrsg. ): Das Problem des Über setzens. Darmstadt 1963.

Such omlinov, M.: Épizod iz literatury tridcatych godov. (Tri povesti

Pavlova); in: Drevnjaja i Novaja Rossija, S. -Peterburg 1875, Nr. 1, S. 55-65.

(Sver beev, Dmitrij Nikolaevic): Zapiski Dmitrija Nikolaevica Sverbeeva (1799-1 826). 2 Bde., Moskva 1899.

Sver beeva, E. A. : Brief an A. N. Popov (22.1./3.2.1847); in: Literaturnoe nasledstvo, Moskva 1952, Bd. 58, S. $701 \mathrm{f}$.

Szpotahski, Stanisław: Adam Mickiewicz 1 jego epoka. 2 Bde., Warszawa-Kraków 1921.

Sz y per, Henryk: Adam Mickiewicz. Poeta i człowek czynu. Kraków 1950.

( Tjut ¿ ev, Fedor Ivanovic): Lettres de Th. J. Tjutscheff a sa seconde épouse, née baronne de Pfeffel; in: Starina i novizna. Istor iceskij sbornik. Petrograd 1916, Buch 21, S. 155-243.

( Tol stoj, Aleksej KonstantinoviC): Pis'ma gr. A.K. Tolstogo; in: Vestnik Evropy, S. - Peterburg 1895, Nr. 10, S. $635 \mathrm{ff}$.

-.- Sobranie socinenij v cetyrech tomach, Moskva 1963/64.

Tretiak, Józef: Karolina Jaenisch; in: ders.: Sekice literackie. Serya I, Kraków 1896, S. 279-295.

( T scher now, Alexander (Hrsg.)): Aus russischen Dichtern (Lyrisches, Episches, Dramatisches) in deutschen Übertragungen. Gesammelt und herausgegeben von Alexander Tschernow. Halle a.d. Saale o.J. (um 1893).

Tschizew skij, Dmitrij: Einige Aufgaben der slavistischen Romantikforschung, in: Die Welt der Slaven, Wiesbaden 1956, S. 18-34.

-.- Hegel bei den Slaven. 2. verbesserte Aufl., Darmstadt 1961. 
--- Puskin und die Romantik; in: Germanoslavica, Brünn-Prag-LeipzigWien 1937, 5. Jg. , H. 1-2, S. 1-31.

--- Zu zwei Gedichten von Karolina Pavlova; in: Ztschr.f. slav. Phil. , 15, 1938, S. $111-116$.

--- und D. Gerhardt: Deutsche Puskkin-Über setzungen von Karolina Pavlova; in: Germanoslavica, Brün-Prag-Leipzig-Wien 1937, 5.Jg. , H. 1-2, S. 32-51.

Turge nev, Aleksandr Ivanovič: Briefe an Vjazemskij; in: Ostaf'evskij archiv knjazej Vjazemskich. Izd. grafa S.D. Seremeteva, S. -Peterburg, Bde. III a - 1899, IIIb - 1908, IV - 1899, passim.

(--) Iz parižskich pisem A. I. Turgeneva; in: Russkij archiv, Moskva 1896, Buch 1, Nr. 2, S. $190 \mathrm{ff}$., passim.

( Turgenev, Ivan Sergeevic): Iz perepiski I. S. Turgeneva s sem'eju Aksakovych; in: Vestnik Evropy, S. -Peterburg 1894, Bd. 1, S. 329344; Bd. 2, S. 469-499.

(Varnhagen von Ense, Karl August): Aus dem Nachlaß Varnhagen's von Ense: Tagebucher von K. A. Varnhagen von Ense, Bd. 14, Hamburg 1870.

Vasil'ev, N.: Karolina Pavlova; in: Moskovskie vedomosti, 1915, Nr.265.

Va smer, Max: Russische und polnische Gedichte im Nachlaß von Karolina Pavlova; in: Ztschr.f. slav. Phil. , 1959, Bd. XXVII, S. 35-49.

Venevitinov, A.V.: Brief an N.F. Pavlov (31.5./12.6.1853); in : Russkij archiv, Moskva 1894, Nr. 2, S. 214.

Verchovskij, Ju.N. : E. A. Boratynskij. Materialy k ego biografii. Iz Tatev skogo archiva Racinskich, Petrograd 1916 .

Vjazem skij, Petr Andreevic: "S stecnen'em cuvstv smotrju na vaś al'bom.."; in: Max Vasmer, Russische und polnische Gedichte im Nachlaß von Karolina Pavlova; in: Ztschr.f. slav. Phil., 1959, Bd. XXVII, S. $36 \mathrm{f}$.

Winke l, Hans-Jürgen zum: Die Briefe russischer Dichter und Journalisten an Berthold Auerbach; in: Ztschr.f. slav. Phil., 1963, Bd. XXXI, S. 123-142.

(W olf sohn, C. Wilhelm): Die schönwissenschaftliche Literatur der Russen. Auserwăhltes aus den Werken der vorzüglichsten russischen Poeten und Prosaisten alterer und neuerer Zeit, ins Deutsche übertragen und mit historisch-kritischer Über sicht, biographischen Notizen und Anmerkungen begleitet von C. Wilhelm Wolfsohn, Bd. 1, Leipzig 1843.

--- ohne Titel (über "Dvojnaja zizn'"); in: Jahrbücher für slawische Literatur, Kunst und Wissenschaft. Hrsg. von J.P. Jordan, Leipzig 1846 , 4. Jg. , H. $11 / 12$, S. 446. 
(---) Nikolaus Pawlow. Erinnerungen von Wilhelm Wolf sohn; ib. , 1846, 4. Jg. , H. 9, S. 337-347; H. 11/12, S. 413-425.

Z a st $r$ ow, Roswitha: Puschkin-Gedichte in deutschen Uber setzungen. Phil. Diss., Masch. -Schr. Bonn 1957.

Zeme nkov, B.: Pamjatnye mesta v Moskve i Leningrade, svjazannye $s$ Belinskim. Teil I: Belinskij v Moskve; in: Literaturnoe nasledstvo, Moskva 1951, Bd. 57, S. 375-394.

Ź ukovskij, Vasilij Andreevic: "Poet nas prav: Al’bom kladbisce... "; in: Max Vasmer, Russische und polnische Gedichte im Nachlaß von Karol ina Pavlova, Ztschr. f. slav. Phil., 1959, Bd. XXVII, S. 35 f.

Die Originale der in dieser Arbeit besprochenen Über setzungen Karolina Pavlovas werden den folgenden Ausgaben entnommen:

Baratynskij, Evgenij Abramovic: Polnoe sobranie stichotvorenij, Leningrad 1957.

(Freiligrath, Ferdinand): Ferdinand Freiligraths Sămtliche Werke, 2 Bde., Hamburg 0.J.

He bel, Johann Peter: Alemannische Gedichte, Freiburg / Breisgau o.J. He in e, Heinrich: Sămtliche Werke, 10 Bde., Leipzig 1911-1915. Jazykov, Nikolaj Michajlovic: Polnoe sobranie stichotvorenij, Moskva / Leningrad 1964.

Schiller, Friedrich: Sămtliche Werke, 5 Bde., 2. Aufl. München 1960. Tolstoj, Aleksej Konstantinovic: Sobranie socinenij v 4 tomach. Moskva 1963.

Venevitinov, Dmitrij Vladimirovic: Polnoe sobranie socinenij. Moskva / Leningrad 1934 (Reprint 1967).

(Ź ukovskij, Vasilij Andreevic): Polnoe sobranie socinenij V.A. Zu ukov skogo v 12-ti tomach. S. - Peterburg 1902. 
and

4hy

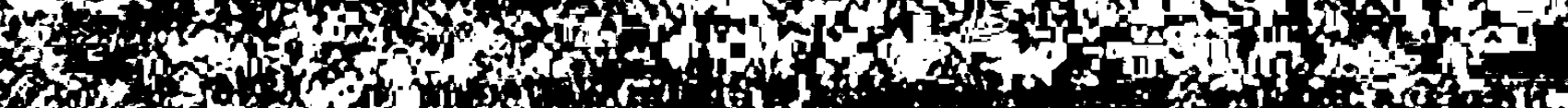

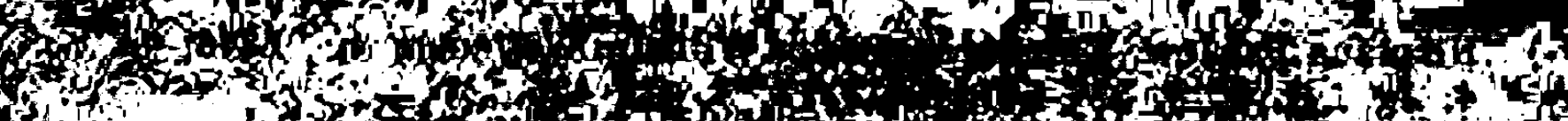

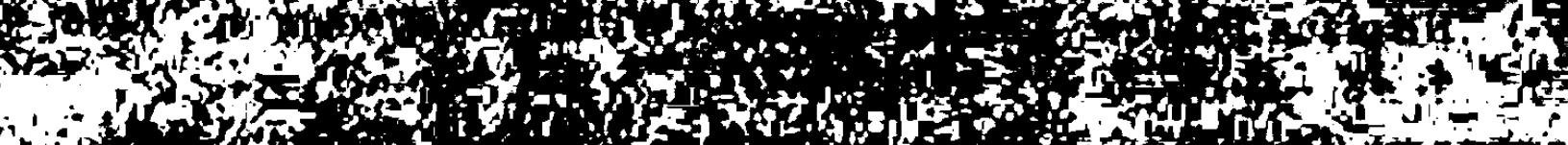

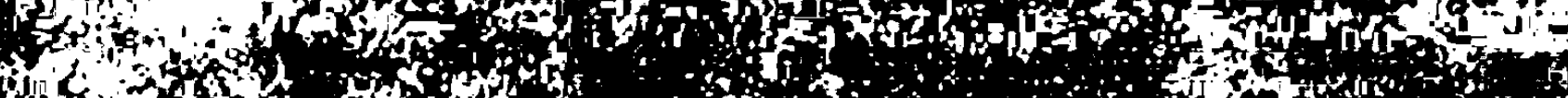

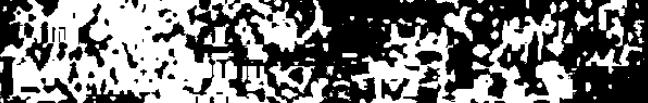

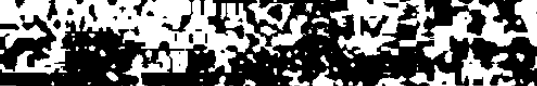

(1)

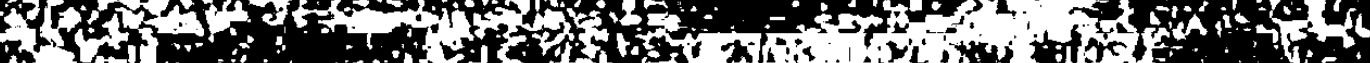

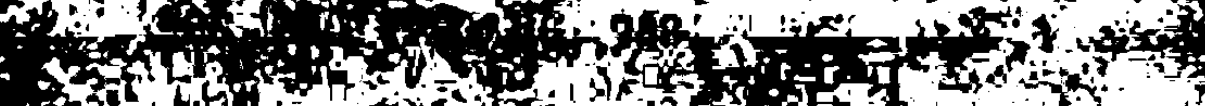

iffor

oncto

430 all istis.

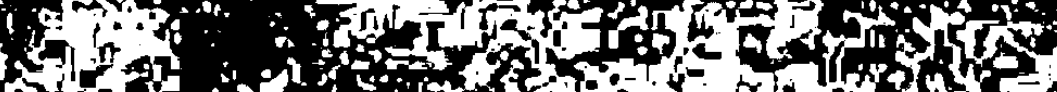

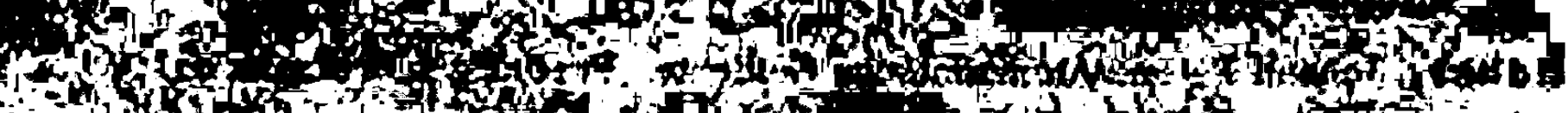

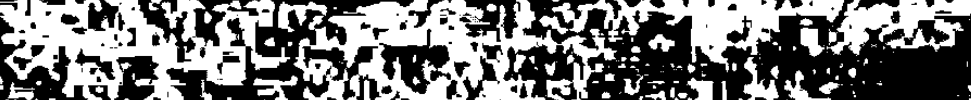
30. f

(1) (1)

Fen

If

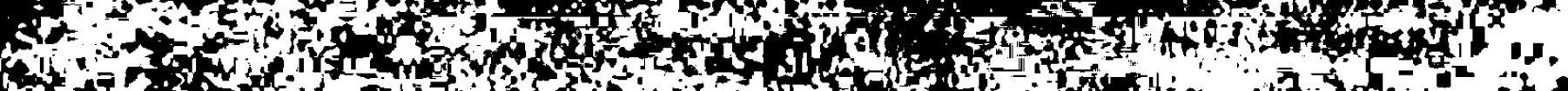
4 Ite

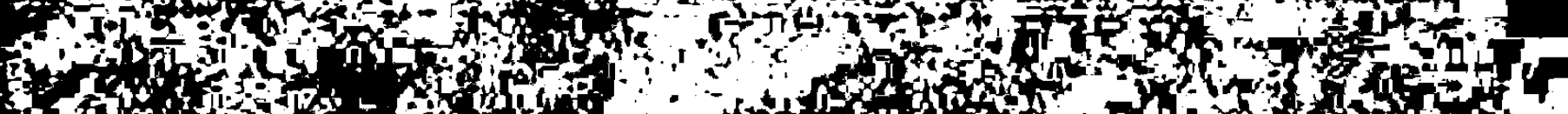

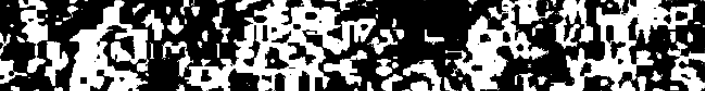

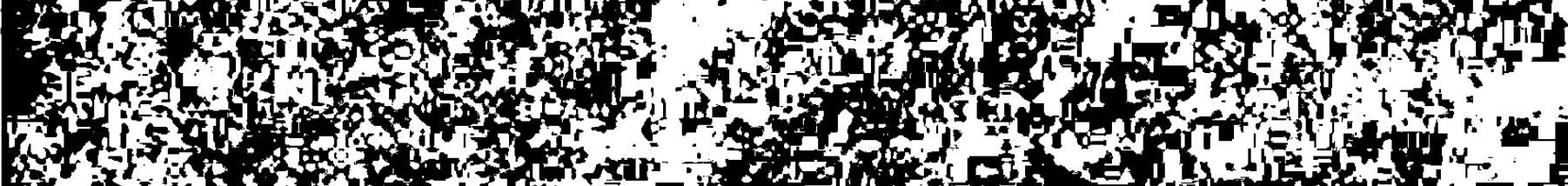

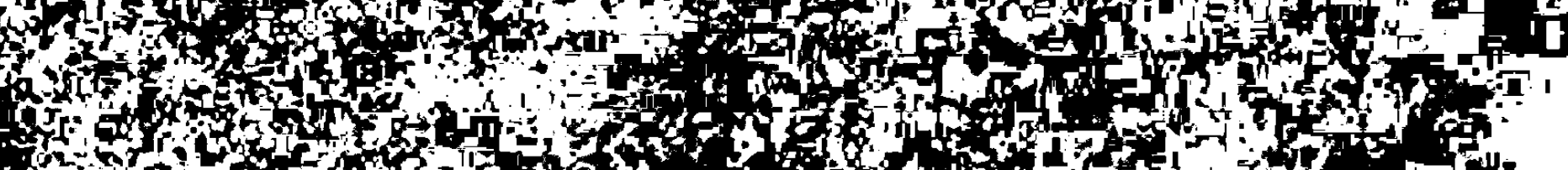
7.

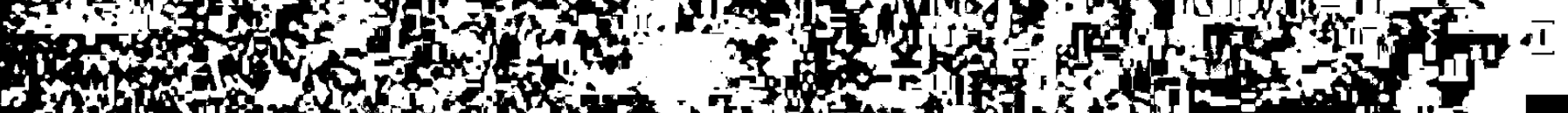

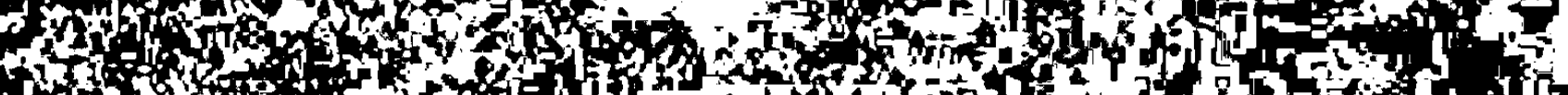

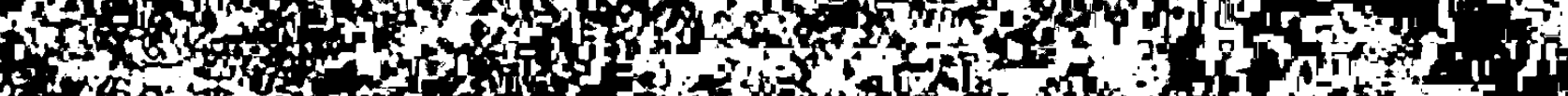

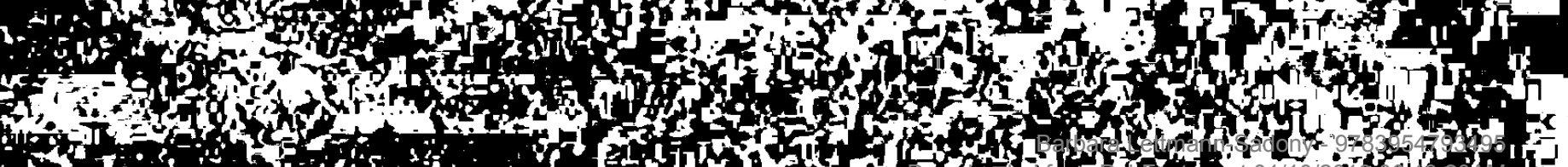
3. 


\section{NACHWORT}

Die vorliegende Arbeit wurde 1970 von der Philosophischen Fakultăt der Johannes Gutenberg-Univer sităt in Mainz als Dissertation angenommen. Sie entstand auf Anregung und unter der Leitung von Herrn Prof. Dr. Friedrich Wilhelm Neumann, dem ich an dieser Stelle fur die Betreuung sehr herzlich danke.

Zu danken habe ich auch den Herausgebern der 'Slavistischen Beitrăge $^{\prime}$ sowie dem Verlag Otto Sagner für die Veröffentlichung in dieser Reihe.

Mainz, im Mai 1971 